UNIVERSITY OF SZEGED

FACULTY OF HUMANITIES AND SOCIAL SCIENCES

DOCTORAL SCHOOL OF EDUCATION

PROGRAMME OF LEARNING AND INSTRUCTION

\title{
Instructional management and stress factors affecting teacher trainers as perceived by the educational leaders of Laos.
}

PhD Dissertation

BY

THONGSAY PHONGPHANIT

Supervisor:

Éva Farkas, PhD. habil.

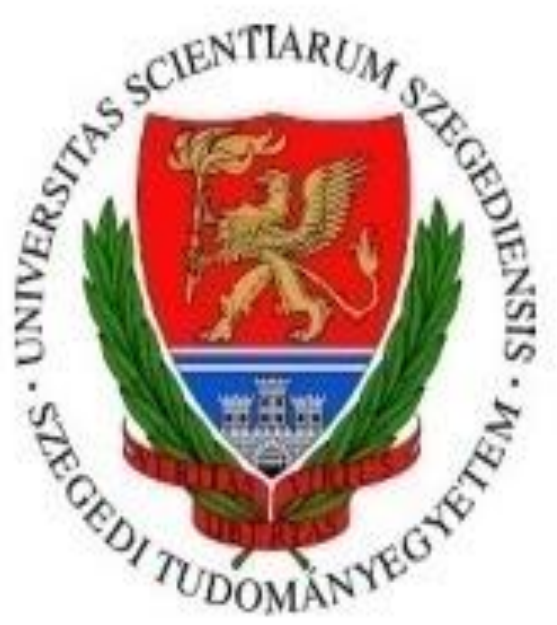

Szeged, Hungary

2019 


\section{Table of contents}

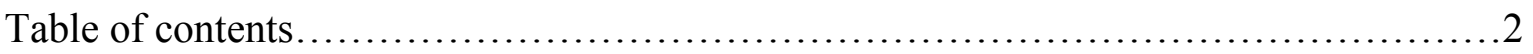

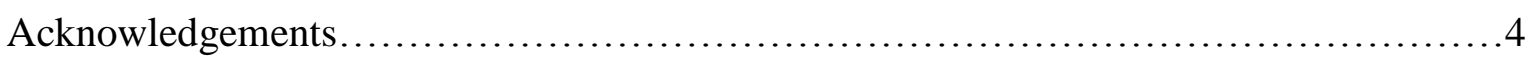

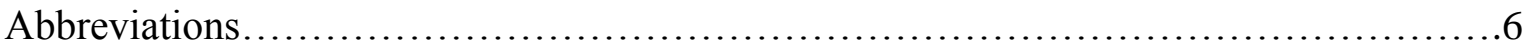

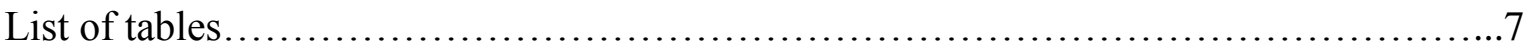

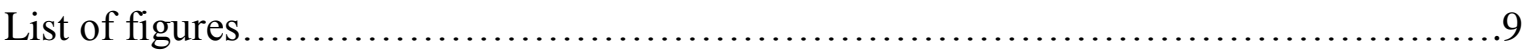

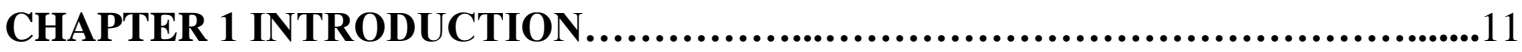

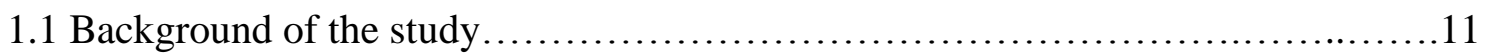

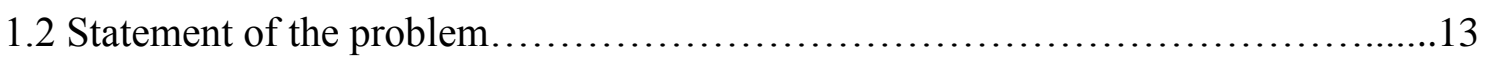

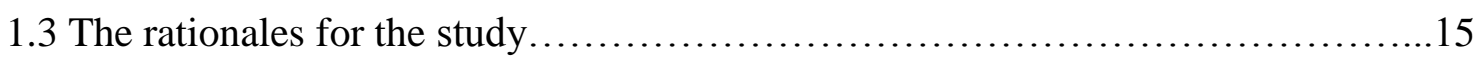

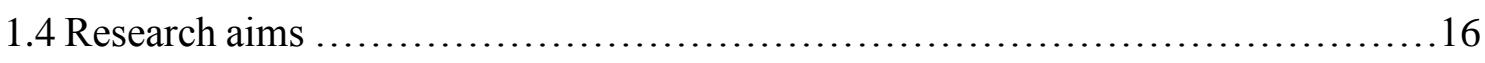

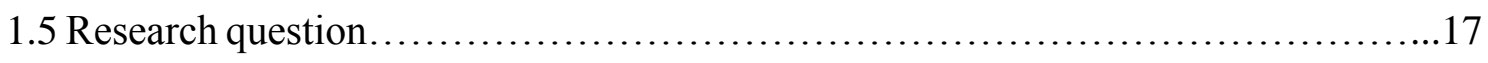

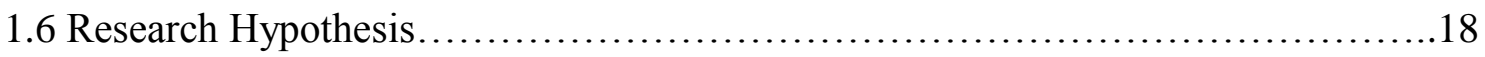

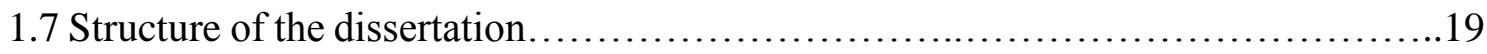

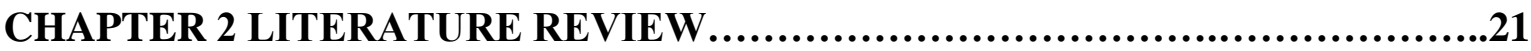

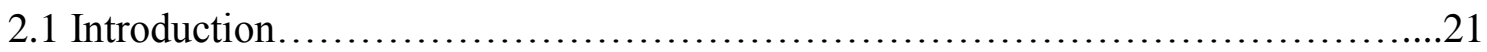

2.2 Conceptualization of construction instrument (study 1,2, and 3) ...................21

2.2.1 The motives toward the self-constructed questionnaires.....................22

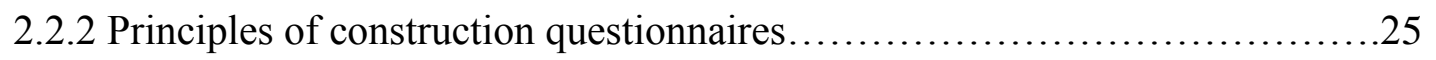

2.2.3 The reasons for using a different Likert scale ................................. 32

2.3 The theoretical background of burnout syndrome among teachers (study 4).........34

2.4 Conceptualization of instructional management (study 5) ...........................

2.5 Perception on management of teachers in Laos culture (study 6) ....................41

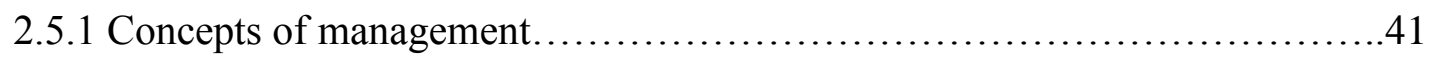

2.5.2 Educational management................................................. 43

2.5.3 Perception of educational leaders toward functioning and responsibilities.....44

2.6 Six tasks for effective management of teachers (Study 6)..........................49

2.6 .1 Teacher demands analysis.................................................. 49

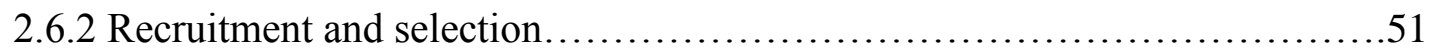

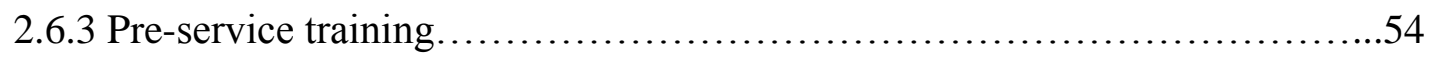

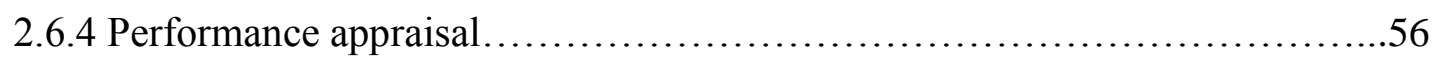

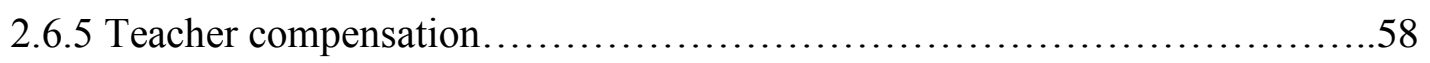


2.6.6 Training needs assessment.............................................59

2.7 Stress factors among teachers by institutional mismanagement (study 6).........60

2.7.1 Relating to teaching load...........................................62

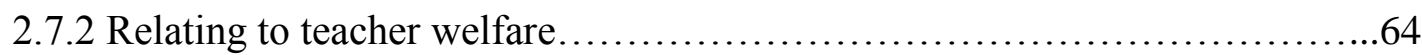

2.7.3 Relating to teacher professional development..........................66

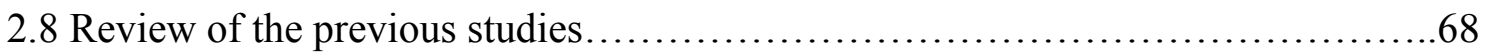

2.9 Educational structure and TTIs in Laos (study 6)...........................69

2.8.1 General education system.........................................69

2.8.2 Teacher Training Institutions (TTIs) ................................. 72

2.10 Defining keywords and keywords expressions............................... 75

2.11 Chapter summary..................................................... 77

CHAPTER 3 METHODOLOGY........................................79

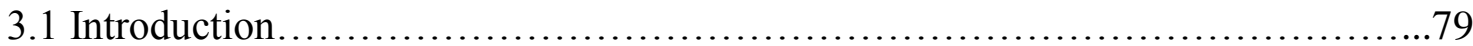

3.2 Target institutions used for the studies..................................... 79

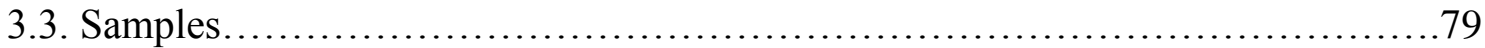

3.4 Instrument and its developmental process.................................. 82

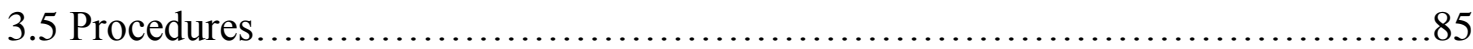

3.5.1 Data collection..................................................... 85

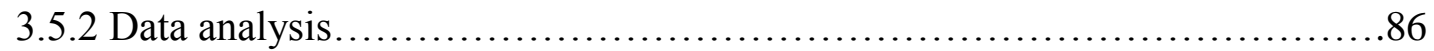

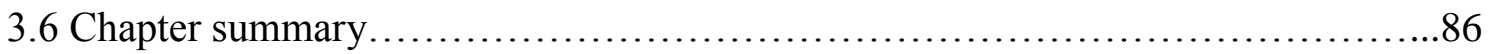

CHAPTER 4 THE FINDINGS..................................................87

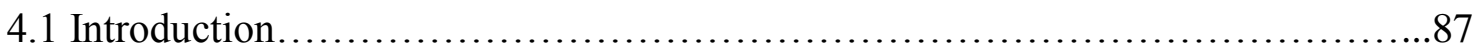

4.2 Findings of study 1: Examining the validity and reliability of questionnaire........87

4.3 Findings of study 2: Re-examining the validity and reliability of questionnaire.....90

4.4 Findings of study 3: A possibility study of using a self-constructed questionnaireconcerning management of teacher in Laos..................................... 94

4.5 Findings of study 4: A cause of teacher's burnout syndrome concerning to schools board management at Practice Schools in Laos..................................100

4.6 Findings of study 5: Instructional management of teaching staff in teacher training-

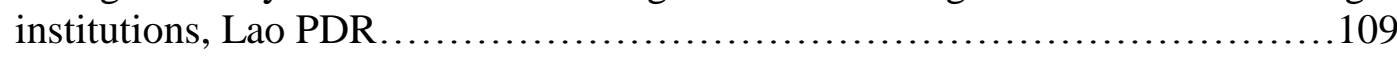

4.7 Findings of study 6 (main study): Instructional management and stress factors affecting teacher trainers as perceived by the educational leaders of Laos...........113

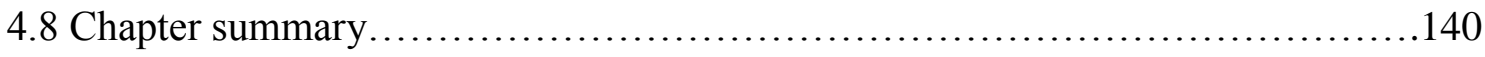


CHAPTER 5 CONCLUSIONS, DISCUSSIONS, IMPLICATIONS, SUMMARY BY

5.1 Introduction. 141

5.2 Conclusions. .141

5.3 Discussions .143

5.4 Implications. 148

5.5 Summary by SWOT analysis............................................. 148

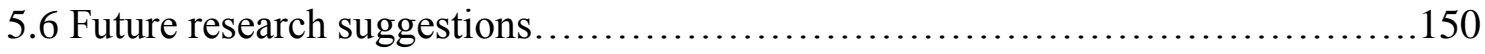

References......................................................................151

Appendix A: Examining the validity and reliability of a self-constructed questionnaire

(Form A: for educational leader) 176

Appendix B: Examining the validity and reliability of a self-constructed questionnaire (Form B: for teacher) 179

Appendix C: Cause of teacher burnout syndrome concerning to school boardManagement Practice Schools in Laos.

Appendix D: Instructional management of teaching staff in teacher training institutions in Lao PDR 182

Appendix E: Instructional management and stress factors affecting teacher trainers as perceived by the educational leaders of Laos. 184

Appendix F: Stress factors among teachers 189 


\section{Acknowledgements}

I owe my deepest appreciation and gratitude to my supervisor Éva Farkas (Dr. habil), who has kindly devoted her time and efforts to guiding me through my studies and the process of writing a dissertation. I have the honor to work with her closely, and also learned a lot from her advises. Despite her busy schedule, she continuously motivates and takes care of me, as if I was a member of her family. Éva, let me take this opportunity to thank You and your family for everything! Please also forward my sincere thanks to your nice colleagues at the Institute of Adult Education in Szeged for their warm welcome whenever I went to meet you.

I would like to acknowledge the Tempus Public Foundation for providing me with an auspicious scholarship called Stipendium Hungaricum that enabled me to study in Hungary. I would also like to thank Vitafort Agro Asia (VAA) for its financial assistance during my $\mathrm{Ph} . \mathrm{D}$. candidature period. My next sincere and heartfelt thanks goes to Klára Tarkó (Ph.D. habil.) for her kindness and patience in providing me with English correction assistance.

My special gratitude and sincere thanks goes to Professor Dr. Csapó Benö, Head of the Doctoral School of Education, who looked for a supervisor for me and helped me in everything. I would like to say thanks to the best reviewers for my home defense, Éva Bacsa, Ph.D, and Dr. Helga Dorner, Ph.D. They became my academic Idols automatically through their beneficial and unique recommendations.

Further, I would like to say thanks to all the Professors and Assoc, Professors who taught the valuable and outstanding courses to me such as Prof. Dr. Gyöngyvér Molnár, Prof. Dr. Csaba Csíkos, Dr. habil. Éva Molnár, Dr. habil. Tibor Vidákovich, Dr. Szilvia Jámbori, Dr. habil. Anikó Kálmán, Dr. habil. Anikó Zsolnai, and Dr. habil. Erzsébet Korom. I would like to give my heartfelt thanks to my Hungarian teachers: Ágnes Sebők and Flórián Várhelyi. I like you all, your teaching styles and your smart knowledge transmission both during Ph.D. courses offered and during the Hungarian language courses. I promise to apply all your ideas to strengthen my teaching career and make it more successful in the future. Also, I am so grateful to the Secretary of the Doctoral School of Education: József Balázs Fejes, and the Secretary of the Institute of Education: Petra Virág, ICT providers, for their kind help with my studies.

I would like to say thanks to You, my local and international classmates, and I will remember these great times, good friendships and shared experiences with Anita Krausz, Dóra Győri-Dani, Alisa Tóth, Szilvia Hegedüs, Maja Kósa, Renáta Kovács, Fanny Dudok, Enikő Bús, Attila Rausch, Yunjun Kong, Linus Kambeyo, Hao Wu, Jargaltuya Ragchaa, Sansarmaa Khurelbaatar, and Davaajav Purevjav. I am also grateful to many other colleagues in the DS, for their kind assistance with my studies and life in Szeged.

I would like to say personal thanks to the Hungary-Laos Association, Laos Embassy and Diplomatic staffs in Vienna, Laotians who have been living in Hungary, Lao students in Hungary, for all your support and motivation. I say thanks to the Ministry of Education and Sports, and the Teacher Training Institutions (TTIs) in Laos for their great efforts in participating in this dissertation's research.

Last but not least comes the most important person: I would like to give my heartfelt thanks to my beloved wife Chansuda, for her background support throughout my study in Hungary; without her long patience, I couldn't go to the final stage of this Ph.D. program and thanks so much to all my siblings for their tireless support.

Finally, I would like to acknowledge and say thanks to each participant and organization in both countries (Hungary and Laos). I feel appreciation towards those 
contributors I earlier listed one-by-one, and would also like to apologize if I have left someone out. Without all of you, this dissertation would not be ready. Thanks! 


\section{List of abbreviations}

$\begin{array}{lll}\text { Lao PDR } & = & \text { Lao People's Democratic Republic } \\ \text { MOES } & = & \text { Ministry of Education and Sports } \\ \text { MOPH } & = & \text { Ministry of Public Health } \\ \text { MOHA } & = & \text { Ministry of Home Affairs } \\ \text { MOFA } & = & \text { Ministry of Foreign Affairs } \\ \text { MOF } & = & \text { Ministry of Finance } \\ \text { PESS } & = & \text { Provincial Education and Sports Services } \\ \text { DESB } & = & \text { District Education and Sports Bureau } \\ \text { VCED } & = & \text { Village's Committees for Education Development } \\ \text { TDA } & = & \text { Teacher Demand Analysis } \\ \text { RaS } & = & \text { Recruitment and Selection } \\ \text { PST } & = & \text { Pre-Service Teacher Training } \\ \text { TPA } & = & \text { Teacher Performance Appraisal } \\ \text { TC } & = & \text { Teacher Compensation } \\ \text { TNA } & = & \text { Training Needs Assessment } \\ \text { TPD } & = & \text { Teacher Professional Development } \\ \text { TTIs } & = & \text { Teacher Training Institutions } \\ \text { TTC } & = & \text { Teacher Training College } \\ \text { FOE } & = & \text { Faculty of Education } \\ \text { NUOL } & = & \text { National University of Laos } \\ \text { DOHE } & = & \text { Department of Higher Education } \\ \text { DOTE } & = & \text { Department of Teacher Education } \\ \text { DOP } & = & \\ \text { FE } & = & \end{array}$




\section{List of tables}

Table 1. Statistical applications used for examination a self-constructed questionnaire......32

Table 2. Type and characteristic of measuring instruments.......................... 34

Table 3. Teacher education training program in Laos............................. 73

Table 4. Samples used for the studies.......................................... 82

Table 5. Summary the step of developmental process a self-constructed questionnaire....85

Table 6 . The procedures of research activities.................................... 86

Table 7. Validity score by IOC. Form A, (Study 1) ................................ 88

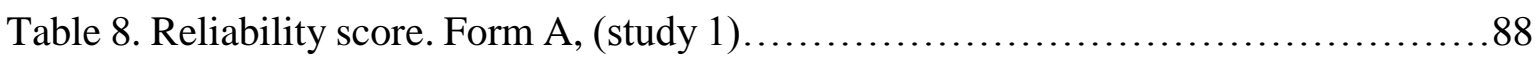

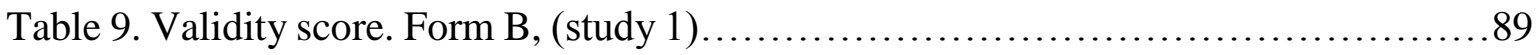

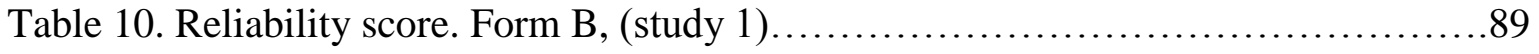

Table 11. Summary of IOC and subscale. Form A, (Study 2)........................ 91

Table 12. Reliability score and correlation between subscale. Form A, (study 2)..........91

Table 13. Validity score by IOC. Form B, (study 2)............................. 92

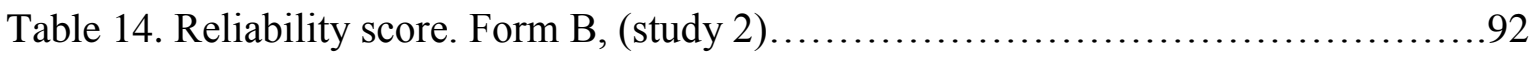

Table 15. Respondents' suggestions for improving the questionnaires (study 2)..........93

Table 16. Validity, and reliability score by complex examinations. Form A, (study 3)... 94

Table 17. Validity and reliability score (continued table).......................... 95

Table 18. Cronbach's Alpha and correlation between subscale. Form A, (study 3).......97

Table 19. Hypothesis examination by gender (study 4) .......................... 105

Table 20. Hypothesis examination by teaching experience (study 4)..................... 106

Table 21. Comparing the problem concerning instructional management (study 5)......111

Table 22. Hypothesis examination of instructional management by teaching experience

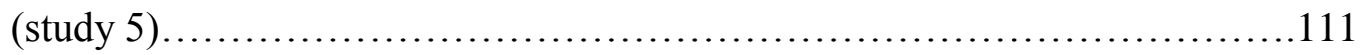

Table 23. Analysis of educational leaders' gender by t-test (study 6)..................126

Table 24. Qualification examination of educational leaders by ANOVA (Study 6)......127

Table 25. Working experience examination of educational leaders by ANOVA (study 6-

Table 26. Examination of working experience of educational leaders by Sheffe (study 6-

Table 27. Perception level of educational leaders between FOE and TTCs by t-test (study

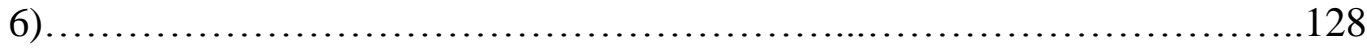

Table 28. Correlation between task and perception distribution (study 6).............. 129 


\section{List of tables (continued)}

Table 29. Analysis of teacher's gender by t-test (study 6 ).............................

Table 30. Qualification examination of teachers by ANOVA (study 6)................131

Table 31. Examination of Teacher's teaching experience by ANOVA (study 6).........133

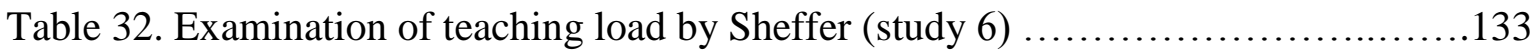

Table 33. Different examination of teacher professional development by Sheffe (study 6)..

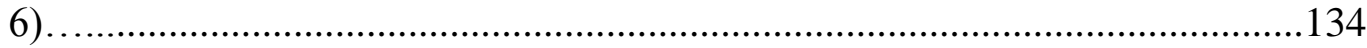

Table 34. Examination stress factors among teachers between FOE and TTCs by t-test(study 6 134

Table 35. Correlation between stress factors among teachers. 135 


\section{List of figures}

Figure 1. Obligation of the educational leader in management of teacher in Laos culture..48

Figure 2. Six tasks of educational leaders (Laos culture) .............................49

Figure 3. Teacher demands analysis........................................... 51

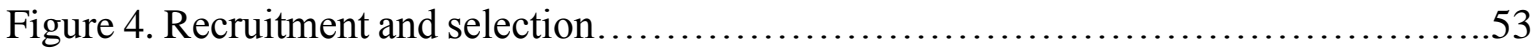

Figure 5. Structure of education system in Laos................................. 72

Figure 6. Number of TTIs, educational leaders, teachers and students within TTIs-Laos...73

Figure 7. Structure of teacher training institutions in Laos............................. 75

Figure 8 . Summary the findings of validity examination by IOC (Form A, study $1-3$ )...98

Figure 9. Summary the findings of reliability examination by Cronbach's Alpha (Form A,

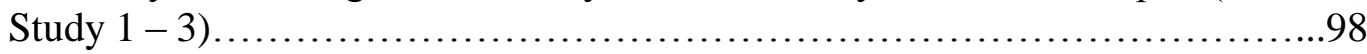

Figure 10. Summary the findings of validity examination by IOC (Form B, study $1-2$ )...99

Figure 11. Summary the findings of reliability examination by Cronbach's Alpha (Form B,

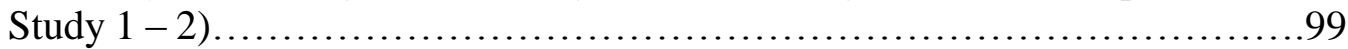

Figure 12. Summary of Cronbach's Alpha of main cause of teacher burnout syndrome (study

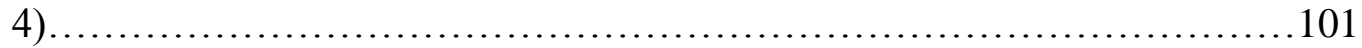

Figure 13. Cronbach's Alpha, mean, SD of teaching load by item (study 4).............102

Figure 14. Cronbach's Alpha, mean, SD of teacher welfare by item (study 4)............103

Figure 15. Cronbach's Alpha, mean, SD of teacher's professional development by item

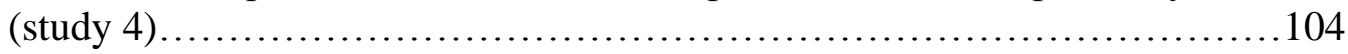

Figure 16. Correlation between subscale (study 4) ............................... 106

Figure 17. Confirmation examination of the main cause of teacher's burnout syndrome (study 4) 107

Figure 18. Summary of four facets by Cronbach's Alpha, M, and SD (study 5)..........109

Figure 19. Overall mean score, SD and Cronbach's Alpha of the six tasks (study 6)........113

Figure 20. Findings of teacher demands analysis by ranking mean, and SD (study 6).....114

Figure 21. Findings of recruitment and selection by ranking mean, and SD (study 6).....115

Figure 22. Findings of pre-service training by ranking mean, and SD (study 6)..........116

Figure 23. Findings of performance appraisal of teachers (study 6) $\ldots \ldots \ldots \ldots \ldots \ldots \ldots \ldots \ldots \ldots$

Figure 24. Findings of teacher compensation by ranking mean, and SD (study 6)........118

Figure 25. Findings of training needs assessment by ranking mean, and SD Study 6).....119

Figure 26. Summary of low perception level of educational leaders (Study 6)............120

Figure 27. Overall score of stress factors among teachers by Cronbach' Alpha (study 6)..121

Figure 28. Findings of stress factor relating to teaching load by ranking M and SD (study 


\section{List of figures (continued)}

Figure 29. Findings of tress factor relate among teachers welfare, by ranking M, and SD (study 6) 123

Figure 30. Findings of three stress factors among teachers relating to teacher's professional Development by ranking $\mathrm{M}$, and SD (study 6) 124

Figure 31. Summary of high stresses factors among teachers by ranking M, SD (study 6) 125

Figure 32. Summary of high hypothesis concerning to the perception of educational leaders

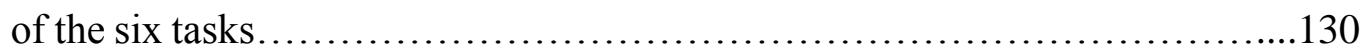

Figure 33. Different qualification levels and teaching load by Sheffe (study 6)..........132

Figure 34. Summary of the hypothesis concerning to the three stress factors among teacher within TTIs Laos 136 


\section{CHAPTER 1 INTRODUCTION}

\subsection{Background of the study}

Teacher Training Institution (TTIs) in Laos play a vital role in educating or providing teacher-students to become quality teachers employed in the public and private sector both across the country. These roles and functions require a high quality proper educational leader, materials and other intuitional resources to manage and support the teaching and learning process, and to accomplish the goals. It requires the organizations to pay attention to the teacher issues as they (teachers) are the practitioners of all projects, plans and activities within the institutions.

As we known, educational leaders and teachers work in the same places and interact with one another (EIU/SHRM, 2013), their trust and empathy in one another must be prioritized (e.g. Doornenbal et.al. 2012; Duret, \& Tournier, 2009; Ali, 2013; Arhipova.et. al. 2018). These traditional synergies are crucial in terms of building a relationship among leaders, teachers, students and the community (Bokdam \& Ende, 2014; Brusoni. et.al. 2014). When teachers feel supported by educational leaders/principals can they expand the same support to their students as well (e.g; Sergiovanni, 2009; Bus, 1995; Amadi, 2008, and Vannasy, et.al. 2014). It is confirmed that collaboration and cooperation amongst personnel, especially teachers and institutional leaders, can contribute to the organization's success.

Currently, there are 16 TTIs in Laos, including the Faculty of Education (FOE) within the Public Universities level and Teacher Training Colleges (TTC) (Decree, No. 4923/MOES/2016-Laos). These institutions are supervised by educational leaders including Dean, Vice Dean, Principal/Director-Deputy Director, Head-Deputy head. These successive positions have obligations in overseeing and controlling the institutions.

Educational leaders in the Laotian culture (Decree, No. 4924/MOES/2016-Laos) have their main functions and responsibilities in operating work described by three acronyms: 6Ms; POSDCoRB, and PARMSCOF (See in 2.6), working as a handbook or management principle for educational leaders (MOES, 1996). Besides, they have to be self-aware in their practices (Decree No. (177/GOL/2012-Laos). However, institutional leaders often neglect their functions and make many teachers face stress syndrome unavoidably.

The stress syndrome among teachers is common, threatening all the time. It is defined as a syndrome of strain, anxiety, worry, pressure, and tension (e.g. Cannon. et. al. 2014; 
Hofmeyer. et. al. 2015; Govardhan et. al., 2012). There can be many stress factors for teachers (e.g. Piscitella, 2016; Jacobson, 2016; Taheri et. al., 2012), such as related personal factors (family relationship, economic background), societal factor (belief and values) and organizational factors (work-related), including division of labor among teachers, role conflicts or ambiguity (e.g. Maslach, Schaufeli and Leiter, 2001; Bai, 2014; Bakker and Costa, 2014). It is well-known that all jobs can face stress syndrome through many factors, and one among those is connected to organization mismanagement through leaders' performance.

Other stress-causing factors can be an inappropriate policy scheme, working conditions, relationship among people, communication, bullying, favoritism, and different motivation (Connolly. et.al. 2017; Daft, 2010; Halasz, 2011, and Kıranl1, 2013; Otara, 2011; Vannasy, et.al. 2014; Gaynor,1998; Rees and Johari, 2010). The educational leaders' perception can be defined as a fabulous and laborious part of their behavior or sensation toward some things and duties authorized (e.g; Thalangsy, 2005; Sonebounnark, 2012, and Thosouvannachinda, 2001). In other words, it is psychological and behavioral that who can manage and be aware of the others (e.g; Ugwulashi, 2012; Wayne and Miskel, 2005; and Phommanimit, 2004). These above ideas showed the leaders'/managers' absent perception toward the subordinates like teachers making many project approvals of the organization become sterile automatically.

However, a core factor to succeed today is managing and administering teacher's growth, together with promoting the learning outcomes of students (Decree, No. (1232/MOES/2010-Laos). Thus, helping educational leaders accomplish their duties requires a core content of knowledge to foster their perception or awareness in analyzing teacher demands to obtain a number of actual requirements and assist the recruitment and selection process successfully and fairly (e.g. Sergiovanni, 2009; Gaynor, 1998, and Champathong and Soukanya, 2008). It means that for a good management of teachers, institutional leaders must start with analyzing teaching positions based on the labor market demands and be strict in recruiting and selecting new teachers.

Besides, educational leaders'/managers' need direct involvement in placing and orienting the working culture to the novices (e.g. Decree, No. (0047/MOES/PO/2014; Doornenbal, et.al. 2012; Duret \& Tournier, 2009; Ellen, 2011; Gaynor, 1998). These above statements were coherent to the MOES-Laos (1996), who have confirmed that educational 
leaders have a major responsibility in applying and benefiting all organization's resources including teachers to drive the institutions towards a better quality.

Also, teachers are more valuable than other resources within institutions of all levels and their profession is the largest labor force in the civil services, in the public and private sectors both (e.g. Condrey, 2010; Connolly, et. al. 2017; Cooper and Alvarado, 2006; Crawford., at. al. 2013, Göttelmann and Yekhlef, 2005); due to the teaching profession being the center or foundation of all occupations including scientists, leaders, engineers, agriculturist, politicians as well as the teachers themselves (e.g. Sergiovanni, 2009; Bus, 1995; Amadi, 2008). These viewpoints attempt to communicate the prestige of teachers as a unique profession through society's perception.

In conclusion, all backgrounds of the study have stated that the perceptions of educational leaders on the issues surrounding teachers is still clouded and against the local and international principles of educational management, as it is evident in case of TTIs across Laos that still face many problems and challenges today which should be examined via multi research activities to find a better way in efficient and effective problem-solving.

\subsection{Statement of the problem}

A large number of previous researches have highlighted at the institutions' mismanagement that caused stress, and served as stress factors amongst teachers and other staff members (e.g. Grissom, 2015; Halasz, 2011; Friedman \& Gavish, 2010; Go. Monachello \& Baum, 1996; Flippo, 1984; Okorie, 2016; Lingam, 2004, and Chongsirikul, 2003) The above researchers have indicated that teacher stress syndrome can originate from various sources such as personal conditions, organizations (lack of reward), and from societal influences. Furthermore, many management shortcomings were found in educational institutions (Barabanshchikova, et. al, 2014), such as the lack of teacher's corporate (Arif et. al., 2017); role ambiguity (Chongsirikul, 2003); working hard and poor workplace conditions (Wozny et.al., 2014, and Bokdam and Ende, 2014); lack of job security (Mutuwong, (2012); teacher welfare and unfairness in professional development (Sprenger, 2011); and the lack of involvement in decision making processes (Levy et. al., 2015). It is noted that management and maintaining of teachers needed to be taken into account and discreetly developed. 
Additionally, further problems are the increasing amount of tasks without authority to make a decision (Namuddu, 2010 and Somboon, 1997); the organization never cares for teachers' feeling of suffering which affects the learning achievement of students (Muguongo et. al. 2015; Viscardi, 2015, and Khan, 2015); different motivation among teachers (e.g. Bose, 2012; Gronn, 2010, and Chalearnswat, 2010); and the unfair distribution of the institutional resources (e.g. Chand, 2015; Channam, 1997, and Chongsirikul, 2003). The above studies showed that the educational leaders' neglecting of their duties relate to the issues surrounding teachers.

Besides, Champathong (2015) added that Lao teachers were not only teaching hard, but they also experienced frustration between senior and junior teachers. In addition, the annual movement report on the progress of TTIs (2016-2017) have highlighted the problems which the teachers complain about such as too many teaching obligations a week, inadequate teaching media or technological devices to assist the classroom processes in a more smart and smooth way, welfare and compensation were lagging and ambiguous, teaching career development was unsystematic, and also a clue in attending the soft-skill-training.

Moreover, the annual movement report on the progress of DOHE, DOTE, and DOP within MOES (2016-2017) have revealed that most educational leaders often failed in analyzing or forecasting teacher demands, which caused the recruitment and selection process of new teachers becoming inappropriate, lacking the provision of the rights and benefits to novice teachers, like orientation or pre-service training, performance appraisal, welfare and compensation, and training needs assessments.

All the above stated information indicate that teachers' stress is connected mainly to the perception level of organizational leaders paying much or little attention to the issues concerning teachers. Even though the Government of Laos, through the MOES, have provided a clear policy and created various legal education programs like teachers' Decrees and Provisions to be the main tool for educational leaders in practice.

However, teacher's losses or painful experiences in their teaching profession within TTIs across Laos still faces challenges today, and that's why my overall goal with this dissertation is to examine the gaps in the perception level of educational leaders of the six tasks and three stress factors among teachers. These two contexts are linked and never separate each other due to organizational obligations as the policy provider ensures all the 
rights and benefits to teachers and if they (teacher) get enough support from the organization, they will pay more attention to their students and other administrative works delegated.

\subsection{The rationales for the study}

Based on the context of the research in social sciences the themes or content the research should focus on are performance or practices, satisfaction, perception or awareness, problems or issues, needs or requirement, and situation (Gay \& Airasian, 2005; Sisaad, 2002; Sinjaru, 2012, and Phousion, 2011). Therefore, I have chosen this research topic as 'Instructional management and stress factors affecting teacher trainers as perceived by the educational leaders of Laos'. It gained a wide interest, and no one has conducted research on this topic in Laos before. This topic is extremely associated with my teaching field in the course of human resource management in education, it was also fully supported by relevant departments within MOES, and TTIs. However, other reasons for choosing the research scope and its components are also addressed.

Regarding the distilling technique of three main causes of teacher burnout syndrome (study 4); four facets or aspects of issues in instructional management (study 5), and three stress factors among teachers (study 6) I have synthesized some extreme problems occurring among teachers at TTIs (See 1.2) and selected some issues of teachers from the literature which, similarity to the Laos context, and TTIs' educational leaders, were strongly supporting and motivating me to conduct the above research as well.

The selected six out of ten tasks used for study 6 was mainly extracted from the annual movement report of the progress in 2016-2017 backward of the DOHE, DOTE, DOP within MOES (See 1.2). These yearly reports were broadly controversial concerning the gaps of perception among leaders/principals toward their functioning concerning the six tasks (See 2.6). These tasks required an examination to prove what these leaders/principals within TTIs ignored or neglected on their practices.

Self-constructed questionnaires were employed for study 4 and 6 as this research topic is rarely found in a completed version in Laos and in international publications concerning the educational leader's perception toward the assignments. In other words, a self-made instrument helps us to follow the scope and cover all aspects of the research study, fit to the context, field, real situation and local respondents. It offers processable data, respondent anonymity, it is inexpensive, easy in data coding, analyzing, and interpreting the outputs, 
The above reasons inspired me to create self-made questionnaires (See more reasons in 2.2.1).

However, for study 5, I have adapted and adopted the questionnaire from the previous study. Other justifications related to applying a different number of points Likert Scales such as 3,4, and 5 in the dissertation, depending on the research design and its latent constructs, context, scope and aims, and objectives of each sub-studies (Soukkhavong, 2010; Sisaad, 2002, and Sinjaru, 2012). Other motives pertinent to Likert scale usage have also been broadly addressed (See details in 2.2.3).

The rationale behind targeting the selected institutions and samples is the following: I have divided the 16 TTIs across Laos into two groups and utilized them in different purposes, considering TTIs according to the minor or major problems they face. So, I have selected 8 TTIs to examine the validity and reliability or quality measurement of the self-constructed questionnaires through study 1,2 , and 3.

The remaining 8 TTIs included Practice Schools as well where a lot of problems occurred. These I have invited for study 4, 5, and 6. In case of study 6 or the main study I have selected only those educational leaders who have a teaching obligation not more than 6 hours a week, and teachers who have a teaching obligation not more than 12 hours a week.

Due to the above indicated reasons, I intend to reveal the mask of educational leaders /principals that are the roots or causes of stress among teachers within TTIs, a reason why I am eager to research this topic. I hope that the findings of the present studies can provide valid information and help to find better ways in problem-solving processes relating to the management of teachers to make the TTIs more efficient and effective in the future.

\subsection{Research Aims}

As I have addressed earlier, and to arrive at all research aims, this dissertation consists of six empirical studies including the main study. The research aims of all studies are proposed as follows:

- Study 1, 2, and 3 aims to examine the validity and reliability of the self-constructed questionnaires by focusing on detecting and eliminating all erroneous words and phrases and looking for the proper words and phrases. These self-made questionnaires were designed to be used in collecting data for study 6 or main study. 
- Study 4 aims to explore the main causes of teachers' burnout syndrome affected by school board mismanagement, by examining three subscales like teaching load, teacher welfare, and teacher professional development; to compare the respondents' opinions and to gather feedback from the respondents for further solutions.

- Study 5 aims to examine the problems concerning the instructional management under the supervision of educational leaders, to compare and to gather suggestions from the teachers to be a guideline in the problem-solving of instructional management within three Faculties of Education in Public Universities in Laos.

- Study 6 or main study aims to (1) examine the perception level of educational leaders of the six tasks; (2) investigate the main stress factors among teachers; (3) compare the independent variables and the dependent variables among educational leaders and teachers respectively, and (4) collect the respondents' suggestions to improve the management of teachers within TTIs-Laos.

\subsection{Research questions}

This study intended to address the overall research questions based on the scope of the study, statement of the problems and research aims as earlier mentioned. In order to support the final research findings, the following questions of each study and the main study will be laid as follows:

\section{Study 1, 2, and 3}

1. How can the present studies 1,2 , and 3 examining the validity and reliability contribute to questionnaire development referring to the management of teachers? What are the respondents' suggestions to improve the questionnaires?

\section{Study 4}

1. What is the main cause of burnout syndrome amongst teachers in practice schools developed due to their school board mismanagement?

2. Are there statistically significant opinions by gender and working experience concerning school board mismanagement?

3. How can teachers' voice or feedback contribute to the decrease and prevention of chronic issues in the teaching profession? 


\section{Study 5}

1. What are the problems concerning instructional management under the supervision of educational leaders?

2. Do the participants have different opinions concerning instructional management?

3. How can the respondents' suggestions contribute to the improvement and development of instructional management's efficiency and effectiveness?

\section{Study 6 (Main study)}

1. How does one of the six tasks' low perception level of the educational leaders within TTIs toward the instructional management?

2. What is the main cause of stress amongst teachers affected by organizational mismanagement?

3. Are there statistically significant differences between the independent variables toward the six tasks, three stress factors and TTIs' level?

4. What suggestions do respondents require to instructional management of teachers in TTIs in Laos?

\subsection{Research hypothesis}

Research hypothesis are classified following the five studies and the main study, and to respond all the above questions, the hypothesis for each study and main study are presented below:

\section{Study 1, 2, and 3}

$\mathrm{H}_{1,2}$, and 3: We expect to obtain strong validity and reliability from each examination of the self-constructed questionnaires respectively (form A and B).

\section{Study 4}

$\mathrm{H}_{4}$ The gender and the teaching experiences of teachers at practice or demonstration schools would result different points of view toward the school-board management. 


\section{Study 5}

$\mathrm{H}_{5}$ Teachers at TTIs in Laos of different gender and teaching experiences are expected to have no significant differences in their opinions concerning the instructional management.

\section{Study 6 (Main study)}

$\mathrm{H}_{6}$ We expect no significant differences in the perception of educational leaders analyzed by gender, qualification level and working experience.

$\mathrm{H}_{7}$ Educational leaders working at different TTI levels (FOE and TTC) are expected to have no differences in the perception level of the six tasks.

$\mathrm{H}_{8}$ In accordance with the previous results, we anticipate strong correlation between the sub-scales (six tasks)

$\mathrm{H}_{9}$ Based on teachers' different gender, qualification levels, and teaching experiences, we expect they will face different stress sources in teaching profession.

$\mathrm{H}_{10}$ Teachers who teach on TTC level expect higher stress in their teaching career than teachers in FOE level.

$\mathrm{H}_{11}$ We hypothesized strong correlation between the subscales (three stress sources).

\subsection{Structure of the dissertation}

This dissertation is comprised of five chapters. Chapter One introduces the context of the study, statements of the problem, the rationale of the study, research aims, research questions, and research hypothesis, as well as the organization of the dissertation is also presented.

Chapter 2 discusses insights about the conceptualization of the constructed instrument to support study 1,2, and 3. Besides, it introduces the theoretical background of burnout syndrome among teachers (study 4); the conceptualization of instructional management (study 5); the perception on principle management of teachers and the main cause of stress factors among teachers (study 6 or main study), the education structure and teacher training institutions in Laos, the key definitions of the whole study, and the chapter summary are also discussed.

Chapter 3 broadly discusses the methodology of each research study and the main study performed within TTIs in Laos, including the target institutions used for the studies, 
the samples and its sampling technique, the instruments and their development, the procedures and the chapter summary are reviewed systematically.

Chapter 4 presents the study findings or analyzed data of six studies included in the main study. Each study is explained and interpreted in accordance with the established research aims, questions, and hypotheses, and finally a chapter summary is conducted. Lastly, Chapter 5 concludes each study by presenting a conclusion, discussions, implications, summary by SWOT analysis, future research suggestions, references list, and the appendices containing the research instruments applied to collect the data of all the studies are attached. 


\section{CHAPTER 2 LITERATURE REVIEW}

\subsection{Introduction}

The perception or awareness of educational leaders toward the functioning and responsibilities relating to issues surrounding teachers and the stress factors among teachers are connected in terms of distrustfulness and conflicts with each other within TTIs in Laos, which is needed to be examined and it is necessary to investigate these gaps from both groups' working performance. Hence, this chapter attempts to review the conceptualization of the self-constructed questionnaires through three examinations (study 1-3). These instruments consist of two forms or sets (form A for educational leaders and form B, for teachers) that aimed to be used to collect the data of study 6 or main study.

Besides, the conceptualization of burnout syndrome among teachers and problems in instructional management are reviewed to support study 4 and 5 respectively, the two context studies (See details in chapter 3). Furthermore, the conceptualization of the perception, and the management of teachers in Laotian culture, the rationale for choosing the six tasks and three stress factors and its concepts are represented in details, the education structure and TTIs in Laos regarding study 6 or main study, defining keywords and key expressions as well as the chapter summary are reviewed.

\subsection{Conceptualization of the constructed instrument}

This section presents the conceptualization of the constructed instrument (questionnaire) pertaining to the $1^{\text {st }}, 2^{\text {nd }}$, and $3^{\text {rd }}$ study, and the reasons for creating a self-constructed questionnaire. As we know the instrument is one of the most important research components; it is a key tool to help the researchers obtain valid information or facts from the target participants (e.g. Radhakrishna, Gliner and Morgan, 2000; Nunnally,1978; Brancato et. al., 2006; Loyal, 2016).

The questionnaire is one of several research instruments that research scholars widely use in quantitative, qualitative as well as mixed researches by adapting or semi-adapting the existing instruments or developing new ones to fit the research field and local situation (Gagne.et.al. 1998). It is also highly useful in collecting individual data and opinions in an appropriate way and in a short time (Aina, 2004; Siniscalco and Auriat, 2005). Besides, it 
can elicit information on feelings, attitudes, beliefs, values and perception (Johnson and Christensen, 2012).

In addition, questionnaires can be adjusted and fixed in various forms like using a Likert scale, closed and open-ended questions to reach all classes of respondents (Wilkinson and Burmingham, 2003). Sinjaru (2012), Likitwattana (2012) and Sisaad (2002) noted that educational research prefers 'closed questions' in three cases: indication of gender (male/female), ranking, and rating 'multiple choice questions. The measurement level of variables can be nominal, ordinal, scale and interval, depending on the depth of information we would like to acquire and the statistics to be performed.

Normally a research instrument can be formed as questionnaire, an interview, observation, diary, focus group discussion, or a semi-interview structure (e.g. Joppe, 2000; Kiranli, 2013; Soukkhavong, 2010; Green and OECD, 2012; Likitwattana, 2012; Kronick, 1999; Winter, 2000). These above stated has confirmed that questionnaires are proper instruments in the field of social science research.

\subsubsection{The motives behind the self-constructed questionnaires and their components involved}

Due to the above described reasons (1.3), I have decided to use questionnaires and openended questions in my current research study, because the construct was applicable in several fields and levels, offering a high visibility for eliciting valid information from the samples selected.

- A self-administered questionnaire helps the researcher develop and create research tools that fit the genre of the research context accurately and visibly elicits the facts (e.g. Sisaad, 2002; Winter, 2000; Soukkhavong, 2010; Olso, 2010; and Joppe, 2000). It is obvious that the researcher will know well the current situation and what the organizations are faced with so far, so the self-developed tools are single ways in the domain of scientific research, and these should be formed to meet the local context and scope of the study.

- A self-made questionnaire can contribute to the precise scientific analysis and anticipations concerning the observed phenomenon (e.g. Johnson and Christensen, 2012; Isaac and Michael, 1995; Likitwattana, 2012; Oppenhein, 1992; Anderson, 2004). I have acknowledged that the research instrument must be firm and familiar to the respondents and they will complete the questionnaires easily and happily. 
- A self-constructed questionnaire can enable the researcher to ask the questions freely, and obtain or gather authentic information from the respondents (e.g. Green and OECD, 2012; Sinjaru, 2012; Kronick, 1999). The author agreed that the research instrument is a key determinant in obtaining answers to all research questions, aims, and hypothesis.

- Educational research aims to elicit valid information from the targeted participants by using various kinds of research instruments and the questionnaire is one amongst those well-recognized research tools (Sisaad, 2002; Gliner and Morgan, 2000; Alwin and Kronick, 1982). The research instrument fits the research scope and the sample, it can be a valid and reliable tool towards acquiring the research findings.

- A self-developed questionnaire allows the researcher time for piloting and choosing the measurement expertise to gain valid, reliable, local-word, brief and interesting information (Siniscalco and Auriat, 2005; Loewenthal, 2004; Kirk and Miller, 1986). It is evident that the research instrument must be created in the language the respondents know, using familiar words and phrases in the constructed instruments.

Concerning the proper number of sample members for examining the validity and reliability of the self-constructed questionnaires, it is important for the empirical study participants to be appropriately informed and understand what is involved in their research participation (Smith and Fogarty, 2016). Aside from expert reviews it has a value in identifying problems with the question that would result in lower survey data quality (Olson, 2010). Selecting appropriate participants will maximize the weight of a well-designed questionnaire of all forms automatically (Phousion, 2011).

A greater total number of participants were taken into the sub-study because the questionnaire was administered in different ways of the measurement; Some scholars (e.g. Hilton, 2015; Hill, 1998; Connelly, 2008; Treece and Treece, 1982) suggested that a piloting or empirical study sample should be $10 \%$ of the sample projected for the large-scale study. Others (e.g. Isaac and Michael, 1995; Hill, 1998) proposed around 10-30 participants in each pilot study.

Van Belle (2002) suggested 12 participants and 30-60 participants of two different categories. Sisaad (2001) and Likitwattna (2012) offered 3-5 specific experts and 20-30 academic staff to assess internal consistency. Johnson and Christensen (2012) recommended we should conduct a pilot study examination with a minimum of 5-10 people. 
Birkett and Day (1994) identified 10 experts and a maximum of 40 academic staff as a group. Sinjaru, T. (2012) proposed 20 people from the total of the main study. Julious (2005) confirmed a group of 12 people out of the major research study. Sim and Lewis (2012) introduced at least 55 people to be included in a pilot study. Olson (2010) proposed around six experts to evaluate the questionnaire.

Therefore, in this dissertation I have invited 128 respondents to take part in the examining of the validity and reliability of the self-constructed questionnaires. The sample included measurement experts, senior teachers, academic staff and teaching staff. These groups had differently responsibilities in assessing the questionnaires, and also, these respondents were excluded from study 6 or main study.

Regarding the importance of loading words and phrase into the questionnaire, worduse with precise and standard definitions is widely utilized in survey questionnaires. Harrison (2007) and Turner (2003) stated that researchers are obliged to use a language that is related to the field of research, local and minority words and phrases, and leave out ambiguous questions, technical jargon, uncommon words and childish language. An examination with specific experts is required to make sure the words are understandable for the selected target group (e.g; Sinjaru, 2012; Tungsujarittam, 2014; Likitwattana, 2012; Brancato et al; and Krosnick, 1999).

Oppenheim (1992) and Warwick and Lininger (1975) suggested the words used in the questions should be understandable to all respondents. Alison (1998) stated that interpretation of those words should be as universal as possible among respondents. Tourangeau and Yan (2007) stated that wording should avoid bias that would push answers one way or another.

Likert (1970) and Thurstone (1928) proposed that the impact of the idiosyncrasies in items' wordings should be minimized. Krosnick (1999) logically thought that the items used should be those few most efficient and effective ones expressing the construct of interest.

The importance of loading words and phrases into the questionnaire can be summarized, so a central perception on the self-constructed instrument has a various and complex component to obtain a high external and internal consistency of the construct before using it for the large-scale research study. 


\section{2..2.2 Principles of constructing the questionnaire}

Several publications outlined the principles and steps of constructing questionnaires depending on the research field, topics, aims or objectives. Sisaad (2001) suggested six principles:

(1) identify aims or objectives clearly of what we need;

(2) make the questions match the research objectives;

(3) schedule the questions on the draft's titles basis;

(4) avoid huge and redundant questions;

(5) minimize the respondents' barriers;

(6) language of communication.

The examiner of the questionnaire should be aware of wording, sentences and phrasing for making the questionnaire easy to understand, and fit to the respondents' qualification background. Each item should focus on one problem, has to avoid multiple answers, has to use familiar or local words and no confidential information should be asked for.

Johnson and Christensen (2012) offered twelve principles of questionnaire construction:

(1) items must match the research aims;

(2) understand well the targeted participants;

(3) use the field-relevant words and local language;

(4) use clear words and single sentences;

(5) do not use 'leaded or loaded' questions;

(6) avoid double-barreled questions, and double negatives;

(7) determine the type of questions needed (open-ended or closed questions);

(8) use mutually exclusive and exhaustive responses for closed-ended questions;

(9) determine the type of measuring scale;

(10) be cautious about reversing the wording to prevent response sets in multi-item scales;

(11) design to meet the perception level of the respondents, and

(12) must conduct a pilot examination in at least three rounds to make sure about its external and internal consistency (validity and reliability).

Sinjaru (2012) recommended seven principles for questionnaire construction:

(1) study and compile the relevant theories and concepts then analyze and synthesize prior to drafting the questionnaire structure;

(2) identify and scope structures and items' language usage; 
(3) discuss with supervisor (improve more, if disagree);

(4) specific experts check (improve more, if disagree);

(5) meet supervisor for piloting or tryout with 20-30 participants out of the main sample of the full-scale study;

(6) analyze data to see the questionnaire's quality;

(7) improve and complete the questionnaire package and offer it to your supervisor for validation.

Likitwattana (2012) offered five principles of questionnaire construction:

(1) identify and scope the basic requirement;

(2) select the type of researchers' instruments appropriately;

(3) draft the structure and consider the wording of each item in the questionnaire;

(4) examine the quality with multi-methods, and

(5) improve and complete the package.

Soukkhavong (2010) offered three sections to be included in questionnaires:

(1) respondents' personal data;

(2) the main aspect of the research study;

(3) additional opinions at the end of each aspect;

Beside the above stated principles regarding the construction of the instrument, some techniques to measure the validity and reliability level are applied to examine the quality of the questionnaires as shown below:

First, validity is often defined as the extent to which an instrument measures what it purports to measure, it determines whether the research measures well (e.g., Winter, 2000; Joppe, 2000; Wainer and Braun, 1998). The question of the explicability of the results does not concern them (Glesne and Peshkin, 1992; Winter, 2000).

Credibility and transferability (Hoepf, 1997) provide the lenses for evaluating the findings of a qualitative research. Through examining the validity of the research instrument, it is to confirm that all research components are connected to one another. The Index of ItemObjective Congruence or IOC is a procedure used for evaluating content validity at the item development stage at > 0.50-1.00 (e.g. Sinjar, 2012; Rovinelli and Hambleton, 1977; \& Likitwattana, 2012).

In addition, all ambiguous wording in the measuring instrument can be minimized (Krosnick, Narayan, and Smith, 1999). It can create a perceived distance between the object 
in the respondents' mind and maximize the rigor of appropriateness of the procedures utilized at the developmental stages (e.g. Alwin and Jackson, 1982; Berk, 1984; Turner and Carlson, 2009).

Hardesty and Bearden (2004) suggested four types of validity examination: internal validity refers to the validity of the measurement and examination itself and focuses on face validity, concurrent, productive and construct validity, whereas external validity refers to the ability to generalize the findings.

Siniscalco and Auriat (2005) offered three kinds of validity examination like content (or face), empirical (or predictive) and concurrent validity. Besides, "validity is the most important characteristic an examination or measuring instrument can possess, and it is also crucial in all forms of research and all types of examinations and measures as well" (Gay and Airasian, 2005. p. 37.).

Also, it involves three main distinct types such as 'content validity, meant to compare the content of the examination to the domain being measured, and determined by expert judgment; criterion-related validity, to observe whether the correlation score from one examination to the criterion measures either the same or different; construct validity is the accumulation of convergent, divergent, and content related evidence to determine that the presumed construct is what is being measured (Sisaad, 2002. p. 47).

Sinjaru (2012) considered the consistency of educational research crucial in becoming sure the research is valid and reliable and would respond to all research questions, aims and hypothesis as well. Validity examination could be conducted through various methods, depending on the major field or area and the specific purpose, questioning, and hypothesis (Ellen, 2011). One of the most preferred techniques of validity examination used widely is the Index of Item-Objective Congruence or IOC. Rovinelli and Hambleton (1977) stated that IOC is an examination procedure used for evaluating content validity at the item development stage.

In other words, validity examination aims to extend whether the examination is what it is supposed to measure and perform. It is generally measured in degrees as a process involving the collection and analysis of data to assess and monitor the examination score variables through the statistical devices. Likitwattana (2012) suggested some validity examination by IOC technique with 3-5 measurement experts for a careful check and 
validation toward consistency based on the acceptance criteria. The IOC formula is presented below:

$$
\begin{aligned}
\text { IOC } & =\frac{\Sigma R}{N} \\
& \text { Where }: \\
\text { IOC } & =\text { Index of Item-Objective Congruence } \\
\mathrm{R} & =\text { Index item score rate by specific expert } \\
\Sigma & =\text { Sum score } \\
\mathrm{N} & =\text { Number of measurement experts } \\
\text { IOC } & \geq 0.5 \text { (criteria of average IOC) }
\end{aligned}
$$

Harrison (1983) proposed a rating criteria IOC examination which is a tool that can help the experts in questionnaire assessment. This base criterion provided three options such as (+1) meaning words and objectives are congruent; (0) meaning not sure about word and objective congruence, and (-1) meaning words and objectives are not congruent.

Besides the above offered rating criteria measurement, it is important to recognize the criteria of interpretation to assist the researcher in indicating the output of data analysis easily. Liker (1970) has introduced the criteria of interpreting IOC values: between 4.215.00 means the highest level, IOC value between 3.41-4.20 means a high level, IOC value between 2.61 - 3.40 means a moderate level; IOC value between $1.81-2.60$ means a low level, and IOC value between 1.00 -1.80 means the lowest level.

Second, reliability in a quantitative method needs to demonstrate that the research instrument behaves in a standardized manner in accordance with the predetermined procedures. The questions are good if the research instrument measures what it is supposed to assess (Almeida, Resende, \& Stobaus (2015). In the wider sense, it is devising an examination and its significance to ensure the explicability of the results (Crocker \& Algina, 1986).

However, reliability and validity are tools of an essentially positivist epistemology. Golafshani (2003) as cited in Winter (2000) and Joppe (2000) have proposed "reliability as the extent to which results are consistent over time and an accurate representation of the total population under study is referred to as reliable if the results of a study can be reproduced under a similar methodology; then the research instrument is considered reliable" (p. 598).

Moreover, Golafshani (2003) as cited in Kirk and Miller (1986) recommended three types of reliability such as examination results, given duplicate, and stability, and the 
steadiness. The stability of measurement over times, and the similarity of examination of a measurement over times, and likeness of criterion insides under the time schedule (p. 598).

Furthermore, Golafshani (2003) as cited in Charles (1995) adheres to the notions that "consistency with which questionnaire [examine] items are answered or the individual's scores remain relatively the same can be determined through the examination-reexamination method at two different times" (p. 598). In addition, Golafshani (2003) as cited in Joppe (2000) detects a problem with the examination-reexamination method that can make the instrument, to a certain degree, unreliable. According to Crocker and Algina (1986) respondents and items play a key role mutually in the measurement process (p. 599).

Ellen A. Drost (2011) considered reliability a major concern when a psychological examination is used to measure some attribute or behavior and it should be performed through an estimate of reliability, like examination - reexamination or the split-half approach. These reliability examinations aim to expose the correlation coefficient between items. Some researchers (e.g. Nunnally, 1978; Loewenthal, 2004; Kline, 1979) maintained that increasing reliabilities much above 0.70 is often a waste of time and funds.

However, the scholastic measurement theory viewed that any score gained by examining questionnaires is composed of both the authentic score, which is unknown and the error in the measurement process. The accurate score is an essential parameter that a person would have received if the measurement were perfectly reliable. In other words, the reliability examination can be thought of as consistency. There are four general estimators that we may encounter in reading research:

- Inter-Rater/Observer authentic: The degree to which different raters/observers give consistent answers or estimates.

- Examination-Reexamination accuracy: The consistency of a measure evaluated all the times.

- Parallel-Forms honesty: The security of two examinations of the same constructs and content.

- Internal Consistency reliability: The consistency of results across items, often part with Cronbach's Alpha. Cronbach (1951) concluded that the Examination of accuracy coefficient for internal consistency of questionnaires should be carried out with maximum 10-60 respondents to see the Alpha-Coefficient score is significantly greater at $>.75$ totally and each item score's significance is greater at $>.80$, to consider item homogeneity. 
Tungsujarittam (2014) proposed some ideas to evaluate the examination's reliability; the KR-20 was used in the study. The examination's reliability shows accurate measures of the examination takers' proficiency whenever the examination is used, with different students and/or different examination takers (Green et. al., 2009a). The KR - 20 values are between $0-1$. The closer the value is to the whole number 1.00 , the greater the examination's reliability is. Conversely, the closer KR-20 gets to 0.00 , the lower consistency the examination has. Thus, the criteria of the examination's reliability greater than 0.60 is acceptable.

Aside from creating a guideline for the educational context, like standards, and prediction through communication structure (Banks, 2000) it also aims at the production of a detailed critical examination and discussion (Green, 2014). Additionally, researchers can obtain more accurate data using questionnaires distributed to a group of anonymous experts at a distance than in face-to-face committee meetings where certain individuals tend to dominate the decision-making process (Delbecq, Van de Ven and Gustafson, 1975).

The reliability measure aims to communicate means and focuses on a non-consensus meeting of the expert panel or anonymous responses with at least 2-3 rounds, (Linstone, Turnoff and Helmer, 2002). Nonetheless, it also helps researchers cope with the unforeseen circumstances concerning wording, phrases and sentence structures in the items.

The process uses three main methods that are trend projection, scenario writing and consulting others. Another method is widely applied as the consensus of the panelists in an anonymous or non-face to face meeting (Sinjaru, 2012).

In my opinion, reliability examination plays a key role in detecting and eliminating incorrect words, terminology, and phrases according to its fit or inappropriateness to the field of the research objectives, scope, subscale and items bank.

Third, in the examination of reliability consistency can be conducted through Delphi technique which is adapted and applied widely in measuring the quality of the research instrument. Joppe (2000) stated that the extent to which results are consistent over time and an accurate representation of the total population under study are referred to as reliability and if the results of a study can be reproduced under a similar methodology, then the research instrument is considered to be valid and reliable.

The iteration is a major means of asking for help from the panelists to polish and treat the deserved stages (Bollen, 2002). The Delphi technique is focused on consensus-building 
by using a series of questionnaires delivered using multiple iterations to collect data from a panel of selected subjects (Chien Hsu and Sandford, 2007).

In addition, to assure the internal and external consistency in the measuring process, the Delphi technique was originally developed by pioneer panelists in the 1950s, as well known in a continuing score amassed process from the previous examination. Throughout the measurement experts in each diagnosis round aimed at detecting and eliminating all the wrong wording, expressions, phrases from the question-items.

This technique was widely applied in terms of measuring and evaluating the research instruments in various fields (Culbertson, 1988). With this in mind, in the field of education various means were used in such predicting of the unforeseen circumstances, planning, teaching methods, assessment and evaluation, curriculum improvement and development. This technique also provides solid procedures and gives a scientific merit to which the examining continues (Greenberg et. al. 2012).

The Delphi examination process is normally performed in at least 2-3 rounds, with similar aims, with the same group of panelists selected from the related field and the computation by SPSS will focus on the score of IOC, Median and Inter-quartile Range or IR.

In the first-round open-ended questions are used to serve as the cornerstone of the content area and field. The experts are asked to relate the constructed quality of a performance examination and whether they agree with the definition and terminology applied in the items, as well as it will achieve the consensus by using rating and interpreting criteria of IOC to complete an explanation of the examination results. However, a minimum of $67 \%$ agreement is required from the participants and this round also aims at deleting items with a low IOC and modify or re-filter words if it is applicable (e.g. Phousion, 2011; Robertson et al; 2017).

In the second round, after the questionnaires have been reviewed, the item summaries are based on the information provided in the first-round with researcher discretion, syntheses, and executive summary, without embedding the personal ideas prior to conducting the third round (Sinjaru, 2012).

Besides, in the second round the consensus begins forming and the actual outcomes can be presented among the participants' responses, robustness checked by panelists with comments pertaining to omitting, remaining items, comparing the two first examinations and 
its revision to confirm the quality of the construct and part of the conducts will be used as the rating criterion (5 points Likert scale).

In the third round, as a final stage of measurement, the same panelists receive the constructed form with a similar aim of examination with the rating scale provided. This round also gives the panelist an opportunity to advise the further scheme of information relating to the items' reliability.

However, the contrasting of the first-two examinations previously would be performed to observe the correlation scores of the first two rounds and its fluctuation by using different Likert scale checklists in accordance with the aims of each examination. For example, curriculum development elicits consensus over the needs of curriculum committees and presents odd digit-points Likert scale mainly to rate and mark the consistent degrees amongst research objectives, word usage, phrases, and sentence structures in each item statement.

The Delphi technique consists of at least two rounds of measurement experts answering questions and expressing justifications for their comments, arranging the opportunity among rounds for modifying and revisions.

In summary, different types of measurement instruments have been discussed like validity (IOC), reliability (Alpha and Correlation), Delphi (Medn and IR), Possibility Index ( $\bar{x}$ and SD) as well as the kinds of Likert scales, range and reasons to utilization through these complex process were widely discussed related to the measurement instrument process. Table 1 below displays the statistical applications used for the examination of the constructed questionnaires.

Table 1 Statistical applications for the examination of the questionnaires

\begin{tabular}{lccc}
\hline \multicolumn{1}{c}{ Statistics applied } & Study 1 & Study 2 & Study 3 \\
Validity examination (by Index of & & $\checkmark$ & $\checkmark$ \\
Item of Objective Congruence or & $\checkmark$ & & \\
IOC) & & $\checkmark$ & $\checkmark$ \\
$\begin{array}{l}\text { Reliability (by Cronbach's Alpha and } \\
\text { Correlation coefficient) }\end{array}$ & $\checkmark$ & - & $\checkmark$ \\
$\begin{array}{l}\text { Delphi (by Median and Interquartile } \\
\text { Range or IR) }\end{array}$ & - & \\
\hline
\end{tabular}

\subsubsection{The reasons for using different Likert scales}

The Likert scale plays a key role in assisting the respondents selected to rate and mark each item statement that fits their current situation, and feel free to express themselves through 
open-ended questions. The rating scale checklist or Likert scale provides a range of choices that often applies four Likert scales in terms of certain tendencies like perception, recognition, reminding, and warning toward the professional ethics or shaking of job awareness on the task delegated (Sisaad, 2002). This kind of Likert scale intends to eliminate the midpoints and use even number of options for their justification from strongly agree to strongly disagree or SA to SD (Shoukkhavong, 2010).

Besides, the odd number, for example, five-, seven- or nine-points Likert scales are commonly used based on the main study, such as situation, problem or issues, needs or requirements, understandability, satisfaction, performance or practices (Phousion, 2011; Sinjaru, 2012). The rating and interpreting statement can be flexible or adjustable, convenient to the objectives of each study, and other options or scale checklists with three to five or more can be applied and retain a measured variable.

A measuring scale can either directly indicate the value of the measured quantity or only indicate its equality to a known measure of the same quantity and its value of the small difference between the measured quantity and the measure having a value very close to each other.

The measuring instrument has to obtain and communicate the quantity degree to which the measure is scored toward the criteria established. Therefore, the examination makers have an obligation to measure the validity of perspectives on the relationship between constructs, variables, and instruments (Gay and Airasian 2005).

The measuring instrument can be conducted several times through multi-techniques to meet the requirements of measurement standardization and serve a variety of objectives (e.g; Sisaad, 2002; Stamm et. al., 2009).

Gay and Airasian, (2003) have noted that measurements use scales which depend on the research field, research topic, aims and its variables. These are the cognitive examinations including achievement, aptitude; affectivity, awareness or perception, consisting of attitude scales such as those from Strongly agree to Strongly disagree, and other five-point Likert scales; project examinations comprising of materials in pictures and people's feelings. For the types and characteristics of the measuring instruments lease see Table 2. 
Table 2. Types and characteristics of measuring instruments

\begin{tabular}{cc|c|c|c}
\hline \multirow{2}{*}{$\begin{array}{c}\text { Type of research } \\
\text { instrument }\end{array}$} & \multicolumn{4}{c}{ The characteristics of the measurement } \\
\cline { 2 - 5 } & Validity & Reliability & Difficulty & Discrimination \\
\hline Questionnaires & $\checkmark$ & $\checkmark$ & - & - \\
Test & $\checkmark$ & $\checkmark$ & $\checkmark$ & $\checkmark$ \\
Attitude & $\checkmark$ & $\checkmark$ & - & - \\
Interviews & $\checkmark$ & $\checkmark$ & - & - \\
Observation & $\checkmark$ & $\checkmark$ & - & - \\
\hline
\end{tabular}

(Source: Sisaad, 2002. p. 122.)

In summary, based on the above-mentioned principles and components of constructing questionnaires, the construction stage should be clear and precise, operated under the local situation and field language, avoiding bias words, phrases, and doublebarreled questions. Besides, these principles of instrument construction have offered a variety of points Likert scales based or depending on the scope of study and its research aims and objectives, just like I have adapted and applied to study 6 (main study).

\subsection{Theoretical background of burnout syndrome among teachers}

This section discusses the concept of teacher's burnout syndrome which is addressed in study 4.Teachers' burnout syndrome is the main obstacle to the quality of education or human resources development, especially in case of preparing the teacher-student for being recruited and employed at any level of the education institution. Burnout can be the state of chronic stress that causes physical and emotional exhaustion, cynicism, detachment, and feelings of lack of success and lack of potential performance. "The chronic perception that one is unable to cope with daily life demands and it is caused by the occupations that put them at risk for burnout" (Dworkin, 2001. p. 76).

It can also cause untrustworthiness and a chronic disease linked to the educational field as one of these problems is derived from the organization and teachers themselves. These chronic dilemma issues become a threatening phenomenon in every professions, affecting many teachers also, either within a single school year or over the course of a number of years.

There is a three-component syndrome of emotional exhaustion, depersonalization and feelings of low personal accomplishment (Jackson. et. al, 1986). Three dimensions of exhaustion, cynicism and inefficacy. Some researchers (e.g. Maslach, 2001; Dworkin, 2001) 
confirmed that burnout originates from the chronic perception that one is unable to cope with daily life demands and it is caused by occupations that put them at risk of burnout.

When one has to negotiate potentially stressful interactions among parents, administrators, counselors, and other teachers, exhaustion exceeds the physical limits. Moreover, Haberman (2004) have seen that job burnout syndrome is a condition of the spirit, when the soul is 'windblown topsoil, a spent strip-mine'.

On the other hand, Moczydłowska (2016) viewed that individuals with particular psychological characteristics such as neuroticism (a mental or personality disturbance not attributable to any known neurological disorders) are more vulnerable. The social environment at the workplace can also have significant impacts on burnout (Jagodics and Szabo, 2014).

Kyriacou (2001) stated that the causes of teachers' burnout come from several sources. Those dilemma issues are highly influenced by administration, management, time pressures, workloads, classroom management and school climate. In addition, financial issues and welfare also become problems influencing teachers' burnout. However, the roots of teachers' burnout syndrome cannot be limited to social and personality factors only, but the organization can also act as the main stress source. According to Haberman (2004) the most powerful cause of stress has to do with teachers' perceptions of administrative support.

They attribute great importance to the socio-cultural and social-structural factors as determinants of illness probability (Cannon, 1992). The primary sources of burnout related to the organizational conditions and the personal characteristics of the helping professional (cited by Roach, 2009. p. 17.). Cultivating a workplace culture where staff members feel influential - where their insights are sought, and their views are heard, may serve to diminish the stress-burnout relationship (Landrum et. al., 2012).

Bauer et. al. (2006) viewed that "burnout has been shown to be more common among women, especially individuals who are divorced or employed part-time". In addition, “Teachers' burnout is one of the most common reasons why effective teachers leave the profession due to an interaction of environmental and physiological factors" (Roloff and Brown, 2011.p. 435.).

Martin et al. (2012) have noted that lower levels of efficacy in student engagement and teachers are also important predictors of burnout development and of an increased likelihood 
to leave the profession. There are several personal characteristics that affect the development of burnout.

Moreover, "Teachers are especially vulnerable as they perceive a great deal of selfworth from their profession, and these demands challenge their sense of identity" (Parkeretal, 2011. p. 319.). Also, "student discipline is considered to be the critical aspect for teachers' exhaustion" (Klusmann, 2008. p. 148.).

An enormous number of job burnout reports has been published and described in diverse views corresponding to the different environmental pressures. These chronic symptoms can cause a negative impact on the job achievement and the organization, public and private both, which has an obligation to solve those problems to promote the product. Some previous research results found job burnout sources like individual and job environment, including the expectation of social welfare, leader behavior, and bullying among laborers (Beehr, 1998; Savicki and Cooley, 1986).

However, the causes of teachers' burnout in the current research are career symptoms influencing their duties impacted by the practice schools and these schools were under the supervision of the Faculty of Education, national University of Laos, the place the author of the present dissertation has been working at for a long time. Teachers' burnout is expected to be caused by three pressure sources as shown below:

1) Burnout syndrome due to teaching load. The practice schools assign too much teaching hours per week to teachers, which is against the Decree No.4923/MOES/PO/2016Laos. The Decree specifies that the teaching load of the teaching staff at higher education level shall not exceed 12 hours a week. However, in practice, they have more teaching load than enacted, which seems to be a main cause of burnout syndrome among teachers.

2) Burnout syndrome relating to teacher welfare. The package of teachers' welfare specified in the Decree No. 177/GOL, 2012-Laos has mentioned that teacher employees deserve verbal praise, intrinsic and extrinsic motivation from the TTIs in order to relieve the disadvantaged circumstances.

Furthermore, teachers' welfare as a psychological and emotional phenomenon is closely associated with social status, especially with the position of the teaching staff as a builder of knowledge, skills, and experiences for young learners to be able to serve and meet the labor market demands. 
3) Burnout syndrome in connection with teacher professional development. The schools board or principals at practice schools has the main function and responsibility to provide short- and long-term trainings for specific purposes, in diverse formal and informal forms, in the home country and abroad (Decree No. 177/GOL, 2012-Laos). The growth occurs as the teacher moves through the professional career cycle (Glatthorn, 1995).

Prempridy (2000) added that part of a good organization management would be a well-functioning and responsible school board and other educational leaders at all levels of the school system who keep in touch to guarantee that teacher employees obtain a full range of professionalism on their teaching career including academic performance and etiquette and morality reinforcement.

It can be concluded that there is no single theory and concept to clarify the definition of job burnout syndrome, especially in the teaching profession, where of the environmental threats include individual and social factors and organization mismanagement. These factors are barriers to the quality of education and other socio-economic development. It should not be ignored; examining the workplace, school board management skills, and other environmental support would play a key role in reaching school quality and efficiency.

\subsection{Conceptualization of instructional management}

The teaching and learning process is the heart or central task of educational institutions in promoting credible and academic freedom in the academic sphere (Soukkhavong, 2010). To achieve the goals, the management and development of teaching methods would be a prioritized task (Gagne, et. al.1998). It calls for educational leaders paying more attention to teachers, students, and other school environments (Thalangsy, 2005). These views shed light to the importance of the instructional management process via multiple methods that can help the students understand more and enjoy their learning.

This section is a brief literature review relating to study 5 which focuses on four issues that teachers in three Faculties of Education in Laos often encounter concerning instructional management, such as creating a lesson plan or planning a presentation in advance for smooth class performance, instructional practice, instruction via technological devices, and instructional assessment and evaluation. 
Soukkhavong (2010) has proposed some teaching methods like applied science, craft and reflective practice. These models emphasize learning how to teach, peer interactions or peer review as well as sharing with one another. O’Neil (2005) suggested five teaching techniques as continuing education versus deficit instruction, organizational structure, curriculum and staff development, teacher personal growth, and re-definition of the administrative role. These models have a focus on improving school efficiency, research development, problem-solving, curriculum development, school activity, behavior, traditional and teaching-learning assessment and evaluation.

Healy (1993) offered four reflective teacher models: observe reflecting; interpretinggeneralizing-conjecturing and applying-examination-validating. Day (2014) raised four models namely the apprentice-expert, the rationalist, the case studies, and the integrative model. Day and Conklin (1992) offered four types of knowledge that are content knowledge, pedagogical knowledge, pedagogical content knowledge and support knowledge.

The UNESCO (1994) noted that a teaching staff and other educators having a charisma is critical, as they can develop not only themselves, but they can also make a fluent change in student learning. Giroux (1983) viewed educators as having a unique role in critique, because they can change not only themselves but can also influence change in students. According to the UNESCO (1994) the nature of universities as organizations is a complex issue, not least because of the changing perceptions of the functions and value of universities in the society. It seemed that the leadership of higher education institutions has been placed under increasing scrutiny since the 1980s, on the basis of experience records for creating a new candid model.

Following CEART-UNESCO (2015), with the global pressures driving change in higher education, the quality of teaching in universities is under increasing scrutiny and students in this level are demanding a better-quality teaching. The UNESCO-EFA (2014) viewed that teachers have every chance to put their motivation, energy, knowledge and skills to work in the service of improving learning for all.

In my point of view, some factors relating to issues faced in instructional management is consequent from the leaders' lack of instructional leadership, that they should pay attention to the investment in both teaching materials, and oriented-skill training amongst teachers continually, and specifically. 
The following four aspects were the problems in instructional management within three Faculties of Education in Laos, that teachers confront today, and there was a need to examine its roots as follows:

First, one of the main responsibilities of the instructor when planning a presentation is to transmit the knowledge and skills to the learners via activities and examples supporting each stage of a lesson plan (Sisomphou, 2007). Creating a lesson plan includes aiming, instruction style, role-play, timeline, field trip, assignments, and a continuous assessment scheme by peer-review mainly (Achinsamacharn, 2012). When creating a lesson plan, it should be generated in a shorter form than the length of the actual lesson (Cunningham, 2009).

In my opinion, a lesson plan is the instructor's preparatory manual to which he or she anticipates the learners' needs and plans how to drive students towards the happy learning, achieving the goals effectively. It should contain more activities, examples, and student roleplays and group discussions instead of students having to face too much contents to cope with the boring phenomena.

Second, instructional practice should be mentioned. After completing the lesson plan, it deals with classroom management of how to transmit the planned lesson that is welldesigned and the relevant activities to aid learners' efficiency and effectivity. The instructor needs more multi-teaching techniques in performing.

Gill (2013) proposed the following teaching styles: the authority or lecture style, the demonstrator or coach style, facilitator, the delegator or group style, and the hybrid or blended style; those deal with the transmission arts of instructors.

Bloom, Englehart, Furst, and Krathwohl (1956) proposed five steps that are presentation, controlled practice, clues, practice, and production. I think these steps can be understood as aside from well-designed lesson plans, the delivery techniques or mediators are one of the most important factors for instructors that should be acquired and be solid about in the major field, and arouse peer-reviews and feedback among students and let them feel free to learn in what they prefer and apt to, instead of the teacher- centered or talkative style.

I think these instructional styles make us re-think about the nature of delivery or the transmission of information. It should not be a single method, and it should strongly promote learning autonomy, be child-centered among student-learners, the instructor has to respect 
the students' potential capacity and coach them through multi-techniques to facilitate or guide them and guarantee a free access to learning sources via search engines or online, smartly and fluently.

Third, instruction via technological devices comes. It is the concept of human-techno and practice concerning the utilization of technologies to help the management, development, evaluation process, instructional resources and the art of communication. It also includes feelings, and the willingness of students to encourage the creation of the learning method as self-learners.

Brown, Kenneth and Srygley (1972) think that instructional media is utilized in learning activities; it affects the effectiveness of the learning tools. Prempridy (2000) added that a wide range of learners' diversity, disparity, and the needs of facilitation to foster the learning outcomes became the priority perception of leaders or principals. Phisane (2015) confirmed the advantage of using technology devices to encourage instructional performance assist the individual learning, advocate collaboration and benefits for instructors.

It can be said that instruction via technological devices is a form of an integrative and complex process involving people, procedures, devices, organization, problem-solving, assessing-evaluating, in which learning in one's country and abroad is the main aim.

Fourth, instructional assessment and evaluation are explained; both terms are often used interchangeably. Assessment applies to individuals' progress or output, while evaluation goes beyond the students' achievement or outcomes (Jabbarifar, 2009). In addition, instructional assessment is a vital activity in the educational institution at all levels to measure the students' learning achievement through diverse teaching methods and techniques.

Channam (1997) and Wheatley (2002) added the processes of creating an appropriate assessment for objectives, and articulating connections between objectives and standards and benchmarks. Geddes and Kooi (1969) proposed that it is the process of monitoring the progress of pupils. These above concepts pointed out the need for a process to find better ways paved for the further improvement of both instructors and learner's performance, to improve and motivate the right person.

All the above stated four facets can be summarized as: instructional management is the way of the teachers preparing the presentation together for a beautiful class performance, 
via multi technological devices and excellent communication or transmitting knowledge and skills towards the learners. An active class relies on activity and new teaching material support. Educational leaders play a key role in fundraising and providing the teacher with multi teaching methods and skills to assist the teacher in utilizing a diverse technology device smoothly, to promote effective classroom performances.

\subsection{Perception on management}

There are no single theories and concepts identified exactly on effective management, it depends on the situation or unforeseen circumstances, and cases such as public governance, business, economics, finance, commerce, and investment as well as education and human resource management. These sectors have their own established vision, mission, perception of ethics, goals, and objectives for their practices. This section presents the concept of management, educational management, and the perception of issues surrounding teachers.

\subsubsection{Concept of management}

Management and administration, these terms may seem to be the same as well as different depending on the field, situation, genre of work and duties. However, some perspectives in the late $20^{\text {th }}$ century referred to administration as a top position and related to planners, policy-makers, decision-makers determining all objectives and issues parameters, while management as middle and lower positions are concerned with putting the plans into practice. Administration neglected to make use of the organization's resources, meanwhile, management attempts to economize and utilize all the resources optimally (e.g. Sergiovanni, 2009; Bush, 1999, Halasz, 2011; Arhipova, 2018).

Management is the process of dealing with or controlling things or people (Prempridy, 2000). Many publications have been published about management, some of those viewed management as a partial, interacting the standpoints of their authors. Those which try to widely describe an approach are frequency rather bland. Hlatshwayo (1996) described it as a downbeat that management is a continuous process through which members of an organization seek to coordinate their activities and utilize their resources in order to fulfill the various tasks of the organization as effectively as possible. Cuthbert (1984) indicated that it is an activity involving responsibility for getting things done through the people. 
Daniel \& Guta (2009) says, that it is a continuous process in a way, as several interrelated activities have to be performed by managers; irrespective of their level to achieve the desired goal. Management is often included as a factor of production along with machines, materials, and money. According to Drucker (1988) the basic task of management includes both marketing and innovation. Stoner \& Freeman (2008) thinks management is the process of planning, organizing, leading and controlling the efforts of organization members and of using all other organizational resources to achieve stated organizational goals.

The ILO (2012) confirmed understanding the importance of human resource policies and practices in the process of recruiting, retaining, and professionally supporting. Brusoni (2014) stated that excellent organizations manage, develop and release the full potential of their people at an individual, team-based level. They promote fairness and equality, involve, and empower their people.

The significance of good management for the effective operation of educational institutions has been increasingly acknowledged during the 1980 and 1990s (Bush, 1995). Leadership is a stage of the process in position or none position toward personal characteristics and charisma that appears between leader and subordinates or employees.

Mette et.al. (2016) think that leader perception impacts every work that requires to facilitate and motivate all subordinates. Perception is a self-management or control, selfregulation and discipline toward professional ethics (Vannasy et. al. 2014). "Managers and leaders in organization are entrusted with employees whom they must work with and through to realize organizational objectives" (Otara, 2011, p. 23).

Perception is a personal characteristic in a sensory stimulation toward the duty's commitment (Thosouvannachinda, 2001). It is a stimulus on organizational culture of how to work together (UNESCO-IIEP, 2016). It is an art of leaders for interpret and express the thoughts through the people (Yukl, 2006). Furthermore, Otara, (2011) added that factor altered perceptual process of leaders often concerns personal habit, motivation, specialization, and social background or social ladder. These causes make leaders themselves become unintentionally blind to their employees automatically.

Teachers or the teaching profession is more important in Laos and in the world today that every government takes into account and each country has its own ways in managing and maintaining teachers. In Lao PDR aside from the Law on education (2015) as the main reference, it is also included in sub-law, rules, and disciplines like teacher's Decrees; 
Ministerial decrees; resolutions, and other relevant enactments to be used as instruments of the supervision process

Normally, the structure of educational institutions in Laos culture have individual divisions of work or tasks, such as personnel issues including teachers that is a central responsibility to every educational leader, and they must involve those tasks as analysis of teacher demands, recruitment and selection, orientation of new teachers, teaching appraisal, welfare supply, and teaching career development, transfer and termination of teachers.

Unfortunately, management of teachers can scarcely be found in publications in Laos and in other information sources, while the teaching profession and their prestige was widely praised and recognized as a single factor helping people to become healthy, happy and welldoing in the society (e.g. NASSP, 2015; OECD, 2004). O'Neill \& McMahon, 2005); they became the main mechanism to boost the country's GDP growth (e.g. Phiengphanyoukorn, 1991, Thomas, 2005, and Sanchez, 2011).

It can be said that management is the process of the educational leaders toward the perception of functioning and responsibilities where they should use their science and arts to manage and oversee all the organization's resources including teachers as well, who worth more than other resources.

\subsubsection{Educational management}

In case of the term 'educational management', the most literature reviews and other related publications have emphasized the significance, purposes or goals in the educational context. Bush (1995) stated that educational management is a field of study and practices concerned with the operation of the educational organization.

Connolly et. al. (2017) concluded that 'educational management entails carrying the responsibility for the proper functioning of a system in an educational institution in which others participate' (p. 3). Educational management is also often used with the relevant organization's partial hierarchy, in which those who are holding higher positions in the ranking order, have more powers and duties than others in lower positions. Prempridy (2000) confirmed that educational management is also often associated with organizational structures that are rigid and inflexible and therefore have no place in the complex and dynamic world of an educational institution. 
The term 'educational leader as a manager or administrator' refers to a person who was appointed as a head of a group, team or organization. He or she is a charismatic person who is able to make a good decision and motivate others to accomplish the goals. Some researchers stated that 'Leadership' is the process of influencing others to understand and agree about what needs to be done and how to do it and the process of facilitating individual and collective efforts to accomplish shared objectives (Hughes, 2002; Northouse, 2004; and Burn, 1978).

Yukl (2006) and O'Leary (2000) proposed, that it is crucial for managers in the business world, but it also plays an important role for coaches, teachers, and parents. Fairholm (2001) suggested that it is a philosophical and developmental relationship among people who share common purposes, motivations and values. According to Louis (2015) leadership is all about organizational improvement; more specifically, it is about establishing agreed-upon and worthwhile directions for the organization in question, and doing whatever it takes to encourage and support people to move in those directions.

So far it can be summarized that educational management is the field of study related to educational leaders' or principals' attempts to utilize their sciences and art to manipulate and use the organization's resources in an economic way to maximize the benefits. In other words, educational management or formerly known as educational administration, often covers the motivating of people to work together through a six factors help, seven functions and eight responsibilities well known as '6Ms, POSDCORB, and PARMSCOF; these acronyms will appear in the next discussions.

\subsubsection{The perception of educational leaders (Lao culture).}

Educational leaders should recognize the word 'perception' as a self-awareness on job or functions assigned. According to several scholars (e.g. Sergiovanni, 2009; Bush, 1995, and Conley \& Bacharach,1990; Mette, et.al. 2016; Schwab. Et. al. 1986) leaders' high or low perception in functioning can influence the subordinates' feelings in working performance. Perception is a self-management or control, self-regulation and discipline toward professional ethics (Thosouvannachinda, 2001). Moreover, some researchers (e.g. Vannasy, et.al. 2014; Freeman, 2007; Hlatshwayo, 1996; Patrick. et.al. 2014, and Otara, 2011) noted that perception of principle management is a hard work because it requires one to be aware of himself as well as be sensitive to his response and reaction to others. 
Educational leaders have to acknowledge the word 'management' which was more widely approached than the administration in both public and private sectors, due to administration as a top position is related to planning, decision-making and determining all objectives, issue parameters, as well as this approach for neglecting to use the organizational resources while the management as a middle and lower position is concerned with planning, and putting the plans into action, decision-making and attempts to economize by utilizing all organizational resources reasonably and optimally (e.g. Sergiovanni, 2009; Bush, 1999, Halasz, 2011; Arhipova, 2018, and Muguongu, 2015).

Teacher training institutions in Laos as public organizations attempt to find the best solution relating to the inefficacy of educational leaders which is, a single way to maximize the productivity with minimizing or economizing the organizational resources utilization of particular teachers, to which educational leaders should be obliged and perceived to perform according to the rules and regulations relating to teachers as enacted should be implemented and bring fairness to teachers.

Educational leaders should know the term 'educational leader as a manager or administrator' that refers to a person who was appointed as head of a group, team or organization. He or she is a charismatic person who is able to make a good decision and motivate others to accomplish the goals. Some researchers stated that 'Leadership' is the process of influencing others to understand and agree about what needs to be done and how to do it and the process of facilitating individual and collective efforts to accomplish shared objectives (Hughes, 2002; Northouse, 2004; and Burn, 1978).

Besides, "the roles and responsibilities of the educational leader are broad and demanding. Requirements from the state, as well as expectations from parents, students, staff members and teachers, frequently pull administrators in competing directions" (Vannasy et al; 2014). In addition, the perception of the responsibility is a common sense of leaders who are aware of the duties without any influence or threat (Sergiovanni, 2009).

Grobler (2002) highlighted at the educational leaders' role in educational institutions of all levels regarding the management of the curriculum, organizational structures, financial and physical resources. The excellence of the educational leader will play a vital role in both recruiting and selecting the proper teacher candidate to teach the vacated subjects (e.g. ILO, 2012; Bose, 2012; Brewster, et.al. 2011; Daniel \& Gupta,2009; Drucker, 2005; Fairholm, 2001; Poempool, 2003; Stoner \& Freeman, 2008; Toth \& Hodi, 2014). 
In addition, MOES-Laos, (1996) that was adapted and adopted from Gluick and Urwick, (1937; Furlong and Barton, 2000; NSHRDP, 2016; Olejniczak, 2013; Ordho \& Nzoka, 2014; Koontz and O'Donnell, 1982) proposed the educational leaders' functions and responsibilities in forming their job with regards to job design and description, decentralization in selecting the right teacher candidate to perform their job best.

However, in Lao culture, the roles and importance of teachers need a good management and maintenance in order to meet the organization (e.g. Ali, 2013; Abdou et. al, 2012; Anderson, 2004; Bolman and Deal, 2000; Bose, 2012; Bush, 2005). This subsection would like to introduce the six factors for effective leaders (6Ms), seven essential functions (POSDCORB) and eight priority matters or affairs (PARMSCOF), these obligations were the main principles of work for educational leaders, which they must perceive and be aware of in their daily operation within the educational institution.

First, they should perceive the six factors for effective educational leaders or 6Ms. It is reasonable that investing in human capital is of high return rate and it needs to manage and utilize resources utterly. Drucker (1988) has created a famous acronym 4 Ms like Man, Money, Material and Management skills. Based on teaching experiences records, I have added two own ideas with further 2Ms like Moral-Motivation and Management of time, with which I hope to help the leaders lead the organization successfully.

- Man/Manpower or personnel, it is the first ' $\mathrm{M}$ ' in this concept that plays a vital role in every organization (e.g. Cannon, 1992; Chand, 2015; Condrey, 2010; Curthbert, 1984; Deem, 2002; Day and Sammon, 2013; EIU/SHRM, 2013; Flippo 1984). It is clear that recruiting and selecting the right labor force can help the organization meet the challenges of the world competition.

- Money: it is the second ' $\mathrm{M}$ ', in the twenty first century; the more competition occurs, the more investment of all organizational resources is required to prove and analyze systematically (e.g. Ganynor, 1998; Glathorn, 1995; Glober, 2002; Goet et al, 1996).

- Material: it is the third ' $\mathrm{M}$ ' and educational leaders at all levels will be committed to acquire and apply materials through modern technological devices.

- Moral-Motivation: it is the fourth ' $\mathrm{M}$ ' to which educational leaders shall turn to promote judgment among people within the organization to harmonize and work smoothly together. These ideas were also raised by many scholars and they stressed that a good leader will not be able to perform well if he/she is without a rote and is not aware of professional 
ethics (e.g. Louis, 2015; Luprichaseth, 2012; Mathis et. al., 2004; Mavis 2014; MOES-DOP 1996-Laos).

- Management of time, as the fifth ' $\mathrm{M}$ ' as the last acronym; we known well that time is a unique or intangible resource which is part of our life, work, and we cannot store and transfer or offer it to others. Time and leaders are like a sheet on two pages that never separate from each other. A good time management can bring massive benefits to organizations in the realm of the competition process (e.g. Ugwalashi, 2012; Mulf et. al. 1999; Sergiovanni, 2009; Mutuwong, 2012; and Slipicevie, 2012). In this case, leaders have to decide on something in the right way, in a limited amount of time, to select the right teacher for teaching the right subjects or courses.

- Management skills, it can assist leaders to promote problem-solving, motivation, professionalism, innovation and technical skills, and providing reward and incentives for workers (Sonebounnark, 2012; Ugwulashi, 2013; UNESCO-IIEP, 2014; Vannasy et. al., 2014). The sixth ' $M$ ' was central to managing all the above resources of the organization, without this skill, we cannot get the highest benefits of those available resources.

Second, educational leaders should understand that seven essential functions of educational leaders in Laos culture or POSDCORB are the most important mechanism tools, and perceive that administration means the higher-level functions, while management is the middle and lower level function, and each function has own established responsibility and task to encourage people to perform their job best (e.g. OECD, 2007; Bose, 2012; Chand, 2015).

Relating to the formulation of functions and responsibilities, Gluick and Urwick (1937) as the pioneers of the vibrant question 'what are the manager's tasks or functions?' later developed the famous acronym POSDCORB which is widely used in all genres and levels within the organization, in both private and public sectors, including education.

Besides, educational leaders/principals shall be responsible to design the work and handle or assign job to personnel individually based on the knowledge, skills, attitude, aptitudes and satisfaction (e.g. Drucker,1995; ECDC, 2017; Eunice, et.al. 2014; European Commission, 2008; Haki Elimu, 2009; Harvey, 1995, and John, et. al. 2017).

These functions are 'Planning, Organizing, Staffing, Directing, Coordinating, Reporting and Budgeting'. Furthermore, several scholars and documents (e.g. Haimann (1974; Lao SABER, 2016; Law of Civil Servant, No (023/NA/2016-Laos; MOES, 2015- 
Laos; MOES-TVET, 2015; MOHA, 2013; Morgan, 2006; O’leary, 2000; Reimer \& Kaptain, 2013; Senge, 2012; Sergiovanni, 2001; Williams .et. al. 2014; World Bank, 2016) proposed some steps relating to the staffing or personnel issues including job analysis, recruitment and selection, orientation and placement, training and development, remuneration, performance evaluation, promotion, transfer, and termination.

In addition, these famous acronym letters or POSDCORB was adapted and adopted for the Lao culture to fit the local situation. It was published in the first handbook for educational administrators issued by MOES in 1996. This book is the main guideline for the novice administrators and managers at all levels of the educational institutions (from kindergarten to university, provincial and district educational offices).

Finally, in the principle or handbook for educational leaders in the culture of educational management and administration in Laos, it must be kept in mind that eight issues or affairs, known as PARMSCOF became a main responsibility for daily work, and each famous acronym or issue has created its own task and activity. In the above presented abbreviation, the letters stand for Personnel, Academic, Research-network, Massorganization, Student activities, Community relations, Office-services, and Financeplanning (MOES, 1996-Laos), and the educational leader has an obligation to utilize these acronyms optimally and fluently to accomplish each issue.

The MOES (1996-Laos) added that each of the above issues has an own task establishment to avoid the overlap in the operation process due to leaders' intertwining and it is also a source of conflict. For instance, the personnel issue constitutes of 10 tasks that are teacher demand analysis, recruitment-selection, pre-service training, performance appraisal, compensation-welfare, professional development, punishment, salary and position promotion, training needs assessment, retirement and termination. Figure 1. summarizes the obligations of the educational leaders in the Laos culture.

Figure 1. Obligations of the educational leader (Laos culture)

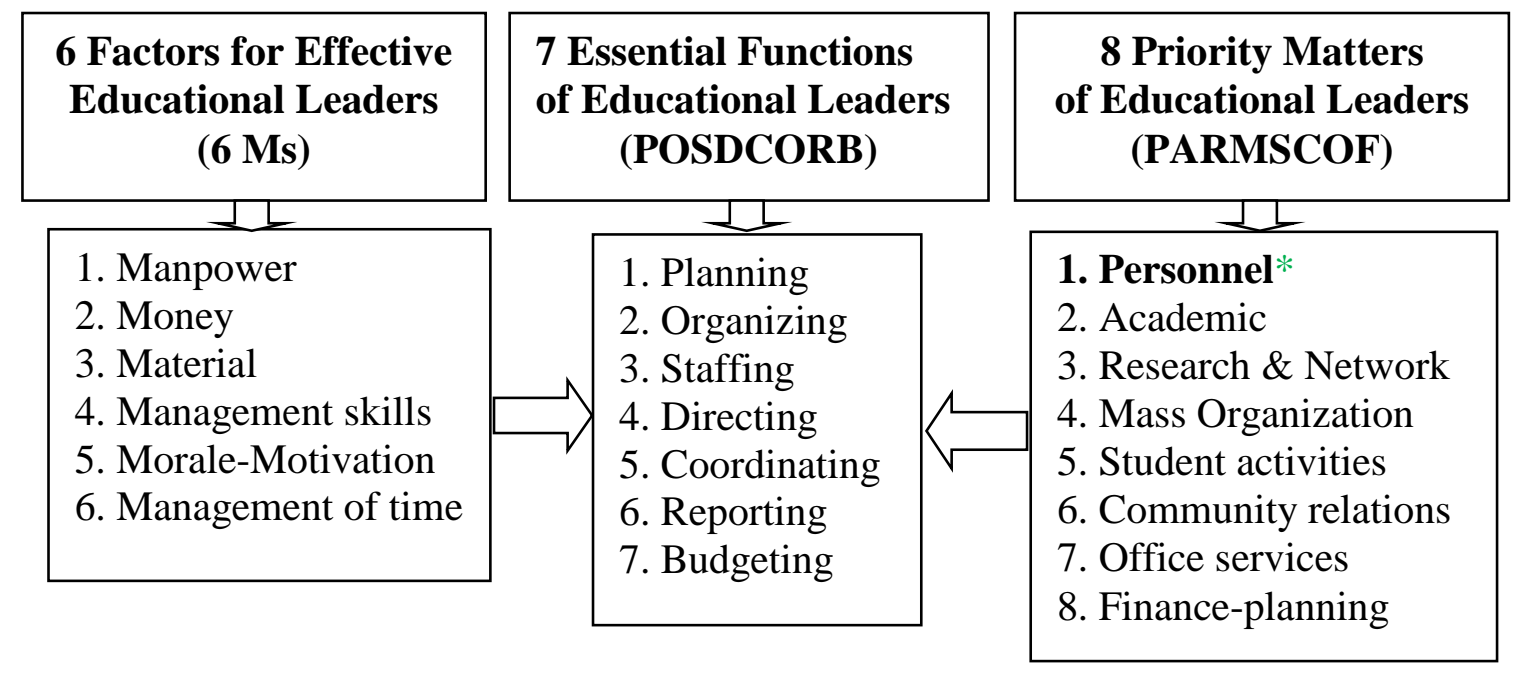




\subsection{Six tasks for the effective management of teachers}

The subchapter is based on the background of the study and its connections as well as a statement of the problems indicated in chapter 1 relating to the efficacy and efficiency of educational leaders/principals toward their assignments. Several previous studies have blamed the educational organization's mismanagement for the problem of teacher shortages (Ayuk, 2012). There is a discrepancy between leaders' perception of the role and teachers' expectations (Nwikina and Nwanekezi, 2010). Unclear job analysis has a negative implication for employees (Nyasha et. al. 2013). These studies' findings have shown the low perception level of leaders or principals on the demands and supply of teachers. Figure 2. depicts the six tasks of educational leaders.

Figure 2. Six tasks of educational leaders examined in the dissertation (Laos culture)

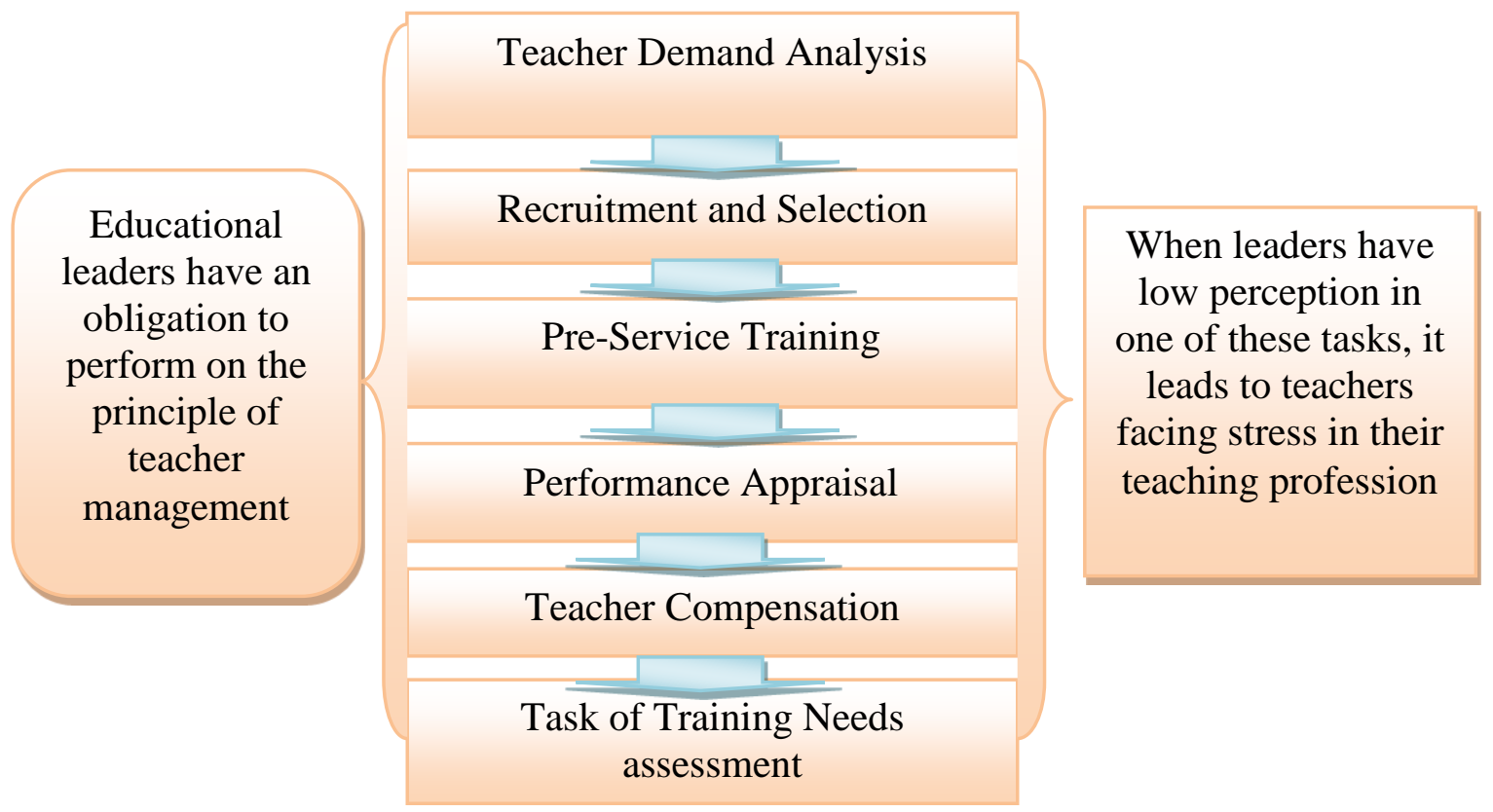

\subsubsection{Tasks of Teacher Demand Analysis (TDA)}

This task aims at proposing a short conceptualization on the above-mentioned job analysis. First of all, to establish and document the job relatedness of the task, position, and the number of required new teacher employees (quotas) in the following year. Second, it can help in operating the process of recruitment and selection, pre-service training, performance appraisal, managing compensation and other teachers' benefits (Sananh, 2009). 
Prien, Goodstein and Gamble (2009) thought that without job analysis, it is difficult to prepare a useful job description, and without a job description, it would be impossible to 'fill' any job vacancy successfully. It is the process of systematically collecting substantial information, job allocating, duty and responsibility (Thosouvannachinda, 2001).

Besides, (Vannasy et. al, 2014) it is the data collection based on rigorous information to be the criteria in job allocating, duty and responsibility. According to Chanthala and Phommanimith (2004) it is the process of gathering relevant data on duty and task responsibility of employees based on their knowledge, skills, aptitude and attitude for better performance.

Sackett and Lacz (2003) considered job analysis a wide variety of systematic procedures for examining, documenting and drawing inference about work activities, workers' attributes, and work context. According to Condrey (2010) it refers to a purposeful, systematic procedure that provides a description; the important job being distinguished from other jobs. Lewis and Doorlag (1998) considered job analysis a good way to aid other concerned tasks, due to supporting most human resources functions.

(1) Job description analysis is an important document, which is descriptive in nature and contains a statement of duty and responsibility. Prempridy (2000) declared that job description is a written narrative describing activities performed. Job description includes

- Responsibility: it comes from the Latin responses, which means 'to respond'. It is the state of being the person who made something happen, which something covered the required duty and task (Vannasy et. al., 2014).

- Duty: it is the conduct coming from parents and superiors, a moral or legal obligation or something a person feels he or she ought to do because it is morally right. It is the task that the team or colleagues have to do together (Chanthala and Phommanimit, 2004).

- Task: the smallest identifiable and essential piece of a job that serves as a unit of work, and as a means of differentiating between the various components of a project (Chanthala and Phommanimit, 2004). It can be said that task is a piece of job or work that describes clearly the duties and responsibilities relating to the specific activities.

(2) Job specification analysis is the process of translating the job description into the terms of human qualifications, which are required for performing a job, or a written statement of qualifications including knowledge, skills, abilities and talent as below: 
- Knowledge: According to Prien et. al. (2009) knowledge is defined as an organized body of information, usually of a factual or procedural nature, that when applied, makes job performance successful.

- Skills: Prien et. al. (2009) considered skills the proficiency in manual, verbal or mental manipulation of people, ideas or thing. Besides, they added that skill is one of those social science words in colloquial language that has many meanings, numerous synonyms such as 'ability', 'competence', 'knack', 'aptitude', and various inexact translations in other languages.

- Ability: It is the quality of being able to do something, meaning especially the physical, mental, financial, or legal power to accomplish something. Prien et. al. (2009) stated that ability is defined as the present capacity to execute a job action, to perform a good function by applying an underlying knowledge base and necessary skills simultaneously.

- Talent or Aptitude: it is a capability; ability; innate or acquired capacity for something, to create specific ability or talent of humans or job seekers. For the summary of the Teacher Demand Analysis Process see Figure 3.

Figure 3. Task 1: Teacher Demand Analysis process

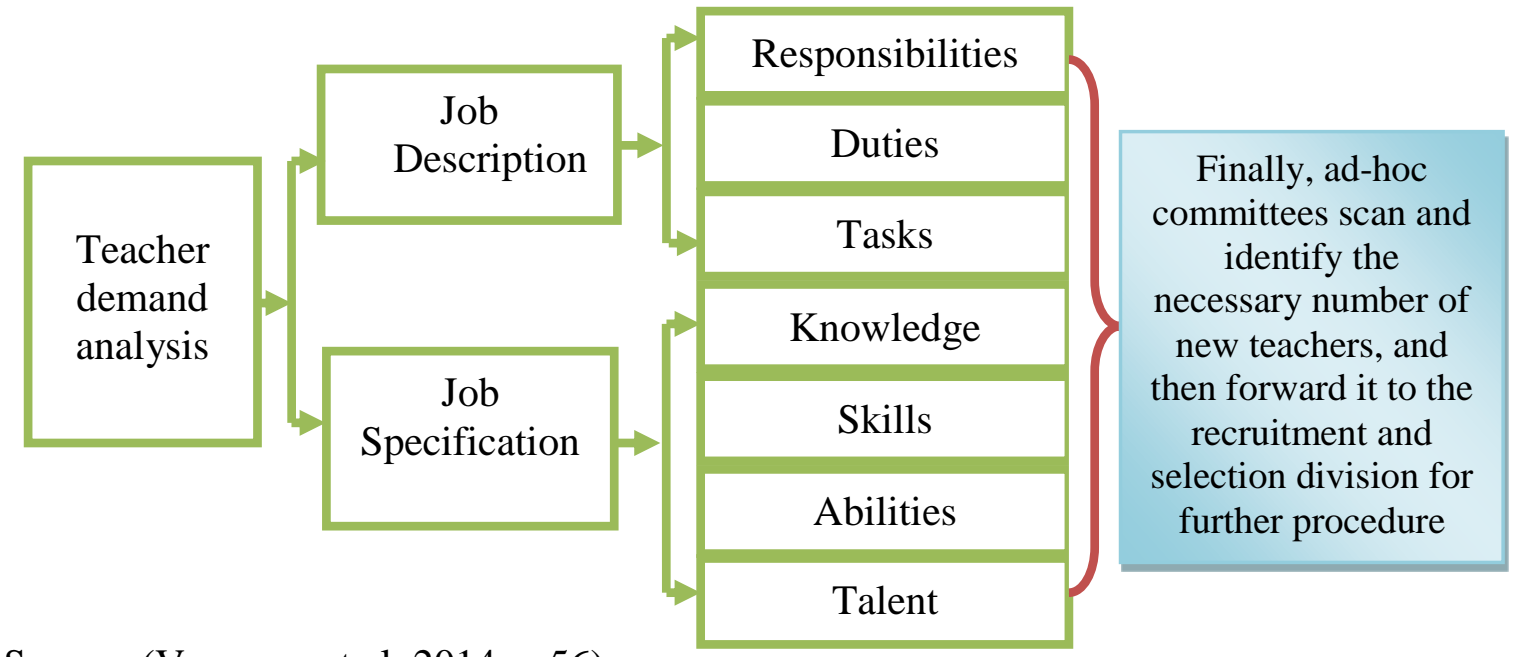

Source: (Vannasy, et.al. 2014.p. 56)

\subsubsection{Tasks of recruitment and selection}

- Aims: According to Cockburn (2000) the two main objectives relate to identifying accurately and sufficiently a detailed job posting, screening the masses of applicants and the methods to be employed in the decision-making process, for hiring the needed very smart people successfully. Besides, according to Provision, No. (720/MOES/2010-Laos; Vannasy 
et. al. (2014) it is crucial to hire and employ the right people to perform the job best and economize resources as well.

- Recruitment: it is the process of searching, attracting, identifying and generating a pool of qualified applicants, obtaining potential job candidates, and encouraging, searching for prospective job seekers or applicants (Flippo, 1984; Chanthala and Phommanimit 2004; Decree on Lao civil servant, No 82/PM, 2003; NeoEase, 2010; Mathis and Jackson, 2004; Engle, Dowling and Festing, 2008).

Vannasy et. al. (2014) proposed six procedures of recruitment, like job announcement, handling and gathering the application form, the deadline of the submission form, reference checking, making a short list and notifying. Hdiggui (2006) stated that there are three types of recruitments: open; internal (open either to current staff members with the required academic credentials); and fixed, short-term contracts to attract staff to deal with present shortages, advertised via social media.

- Selection: it is the process of choosing individuals from the pool of qualified candidates who have relevant qualifications or performed most successfully, to hold a position in an organization. Doorenenbal et. al. (2012) considered selection the process of assessing the disparity among applicants; a two-way process between the individual and the organization; prediction on success if hiring; and performance appraisals.

Neo Ease (2013) offered eight steps of selection methods: a preliminary interview, selection examinations, employment interview, reference and background checks, selection decision, physical examination, job offer, and final approval. PSC (2015) stated that people are the most important factors because they are the key components of whether an organization will achieve its objectives or not.

Some scholars (Prien et. al., 2009; Doorenenbal et. al., 2012; Sonebounnark, 2012; and Vannasy et. al., 2014) suggested, there are five steps in the selecting procedures like examination, aptitude examination, interview, teaching practice examination, personality examination, health checking, addiction and honesty examination. Figure 4 on the next page shows the relationship lines of the recruitment and selection process and each of their operation procedures. 
Figure 4. Task 2: Recruitment and selection process

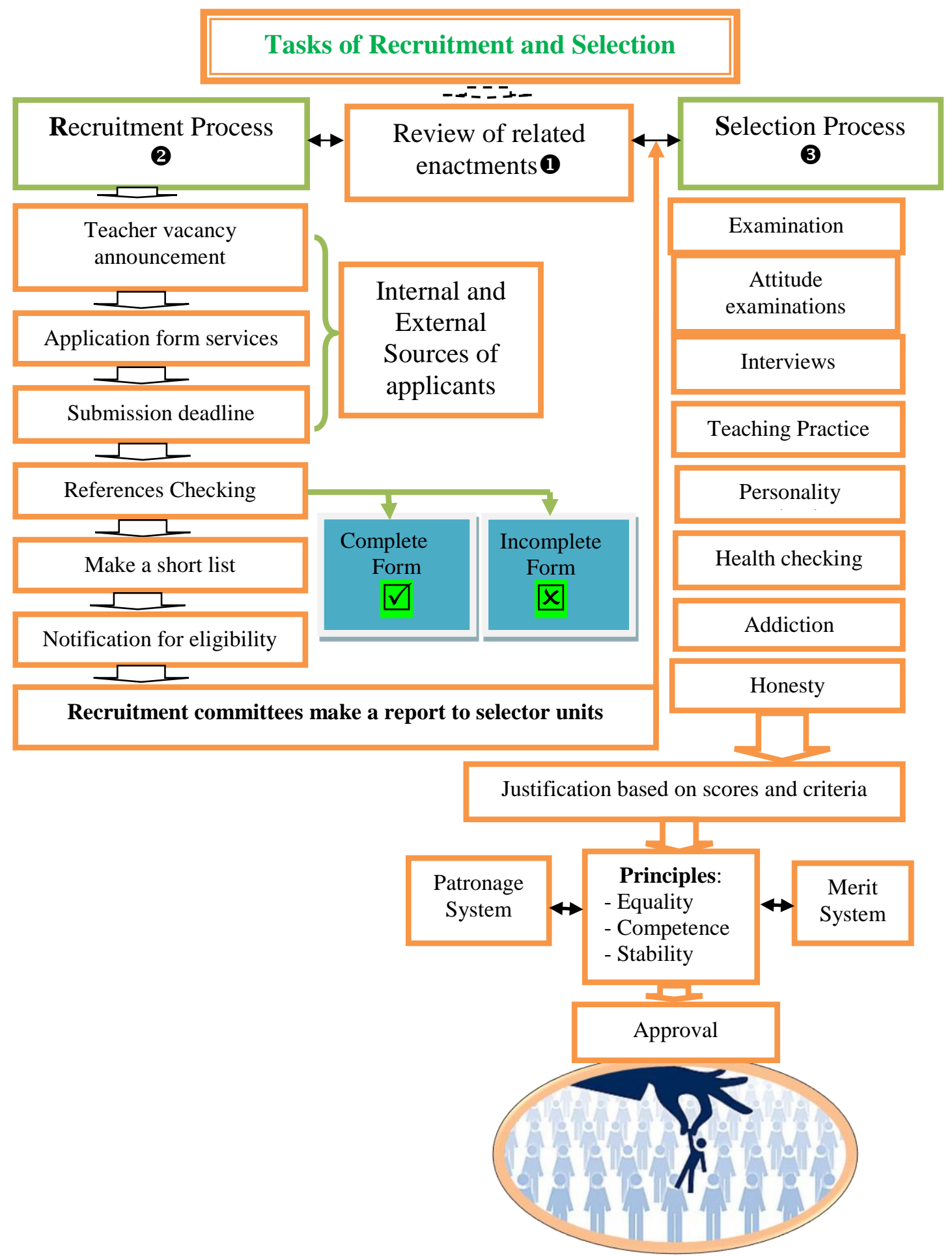

(Source: Decree, No. (0047/MOES/PO/2014-Laos. p. 23)

It can be summarized that recruitment is a process of attracting teacher applicants to apply for the job based on their specialized field obtained. Selection is the most important process of choosing the right teacher candidate for filling up vacant subjects, and educational 
leaders' low perception on both of the processes, will be a major cause of stress factors among teachers, and the institution fails in building and maintaining teachers.

\subsubsection{Tasks of pre-service training}

- Aims: it is a regular task of an organization to provide novices with the basic information to understand the organizational culture. This information is about rules and regulations, disciplines, cross-cultural interactions, values, beliefs, personal and interpersonal traits, and gender education opportunities, and other terms and conditions in practice that they feel comfortable with to boost the organization's growth (Hdiggui, 2006; UNESCO, 2011).

In other words, the task of pre-service teacher training the organization is obliged to fulfill is to provide information about job-oriented skills in the pedagogical practice inevitable to meet the increasing demands associated with the teaching profession. Several authors (Mergler, 2012; Bransford, Darling-Hammond and LePage, 2005; Tardif, 2011; Chanthala and Phommanitmith, 2004) stated that training aims to upgrade or improve specific knowledge, skills and attitude of the personnel regularly.

- Importance: PST can benefit both the organization and the novice teachers in performing the required job-related skills (e.g. Sloman, 2005; Truelove, 1992; Wills, 1994), and helps to know with whom (student) and how to communicate (ILO, 2012; and Anderson, 2004), promotes personal learning facilitation (Bransford et. al., 2005), practice-to-theoryto-practice relationship (ILO, 2012), promotes the career's attitude, norm and behaviors (Knorr, 2012), improves novice teacher performance and ability in certain teaching career (Tafida, 2009).

- The components: there are a lot of literature reviews proposed, such as Cooper and Alvarado (2006) who describe their practical experiences as the most valuable components of their teacher preparation program. Many practical experiences gain narrow emphasis and are disconnected from students' previous coursework.

Thaveesouvanh (2001) suggested that some components should be performed which are related to oriented skills, clear categories of participants, on-the-job and off-the-job training, as well as enhancing specialized skills in planning a lesson and in activity design, and the technique in transmitting knowledge to the learner. 
Besides, Thaveesouvanh (2001) proposed the following relevant components for the trainees as significant training sources:

- Handout of training materials, copies prepared in advance prior the starting date, a distributed material that can make the trainee have a high perspective and perception on the training operation.

- Pre-service training objectives are the enrichment of the novice's knowledge and skills as well as the teaching ability, classroom management, culture and behavior.

- Training design means the content of the programs, which is the main factor of the training activity in supporting trainees' capacity onward. The contents must include a commitment to the training objectives, the current situation, validity and modernization.

- Training methods or techniques are the appropriate methods to be applied based on the content program, trainees' background and practical work.

- Training programs are the trainer's outline of the training process he or she will use in a training program, including the activity and the time length of each training session.

- Training Operation means to put the training program into action or practice. The trainers must manage to follow the training scheme, including punctuality, assisting staff, and training material.

- Assessment and Evaluation means the trainers' or training managers' activities such as pre-examination, continue and post examination in order to adjust the training activity and trainees' gaining of new skills and how to move on.

- Feedback is trainers' or training managers' task to gather some information regarding strengths and weaknesses, challenges and opportunities, and training achievement.

In my understanding pre-service training or job orientation is a process of providing relevant information of institutions to the novice, concerning the rights, benefits, and other obligations and commitments to assist novice staff avoiding a mistake during teaching performance. In turn, when educational leaders neglect or ignore the dissemination of related information sources, it can cause miscommunication between leaders and teachers that can be stress factors among teachers because they work without incentives or other commitments. 


\subsubsection{Tasks of performance appraisal (PA)}

PA is the systematic appraisal of the teacher individually with regards to his/her performance concerning the functions and responsibilities; this monitoring enables him/her to improve and develop his/her teaching career.

- Aims: Teacher appraisal is a mechanism for improving teaching and learning and it is also one of the several tasks of educational leaders in educational institutions at all levels that has to be performed regularly. Ministerial Decision on teacher performance appraisal, No. 204/MOES/PO/2017-Laos stated that PA would help educational organizations in getting valid information about teachers' professional growth and other teacher competencies.

PA also plays a vital reference in raising salary or increments, position, teachers' honors, decreasing and increasing the number of existing teachers, benefits and termination based on the appraisal result (e.g. Drucker, 2013; Karkoulian, 2002; Schmidt \& Hunter, 1992). In addition, this enactment also mentioned the eligible, appraisal tools, ad-hoc committee, conscientiousness, methods and techniques, appraisal schemes, norms and criteria, portfolio, utilization rate criteria and duration and flowchart of appraisal practices. Chanthala and Phommanitmit (2004) stated that teacher performance appraisals are the organization's tasks to regularly assess their employees' competencies, weaknesses, encourage and improve the staff, as well as it helps placing the right man in the right position.

- Method of teacher utilization: the utilization rate of teachers is a function of a frequency rate and an occupancy rate, where the frequency rate measures the proportion of time and space used compared to its availability. According to Duret and Tounier (2009) it is using the teachers in a way that responds to both the needs and constraints of the education system and teachers' own capacities and aspirations.

Chanthala and Phommanitmit (2004) consider it the result of actual teaching loads divided by the authorized teaching obligations. For instance, to calculate Utilization rate the actual number of teaching hours has to be compared to the theoretical duration of use: U.T. $=($ actual number of periods taught divided by a theoretical number of periods to be taught on school premises) x 100. Example: each classroom can be used for 50 instructional periods per week, and if that room is used for just 25 periods per week, its utilization rate is $(25 / 50)$ $\mathrm{x} 100=50 \%$. 
Besides, Afful-Broni and Duodu (2013) proposed the Space Utilization Rate or SUR, which compares average group size in a classroom to the room's theoretical capacity: S.U.R $=$ (average class size/classroom capacity) $\mathrm{x}$ 100. Thomspon (1995) suggested that the utilization of teachers often concerns the enhancing of teacher's commitment to quality seeking and self-development through appropriate career patterns, promotion systems, and other incentives.

OECD (2004) introduced a full-time equivalent which is determined by calculating the ratio of their hours worked compared to the statutory hours of a full-time teacher during the school year. For example, 'a teacher who works one-third of the statutory hours of a fulltime teacher equals one-third of a full-time equivalent teacher' (OECD, 2004.p. n/a). The Ministerial Decision on teacher performance appraisal (No. 204/MOES/PO/2017-Laos) offered peer-assessment and external appraisals for bringing an optimum and making a good organizational climate.

- The components: policymakers and educational leaders attempting to shape and improve the appraisal method for the teaching staff would naturally recognize the goal and objective of assessment important in providing welfare and shaping teacher's performance within the educational institutions (Thompson, 1995), and (Yoodee, 2012).

Prempridy (2000) suggested several components like formulating the criteria of appraisal in particular subject matters or general ways, design norm and criteria for the specific purpose, collecting data, analysis of data and employing the found result for improving teachers' career, as well as for providing punishment and incentives properly.

The Ministerial Decision on teacher performance appraisal (No. 204/MOES/PO/2017Laos) has identified seven components of PA such as:

(a) eligibility of teachers: they must be teacher civil servants of at least one year of employment, with a teaching obligation more than $50 \%$ per week, and no criminal records;

(b) standardization, including a good political perception, ethical career, excellent academic record, self-knowledge pursuit;

(c) appraisal method, including peer-assessment, organizational assessment (ad-hoc committee from internal and external sources);

(d) criteria of scoring, consisting of four levels like 1) basic level or needs assistance, 2) continuous improvement level or moderate, 3) applicable level or good, 4) creativity level or excellence; 
(e) portfolio checking, comprises that he/she must possess certificate of training, seminar, workshop, and other academic activities, lesson plans, teaching materials and all of the portfolio package must be authorized by relevant organizations;

(f) flowchart of appraisal, where the operation must be completed between February and April in each year; every public sector level shall make a report as well in accordance with the hierarchy, not exceeding the yearly period of April to May;

(g) applying the result of assessment will take place in the following year, including a raise in salary or position, and payment of other benefits.

In my opinion, teacher performance appraisal is a significant process by which an educational leader examines and evaluates teachers' teaching efficacy and behaviors to contrast it with the preset enactments and apply the results to provide feedback to show what needed to improve and the reasons to provide an orientation or soft-skill training and who will be compensated, position promotion, demoted, retained.

\subsubsection{Tasks of teacher compensation (TC)}

TC aims to predispose teachers to pay attention to work as teaching career within institutions, and to keep the existing teaching staff as well. It is also used to stimulate and motivate teacher employees to work optimally and promote career ethics and morality. Harris (2007) figured out that 'reward systems can potentially encourage specific behaviors among existing teachers. It is also providing some teachers' incentives to remain in teaching and others with incentives to leave or attract different types of people into the teaching profession' (Harris, (2007. p. 5.).

Gottelmann and Yekhlef (2005) state, that the management of teachers has attracted growing attention among national decision-makers and international agencies concerned with educational development. Torjman (2005) suggested two policy practices like vertical and horizontal practices. Fitzpatrick (2000) added that horizontal management is seen as a way to ensure the state government acts as a vibrant, cohesive and coherent national institution.

The UNESCO (2015) stated that the most important dimensions of teacher preparation and work need to be covered by policy and programmed in a multi-year framework. According to Ingvarson, et. al. (2005) the teaching profession, and consequently the teacher employment system, is undergoing a number of crucial reforms. 
Act CXC of 2011 on Hungarian National Public Education, article 36, section 64 mentioned teachers' devotion to the teaching profession and their right to receive social welfare from the organization as other laborers do.

Act CCIV of 2011 on Hungarian National Higher Education, part three, chapter VII, article 13 on 'Positions and conditions of employment' clearly identifies the prerequisites of becoming an instructor in higher education classified as assistant professor, lecturer, college or university associate professor, college or university professor. Article 20 'on wages and salaries' is made on the Annual Budget Act, Act on the Legal Status of Public Servants and the Government has a responsibility to manage the above mentioned to support group and individual instructors more effectively.

Decree on Lao teacher civil servant, No.177/GOL/2012 declared the teachers' right to receive a social welfare. Besides, this decree also provided statements on salary, position, raising subsidies and career development based on their teaching performance.

The above Decree has mentioned that the state government strongly supports teachers in different levels also, like teachers in higher education receive each month a subsidy consisting of $10 \%$ of their basic salary, at vocational education they get $15 \%$, at secondary school $20 \%$ and at primary school and kindergarten they get $25 \%$ of their basic salary respectively. Furthermore, the teacher has the right for further knowledge development, annual leave, maternity leave, and some benefits for their children at school, offered by the property owner, free of charge.

In my point of view welfare or compensation became major tools of leaders or managers in leading the organization towards success because laborers were not machines, they have felt in what maintenance should deserve decently. However, welfare and compensation of teachers in Laos culture have covered a valuable total package including cash and non-cash payment that the organization offers in term of the rate of return working life and another teachers' devotions.

\subsubsection{Tasks of training needs assessment}

Training Needs Assessment (TNA) is the method of determining if a training need exists and, if it does, what training is required to fill the skill gaps. It is a utilized tool to identify what educational courses or activities can help the management process and the employees 
to improve their skills and work productivity (e.g. IOE, 2012; Saloman, 2005; Strock, 2014; Trutkowski, 2016; Wallance, 1991; Williams \& Mary,2015).

According to Labesse (2008) the skill-based approach aims to raise the performance of the professional staff to a maximum level, rather than simply correct their shortcomings. Firdousi (2011) states that training needs assessment is a useful tool to identify what educational courses or activities should employees be provided with to develop their classroom management skills and promote a high performance.

Gupta et. al. (2007) think, that by today, it has become a concern of every proactive manager who uses it for developing and implementing varied practical solutions for individuals, work groups and organizations. According to Wright and Geroy (1992) TNA should be a systematic process of collecting data, analysis and interpretation of data on individual, group and/or organizational skill gaps.

Khsent (2003) suggested four types of TNA which is regarding the upgrading of knowledge and skills to enhance and promote career more efficiently and effectively. Vannasy et. al. (2014) think, the importance of training needs assessment lies in its aiding an organization in achieving the goals and reducing gaps between employee skills and the skills required by the job and department or by the two levels of needs assessment as organization, and on the individual level.

I think that training needs assessment is a way of eliciting information from the employees by making a survey of skills needs rigorously. This task is very important toward the efficacy and successful institutions to which leaders or managers have a responsibility to find the better way in empowering subordinates' potential capacity to perform the assignment best. In contrast, institutions that do not pay proper attention can cause gaps in knowledge and skills pursuing among teachers, and other pressures that lead teachers feel stress in the teaching profession.

\subsection{Stress factors among teachers caused by organizational mismanagement}

This section presents relevant theories and concepts relating to the second context in study 6 or main study, as I have stated in (1.3) concerning the rationale for choosing six out of ten tasks. According to several researchers (Meyer, 2001; Piscitella, 2016; Schaufeli, et .al., 
1993; Selye, 1936; Shalom, 2014; Ukandu \& Ukpere, 2011; Blazer, 2010 and Vandenberghe, \& Huberman, 1999) it is unavoidable to have misunderstanding and miscommunication between employers and employees in the educational institutions. They are often conflicting in part about putting or placing position, academic performance, compensation supplies, and other teachers' benefits schemes (e.g. Freudenberger, 1974; Gold .et. al.1989; Dworkin, 1987, and Jacobson, 2016).

Several research studies have confirmed that the sources of stress among teachers are derived from various factors, like personal habits and chronic disease, social threats, colleagues, working culture, and organizational management. One of the most valuable findings relating to leaders' shortcomings that explored by Yan and Xin (2007) revealed that:

'Education administrators at counties focus on regulations and efficiency, ignoring teachers' individuality, emotional needs, dignity and call for concern and respect. Conflicts between high school teachers and educational administrators are inevitable, including the conflicts between overloaded work pressure under strict school management and teachers' call for flexibility, the conflict between the redundant roles of teachers and school's lack of specific organizational objectives, and the conflict between unfair educational evaluation and teachers' call for fairness' (Yan and Xin, 2007. p. 44.). These findings prove that the sources of stress in the teaching career is rooted in many causes like organizational mismanagement which is one among those sources frequently happening so far.

The term 'stress' seems to become a mass phenomenon, receiving constant media attention; however, the uncountable international studies still could not give a clear answer. It is supposed that job stress factors are correlated to the syndrome of stress or pressure that causes depression and fatigue, and those phenomena are often related to the work or job environmental climate (e.g. Arora et. al., 2011; Schaufeli, et. al., 1993; Jackson et. al., 1986; Taheri et. al., 2012; Ferriero and Powers, 1982; Whitehead, 2001).

However, this part of the dissertation attempts to clarify that part of organizational management that affects job stress factors; such could be the teaching load, teacher welfare, and teacher professional development. These sources of stress factors were mentioned in the annual movement report of TTIs 2016-2017 in Laos.

Freudenberg was a German psychologist who was the first who logically explained stress factors through his own physical and psychological experiences while working as a volunteer with young people who engaged in illegal drug trade. Selye (1991), one of the 
pioneers in the field, has indicated that stress as a concept suffers from the mixed blessing of being too well known and too little understood.

Whitehead (2001) states stress is the person's response to some disturbing or threatening stimuli. Espnes and Mykletun (2002) described stress as an alarm, resistance, and exhaustion (see also Burns,2013; Cannon et. al. 2014; Center on Education and Policy, 2005; Charles \& Grusky, 1995; Comb, 1964; Foley, 2013; Hofmeyer et. al., 2015; Robertson, 2008).

'Stress' is applied for many different kinds of careers, situations, cases and environmental atmosphere that can cause a massive confusion today, due to its common use in various levels and diverse causes of stress. Stress is a characterized or human syndrome or symptom developing through tension, pressure, strains, pain, grief, a burden and emotional threats (e.g. Gold and Chrousos, 2002; Govardhan et. al., 2012; Travers and Cooper, 1996; Pines and Keinan, 2005; Schaufeli and Buunk, 2003; Selye, 1991 and Espnes and Mykletun, 2002).

In other words, 'stress' is the source of all lives' symptoms, anxiety, suffering, hassle and worry (e.g. Richardson and Watt, 2006; Porter and Umbach, 2006). In addition, stress is also seen as the syndrome of nervousness, trauma, trouble, hardship, illness and pain (e.g. Naemiratch and Manderson, 2009; Lazaurs and Folkman, 1984; Guglielmi and Tatrow, 1998; Friedman, 1991; Blanch, Aluja and Biscarri, 2003).

By the above addressed information included in the annual movement report on the progress of TTIs, and few relevant departments within MOES in charge of the supervision of higher education institutions in Laos, these quotes have identified the shortcoming or weakness of organizations that affect the teachers or employees and lead them face stress syndrome unavoidably. Three main stress factors caused by the organization I have extracted, and synthesized which are introduced below:

\subsubsection{Relating to teaching loads}

The organization's bad practice of assigning teachers to perform on the proper subjects or courses without consultation and also supply them with a lot of activities and substituteteaching hours led them unavoidably stressful. 'Stress factors in teaching profession' is an exhaustion or fatigue symptom caused by a prolonged response to chronic emotional and interpersonal stressors in the teaching career. 
In other words, it is expected to be defined by three sources in the educational institutions like exhaustion, cynicism, and inefficacy, which issues are affected by the organizational leader's lack of leadership (e.g. Maslach, Schaufeli and Leiter, 2001; Haberman, 2004; Rowan and Geraldine, 2016; Dworkin, 1987; Freedman, 2004; and Bai, 2014). Causes of stress factors generally related to two main sources like situational and individual factors (e.g. Bakker and Costa, 2014; Gold, 2001).

'Stress factors in the teaching profession' is a depression syndrome, which derives from various pressure sources. It was first used in 1974 by Herbert J. Freudenberg (German psychologist). Teachers' stress is arguably one of the most popular common research topics concerning the different occupations. Stress factors are the resistance of all lives, especially of people, who have a job and are working long since under the environmental threats of such a workplace condition, leaders' and colleagues' misbehavior and other pressures.

Besides, causes of teachers' stress factors can be derived from the relationship to colleagues (Bivona, 2002), social-cultural and socio-structural factors (Cannon, 1992; Selye, 1936; and Meyer, 1993), unhealthy behaviors (Dworkin, 1987), ambivalent stereotyping of the teacher welfare process (Lewis, 1998; Phongphanit, 2017d), stress management programs and increased workload (Taris, 2006), and depersonalization, social tension, organization (Iverson et. al., 1998). The employer also suffers from such a situation and the lack of career ethics to perform the assignments (Moczydłowska, 2016).

Moreover, lack of communication and ambiguity also plays a role. Beheshtifar and Omidvar (2013) suggested that the organization should find the way to prevent the chronic syndrome. Wood and McCarthy (2002) noted that a highly stressful occupation is associated with high level of stress factors. Hastings and Bham (2003) thought that organizational policy and leaders' behavior causes teacher rivalry amongst others. Champathong et. al. (2015) and Roach (2009) confirmed that teachers in public schools face poor administration and misbehaviors.

In addition, the causes of teachers' stress factors are related to gender variables and deficit training (Dworkin, 1987; Friedman, 2010), lack of motivation from the organization (Fisher, 2011; Farber, 2000), gender disparities (Bauer et. al., 2006), lower levels of efficacy in teacher engagement (Roloff and Brown, 2011; Martin et. al., 2012), and demands challenging their sense of identity (Parker et. al., 2011; Klusmann et. al., 2008; Day et. al., 
2017). Moczydłowska (2016) stated that managers are not accompanied by the actions of the change situation.

'Teaching load' in Laos culture is the quantity of teaching-hours per week the organization provides the teachers with to teach a particular subject. However, the allocating process may be scarce or inappropriate or unfair due to the organizations' inattention to the education enactment and that is expected to become a cause of teachers' stress factors. Normally, Lao teachers at the higher education level will have not more than 12 teaching hours a week (Decree No. 177/GOL/2012-Laos).

\subsubsection{Relating to teacher welfare}

Teacher welfare or better known as benefits is a part of the laborer's compensation (employee and employer). In other words, teacher welfare is direct and indirect benefits or financial and non-financial supplies. Welfare and occupation as a sheet with two pages never separate and the organization needs to be clear in practices to boost the capacity of production.

Normally, teacher welfare consists of the economic security, professional adequacy, personal security and working conditions (e.g. Lao National Teacher's Funds, No. 700/GOL/1995). In turn, according to Prepridy (2000), the well-designed policy and other attractive schemes will be automatically sterile due to the organization's lack of communication and lack of attention on implementing in practice, and because of the poor working environment (Guglielmi and Tatrow, 1998).

Decree on Lao teacher civil servant (No. 177/GOL/2012-Laos) indicated that the organization, the employees and the benefits are inseparable and those are major factors directly affecting the success or lack of success of an organization. Manandhar (2015) added that the organization can achieve its objectives only when its employees are happy and committed to their work.

Opatha (2009) confirmed that employees cannot work as machines. Polychroni (2000) emphasized the lack of incentives and support from the government; while Jacobson (2016) focused on the learning network. The Law on civil servant (2016-Laos), Chapter 6 talks about Civil servants' benefits defined as a set of package remunerations including salary, subsidies, pension, a single lump sum payment, reward, bonus, and other benefits that are pay-based on the job performance. 
Besides, the organization also provides some basic facilities following the enactments. Anyhow, the organization's lack of career ethics and disregard of responsibilities can affect the employees' expectations and lead to stress factors. As Yan and Xin (2007) noted, they themselves don't know what teachers should do and what they should not do for there are no specific and clear rules about the range of teachers' work.

The Law on Education (2016-Laos), Part 3 on 'Teacher and educational personnel'; chapter 1 'Teacher'; Section 52 'Teacher incentives scheme' has mentioned that teachers are subjects to the benefit incentive scheme through their professional performance, to upgrade educational qualification, livelihood, and social status, receive a leave, retirement, and other incentives in accordance with the law and regulations.

In addition, this section also added that legal internal and external individuals, entities and organizations of public and private sectors shall be involved in assessing and facilitating the teachers' function. Anyway, those enactments are neither effective nor dependent on the organization's awareness in real practice. Yan and Xin (2007) noted that the interaction between teachers and administrators affect teachers' emotion, especially at a country where educational laws are usually not effectively executed.

Besides, Moczydłowska (2016) declared that managers see numerous factors and sources which raise the risk of stress factors and occur on different levels of the organization's structure. Glatthorn (1995) thinks that a teacher training fund could be established within an organization to support teachers' self-regulated learning and sharing ideas among themselves. Dworkin (1987) stated that the causes of teachers' stress factors in the public schools includes unclear policy recommendations, substantial organizational changes, deployment practices and the administrative style of school principals.

Likewise, Friedman (2003) confirmed that there is a lack of trust in teachers' professional development. Fisher (2011) have seen that low wages and accountability, as well as lack of support from administrators, can cause stress factors. Motivation to praise or verbalize is a leader's trait towards the followers (e.g. Prempridi, 2000). Ukandu and Ukpere (2011) think that motivation increases the level of performance of employees and increases their commitment in the workplace. Shen et. al. (2012) added that culture and support are more important than money and resources.

However, some of Lao educational enactments have mentioned that the Lao teaching profession still confronts many challenges, and it also seems that some previous stress 
factors researches also deal with organizational reforms, working culture, policy changes, laborer behaviors, the organization neglecting to cultivate professional ethics and etiquette to its personnel within the institutions. These all can lead to misbehaviors and bullying one another and can become job stressors (e.g. Maslach and Leiter, 1988; Day et. al., 2017; Prempridy, 2000; Kaliath et. al., 1998).

Decree on Lao teacher civil servant (No. 177/GOL/2012-Laos), category IV 'Policy, Salary and Teacher welfare' Section 14 on 'teacher policy 'indicates that the teaching personnel has a right to obtain other benefits in accordance with the rules and regulations referring to civil servants. Additionally, the teacher will receive extra policies like academic position, academic status, social honor, living conditions, praising and admiration, annual leave, maternity leave at least six months per time per child, a single lump sum payment, pension, yearly salary raise (it is in every two years for general civil servants).

Teachers teaching at rural areas will receive an extra policy from the government. Furthermore, this decree also regulates the teaching hour per week obligations, and the subsidies for teaching profession. Teacher welfare or benefit is a set of reward packages, financial and non-financial, which teacher education has a right to receive from an organization, based on the contracted and other welfare enactments issued.

Usually, Lao teachers have extra benefits compared to other civil servants, like extra subsidies, holiday, sickness and maternity leave, and grant for professional development. Anyhow, that welfare scheme seems to be clouded in practice and that may lead to teachers' stress factors (Decree No. 177/GOL/2012-Laos).

\subsubsection{Relating to teacher professional development}

The teaching profession is one of those few jobs where professionals work close to people and it is also very crucial among those few jobs, because teacher training institutions have huge responsibilities in building the quality of teacher-students or trainees to become teachers working for the sake of many young children.

Thus, teaching skills training or on-the-job training should be conducted continually in order to promote learning achievement. Vinesh (2014) noted that there is still a big gap between the knowledge and skills passed and acquired in the institutions. According to Ukandu and Ukpere (2013), Woźniak (2006) and Yong (1995) staff development today has been eroded as the majority of the employers do not take proper training of workers into 
consideration. Maxwell et. al. (2004) added that managers do not empower their employees with training because they are afraid that trained employees decide to leave them.

Go et. al. (1996) confirmed that managers in the fast food industry support training and development of employees, but do not put it into practice. Ukandu and Ukpere (2011) indicated that managers or organizations often plan ahead, yet the training is poor or nonexistent and employees are reprimanded for their poor performance. The annual movement report of 2016-2017 of TTIs-Laos have revealed that staff development is still a challenge for us due to the lack of supporting resources; our organizations have fewer experiences in cooperating with the relevant institutions or networks.

Howard and Johnson (2004) added that poor teacher-student relationships, time pressure, role conflict, poor working conditions, and the lack of training participation are the roots of the stress factors symptom. Cannon (1992) agreed that disparity in skill gaps development affects not only employees themselves, but the organization's capacity to join the competition process also. Gold (2001) has stated that teachers are often isolated from their peers, leading to depersonalization. Yan and Xin (2007) claimed that they ignore the gradual growth of teachers' professional skills and harm some teachers' pride.

Decree No. 177/GOL/2012-Laos, section 23 specified that the teacher personnel of institutions have a right to receive scholarship from the government to continue their studies and improve their knowledge and skills in formal and informal ways within international institutions.

Besides, the teacher personnel have the right to upgrade the political-theories and government's statements and policies once a year. In contrast, deficit or gaps in training involvement among teacher personnel still faces challenges today and tends to be a cause of stress factors. Herioux (2012) viewed that teachers' dissatisfaction often leads to stress factors and that can be the result of administrative demands and performance pressures.

In summary, stress factors are a group of fatigue syndrome under the unwanted feeling the individual experiences through prolonging work. Teacher stress derived not only from personal behaviors, socio-economic pressure, but social values and beliefs as well. The organization, where teachers work is also a main cause of stress like leaders' personal behaviors, miscommunication, and inefficiency in managing duties and responsibilities such as allocation of teaching hours not following the legal regulations, ambiguity in providing welfare and other benefits, and imbalance in teaching career development. 


\subsection{Review of the previous studies}

In the present section, I would like to summarize some previous studies which are connected to the six studies. These reviews are to be used as pillar supports and for the validation of each study findings as follow:

Regarding to developmental process of research questionnaires (study 1 - 3) used for the major study there was an instrument examiner to validate the external and internal consistency of the questionnaire prior to administering the completed version to the actual samples.

Besides, Soukkhavong, (2010) have found that the right word and sentence structure in each item statement must correlate. Sinjaru (2012) emphasized the sematic differential scale to rate and mark the individual statements. Sisaad (2002) have offered more choices or options through measurement scales as a kind of diagnostic or rating round in the field of mixed research. Likitwattana (2012) have noted that open ended questions were useful for both examiner or measurer and respondents to understanding each other. Phousion (2011) added that wording and the phrases used should fit the local respondents and the study.

As we know teachers' burnout syndrome (study 4) is a reaction to chronic stress among teachers, and those dilemma issues confronted are often more related to the organization's pressure than to teachers' own-tensions like personal factors and social pressure, and most teachers stated they need their leaders or principals pay attention toward the professional ethics through teachers' issues and enough investment into the teaching media, materials and instructional equipment as well as morality and motivation to teachers (e.g. Blazer, 2010; Whitehead, 2001; Sichambo, Maragia and Simiyu, 2012; Toth and Hodi, 2014; Roloff \& Brown, 2011; Herioux, 2012; Küçükoğlu, 2014, and Landrum et. al., 2012).

Furthermore, previous studies associated with study 5 were rare but those results were always concerned with the manager's or principal's lack of perception in visibility and feasibility toward the networking and using a modern technological device to support the instructional process that made classroom boring and the institution discreditable (e.g. Phisane 2014; Mayer, 2008; Manivong, 2012; Sisomphou, 2007; Phiengphanyoukorn, 1991, and Decree, No.1728/MOES/2015-Laos).

Regarding the instructional management and stress factors affecting teacher trainers as perceived by the educational leaders of Laos (study 6) Champathong (2015), and Ayuk, 
(2012) have revealed an imbalance or shortage among natural- and social sciences teachers both. Some scholars (Nwikina and Nwanekezi, 2010; Nyasha et. al., 2013; Mavis 2014; AjaOkorie, 2016; Namuddu, 2010; Muguongo et. al., 2015; and Khan, 2015) have revealed a lack of administrative support in forecasting teacher requirements or in job analysis and its recruiting process.

Besides, several researchers (Akala, 2014; Abdou and Zaalouk, 2012; Hudson, 2011; Eunice et. al. 2014, Chongsirikul, 2003; and Campos, 2009) have found problems mainly in the policy of teachers, restricted autonomy in selecting staff and mentor of teachers; educational materials out of date, inadequate practices of policymakers and teacher performance appraisal ambiguity. Also, Lingam (2004), Somboon (1997) and Viscardi (2015) widely complained about professional development, compensation and teachers not being involved in all decision-making processes.

In summary, teacher's burnout and stress sources were found and rooted in the aspects of organization mismanagement and leaders' or principals' behaviors or emotional manner. These phenomena are often overlooked by those concerned, but these were the main causes of stress among teachers and also made the organization unsuccessful. Therefore, the high positions' possessor should perceive and respect the career ethics related to teachers' issues as a priority task and it is vital for leaders/principals or educational institutions at all levels to be attentive and perform practices routinely.

\subsection{Education structure and TTIs in Laos}

\subsubsection{General education system}

Decree No. 282/PM/2011-Laos lays the basis of the role and responsibilities of operation and processes. The Ministry of Education and Sports (MOES) is a central government organization with main functions and responsibilities for the macro management and administration of the education and sports sector.

MOES consists of one Minister, four Vice-Ministers, and two Assistants to support the Minister. Administration departments are made-up of Cabinet of MOES, and five Departments like Organization and Personnel, Planning, Finance, Inspection, External Relations. The office of Lao National Commission for UNESCO, Internal Olympic Commission Relations. 
There are Technical Departments for Preschool and Primary Education, Secondary Education, Teacher Training, Technical and Vocational Education, Higher Education, NonFormal Education, Physical and Art Education, Students Affairs, Elite Sports, Sport for All, Research Institute for Education Sciences, Institute for Educational Administration Development, Education Standard and Quality Assurance Center, Private Education Advisory Council Office, Information and Communication Technology Center for Education and Sports, The Information and Media Center.

Besides, MOES also established local education and sports sectors such as Provincial Education and Sports Services (PESS), District Education and Sports Bureau (DESB) and Village Education Development Committees (VEDC); the state Educational Materials Production Enterprise and the State Education Printing Enterprise.

Structure of education in Laos follows primary education, which has five years of study, the secondary school including two categories: (a) Lower secondary education is a basic education that has four years of study; and (b) Upper secondary education is the continuation of studies from lower secondary education, which has three years of study.

Technical and Vocational Education, which is technical professional education and training for learners and trainees to have specific knowledge and capacity, skills, profession, job-orientation, labor discipline, and to respond to the demands of the labor market. The Technical and Vocational education structure consists of Technical and Vocational Education Certificate level, Diploma level and Higher Diploma level as defined in the Technical Vocational Education Law.

Formal education is systematic teaching and learning in schools, with a timetable and school calendar, and curriculum content that meets the national education standards. Formal education consists of early childhood education; general education; technical and vocational education, and higher education.

Non-Formal Education is a kind of teaching and learning, which is conducted based on curricula, contents and various levels, similar to the Formal Education setting. However, the methodology, time and mode of teaching and learning shall be flexible to learners and learning shall be in parallel with basic vocational training. Non-Formal Education consists of regular non-formal and informal education.

Higher Education follows upper secondary education, intermediate vocational education or equivalent, and the education curricula starting from Associate Degree to 
Doctoral Degree to promote lifelong learning aims to develop technical staff, specialists, researchers and scientists. The structure of Higher Education is made up of an Associate Degree, Bachelor's Degree, Master's Degree, Doctoral Degree, and Postgraduate Education.

Besides, Education management and administration are the attempts to adapt and adopt the western ideologies to fit the local situation by promoting decentralization, deconcentration, individual learning, and researches. In addition, the reform is associated with improvement and creating a legal education, investment, the society's attitude toward education, teaching and learning culture, and institutions' environments.

In addition, the reform also regards teachers' behavior, role and responsibilities, and the relationship of teacher and students, gender education, equal opportunities, and professional development.

Furthermore, concerning the investment in the education sector, the main funding sources are (1) Government budget; (2) Contributions of communities, individuals, families, and international and external social organizations and international agencies.

Moreover, other relevant component of the education structure in Laos is the start of the academic year which is in most cases September 1 for the first semester, except for public universities and colleges where it normally starts two-three weeks later. Therefore, from primary to vocational education midterm examinations are organised on the 8th week, during the end of October.

Regarding the educational assessment and evaluation in the Laos context, such as the scores or marks applied from primary school to vocational school from 5 up to 10 depend on the students' active performance. These are criterion marks, meaning he or she passed an exam on the subjects, marks below 4 mean he or she failed.

The higher education level applies the credits worth and follows the grading system based on the Decree on Lao student's assessment and evaluation No. 682/NUOL/2012-Laos. The grading system presents students' performance as grade (A) excellent; $(\mathrm{B}+)$ Very good; (B) Good; (C+) Fair Good; (C) Fair; (D+) Poor; (D) very poor; (F) Fail; (I) Incomplete. Figure 5 shows the structure of the education system in Lao P.D.R. 


\section{Figure 5. Structure of the education system in Laos}

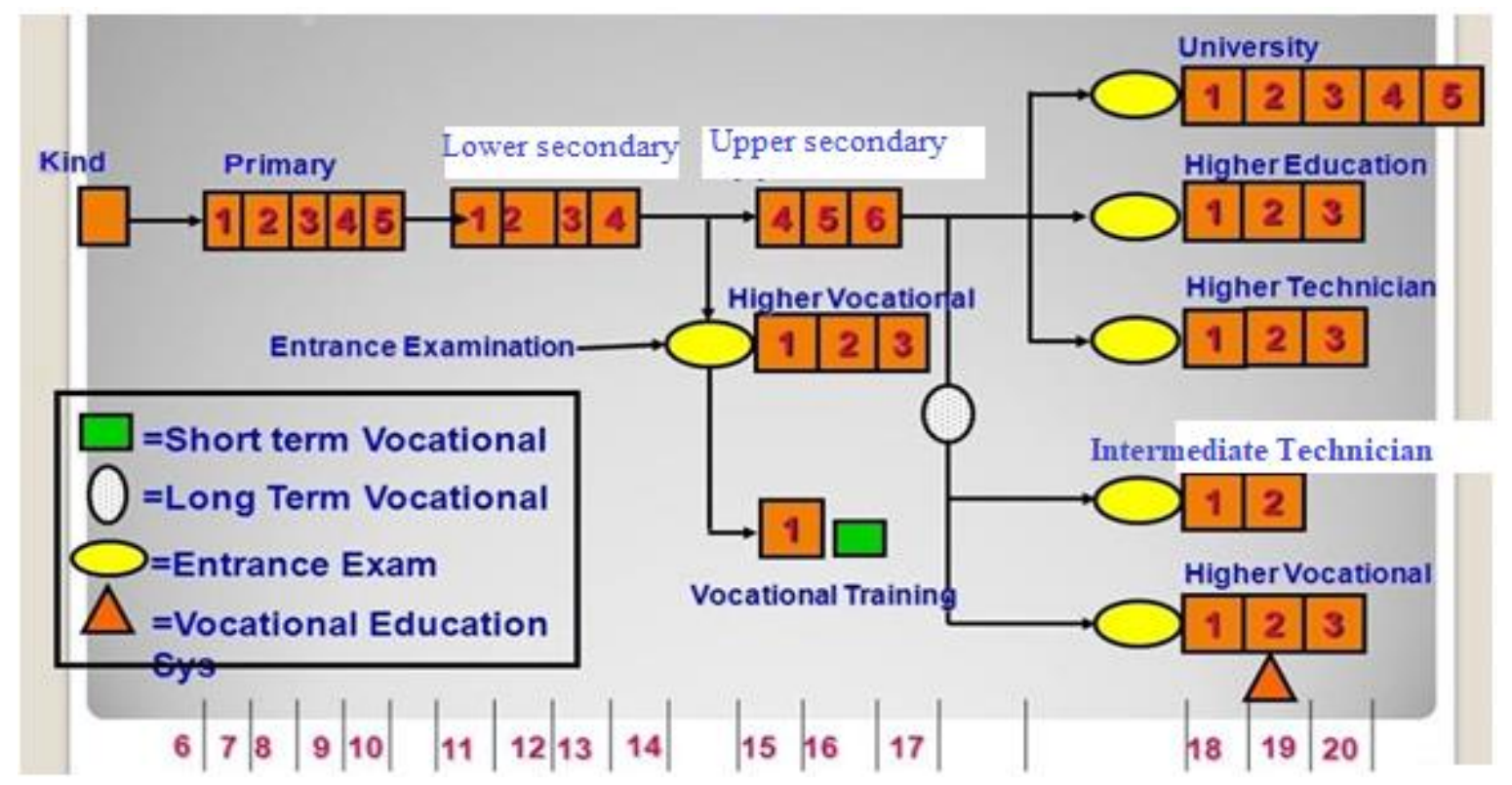

\subsubsection{Teacher Training Institutions (TTIs) in Laos}

Teacher Training Institutions (TTIs) are the first comprehensive or full-fledged TTIs in the history of Lao PDR. Through Decree, No. 4924/MOES/OP/(2016-Laos), TTIs were established by the merge of the existing 16 teacher training institutes which were then operated under different levels and belong to different departments within MOES like Higher education and Teacher Education department.

As already discussed in chapter one, currently TTIs comprise of 16 teacher higher education institutions: 4 Faculties of Education residing in Four Public Universities, 8 Teacher Training Colleges (TTC); one Art Education College, and one Physical Education College; two Buddhist Teacher Training Colleges. There is also an Institute of Vocational Development for offering vocational teacher training. Initially, the TTIs conducted the teaching and learning-based differentiation degrees and programs following the demand of the labor market (See Figure 6.). 
Figure 6. Number and distribution of TTIs, Educational Leaders, Teachers and Students within TTIs of Laos (2016-2017)

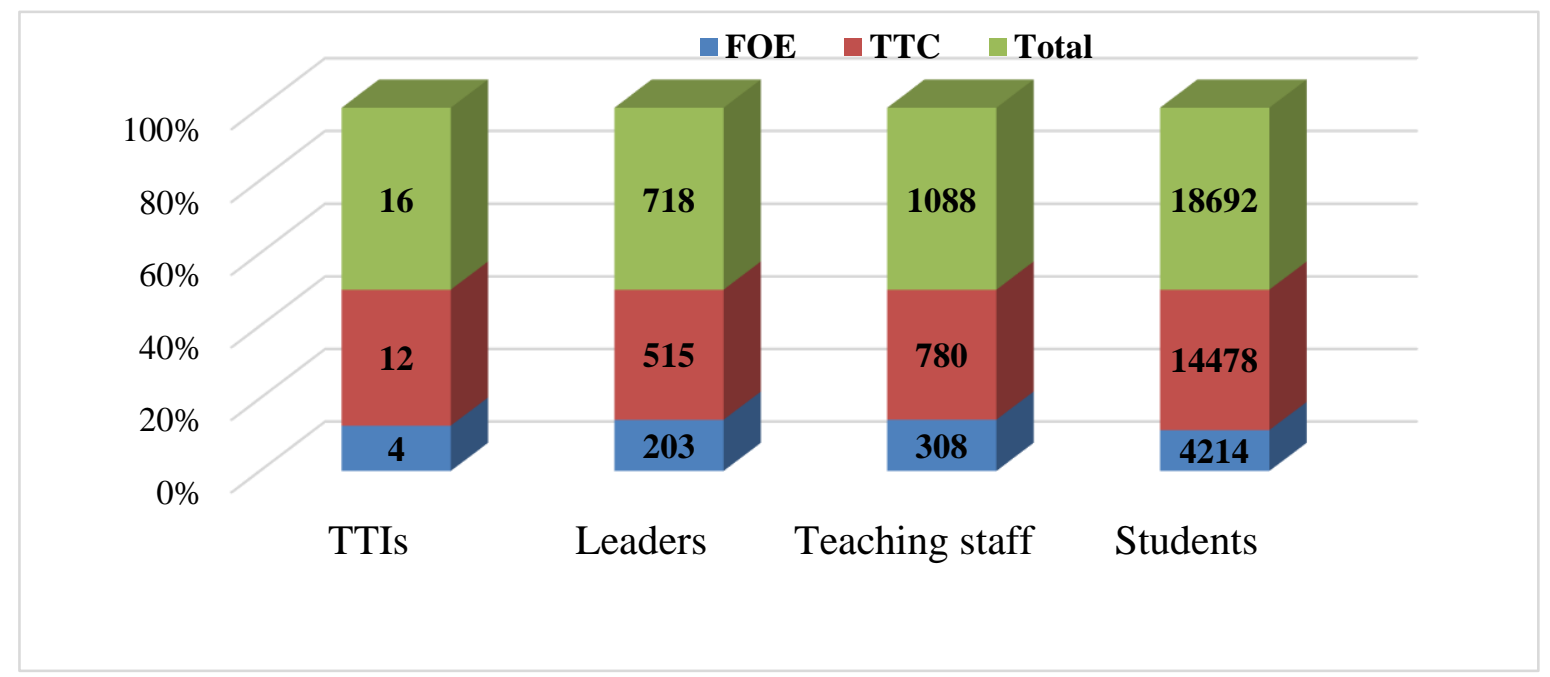

(Source: http://MOES.edu.la/) p. 36.)

Each TTI has formed its own eligibility criteria of enrolment, but most of the teacherstudents (60\%) were under the Government scholarship (No.4924/MOES/OP/2016-Laos). Thus, those students who have a high academic record at secondary education are taken as priority from the government and they can be directly enrolled in TTIs, to become a teacher in Preprimary, Lower secondary school, which provides more options such as higher diploma degree $(12+2$ or Bachelor decree $12+4)$.

To become a teacher employed in upper secondary school which provide a multibachelor degree like (12+4 full time study, bridge program 2.5 years of study and continuing program 2.5 years of study, these last two programs provide teacher-students with advanced performance in a degree program at one institution as recognition of previous academic achievement records in a similar field of the study in another institution (See Table 3.).

Table 3. Teacher education training programs in Laos

\begin{tabular}{|c|c|c|c|c|}
\hline Type of Diploma & $\begin{array}{c}\text { Eligibility } \\
\text { admissions }\end{array}$ & $\begin{array}{c}\text { Offered } \\
\text { program }\end{array}$ & $\begin{array}{c}\text { Credits } \\
\text { worth }\end{array}$ & $\begin{array}{c}\text { Teaching } \\
\text { practice }\end{array}$ \\
\hline $\begin{array}{c}\text { Higher and } \\
\text { Bachelor diploma }\end{array}$ & $\begin{array}{c}\text { Grade 9/ } \\
\text { Grade 12 }\end{array}$ & $\begin{array}{c}\text { Preprimary school } \\
(12+2 \text { or 12+4) }\end{array}$ & $120-148$ & 8 weeks \\
\hline $\begin{array}{c}\text { Higher and } \\
\text { Bachelor diploma }\end{array}$ & $\begin{array}{c}\text { Grade 9/ } \\
\text { Grade 12 }\end{array}$ & $\begin{array}{c}\text { Primary school } \\
(12+2 \text { or 12+4) }\end{array}$ & $120-145$ & 8 weeks \\
\hline $\begin{array}{c}\text { Higher and } \\
\text { Bachelor diploma }\end{array}$ & $\begin{array}{c}\text { Grade 9/ } \\
\text { Grade 12 }\end{array}$ & $\begin{array}{c}\text { Lower Secondary } \\
(12+2 \text { or 12+4) }\end{array}$ & $130-160$ & 8 weeks \\
\hline Bachelor diploma & Grade 12 & $\begin{array}{c}\text { Upper Secondary } \\
(12+4)\end{array}$ & 136 & $10-12$ weeks \\
\hline
\end{tabular}

(Source: http://MOES.edu.la/ p. 79.) 
To develop the quality of teaching and learning by improving teachers' capacity and fostering teachers' incentives better, the MOES, in cooperation with some teacher education institutions in the neighboring and regional countries, governments and non-government organizations intend to increase the potential for producing a quality teacher education by forming bilateral and multilateral cooperation.

For example, the Swedish International Development Cooperation Agency developed a project called Teacher Training Enhancement and Status of Teachers (TEXAMINATION) during 2002 to 2010; the Japan International Cooperation Agency (JICA) had a project during 2010-2013 in some particular southern provinces; those projects aimed at enhancing pre- and in-service teachers, especially some educators with non-teaching licenses.

TTIs Management or supervision for public institutions depends on a vertical and horizontal cooperation basis. For instance, TTI is responsible for the university and higher education department of the Faculty of Education and TTC is in charge of the teacher education department. However, the teachers at some pre-primary and secondary schools of the capital city and provinces shall be supervised by their own local offices such as the Provincial Education and Sports Services (PESS) that are responsible for recruiting teachers based on the Department of Administration and Civil Servants Quota.

Besides, applications for quotas can be submitted by each school through the District Education and Sports Bureau (DESB), PESS, and MOES for lower secondary school teachers and through PESS and MOES for upper secondary school teachers.

In terms of teacher deployment, the Ministry grants final approval of assignments based on the teacher applications or on a recommendation by the evaluation committee through DESB, PESS, and Department of Organization and Personnel (DOP). Both in- and pre-service teacher training is under the control of the Department of Teacher Education (DTE), MOES. DTE is also responsible for overseeing activities that are conducted by teacher training institutions.

Teacher transfer and termination in Laos culture is operated based on three main categories such as personal reason (family settlement, make a mistake-severity, health condition), organizational reason (position promotion or demotion of position) and death. Figure 7. depicts the structure of TTIs in Laos. 
Figure 7. Structure of Teacher Training Institutes in Laos (TTIs)

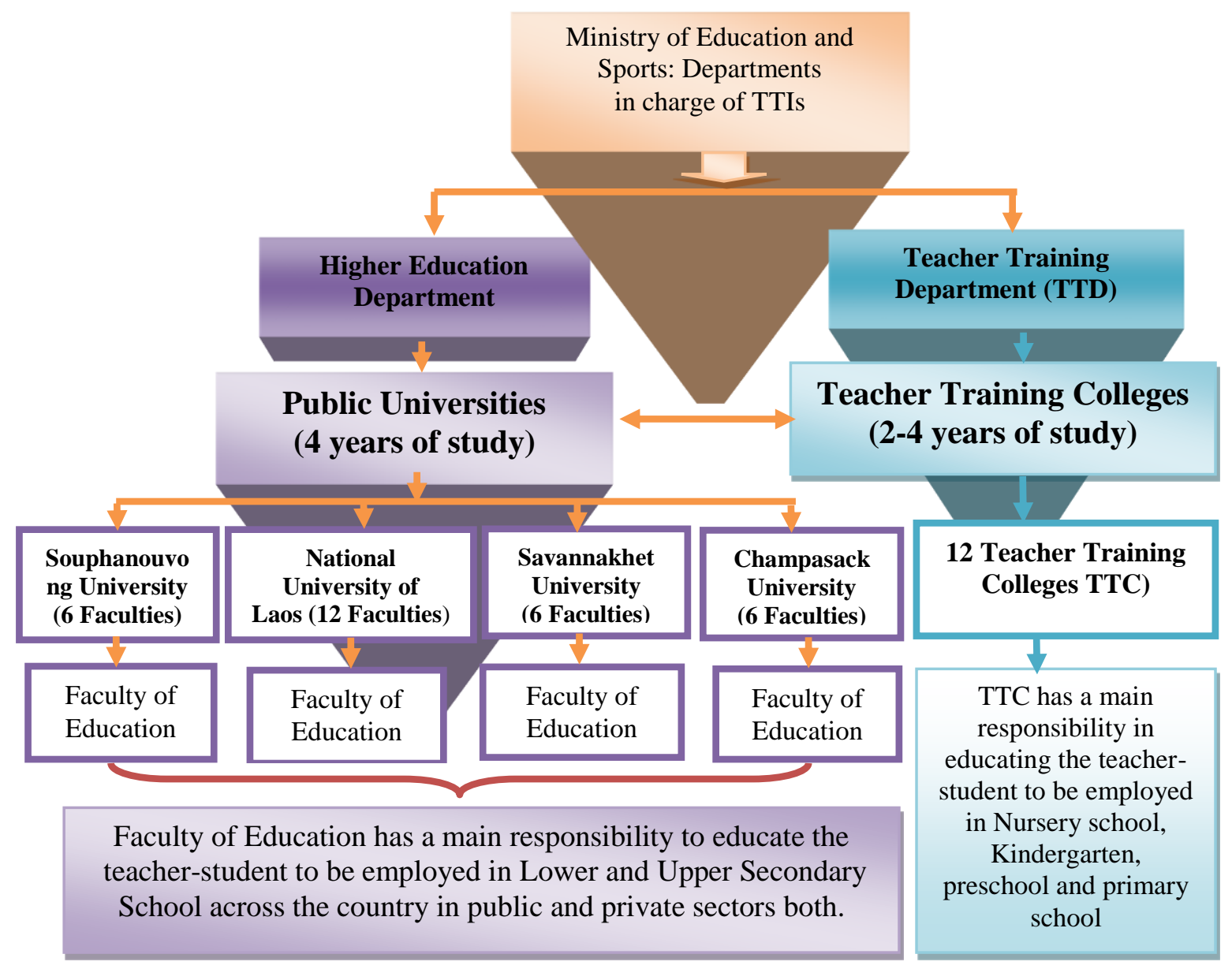

(Source: http://MOES.edu.la/ p. 34.)

\subsection{Defining keywords and key expressions}

The following definitions are related solely to the context of TTIs in Laos that I have extracted from the whole theories, conceptualizations, legal educations in Laos pertaining to study 1 to 6 or main study. In order to facilitate the audience's uniformity in understanding, the definitions for each study were listed as follows:

Instructional management: it is a process in overseeing each classroom procedure, monitor, progress, space, time, materials, and equipment utilization. These tasks and activities concern school leaders or principals to incorporate among teachers toward the decision-making process of how-to adapt and utilize those instructional sources to maximize a benefit and that satisfies instructors and students the most.

Management of Teacher: it refers to the educational leaders in TTIs who apply their skills and abilities to manage and supervise teachers to provide their best performance and 
to satisfy some basic welfare needs systematically (e.g. Lao Law on education, 2016; Brewster, et. al. 2011; Chanthala and Phommanimit, 2004).

Teacher Training Institution (TTIs): it is the first comprehensive institute in Laos created by the merge of the 4 Faculties of Education (FOE) from 4 Public Universities and 12 Teacher Training Colleges (TTC) called hereinafter as Teacher Training Institutions or TTIs. FOE and TTC (Decree on forecasting and annual building plan of teacher, No. 4924/MOES/OP/2016-Laos).

Educational Leader's perception level of the six tasks: awareness and comprehension of an individual concerning teacher demand analysis, recruitment and selection, pre-service teacher training, teacher performance appraisal, teacher compensation, and training needs assessment, that should be their priority functions (Decree, No. 4924/MOES/OP/ 2017).

Teacher: it means the teacher employees who are assigned to teach a particular subject based on their specialized knowledge and who have the right to receive all kinds of compensations and other benefits (Lao Law on Education, 2016).

Teacher Management in Teacher Training Institutions (TTI): it means the appointed educational leader performing the job-oriented managing and utilizing of the teachers and other resources. In addition, the educational leader also has a responsibility to manage some tasks related to teacher management within TTIs as follows:

Teacher demand analysis: it means the process of collecting and analyzing data systematically to determine the demands in details, including job specification and job qualification (e.g; Thosouvannachinda, 2001; Vannasy, et. al.; 2014).

Recruitment and Selection of teachers: Recruitment means the processes of job vacancy announcement via multimedia for searching and attracting the new qualified teacher applicant. Selection is the core process in picking or choosing the right teacher candidate by using multiple selection techniques (Law on Lao civil servant, No 023/NE/2016). These both play a vital role in obtaining the right candidate to occupy the vacant position (Doorenenbal, et. al., 2012).

Pre-service training: it means the educational leader in TTIs providing some necessary information to novice teachers about decrees, provisions, legal educations, working culture, line of work, policy, organizational achievement, network, legal obligations and vision (Law on Civil Servant, No. 023/NE/2016-Laos), Patrick et. al., 2014; Wills, 1994; Chanthala and Phommanimith, 2004; Bransford, et. al., 2005; and Knorr, 2012). 
Performance appraisal: it means a systematic evaluation process to explore skill gaps among teachers, to boost their professional growth. The result of appraisal can help in allocating the compensation to teachers in TTIs transparently and precisely (Chanthala and Phommanimith, 2004; Hdiggui, 2006).

Teacher Compensation: it means the process of supplying a valuable package of benefits including salary, extra pay, pension, and this process is based on the result of staff appraisal or evaluation, legal information, other provisions and decrees related (e.g. Gottelmann and Yekhlef, 2005; Torjman, 2005; Fitzpatrick, 2000; UNESCO, 2015).

Training Needs Assessment: it means the educational leader in TTIs conducting a survey with the help of multifarious techniques to obtain information about the teachers' needs (skill gaps), to improve and develop their knowledge and skills relating to the teaching profession, and organize the right training (e.g. Ferreira and Abbad, 2013; Trutkowski, 2016; Vannasy, et. al.; 2014).

Teaching load: it means the TTIs allocating too much teaching hours a week to work, cross-subjects taught, and teachers face a huge number of administrative tasks. In these cases, the management does not follow the Decree No. 4924/MOES/PO/2017-Laos. Prepridy (2000) concluded that leaders' lack of awareness of the above functions can cause teachers' burnout syndrome.

Teacher welfare: it means the TTIs always ignoring to supply teachers with all kinds of value packages of benefits and compensations the teachers are entitled to, and that is against the Decree No.177/GOL/2012-Laos.

Teachers' professional development: it means the TTIs often neglecting teachers' professional development and other career advancements, and that does not meet the Decree No 177/GOL, 2012-Laos. The above can lead to the teachers' burnout syndrome. According to Glatthorn (1995) a growth occurs as the teachers move through the professional career cycle.

Purposive sampling: purposive sampling is based on the characteristics of a population and the objectives of the study. It is also known as judgmental, selective or subjective sampling (Gay and Airisian, 2005).

\subsection{Chapter summary}

Perception is a personal intellectual and psychological process which is instinctive as it is individual self-awareness toward the functions and responsibilities without bias to others. 
Management is a process of science and art in communicating and controlling to getting things done through people, or it is a set of principles associated with planning, organizing and selecting the right staff to achieve the institution's goals.

Educational leaders or managers are appointed by the top educational institutions, they play a key role in the utilization of teachers and other organizational resources in driving the institutions to success.

The education system in Laos consists of pre-primary and primary school (five years of study), and secondary school (seven years of study), and higher education including college and university (two to six years of study) based on the selected courses or programs. 


\section{CHAPTER 3. METHODOLOGY}

\subsection{Introduction}

I have broadly mentioned concerning the problems of the study (1.2); rationale of the study (1.3), and other relevant reasons in chapter two in order to assist the readers in understanding the main purpose of this dissertation. Thus, this study employed a mixed research study design to examine insight about the educational leaders' or principals' perception of their functioning and responsibilities. The chapter describes the methodology of the empirical study through five studies and the main study. The description is grouped around the target institutions, samples, instruments, procedures, statistics applied and chapter summary.

\subsection{Target institutions used for the study}

As presented in (1.3), in Laos there are currently 16 Teacher Training Institutions (TTIs) nationwide. I have divided them into two institution groups to employ for different purposes, like the haft was used for examining or measuring the validity and reliability of selfconstructed questionnaires. The selection process of target institutions was based on considering those TTIs which face less or more problems from among those quoted in the annual movement report (2016-2017), and also used a quota sampling technique (Gay and Airisian, 2005).

\subsection{Samples}

This section presents the people participating in the studies, divided into three main groups. The first group, consisting of 128 sample members included measurement experts, academic staffs; and senior teachers from the selected TTIs and some experts from MOES. This first group was employed in study 1,2, and 3. They have examined and evaluated the constructed questionnaires designed for data collection in study 6 or main study. Most of them were graduates, instructors and had a work related to educational personnel management and research instrument design.

In the second group, there were 104 teachers from practice- or Demonstration schools which are under the supervision of the Faculty of Education and 196 teachers from three Faculties of Education employed to study 4 and 5 respectively. The third group consisted of 138 educational leaders and 213 teachers. These sample members worked in the same TTIs 
across Laos and I have employed them for study 6 or main study. All of the above-mentioned samples were obtained by using quota and purposive sampling, and their background information is presented through each study and the main study as below:

\section{Sample for study 1}

This study enrolled 10 measurement experts and 40 academic staff members, who worked in the field of educational personnel at the Ministry of Education and Sports, and at the Faculty of Education in Laos. They examined the two forms of questionnaires (educational leader and teacher). The most of these participants were female (53.75\%) and mostly possessed a master's degree (56.25\%) and had working experiences of more than 16 years (42.5\%). Only 2 out of 50 participants obtained a Ph.D.

\section{Sample for study 2}

The participants of study 2 were 25 people ( 5 measurement experts and 20 administrative staff members respectively). These participants had different purposes in examining the validity and reliability of the questionnaires. $53 \%$ of these participants were female, $62 \%$ and $56 \%$ respectively were graduates and had a working experience of more than 16 years in the field of human resources.

\section{Sample for study 3}

Based on the concepts of an empirical research design, the number of participants in the piloting of research instruments is a small sample of 20-60 people, similar in composition to the population from which you are sampling (Sudman and Bradburn, 2004). Thus, study 3 involved 53 participants, including five measurement experts (9.43\%) and 48 educational leaders $(90.57 \%)$. The $66.7 \%$ of respondents had a Bachelor degree and the rest graduated from Master programs. $68.8 \%$ of participants have been working for more than 15 years and $31.3 \%$ had less than 15 years of working experience.

\section{Sample for study 4}

There were 104 teacher civil servants enrolled from practice schools or demonstration schools. There were 24 kindergarten school teachers (23\%), 28 primary school teachers $(27 \%)$ and 52 secondary school teachers $(50 \%)$. These practice schools were under the 
supervision of the Faculty of Education, National University of Laos, the place I have been working for as a lecturer.

Among the 104 teachers the distribution by gender was: female (67.3\%), male (32.7\%). The age distribution was: participants aged above 30 years covered $75 \%$ of the sample, the proportion of those below 30 years was (25\%). The majority of respondents possessed a Bachelor degree (57.7\%) and the rest had a Master degree (42.3\%). 58.7\% had a more than 10 years teaching experience, while $41.3 \%$ had a teaching experience of less than 10 years.

\section{Sample for study 5}

There were 196 teachers asked from three Faculties of Education within three Public Universities across Laos. 92 (46.90\%) were male, and 104 (53.10\%) were female teachers, 63 teachers $(32.10 \%)$ had a teaching experience less than 10 years and 133 teachers $(67.90 \%)$ had a teaching experience of more than 10 years.

\section{Sample for study 6 (main study)}

As I have stated earlier, there were 8 out of 16 TTIs in Laos selected to take part in the main study. I have decided to focus solely on 213 teachers and 138 educational leaders who have teaching obligations not more than 12 hours and 6 hours a week respectively (Decree No. 177/GOL/2012-Laos). These sample sizes were obtained by using purposive sampling technique (Gay and Airisian, 2005). Both sample-groups worked within the 8 TTIs-Laos. The majority of educational leaders were men (65.2\%), obtained a Master Degree (54.3\%), Bachelor Degree (31.9\%), and possessed a Ph.D. Degree (13.8\%), and half (50\%) of them have been working since more than 16 years. Whereas, the majority of teachers were women (65.3\%), and obtained a Bachelor Degree $(63.8 \%)$ as well as they have been teaching between 5-10 years $(57.3 \%)$ (See Table 4.). 
Table 4. The samples used for the study

\begin{tabular}{ccc}
\hline Sources of samples (Laos) & Employed for study & $\begin{array}{c}\text { No. of } \\
\text { participant }\end{array}$ \\
\hline $\begin{array}{c}\text { Ministry of Education and Sports, National } \\
\text { University of Laos, and two TTIs }\end{array}$ & Study 1 & $\mathrm{~N}=50$ \\
\hline $\begin{array}{c}\text { District Education Offices, Vientiane } \\
\text { capital and one TTI }\end{array}$ & Study 2 & $\mathrm{~N}=25$ \\
\hline Two TTIs & Study 3 & $\mathrm{~N}=53$ \\
\hline $\begin{array}{c}\text { Three Practicing schools under the } \\
\text { supervision of FOE }\end{array}$ & Study 4 & $\mathrm{~N}=104$ \\
\hline $\begin{array}{c}\text { Three FOEs within TTIs } \\
8 \text { TTIs excluded from the five studies }\end{array}$ & Study 5 & $\mathrm{~N}=196$ \\
\hline & Study 6 (main study) & $\mathrm{N}=351$ \\
\hline
\end{tabular}

\subsection{Instruments and its developmental process}

As I have broadly indicated in 1.3 and 2.2.1 concerning the rationales behind using selfconstructed questionnaires, I was eager to develop an instrument myself in order to meet the local context or field of the study, the local respondents, and the situation.

\section{Study 1-3}

A questionnaire based on the principles of instrument construction was reviewed and applied carefully. This construct is of mixed format, based on a rigorous literature review on the principles of constructing an instrument. The questionnaire was divided into two forms (form A and form B) to meet the different samples (educational leader and the teacher).

Form A, consisted of 6 subscales (tasks) with 63 items in total, and Form B, comprised of 3 stress factors with 25 items in total. Besides, each form has provided an open-ended question placed at the end of each issue or aspect for the participants' feedback. The development process constituted of a two stages examination by using three techniques as below:

First stage, the validity examination (IOC technique) by using 3 points Likert scale such as $(+1)=$ the questionnaire meets the Index of Item-Objective Congruence (IOC); $(0)$ $=\mathrm{IOC}$ is not sure, $(-1)=$ does not meet IOC, this step was rated and marked by 5 measurement experts.

As the second stage, I have selected the only Item which was accepted by IOC to ask 20-30 academic staff members. They were responsible for rating and marking the 
'understandable word' load in the question by applying 5-point Likert scales. This stage aims to monitor the reliability level through a Cronbach's Alpha value, Correlation coefficient, Interquartile Range (IR) and Median (Mdn). The study activities were carried out through study 1 to 3 , and the study findings are introduced in 4.2 to 4.4 .

\section{Study 4}

In study 4 I have used questionnaire form B after it passed the qualifying examination. The completed version comprised of 18 items altogether asking about the allocated teaching load, welfare and teaching career development by using a five-points Likert scale and presented open-ended questions at the end of each aspect for the teachers' free suggestions.

\section{Study 5}

I have adapted a ready questionnaire created by Phisane (2014). The questionnaire consisted of 38 items totally, covering four main facets such as creating a lesson plan (12 items), instructional conduct ( 8 items), instruction via technological devices (10 items) and instructional assessment (8 items). A five-points Likert scale was used (Vagias, 2006). Openended questions were also provided to elicit information from the respondents to become guidelines for further problem-solving concerning instructional management.

\section{Study 6 or main study}

I have utilized the completed version of both questionnaire forms as proposed above to collect data from 351 participants (138 educational leaders and 213 teachers). The questionnaire form A (for educational leaders) contained six tasks, 52 items in total, and the questionnaire form B (for teachers) consisted of 18 items in total.

The following part describes the details of the completed forms and its characteristics divided into three sections in each form as shown below:

1) Questionnaire form A: Instructional management and stress factors affecting teacher trainers as perceived by the educational leaders of Laos. It is divided into three sections presented as follows:

Section 1: asking about respondents' socio-demographical information with the help of a checklist - Gender: male ( ); female ( ); qualification level: Bachelor ( ); Master ( ); Doctoral ( ); working experience: less than 10 years ( ); 10-15 years ( );16 years and more ( ); TTIs location: FOE ( ); TTC ( ).

Section 2: Leaders' perception level of the 6 tasks with the help of 52 items: 
(1) Teacher demand analysis - 7 items;

(2) Recruitment and selection - 8 items;

(3) Pre-service training - 8 items;

(4) Appraisal performance - 10 items;

(5) Teacher compensation - 13 items;

(6) Training Needs Assessment - 7 items

Four-points Likert scales were adopted from Vagias and Wade (2006) as shown below:

4 represents a very high perception

3 represents a high perception

2 represents a low perception

1 represents a very low perception.

Section 3: I have created open-ended questions and placed them at the end of each issue or aspect for the respondents' feedback and also used two short stories as attitude examination to monitor the leaders' decision-making skills in the staff selection process (See Appendix A).

2) Questionnaire form B: Stress factors among teachers at TTIs. This questionnaire (form B) constitutes of three sections introduced below:

Section 1: The respondents' socio-demographical information including Gender: male ( ), female ( ). Educational qualification < Bachelor ( ); Bachelor Degree ( ); Master Degree ( ); Workplace: FOE ( ); TTC ( ). Teaching experiences: <5 years ( ); 5-10 years ( ); 11 years and more ( ).

Section 2: Stress factors among teachers, measured with the help of 18 out of 25 items altogether and divided into three stress factors in teaching profession, as shown below:

(1) Teaching load - 5 items;

(2) Teacher welfare - 8 items;

(3) Teachers' professional development - 5 items. Five-points Likert scales were adapted from Vagias and Wade (2006) as shown below:

5 represents a very high-level of stress factor

4 represents a high-level of stress factor

3 represents a neutral level of stress factor

2 represents a low-level of stress factor

1 represents a very low-level of stress factor 
Section 3: At the end of each stress factor an open-ended question was presented for gathering the teachers voice or feedback related to what they miss from or what is painful in the teaching profession under the supervision of educational leaders. (See both forms in Appendix D). Table 5 below denotes the timelines, the instruments applied and the type of measurement scale.

Table 5. Summary of the steps of the developmental process of a self-constructed questionnaire

\begin{tabular}{|c|c|c|c|}
\hline Timeline & Instruments applied & Types & Findings \\
\hline $\begin{array}{c}\text { Study 1 } \\
\text { August } 2016 \\
\end{array}$ & $\begin{array}{c}\text { Form A \& B } \\
\text { (A quality examination) }\end{array}$ & $\begin{array}{l}\text { 3- and 5-point Likert scales, } \\
\text { open-ended questions }\end{array}$ & See 4.2 \\
\hline $\begin{array}{c}\text { Study } 2 \\
\text { January } 2017\end{array}$ & $\begin{array}{l}\text { Form A \& B } \\
\text { (Continue re- } \\
\text { examination) }\end{array}$ & $\begin{array}{l}\text { 3- and 5-point Likert scales, } \\
\text { open-ended questions }\end{array}$ & See 4.3 \\
\hline $\begin{array}{l}\text { Study } 3 \\
\text { June } 2017\end{array}$ & $\begin{array}{l}\text { Form A } \\
\text { (Continue re- } \\
\text { examination) }\end{array}$ & $\begin{array}{l}\text { 3- and 5-point Likert scales, } \\
\text { open-ended questions }\end{array}$ & See 4.4 \\
\hline $\begin{array}{r}\text { Study } 4 \\
\text { July } 2017\end{array}$ & $\begin{array}{l}\text { Form B (completed } \\
\text { version) }\end{array}$ & 5-point Likert scales & See 4.5 \\
\hline $\begin{array}{c}\text { Study } 5 \\
\text { August } 2017\end{array}$ & $\begin{array}{l}\text { Semi-adapted } \\
\text { (Phisane, 2015) }\end{array}$ & 5-point Likert scales & See 4.6 \\
\hline $\begin{array}{l}\text { Study } 6 \\
\text { September } \\
2017\end{array}$ & $\begin{array}{c}\text { Form A \& B } \\
\text { (Completed version) }\end{array}$ & $\begin{array}{l}\text { 4-point Likert scales (form A), } \\
\text { and 5-point Likert scales (form } \\
\text { B), and open-ended questions }\end{array}$ & See 4.7 \\
\hline
\end{tabular}

\subsection{Procedures}

\subsubsection{Data collection}

A letter of consent was approved and signed by the supervisor and forwarded through the relevant organizations and TTIs in Laos. Also, the letter of consent has indicated the objectives of data collection and confirmed the confidential nature of the study in order to give them a comfortable feeling when expressing their opinions in the questionnaire. Both forms of the questionnaire were in Lao language. I have personally distributed them to the sample members selected in accordance with the above presented target institutions including five studies and the main study. Data collection took place in Laos for more than two years (June 2016 to August 2017) in different times and TTIs and educational offices selected as earlier discussed (See Table 6.). 
Table 6. The procedures of research activities

\begin{tabular}{|c|c|c|c|c|}
\hline Timeline & Questionnaires & Language & Method & Study site \\
\hline $\begin{array}{c}\text { Study 1 } \\
\text { August } 2016\end{array}$ & Form A \& B & $\begin{array}{c}\text { Lao } \\
\text { version }\end{array}$ & $\begin{array}{c}\text { Paper \& } \\
\text { pencil }\end{array}$ & MOES, Laos \\
\hline $\begin{array}{c}\text { Study } 2 \\
\text { January } 2017\end{array}$ & Form A \& B & $\begin{array}{l}\text { Lao } \\
\text { version }\end{array}$ & $\begin{array}{l}\text { Paper \& } \\
\text { pencil }\end{array}$ & $\begin{array}{l}2 \text { TTIs and DESB- } \\
\text { Laos }\end{array}$ \\
\hline $\begin{array}{c}\text { Study } 3 \\
\text { June } 2017 \\
\end{array}$ & Form A & $\begin{array}{l}\text { Lao } \\
\text { version }\end{array}$ & $\begin{array}{l}\text { Paper \& } \\
\text { pencil }\end{array}$ & $\begin{array}{l}3 \text { TTIs-Laos, excluded } \\
\text { from the main study }\end{array}$ \\
\hline $\begin{array}{c}\text { Study } 4 \\
\text { July } 2017\end{array}$ & Form B & $\begin{array}{l}\text { Lao } \\
\text { version }\end{array}$ & $\begin{array}{c}\text { Paper \& } \\
\text { pencil }\end{array}$ & $\begin{array}{l}3 \text { practice schools, } \\
\text { Laos. }\end{array}$ \\
\hline $\begin{array}{c}\text { Study 5 } \\
\text { August } 2017\end{array}$ & Semi-adapted & $\begin{array}{l}\text { Lao } \\
\text { version }\end{array}$ & $\begin{array}{l}\text { Paper \& } \\
\text { pencil }\end{array}$ & $\begin{array}{l}3 \text { TTIs-Laos, excluded } \\
\text { from the main study. }\end{array}$ \\
\hline $\begin{array}{c}\text { Study } 6 \\
\text { September } 2017\end{array}$ & Form A \& B & $\begin{array}{c}\text { Lao } \\
\text { version }\end{array}$ & $\begin{array}{l}\text { Paper \& } \\
\text { pencil }\end{array}$ & 8 TTIs-Laos \\
\hline
\end{tabular}

\subsubsection{Data analysis}

Based on the research design, the analysis of data was organized and conducted following the research aims and hypothesis. The Statistical Package of Social Sciences (SPSS) was used to analyze raw data of all the studies including the content analysis of the open-ended questions in order to monitor the frequency, and percentage. Descriptive statistics were applied to see the IOC score, mean value, standard deviation, Mdn, IR, Cronbach's Alpha, Correlation coefficient, t-test, f-examination (One-way ANOVA), Scheffe or paired samples t-test.

\subsection{Chapter summary}

The purpose of this chapter was to present the methodology of the sub-studies and the main study, including the target institutions, samples, instrument and its stage of construction, procedures, data analysis as well as statistical applications. Besides, the rationale behind choosing the target institutions, samples used for different purposes, characteristics of questionnaires, measurement scales (3, 4, 5 points Likert scales) were employed and discussed clearly in section 1.3. It is noted that every scientific research has to have an appropriate study design and methodology in order to arrive to answers to all the research aims and questions in a scientific and reliable way. 


\section{CHAPTER 4 THE FINDINGS}

\subsection{Introduction}

This section presents the findings of the five studies and the main study: 1) Examining the validity and reliability of research-questionnaires, 2) Re-examining the validity and reliability of research questionnaires, 3) A possibility study of using a self-constructed questionnaire for examining teacher management in Laos, 4) Causes of teachers' burnout syndrome concerning school board management at practice schools in Laos, 5) Instructional management of teaching staff in teacher training institutions, Lao PDR. 6) The study 6 or main study: Instructional management and stress factors affecting teacher trainers as perceived by the educational leaders of Laos'. The findings, discussions, and summary will be introduced respectively.

\subsection{Findings of study 1. Examining the validity and reliability of the questionnaires}

This study aimed to detect and eliminate all erroneous words and phrases and replace them by appropriate word loadings. 10 measurement experts and 40 academic staff members took part to assess and evaluate the self-made questionnaires. The questionnaires are divided into two forms (form A: educational leader, and form B: teacher). The data collection took place in the Ministry of Education and Sports, Lao PDR in August 2016 by paper and pencil.

\subsubsection{Validity and reliability of the questionnaire (form A)}

The section presents the overall IOC scores of six sub-scales (task) at $\left(\sum \mathrm{IOC}=0,60 ; \geq 0.50\right)$ and scores observed in case of each item. 19 out of 63 items needed to be eliminated because these items had IOC $\leq .50$ (items $6,17,18,21,23,29,37,38,39,41,45,48,52,55,58,59$, 61, 62 and 63 respectively). Table 7 shows the No. of original items, No. of IOC accepted, sum of all and each sub-scale1s IOC score. 
Table 7. Validity score by IOC, Form A (study 1)

\begin{tabular}{lcccc}
\hline \multicolumn{1}{c}{ Sub-scale (Task) } & $\begin{array}{c}\text { No. of original } \\
\text { items }\end{array}$ & $\begin{array}{c}\text { IOC } \\
\text { accepted }\end{array}$ & $\begin{array}{c}\Sigma \text { IOC } \\
\text { score }\end{array}$ & Results \\
\hline Teacher demand analysis & 9 & 8 & .80 & Accepted \\
$\begin{array}{l}\text { Recruitment and } \\
\text { selection }\end{array}$ & 9 & 7 & .44 & Improvement \\
Pre-service training & 9 & 7 & .64 & Accepted \\
Performance appraisal & 11 & 8 & .65 & Accepted \\
Teacher compensation & 18 & 12 & .63 & Accepted \\
Training needs & 7 & 2 & .48 & Improvement \\
assessment & 63 items & 44 items & .60 & Accepted \\
\hline \multicolumn{1}{c}{ Total =6 subscales } & & & &
\end{tabular}

IOC acceptable $\geq .50$

The reliability examination was carried out through two techniques like Cronbach's alpha and Correlation coefficient. The data analyzed show that the majority of respondents agreed through the Cronbach's Alpha with overall scores at $\left(\sum \alpha=0.80\right)$, and the correlation coefficient between sub-scales showed a relatively low level of internal consistency. Based on the analyzed data, there is a need to continue re-examination in order to reach the measurement standardization. Table 8 below displays the Cronbach's Alpha value and correlation between sub-scale (task).

Table 8. Reliability score, form A (study 2)

\begin{tabular}{l|c|ccccccc}
\hline \multicolumn{1}{c|}{ Sub-scales } & $\begin{array}{c}\text { No. of } \\
\text { Items }\end{array}$ & $\boldsymbol{\alpha}$ & $\mathbf{1}$ & $\mathbf{2}$ & $\mathbf{3}$ & $\mathbf{4}$ & $\mathbf{5}$ & $\mathbf{6}$ \\
\hline 1. Teacher demand analysis & 8 & .37 & - & .185 & .236 & .026 & $.524^{*}$ & .157 \\
2. Recruitment and Selection & 7 & .64 & - & .353 & $.464^{*}$ & .190 & -.264 \\
3. Pre-service training & 7 & .75 & & - & $.510^{*}$ & .254 & -.191 \\
4. Appraisal performance & 8 & .72 & & & - & & -.187 & -.440 \\
5. Compensation & 12 & .71 & & & & - & \\
6. Training needs assessment & 2 & .37 & & & & & & - \\
\hline Total=6 sub-scales (tasks) & 44 items & .80 & & & & & & \\
\hline
\end{tabular}




\subsubsection{Validity and reliability (form $B$ )}

The study found overall IOC score at $\left(\sum \mathrm{IOC}=0.68 ; \geq 0.50\right)$, and the scores observed in case of the individual items. 7 out of 25 items needed to be discarded because these items were IOC $\leq .50$ (Items 1, 5, 6, 11, 15, 20, and 23 respectively). Table 9 below indicates the details of the analyzed data.

Table 9. Validity score by IOC, form B (study 1)

\begin{tabular}{lcccc}
\hline \multicolumn{1}{c}{ Sub-scale (stress factor) } & $\begin{array}{c}\text { No. of original } \\
\text { items }\end{array}$ & $\begin{array}{c}\text { IOC } \\
\text { accepted }\end{array}$ & $\begin{array}{c}\Sigma \text { IOC } \\
\text { score }\end{array}$ & Results \\
\hline Teaching load & 8 & 5 & .65 & Accepted \\
$\begin{array}{l}\text { Teacher welfare } \\
\begin{array}{l}\text { Teacher professional } \\
\text { development }\end{array}\end{array}$ & 10 & 8 & .70 & Accepted \\
\hline \multicolumn{1}{c}{ Total =3 subscales } & 25 items & 18 items & .68 & Accepted \\
\hline
\end{tabular}

IOC acceptable $\geq .50$

In addition, Table 9 presents the reliability examination by Cronbach's Alpha and the Correlation coefficient between sub-scales (stress factor). The analysis indicated a relatively high level of reliability and a strong relationship between sub-scales. Thus, it can be said that questionnaire form B is of high internal consistency, and it is ready to be used to collect data for the main study. However, I wish to re-examine it to confirm and meet the measurement standardization.

Table 10. Reliability score, Form B (study 1)

\begin{tabular}{l|c|cccc}
\hline \multicolumn{1}{c|}{ Sub-scale } & Item & Alpha & $\mathbf{1}$ & $\mathbf{2}$ & $\mathbf{3}$ \\
\hline Teaching load & 5 & .92 & - & $.652^{* *}$ & $.538^{* *}$ \\
Teacher welfare & 8 & .88 & - & $.613^{* *}$ \\
Teacher Professional Development & 5 & .92 & & & - \\
\hline${ }^{* *} \mathrm{p}<.01$ & &
\end{tabular}




\subsubsection{Summary}

Based on the IOC score, Cronbach's alpha and correlation between sub-scales of both selfconstructed questionnaires (form A, for educational leaders and form B, for teachers), there were 19 out of 63 items and 18 out of 25 items accepted by IOC scores. This study also found a wide fluctuation of internal consistency in both forms, especially in case of form A where the external structure of the instrument was uncertain and needed a re-examination to meet the standardization of the measurement process.

\subsection{Findings of study 2. Re-examining the validity and reliability of questionnaires.}

This study aimed to expand the level of validity and reliability of the questionnaires, and to gather the respondents' suggestions or feedback to improve the self-constructed questionnaires to fit the context of study and local situation. There were five measurement experts and 20 academic staff members from two District's Education and Sports Bureau (DESB) and one TTI invited to the study, and the data collection was carried out in Laos in January 2017 by paper and pencil.

\subsubsection{Validity and reliability of the questionnaire (form $\mathrm{A}$ )}

The analysis of the six sub-scales with 63 items, some feedbacks, and the omitting of some items, and revising the questionnaire in both forms was performed. Based on the data analyzed in the six sub-scales (tasks) showed a high-level overall IOC score $(\Sigma \mathrm{IOC}=.81)$

and the $\Sigma$ IOC values of each sub-scale were at a high level too. However, this IOC examination also found that 5 out 63 items in total were needed to be eliminated because these items were of low IOC score, such as item 6 in sub-scale 1; item 16, and 17 in subscale 2; 44 and 45 in sub-scale 5 Most of the words loaded in these question-items was related to bias, ambiguity, and against the Laos government's policies (See Table 11.). 
Table 11. Summary of the $\Sigma$ IOC and Sub-scale. Form A, (study 2)

\begin{tabular}{lcccc}
\hline \multicolumn{1}{c}{ Sub-scale (Task) } & $\begin{array}{c}\text { No. of original } \\
\text { items }\end{array}$ & $\begin{array}{c}\text { IOC } \\
\text { accepted }\end{array}$ & $\begin{array}{c}\Sigma \text { IOC } \\
\text { score }\end{array}$ & Results \\
\hline Teacher demand analysis & 9 & 8 & .68 & Accepted \\
Recruitment and selection & 9 & 7 & .64 & Accepted \\
Pre-service training & 9 & 9 & .91 & Accepted \\
Performance appraisal & 11 & 11 & .89 & Accepted \\
Teacher compensation & 18 & 16 & .81 & Accepted \\
Training needs assessment & 7 & 7 & .94 & Accepted \\
\hline \multicolumn{1}{c}{ Total =6 subscales } & 63 items & 58 & .81 & Accepted \\
\hline
\end{tabular}

IOC acceptable $\geq .50$

The reliability examination found: (1) teacher demand analysis ( 8 items) Alpha $=.57$; (2) recruitment and selection (7 items) Alpha $=.60$; (3) pre-service training (9 items) Alpha $=.68$; (4) performance appraisal (11 items) Alpha =.78; (5) teacher compensation (16 items) Alpha $=.82$, and (6) training needs assessment $(7$ items $)$ Alpha $=.51$. The correlation coefficient between sub-scales were found at a fluctuating level, especially sub-scale 2 and 3 were relatively low which means they need revision and re-examination to meet the interpretation criteria (See Table 12.).

Table 12. Reliability score, correlation between sub-scales, Form A (study 2)

\begin{tabular}{|c|c|c|c|c|c|c|c|c|}
\hline Subscale & $\begin{array}{c}\text { No. of } \\
\text { item }\end{array}$ & $\begin{array}{c}\text { Cronbach's } \\
\text { Alpha }\end{array}$ & 1 & 2 & 3 & 4 & 5 & 6 \\
\hline 1.Teacher demand analysis & 8 & .51 & - & .443 & .427 & $.512 *$ & $.473^{*}$ & $.690 * *$ \\
\hline $\begin{array}{l}\text { 2. Recruitment and } \\
\text { Selection }\end{array}$ & 7 & .60 & & - & .434 & $.718^{* *}$ & $.516^{*}$ & $.625^{* *}$ \\
\hline 3. Pre-service training & 9 & .68 & & & - & $.757^{* *}$ & $.829^{* *}$ & $.444^{*}$ \\
\hline 4. Appraisal performance & 11 & .78 & & & & - & $.758^{* *}$ & $.592^{* *}$ \\
\hline 5. Compensation & 16 & .82 & & & & & - & $.447^{*}$ \\
\hline $\begin{array}{l}\text { 6.Training needs } \\
\text { assessment }\end{array}$ & 7 & .57 & & & & & & - \\
\hline
\end{tabular}




\subsubsection{Validity and reliability of the questionnaire (form B)}

Re-examining the validity and reliability of the questionnaire (form B) showed the overall IOC score being at a high level $(\Sigma \mathrm{IOC}=.86)$ and the $\Sigma \mathrm{IOC}$ values of each sub-scale were of relatively high level too. However, this re-examination found the remaining number of Items accepted the same as in the previous study but the latter study's score in the overall and in the individual item jumped to a high level.

Table 13. Validity score by IOC, form B (study 2)

\begin{tabular}{lcccc}
\hline Sub-scale (stress factor) & $\begin{array}{c}\text { No. of original } \\
\text { items }\end{array}$ & $\begin{array}{c}\text { IOC } \\
\text { accepted }\end{array}$ & $\begin{array}{c}\Sigma \text { IOC } \\
\text { score }\end{array}$ & Results \\
\hline Teaching load & 8 & 5 & .75 & Accepted \\
Teacher welfare & 10 & 8 & .84 & Accepted \\
$\begin{array}{l}\text { Teacher professional } \\
\text { development }\end{array}$ & 7 & 5 & 1.00 & Accepted \\
\hline \multicolumn{1}{c}{ Total = 3 subscales } & 25 items & 18 items & .86 & Accepted \\
\hline
\end{tabular}

IOC acceptable $\geq .50$

Besides, after examining questionnaire form B to observe the IOC score next came the reliability analysis which revealed: (1) teaching load (5 items) Alpha $=.92$; (2) teacher welfare (8 items) Alpha $=.97$, and (3) teacher professional development (5 items) Alpha $=.99$, while the examination of the correlation coefficient between subscales found a strong correlation. This questionnaire (form B) is ready to be used for collecting data for the main study (See Table 14.).

Table 14. Reliability score, Form B (study 2)

\begin{tabular}{lccccc}
\multicolumn{1}{c}{ Sub-scale } & Item & Alpha & $\mathbf{1}$ & $\mathbf{2}$ & $\mathbf{3}$ \\
\hline 1. Teaching load & 5 & .92 & - & $.765^{* *}$ & $.814^{* *}$ \\
2. Teacher welfare & 8 & .97 & - & $.892^{* *}$ \\
3. Teacher Professional Development & 5 & .99 & & & - \\
\hline$* * . p<0.01$ & & & &
\end{tabular}




\subsubsection{The feedback of the respondents}

Those feedbacks were associated with the wording and sentence structure and they also revised some word-fits to meet the research field that the author has classified into categories and groupings in accordance with the word-modification shown below (Table 15.):

Table 15. Respondents' suggestions for improving the questionnaires (study 2)

\begin{tabular}{|c|c|c|}
\hline $\begin{array}{l}\text { Original of Sub- } \\
\text { scales }\end{array}$ & New phrase suggestions & Experts' justifications \\
\hline Job analysis & Teacher demand analysis & $\begin{array}{l}\text { Job analysis is a wider } \\
\text { description and sector }\end{array}$ \\
\hline $\begin{array}{l}\text { Utilization rate of } \\
\text { teacher }\end{array}$ & $\begin{array}{c}\text { Teacher performance } \\
\text { appraisal }\end{array}$ & $\begin{array}{c}\text { It covers several responsibilities } \\
\text { of teachers }\end{array}$ \\
\hline Teacher Policy & Teacher compensation & $\begin{array}{l}\text { Compensation is a part } \\
\text { of policy domain }\end{array}$ \\
\hline $\begin{array}{l}\text { Manuscript of } \\
\text { wording }\end{array}$ & Re-wording & Experts' justifications \\
\hline Aptitude, multi skills & $\begin{array}{l}\text { Ability, additional } \\
\text { teaching skill }\end{array}$ & $\begin{array}{l}\text { 'Aptitude' is natural ability, wider. } \\
\text { 'Ability' indicates a specific } \\
\text { purpose. }\end{array}$ \\
\hline $\begin{array}{l}\text { Teaching practices, } \\
\text { Feedback, }\end{array}$ & $\begin{array}{l}\text { Teaching practicum, peer } \\
\text { review }\end{array}$ & $\begin{array}{l}\text { Teaching practicum is the official } \\
\text { expression. Peer reviews are } \\
\text { optional among teachers in mutual } \\
\text { reflections }\end{array}$ \\
\hline Patronage, nepotism & $\begin{array}{l}\text { - Consistency of } \\
\text { Treatment and Fairness } \\
\text { - Merit, morality, equity. }\end{array}$ & $\begin{array}{l}\text { In case of selecting a new teacher } \\
\text { employee, 'nepotism' will bring an } \\
\text { organization deterioration }\end{array}$ \\
\hline Birth leaving & Maternity leave & Official terms \\
\hline
\end{tabular}

\subsubsection{Summary}

As a result the re-examination of both questionnaires brought better validity levels as there were 58 out of 63 items (form A) and 18 out of 25 items (form B) accepted by IOC scores and its reliability measured through Cronbach's alpha and correlation between subscales have revealed a high internal consistency, especially in case of questionnaire form B which is ready to be used for piloting prior to applying it to collect data for the main study in the future. However, I would like to continue measuring with form 'A' in study 3 to ensure it has a valid internal consistency before employing to collect data for the main study. 


\subsection{Findings of study 3 . A possibility study of using a self-constructed}

\section{questionnaire for studying the management of teachers in Laos.}

This study aimed to extend the reliability level of the two latter studies, to collect feedbacks to be a guideline for increasing the constructs' reliability, and to explore the possibility index value of using the self-made questionnaire. There were 53 participants in the sample, including measurement experts and academic staff members from two TTIs. The data collection took place in June 2017 in Lao PDR, by paper and pencil.

\subsubsection{Validity of questionnaire (form A) by IOC, Mdn, IR, and PI.}

The validity examination by IOC and Delphi technique was carried out by the expert panelists to measure the Index of Item-Objective Congruence (IOC); Median (Mdn) and Inter-quartile Range (IR). The examiners obtained an IOC score between 0.50 to 1.00 ; Mdn score $>3.50$ to 5.00 and $\mathrm{IR}<1,50$, which were acceptable.

Table 16. Validity and reliability scores by complex techniques. Form A (Study 3)

\begin{tabular}{|c|c|c|c|c|c|c|c|c|c|c|c|c|}
\hline \multirow{3}{*}{$\begin{array}{l}\text { Sub- } \\
\text { scale }\end{array}$} & \multirow{3}{*}{$\begin{array}{c}\text { No. } \\
\text { of } \\
\text { item }\end{array}$} & \multirow{3}{*}{ IOC } & \multicolumn{4}{|c|}{$N=5$} & \multirow{2}{*}{\multicolumn{3}{|c|}{$\begin{array}{l}\sum M d n>3.50-5.00 \& \\
\sum I R<1.50 \text { (accepted) }\end{array}$}} & \multirow{2}{*}{\multicolumn{3}{|c|}{$\begin{array}{l}\text { Possibility Index }(\mathrm{N}=48) \\
(\mathrm{PI}=3.51-5.00 \text { Accepted })\end{array}$}} \\
\hline & & & \multicolumn{2}{|c|}{ Round 3} & \multicolumn{2}{|c|}{ Round 1} & & & & & & \\
\hline & & & Mdn & IR & Mdn & IR & Mdn & IR & Result & $\bar{x}$ & SD & Result \\
\hline \multirow{9}{*}{ 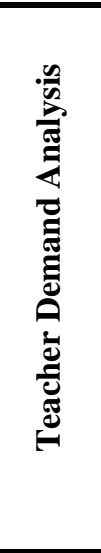 } & 1 & 1.00 & 4.00 & 1.00 & 1.00 & .50 & 3.00 & .50 & Revise & 4.77 & .42 & $\checkmark$ \\
\hline & 2 & .60 & 4.00 & 1.00 & 1.00 & .50 & 3.00 & .50 & Revise & 4.50 & .54 & $\checkmark$ \\
\hline & 3 & 1.00 & 4.00 & 1.00 & 1.00 & .50 & 3.00 & .50 & Revise & 4.52 & .58 & $\checkmark$ \\
\hline & 4 & .80 & 5.00 & 1.50 & 1.00 & .50 & 4.00 & 1.00 & $\checkmark$ & 4.18 & .70 & $\checkmark$ \\
\hline & 5 & 1.00 & 4.00 & 1.50 & 1.00 & .50 & 3.00 & 1.00 & Revise & 4.45 & .61 & $\checkmark$ \\
\hline & 6 & .60 & 5.00 & .50 & 1.00 & .50 & 4.00 & .00 & $\checkmark$ & 4.33 & .66 & $\checkmark$ \\
\hline & 7 & .80 & 5.00 & 1.00 & 1.00 & .50 & 4.00 & .50 & $\checkmark$ & 4.52 & .61 & $\checkmark$ \\
\hline & 8 & -.40 & 1.00 & 1.00 & .00 & 1.50 & .00 & -.50 & $x$ & $x$ & $x$ & $x$ \\
\hline & 9 & -.20 & 1.00 & .50 & .00 & .50 & 1.00 & .00 & $x$ & $x$ & $x$ & $x$ \\
\hline \multirow{9}{*}{ 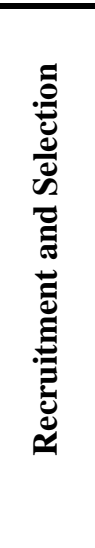 } & 10 & .60 & 5.00 & 1.00 & 1.00 & .50 & 4.00 & .50 & $\bar{\checkmark}$ & 4.31 & .58 & $\checkmark$ \\
\hline & 11 & 1.00 & 5.00 & 1.00 & 1.00 & .50 & 4.00 & .50 & $\checkmark$ & 4.56 & .58 & $\checkmark$ \\
\hline & 12 & .80 & 4.00 & 1.00 & 1.00 & .50 & 3.00 & .50 & Revise & 4.45 & .61 & $\checkmark$ \\
\hline & 13 & .80 & 5.00 & 1.00 & 1.00 & .50 & 4.00 & .50 & $\checkmark$ & 4.43 & .50 & $\checkmark$ \\
\hline & 14 & .80 & 5.00 & 1.00 & 1.00 & .50 & 4.00 & .50 & $\checkmark$ & 4.37 & .56 & $\checkmark$ \\
\hline & 15 & .80 & 5.00 & 1.00 & 1.00 & .50 & 4.00 & .50 & $\checkmark$ & 4.54 & .54 & $\checkmark$ \\
\hline & 16 & .60 & 4.00 & 1.00 & 1.00 & .50 & 3.00 & .50 & Revise & 4.66 & .51 & $\checkmark$ \\
\hline & 17 & -.20 & 1.00 & 1.50 & .00 & 1.50 & 1.00 & 1.00 & $x$ & $x$ & $x$ & $x$ \\
\hline & 18 & .80 & 5.00 & 1.00 & 1.00 & .50 & 4.00 & .50 & $\checkmark$ & 4.45 & .61 & \\
\hline
\end{tabular}


Table 16 above shows the results of various analysis through complex techniques concerning the subscales of Teacher demand analysis (TDA) and Recruitment and Selection (RaS). It was found that 2 out of 9 items in TDA and 1 out of 9 items in RaS needed to be omitted due to IOC value below 0.50, while 4 out of 9 items in TDA and 2 out of 9 items in RaS needed to be revised because the Mdn and the IR value did not match the criteria provided. These question-items had to be omitted and revised when vagueness and words that were incomprehensible occurred.

Regarding the possibility index examined with the help of 48 educational leaders who rated and marked the degree of the comprehensibility of words and phrases in the questionitems, respondents had to justify the feasibility level of utilization for the large-scale study. The rating criteria of understandable words from left to right (5-1) represents each degree and help in decision-making. In subscale TDA and RaS a high possibility index degree was found, with a mean score minimum-maximum at $\bar{x} 4.31$ to 4.77 respectively.

Table 17 . Validity and reliability score by complex techniques, form A (continued table)

\begin{tabular}{|c|c|c|c|c|c|c|c|c|c|c|c|c|}
\hline \multirow{3}{*}{$\begin{array}{l}\text { Sub- } \\
\text { scale }\end{array}$} & \multirow{3}{*}{$\begin{array}{c}\text { No. } \\
\text { of } \\
\text { Ite } \\
\text { m }\end{array}$} & \multirow{3}{*}{$\begin{array}{l}\text { IOC } \\
\text { Scor } \\
\text { es }\end{array}$} & \multicolumn{4}{|c|}{$\mathbf{N}=\mathbf{5}$} & \multirow{2}{*}{\multicolumn{3}{|c|}{$\begin{array}{c}\sum M d n>3.50-5.00 \text { and } \\
\sum I R<1.50 \text { (accept) }\end{array}$}} & \multirow{2}{*}{\multicolumn{3}{|c|}{$\begin{array}{c}\text { Possibility Index } \\
(\mathrm{N}=48) \\
(\mathrm{PI}=\mathbf{3 . 5 1 - 5 . 0 0} \text { Accept })\end{array}$}} \\
\hline & & & \multicolumn{2}{|c|}{ Round 3} & \multicolumn{2}{|c|}{ Round 1} & & & & & & \\
\hline & & & Mdn & IR & Mdn & IR & Mdn & IR & Result & $\bar{x}$ & $\mathrm{SD}$ & Result \\
\hline \multirow{9}{*}{ 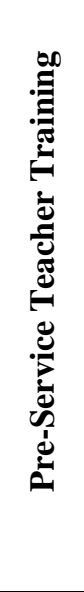 } & 19 & $\begin{array}{c}1.0 \\
0\end{array}$ & 4.00 & .50 & 1.00 & .50 & 3.00 & .00 & Revise & 4.52 & .50 & $\checkmark$ \\
\hline & 20 & .60 & 5.00 & 1.50 & 1.00 & .50 & 4.00 & 1.00 & $\checkmark$ & 4.64 & .63 & $\checkmark$ \\
\hline & 21 & -.20 & 1.00 & 1.50 & .00 & 1.00 & 1.00 & 1.00 & $x$ & $x$ & $x$ & $x$ \\
\hline & 22 & .80 & 5.00 & 1.00 & 1.00 & .50 & 4.00 & .50 & $\checkmark$ & 4.35 & .72 & $\checkmark$ \\
\hline & 23 & .80 & 5.00 & 1.50 & 1.00 & .50 & 4.00 & 1.00 & $\checkmark$ & 4.37 & .73 & $\checkmark$ \\
\hline & 24 & .60 & 5.00 & 1.00 & 1.00 & .50 & 4.00 & .50 & $\checkmark$ & 4.33 & .66 & $\checkmark$ \\
\hline & 25 & .80 & 4.00 & 1.00 & 1.00 & .50 & 3.00 & .50 & Revise & 4.16 & .69 & $\checkmark$ \\
\hline & 26 & .80 & 5.00 & 1.00 & 1.00 & .50 & 4.00 & .50 & $\checkmark$ & 4.31 & .71 & $\checkmark$ \\
\hline & 27 & -.40 & 1.00 & 1.50 & .00 & 1.00 & 1.00 & 1.00 & $x$ & $x$ & $x$ & $x$ \\
\hline \multirow{8}{*}{ 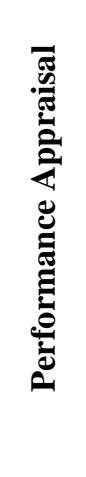 } & 28 & .80 & 5.00 & 1.00 & 1.00 & .50 & 4.00 & .50 & $\checkmark$ & 4.37 & .63 & $\checkmark$ \\
\hline & 29 & 1.0 & 5.00 & 1.00 & 1.00 & .50 & 4.00 & .50 & $\checkmark$ & 4.22 & .66 & $\checkmark$ \\
\hline & 30 & .80 & 5.00 & 1.00 & 1.00 & .50 & 4.00 & .50 & $\checkmark$ & 4.25 & .69 & $\checkmark$ \\
\hline & 31 & .60 & 5.00 & .50 & 1.00 & .50 & 4.00 & .00 & $\checkmark$ & 4.14 & .71 & $\checkmark$ \\
\hline & 32 & .60 & 5.00 & 1.00 & 1.00 & .50 & 4.00 & .50 & $\checkmark$ & 4.20 & 1.05 & $\checkmark$ \\
\hline & 33 & .60 & 5.00 & 1.00 & 1.00 & .50 & 4.00 & .50 & $\checkmark$ & 4.27 & .91 & $\checkmark$ \\
\hline & 34 & .80 & 4.00 & 1.00 & 1.00 & .50 & 3.00 & .50 & Revise & 4.31 & .77 & $\checkmark$ \\
\hline & 35 & .00 & 1.00 & .50 & .00 & 1.00 & 1.00 & -.50 & $x$ & $x$ & $x$ & $x$ \\
\hline
\end{tabular}




\begin{tabular}{|c|c|c|c|c|c|c|c|c|c|c|c|c|}
\hline & 36 & .60 & 5.00 & .50 & 1.00 & .50 & 4.00 & .00 & $\checkmark$ & 4.33 & .63 & $\checkmark$ \\
\hline & 37 & 1.0 & 5.00 & 1.00 & 1.00 & .50 & 4.00 & .50 & $\checkmark$ & 4.33 & .63 & $\checkmark$ \\
\hline & 38 & .80 & 5.00 & 1.00 & 1.00 & 1.00 & 4.00 & .00 & $\checkmark$ & 4.22 & .77 & $\checkmark$ \\
\hline \multirow{18}{*}{ 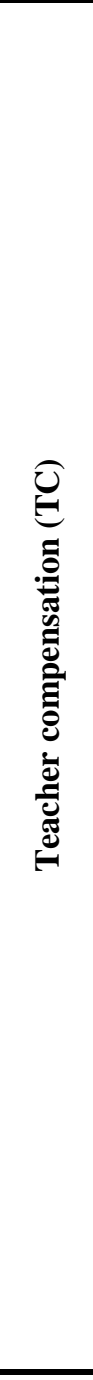 } & 39 & .80 & 4.00 & 1.00 & 1.00 & .50 & 3.00 & .50 & Revise & 4.50 & .54 & $\checkmark$ \\
\hline & 40 & .60 & 5.00 & 1.00 & 1.00 & .50 & 4.00 & .50 & $\checkmark$ & 4.37 & .67 & $\checkmark$ \\
\hline & 41 & 1.0 & 5.00 & .50 & 1.00 & .50 & 4.00 & .00 & $\checkmark$ & 4.04 & .74 & $\checkmark$ \\
\hline & 42 & .80 & 5.00 & 1.00 & 1.00 & .50 & 4.00 & .50 & $\checkmark$ & 4.37 & .63 & $\checkmark$ \\
\hline & 43 & .80 & 4.00 & 1.00 & 1.00 & 1.00 & 3.00 & .00 & Revise & 4.29 & .65 & $\checkmark$ \\
\hline & 44 & .80 & 4.00 & 1.00 & 1.00 & 1.00 & 3.00 & .00 & Revise & 4.29 & .74 & $\checkmark$ \\
\hline & 45 & .60 & 5.00 & 1.00 & 1.00 & .50 & 4.00 & .50 & $\checkmark$ & 4.43 & .61 & $\checkmark$ \\
\hline & 46 & .80 & 4.00 & 1.00 & 1.00 & .50 & 3.00 & .50 & Revise & 4.33 & .59 & $\checkmark$ \\
\hline & 47 & .60 & 5.00 & .50 & 1.00 & .50 & 4.00 & .00 & $\checkmark$ & 4.04 & .74 & $\checkmark$ \\
\hline & 48 & $\begin{array}{c}- \\
.40 \\
\end{array}$ & 1.00 & .50 & .00 & 1.00 & 1.00 & -.50 & $x$ & $x$ & $x$ & $x$ \\
\hline & 49 & .80 & 5.00 & 1.00 & 1.00 & .50 & 4.00 & .50 & $\checkmark$ & 3.95 & 1.18 & $\checkmark$ \\
\hline & 50 & $\begin{array}{c}- \\
.40 \\
\end{array}$ & 1.00 & .50 & .00 & 1.50 & 1.00 & $\begin{array}{c}- \\
1.00\end{array}$ & $x$ & $x$ & $x$ & $x$ \\
\hline & 51 & $\begin{array}{c}- \\
.40 \\
\end{array}$ & 1.00 & 1.00 & .00 & 1.00 & 1.00 & .00 & $x$ & $x$ & $x$ & $x$ \\
\hline & 52 & 1.0 & 5.00 & 1.00 & 1.00 & .50 & 4.00 & .50 & $\checkmark$ & 4.14 & .68 & $\checkmark$ \\
\hline & 53 & .80 & 4.00 & 1.00 & 1.00 & .50 & 3.00 & .50 & Revise & 4.29 & .79 & $\checkmark$ \\
\hline & 54 & .80 & 4.00 & 1.00 & 1.00 & .50 & 3.00 & .50 & Revise & 4.31 & .65 & $\checkmark$ \\
\hline & 55 & $\begin{array}{c}- \\
.40 \\
\end{array}$ & 1.00 & 1.00 & .00 & 1.00 & 1.00 & .00 & $x$ & $x$ & $x$ & $x$ \\
\hline & 56 & $\begin{array}{c}- \\
.20 \\
\end{array}$ & 1.00 & 1.00 & .00 & .50 & 1.00 & .50 & $x$ & $x$ & $x$ & $x$ \\
\hline \multirow{7}{*}{ 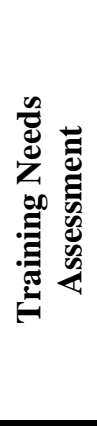 } & 57 & 1.0 & 5.00 & 1.00 & 1.00 & 1.00 & 4.00 & .00 & $\checkmark$ & 4.22 & .75 & $\checkmark$ \\
\hline & 58 & .80 & 5.00 & 1.00 & 1.00 & .50 & 4.00 & .50 & $\checkmark$ & 4.41 & .67 & $\checkmark$ \\
\hline & 59 & .60 & 5.00 & 1.00 & 1.00 & .50 & 4.00 & .50 & $\checkmark$ & 4.33 & .63 & $\checkmark$ \\
\hline & 60 & .80 & 4.00 & 1.50 & 1.00 & 1.00 & 3.00 & 1.00 & Revise & 4.47 & .68 & $\checkmark$ \\
\hline & 61 & .80 & 5.00 & 1.50 & 1.00 & 1.00 & 4.00 & 1.00 & $\checkmark$ & 4.22 & .66 & $\checkmark$ \\
\hline & 62 & 1.0 & 5.00 & 1.50 & 1.00 & 1.00 & 4.00 & 1.00 & $\checkmark$ & 4.47 & .58 & $\checkmark$ \\
\hline & 63 & .60 & 5.00 & 1.00 & 1.00 & .50 & 4.00 & .50 & $\checkmark$ & 4.18 & .64 & $\checkmark$ \\
\hline
\end{tabular}

Table 17 above, shows the results of the examination performed with complex techniques on the subscales Pre-Service Teacher Training (PST) and Teacher Performance Appraisal (PA). The analysis of data indicated that 2 out of 9 items in PST and 1 out of 11 items in PA had to be erased due to having a low IOC value <.0.50; and the other complex examination showed a central tendency. 
Besides, PST items 19 and 25 were below the required Mdn value so these two items had to be revised to reach the criteria at $>\operatorname{Mdn} 3.50$. Furthermore, this examination discovered 1 out of 11 items to be deleted as the result of an IOC value $<0.50$ and 1 out 11 items had to be revised because the Mdn value was lower than the criteria provided.

The possibility index was examined with the help of 48 educational leaders who had to rate and mark the degree of comprehensible words and phrases in the question-items. The data analysis found a high degree of possibility index in both subscales PST and PA.

In addition, the examination results obtained by complex techniques concerning subscales Teacher Compensation (TC) and Training Needs Assessment (TNA) revealed that 5 out of 18 items in TC had to be cut out and 6 out of 18 items had to be revised, as these question-items had a low Mdn value $<3.50$, which is not acceptable. The majority of respondents thought that uncertain words and sentence structures as well as ambiguous words, negative words and bias phrases and sentences caused their confusion and suggested to develop the relevance of words.

\subsubsection{Reliability level by Cronbach's alpha and correlation coefficient}

Table 18 displays the results of the examination of Cronbach's alpha and correlation of the six subscales ranging from low to high at $\alpha=0.88-0.97$ respectively. It indicates that 52 items in total under the six subscales (tasks) have a relatively high internal consistency (for the overall subscale: 0.70; and for the subscales individually: 0.80) which is considered acceptable (Cronbach, 1951). In addition, the suitable correlation coefficient between subscales must be reached (Low $r=.836^{* *}$ to $r=.975^{* *}$ high), and if the score values are closer to +1 the correlation between two or more variables is stronger or highly positive (See Table 18.).

Table 18. The Cronbach's Alpha and Correlation between subscales. Form A (study 3)

\begin{tabular}{|c|c|c|c|c|c|c|c|}
\hline Sub-scale (tasks) & Alpha & 1 & 2 & 3 & 4 & 5 & 6 \\
\hline Teacher demand analysis & .88 & - & $.975^{* * *}$ & $.955^{* *}$ & $.927^{* *}$ & $.883^{* *}$ & $.836^{* *}$ \\
\hline Recruitment and Selection & .94 & & - & $.954^{* *}$ & $.944^{* *}$ & $.943^{* *}$ & $.901^{* *}$ \\
\hline Pre-service teacher training & .93 & & & - & $.943^{* *}$ & $.916^{* *}$ & $.852^{* *}$ \\
\hline Performance appraisal & .95 & & & & - & $.935^{* *}$ & $.910^{* *}$ \\
\hline Teacher compensation & .97 & & & & & - & $.953^{* *}$ \\
\hline Training needs assessment & .95 & & & & & & - \\
\hline
\end{tabular}
**. $\mathrm{p}<0.01$. 


\subsubsection{Summary}

This study 3 was the final stage of the developmental process of a self-made questionnaire that re-examined only form A by focusing on eliminating all of the erroneous words and phrases loaded in the questions. The results have shown that 52 out of 63 items was accepted by IOC scores and internal consistency was strong positive both according to Cronbach's alpha and a correlation between subscales, and this form A is a measurement tool confirmed to be used further for the main study. Figures 8 - 11 below displays all the study findings associated with the developmental process of the self-constructed questionnaires (form A and B, study 1,2 , and 3).

Figure 8 . Summary of the findings of validity examination by IOC (form A, study 1 - 3)

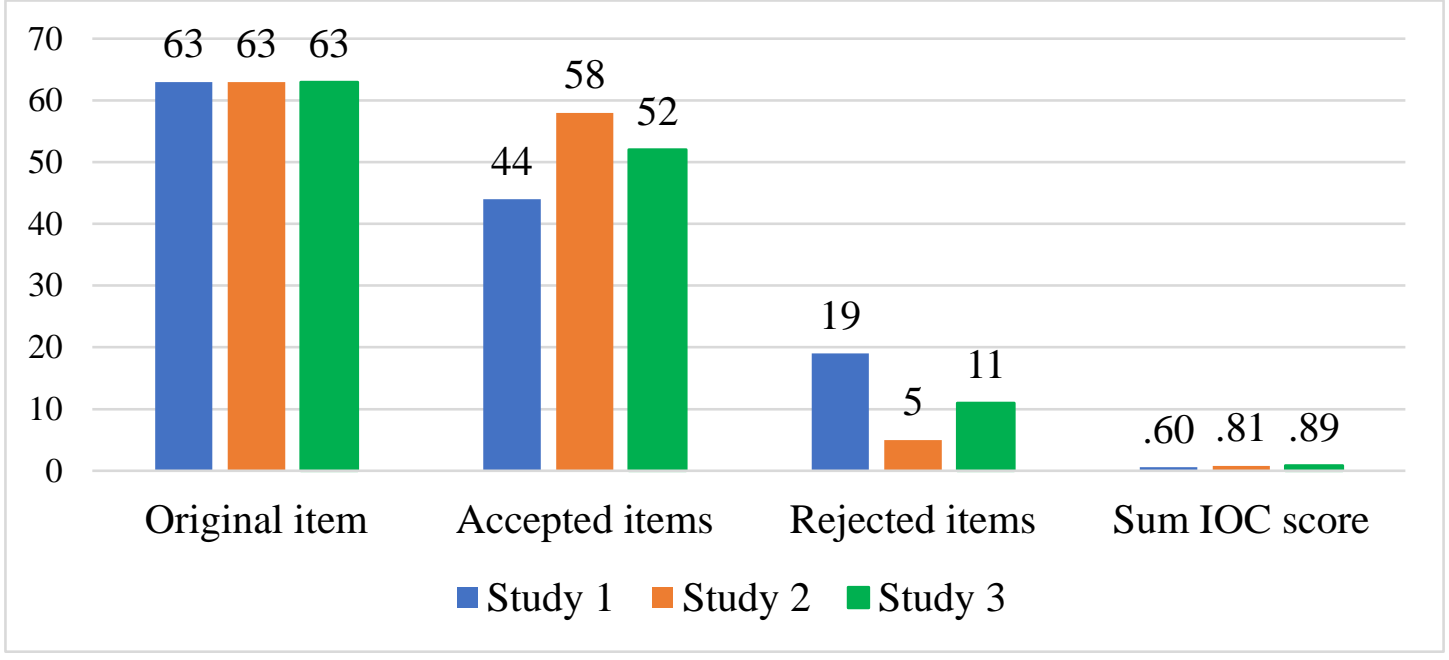

Figure 9. Summary of the findings of reliability examination by Cronbach's Alpha (form A, study 1-3)

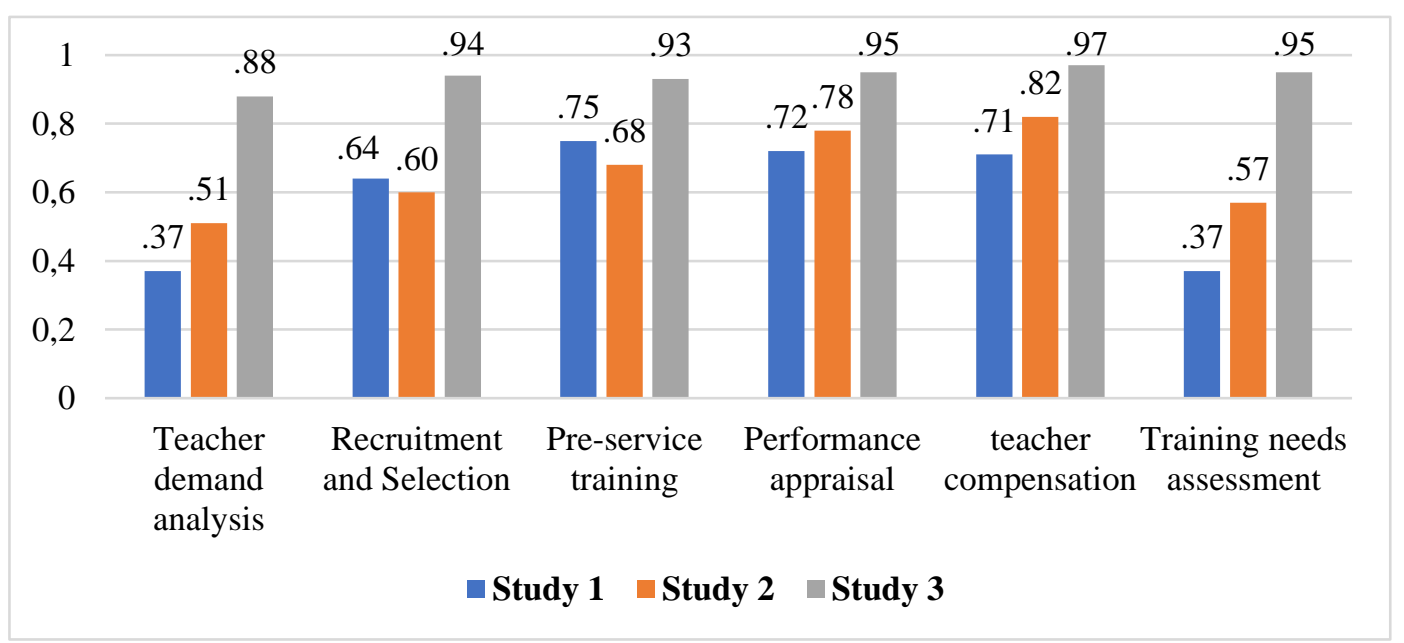


Figure 10. Summary of the findings of validity examination by IOC (form B, study 1 - 2)

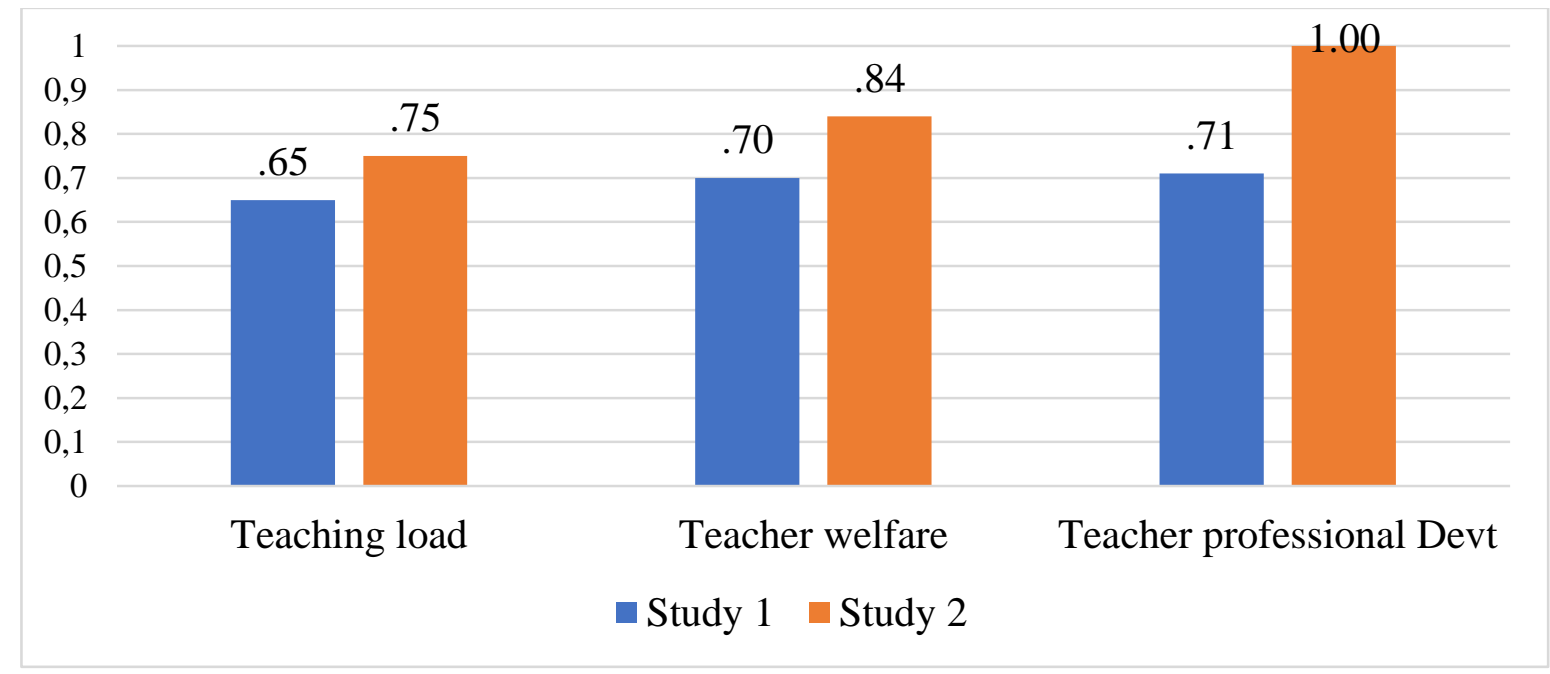

Figure 11. Summary of the findings of reliability examination by Cronbach's Alpha (form B, study 1 - 2)

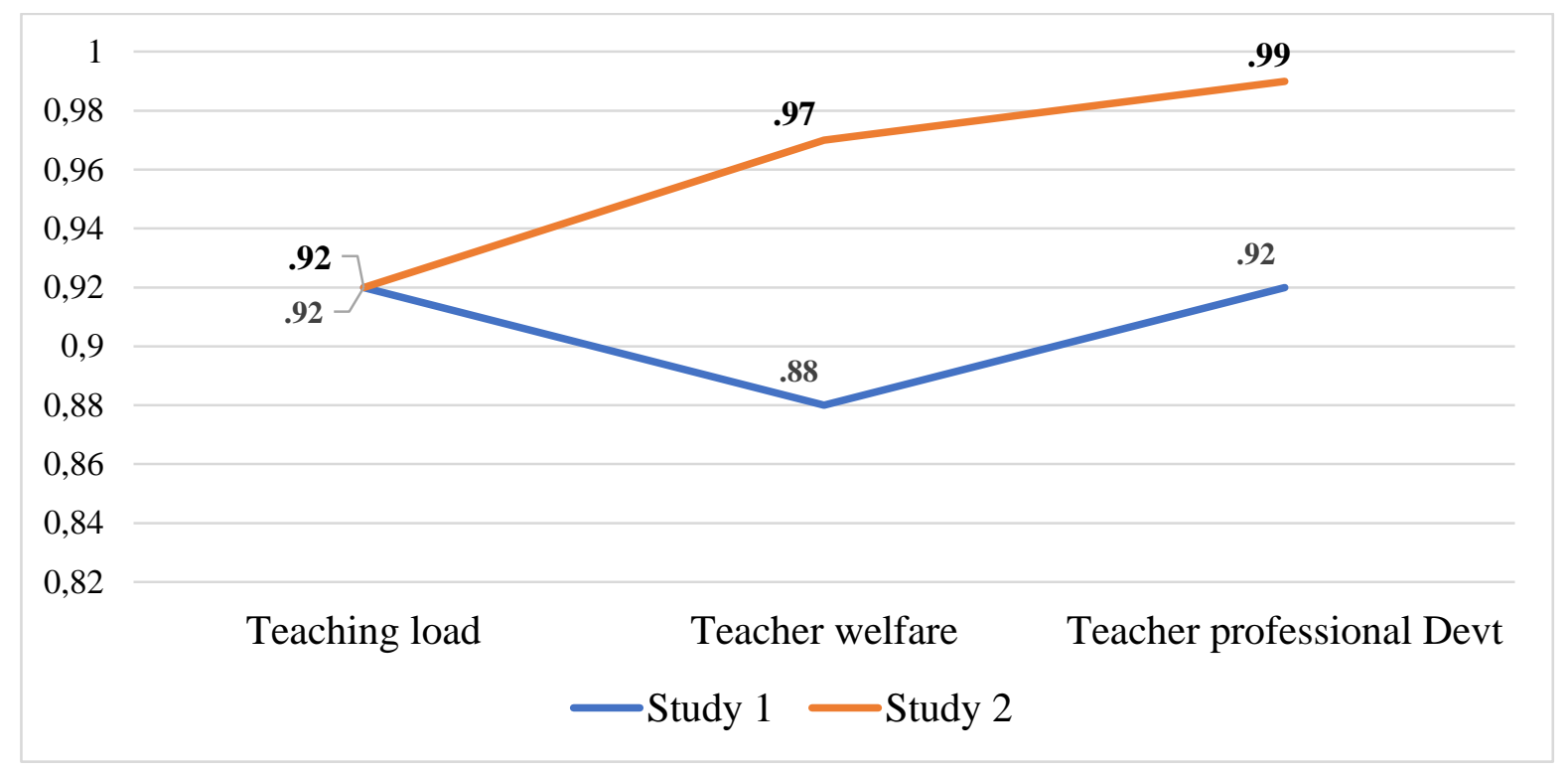




\subsection{Findings of study 4. Causes of teacher's burnout syndrome concerning school board management at practice schools in Laos.}

\subsubsection{Introduction}

School as an organization, where all teachers work together, can have major pressure like unclear role description, teaching load, extra responsibilities, the pressure of tasks; time, working conditions, such as system-level of teaching assessment rigidly, tightly. Besides, the schools often face changing rules and regulations, cynicism among teachers, taught cross-subjects, delaying salary, imbalance in professional development and other school subsidies that were ambiguities and opaque deals with school board management.

As mentioned above, I would like to form the following objectives: to explore the main causes of teachers' burnout affected by school board management, by examining three subscales like teaching load, teacher welfare, and teacher professional development; to compare the respondents' opinions and to gather feedback from the respondents for further solution.

In this study 4 there were 104 teacher civil servants enrolled from practice schools or Sathid schools in Laos culture (See the details in 3.2.4). These schools were under the supervision of the Faculty of Education, the National University of Laos where I have worked as a lecturer. A self-made questionnaire including open-ended questions (form B as a completed version) was employed in this study. The data collection was carried out in June 2017 by paper and pencil.

\subsubsection{The main causes of teachers' burnout syndrome}

This section presents the analysis of data relating to the causes of teachers' burnout owing to the school boards management at Sathid practice schools in Laos. The administration culture of these schools was under the supervision of the Faculty of Education in Public Universities in Laos. These schools are one of those that belong to the Faculty of Education. This Faculty is located in Vientiane, the capital of Laos.

The Sathid practice schools' structure in Laos constitutes of Nursery school, Preprimary School, Kindergarten, Primary School, Lower and Upper Secondary Schools. These are the places where teacher students in their final year fulfill their pedagogical 
requirements such as observation of classroom management, creating a lesson plan, and teaching practice.

Figure 12. Summary of Cronbach's alpha, $\bar{x}$ and SD of main causes of teachers' burnout (N $=104)$

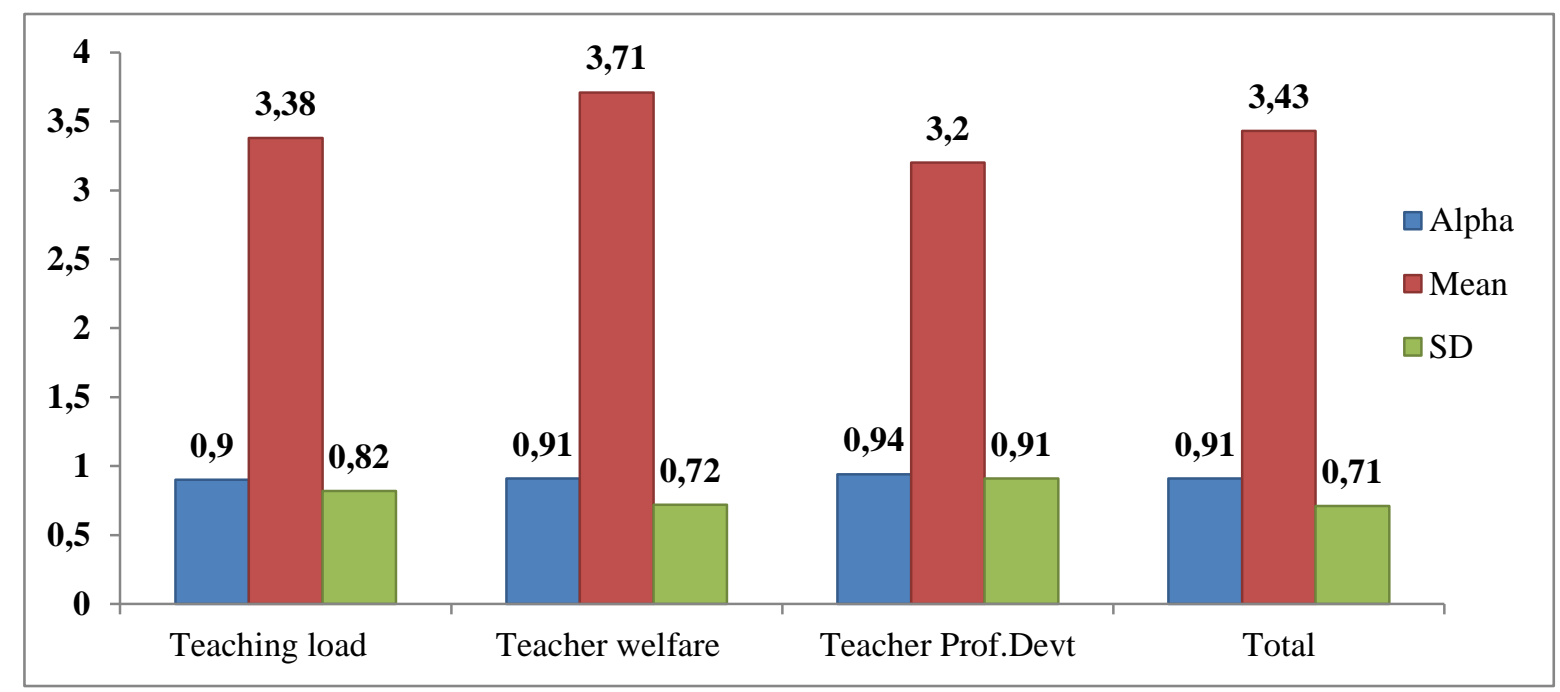

Interpretation criteria $<1.00-3.50 ;>3.51-5.00$ (Sinjaru, 2012)

Figure 12 shows the overall alpha and mean scores of the three subscales: teaching load, teacher welfare and teacher professional development. It consists of 18 items that were rated and marked by 104 teachers relating to school board management, which were expected to cause teachers' burnout. The study found high internal reliability $\left(\sum \alpha=0.90-\right.$ $0.91)$ to which 104 teachers has agreed to as a teaching stress situation due to school-board management.

The data analysis to monitor the mean score of causes of teachers' burnout found that 1 out of the 3 subscales had a high causal level: teacher welfare $(M=3.71, S D=0.72)$; the two remaining subscales were found to be moderate level causes of teachers' burnout: teaching load $(M=3.38, S D=0.82)$ and teacher professional development $(M=3.20, S D=0.90)$. Next, Figure 13 shows the value of alpha, mean and standard deviation by items in the subscale of teaching load (five items). 
Figure 13. Cronbach's Alpha, mean and SD of teaching load by items $(\mathrm{N}=104)$

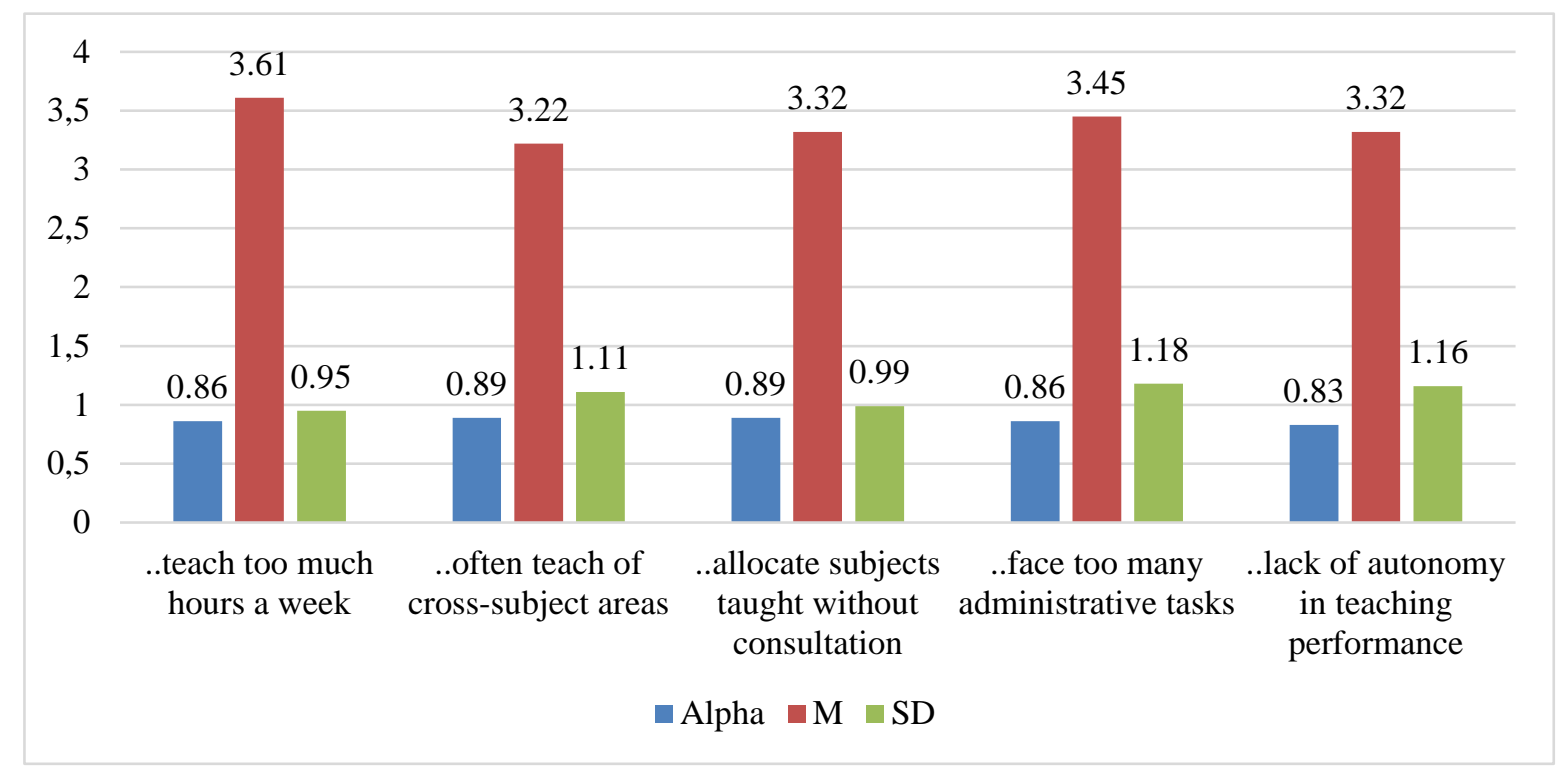

Interpretation criteria $<1.00-3.50 ;>3.51-5.00$ (Sinjaru, 2012)

Figure 13 displays the results of data analysis aiming to monitor the value of alpha, mean and standard deviation. The analysis found that the alpha value ranged from 0.83 to 0.89 , and it indicated a high internal reliability. This study also found that 1 out of 5 items, that is teach too many teaching hours per week, was at a main cause level concerning teachers' burnout (Alpha $=.86 ; \mathrm{M}=3.61, \mathrm{SD}=0.95$ ), and the remaining four items were at a moderate level.

The remaining 4 items were moderate level causes of teachers' burnout: face too many administrative tasks (Alpha $=.86 ; \mathrm{M}=3.45, \mathrm{SD}=1.18$ ); allocate subject taught without consultation (Alpha $=.89 ; \mathrm{M}=3.32, \mathrm{SD}=0.99$ ); lack of autonomy in teaching performance $($ Alpha $=.83 ; \mathrm{M}=3.32, \mathrm{SD}=1,16)$ and often teach cross-subject areas (Alpha $=.89 ; \mathrm{M}=3.22$, $\mathrm{SD}=1.11)$. 
Figure 14. Cronbach's Alpha, Mean and SD of teacher welfare by items $(\mathrm{N}=104)$

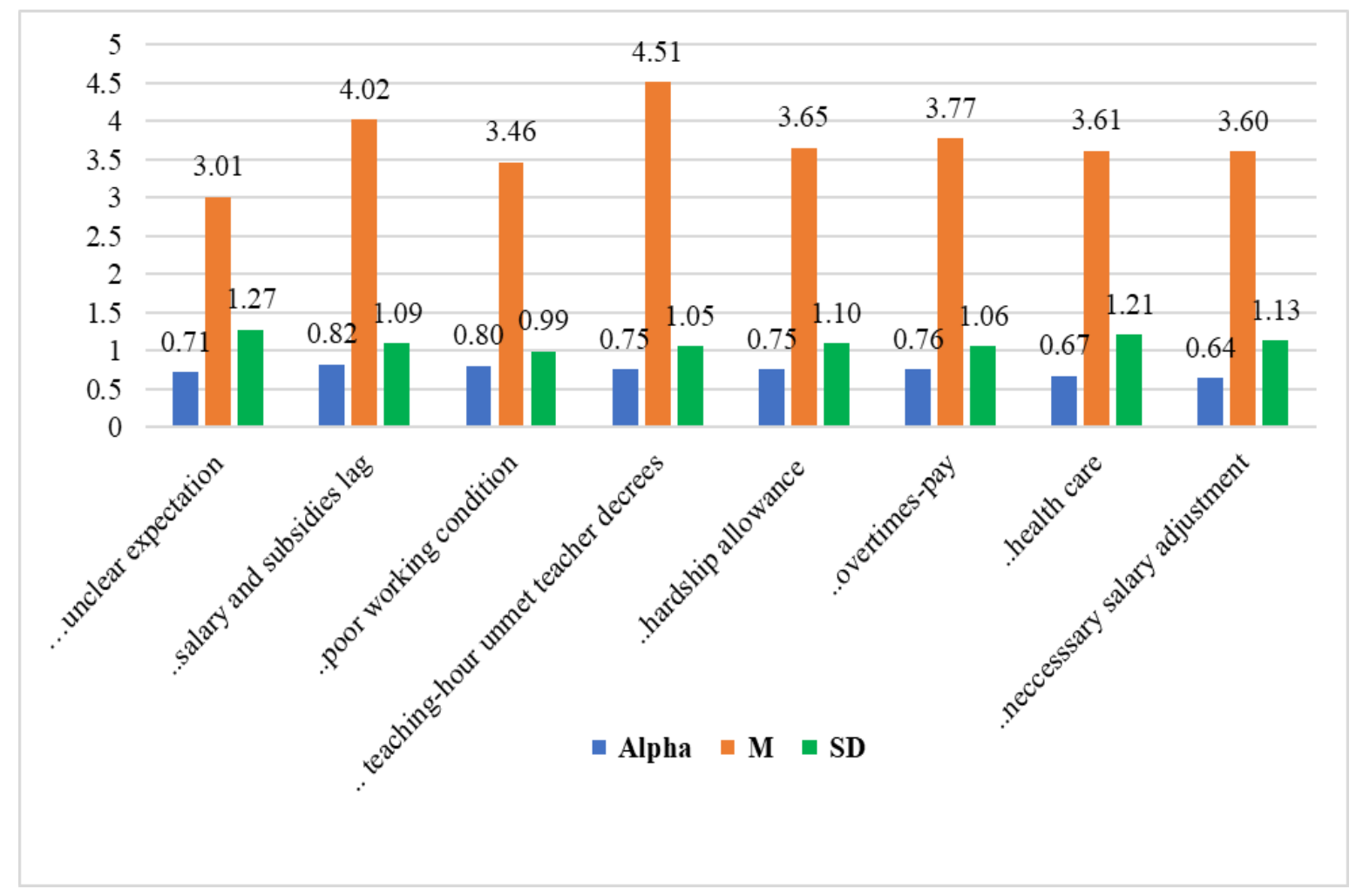

Interpretation criteria $<1.00-3.50 ;>3.51-5.00$ (Sinjaru, 2012)

Figure 14 shows that the data analysis relating to the alpha value by item was found to relatively satisfy that author's rank from high to low value such as salary and subsidies lag ( $\alpha=0.82)$; poor working condition $(\alpha=0.80)$; overtimes-pay $(\alpha=0.76)$; provide teachinghour unmet teacher's decrees $(\alpha=0.75)$; hardship allowance $(\alpha=0.75)$; unclear expectation $(\alpha=0.71)$; healthcare $(\alpha=0.67)$ and necessary salary adjustment $(\alpha=0.64)$.

Meanwhile, this study found 6 out of 8 items having high causal level concerning teachers' burnout: teaching-hour unmet teacher's decrees $(\mathrm{M}=4.51, \mathrm{SD}=1.05)$; salary and subsidies lag ( $\mathrm{M}=4.02, \mathrm{SD}=1.09)$; overtimes-pay $(\mathrm{M}=3.77, \mathrm{SD}=1.06)$; hardship allowance $(\mathrm{M}=3.65, \mathrm{SD}=1.10)$; health care $(\mathrm{M}=3.61, \mathrm{SD}=1.21)$; necessary salary adjustment $(\mathrm{M}=3.60$, $\mathrm{SD}=1.13)$ respectively. Besides, two residual items, like poor working condition $(\mathrm{M}=3.46$, $\mathrm{SD}=0.99)$, and unclear expectation $(\mathrm{M}=3.01, \mathrm{SD}=1.27)$ were of low causal level concerning teacher's burnout syndrome. 
Figure 15. Cronbach's Alpha, mean and SD of teacher professional development by item $(\mathrm{N}=104)$

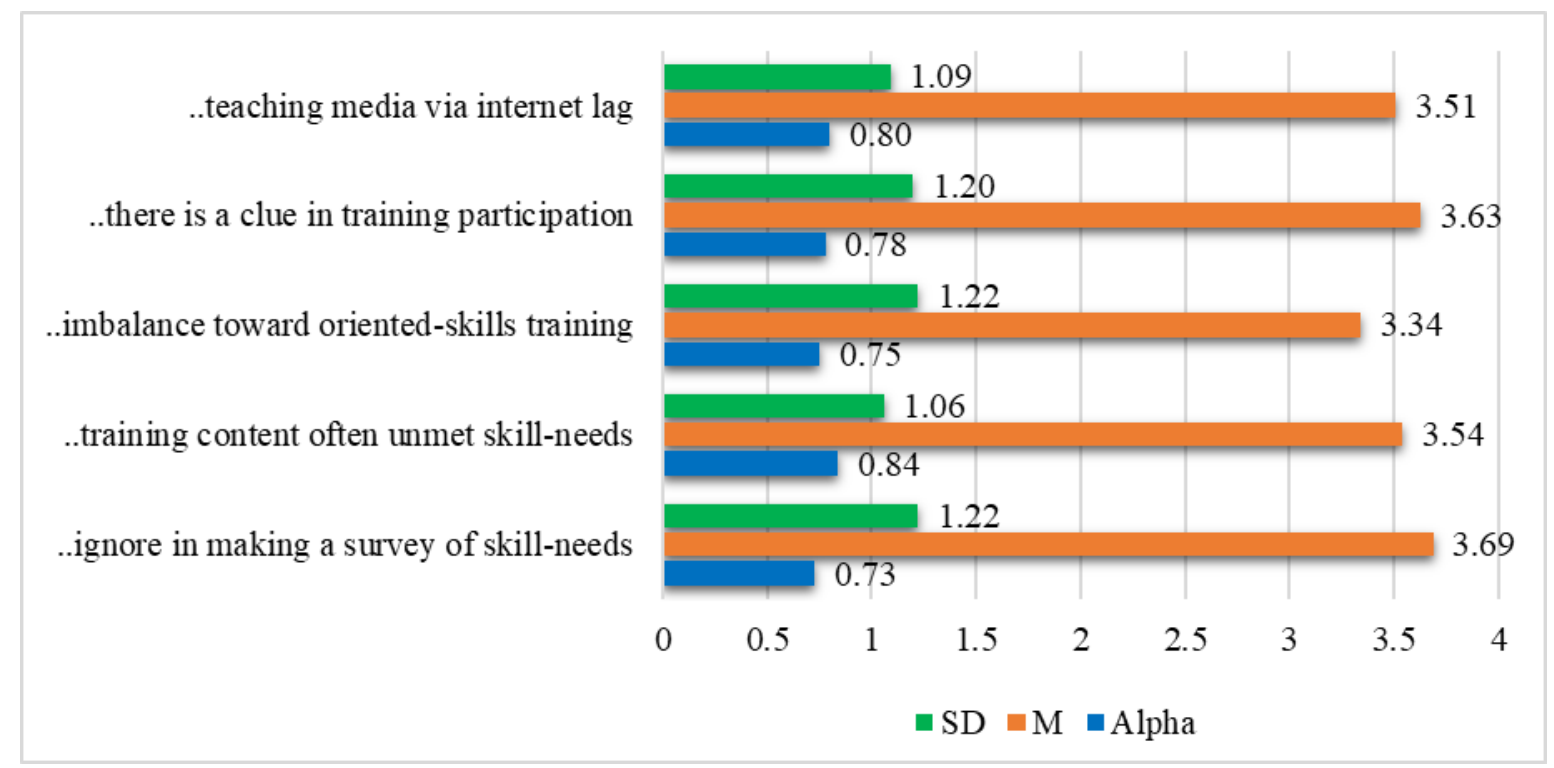

Interpretation criteria< 1.00-3.50;> $3.51-5.00$ (Sinjaru, 2012)

Figure 15 shows the data analysis concerning teacher professional development to observe the alpha value, mean and standard deviation. The data analysis regarding the alpha of each item found a relatively high internal reliability level that the author has ranked from high to low like training content often unmet skill-needs $($ Alpha $=0.84)$; teaching media via internet lag (Alpha $=0.80)$; there is a clue in training participation (Alpha $=0.78)$; imbalance toward oriented-skills training (Alpha $=0.75)$, and ignore making a survey of skill-needs (Alpha $=0.73$ ) respectively.

Also, Mean and SD analyzed found that 4 out of 5 items had high causal level concerning teachers' burnout syndrome. The alpha value ranks from high to low, like ignore making a survey of skill-needs $(\mathrm{M}=3.69, \mathrm{SD}=1.22)$; there is a clue in training participation $(\mathrm{M}=3.63, \mathrm{SD}=1.20)$; training contents unmet skill needs $(\mathrm{M}=3.54, \mathrm{SD}=1.06)$; teaching media via internet lag $(\mathrm{M}=3.51, \mathrm{SD}=1.09)$. In addition, this study also found an item pertaining to the causes of teachers' burnout syndrome at a moderate level, such as imbalance in oriented-skills training $(\mathrm{M}=3.34, \mathrm{SD}=1.22)$. 


\subsubsection{Hypothesis examination by gender and working experience}

Different gender and teaching experiences records among teachers at practice or demonstration schools are expected to bring different points of view toward the school-board management. The descriptive statistics analysis below was created to monitor the significance of the different opinions of teachers toward school board management.

Table 19. Hypothesis Examination by gender (study 4. N=104)

\begin{tabular}{|c|c|c|c|c|c|c|}
\hline \multirow{2}{*}{$\begin{array}{l}\text { Causes of Teachers' } \\
\text { Burnout syndrome }\end{array}$} & \multicolumn{2}{|c|}{ Male } & \multicolumn{2}{|c|}{ Female } & \multirow{2}{*}{$t$} & \multirow{2}{*}{$P$} \\
\hline & $\mathbf{M}$ & SD & $\mathbf{M}$ & SD & & \\
\hline Teaching load & 3.65 & .577 & 3.31 & .795 & $0.04 *$ & 0.16 \\
\hline Teacher welfare & 3.71 & .840 & 3.73 & .715 & 0.40 & 0.88 \\
\hline Teacher Professional development & 3.37 & .989 & 3.13 & .916 & 0.91 & 0.21 \\
\hline
\end{tabular}

Sig $<0.05$

Table 19 shows the examination of the hypothesis by gender relating to the respondents' opinions concerning school board management. The sample consisted of 104 teachers at Sathid practice schools including nursery school, kindergarten, preprimary school, primary, lower secondary and upper secondary school. The hypothesis examination found that teaching load was statistically significantly different at $<0.04$ if $t<0.05$, leading to reject the null hypothesis. That means, the respondents have a different stress source in their teaching career affected by school board management. The other two subscales, like teacher welfare and teacher professional development were not significantly different at 05 .

Thus, this examination needed to explore further the different opinions among the teachers concerning teaching load and the author continued examination through Sheffe technique to record the differences between male and female opinions. The analysis found that male teachers experienced a higher teaching stress or pressure than the female teachers, and it is also congruent with the general perceptions that female teachers have more jobrelated efforts, endeavors and experiences than the male teachers 
Table 20. Hypothesis examination by teaching experiences (study 4. $\mathrm{N}=104$ )

\begin{tabular}{lccccccc}
\hline $\begin{array}{c}\text { Cause of teacher burnout } \\
\text { syndrome }\end{array}$ & \multicolumn{2}{c}{$<\mathbf{1 0}$ years } & \multicolumn{2}{c}{$>\mathbf{1 0}$ years } & $T$ & $\boldsymbol{P}$ \\
Teaching load & $\mathbf{M}$ & $\mathbf{S D}$ & $\mathbf{M}$ & $\mathbf{S D}$ & & \\
Teacher welfare & 3.61 & 0.70 & 3.29 & 0.75 & .41 & .08 \\
Teacher Prof-Devt & 3.88 & 0.64 & 3.61 & 0.80 & .12 & .06 \\
\hline
\end{tabular}

Sig $<0.05$

Table 20 shows the output of the hypothesis examination about the respondents' teaching experiences consisting of two sub-variables $(<10$ years and $>10$ years). Three subscales were used in order to observe the respondents' opinions concerning school board management. The data analysis found that there were no statistically significantly different opinions among teachers by their teaching experience records.

\subsubsection{Correlation coefficient between subscales and confirmation of agreement} level.

The Pearson product-moment correlation coefficient is a measure of the strength or weakness of an association that exists between two or more variables measured, to monitor its internal consistency via interval scale. Figure 16 below shows the correlation examination between three subscales and the sum.

Figure 16. Correlation between subscales

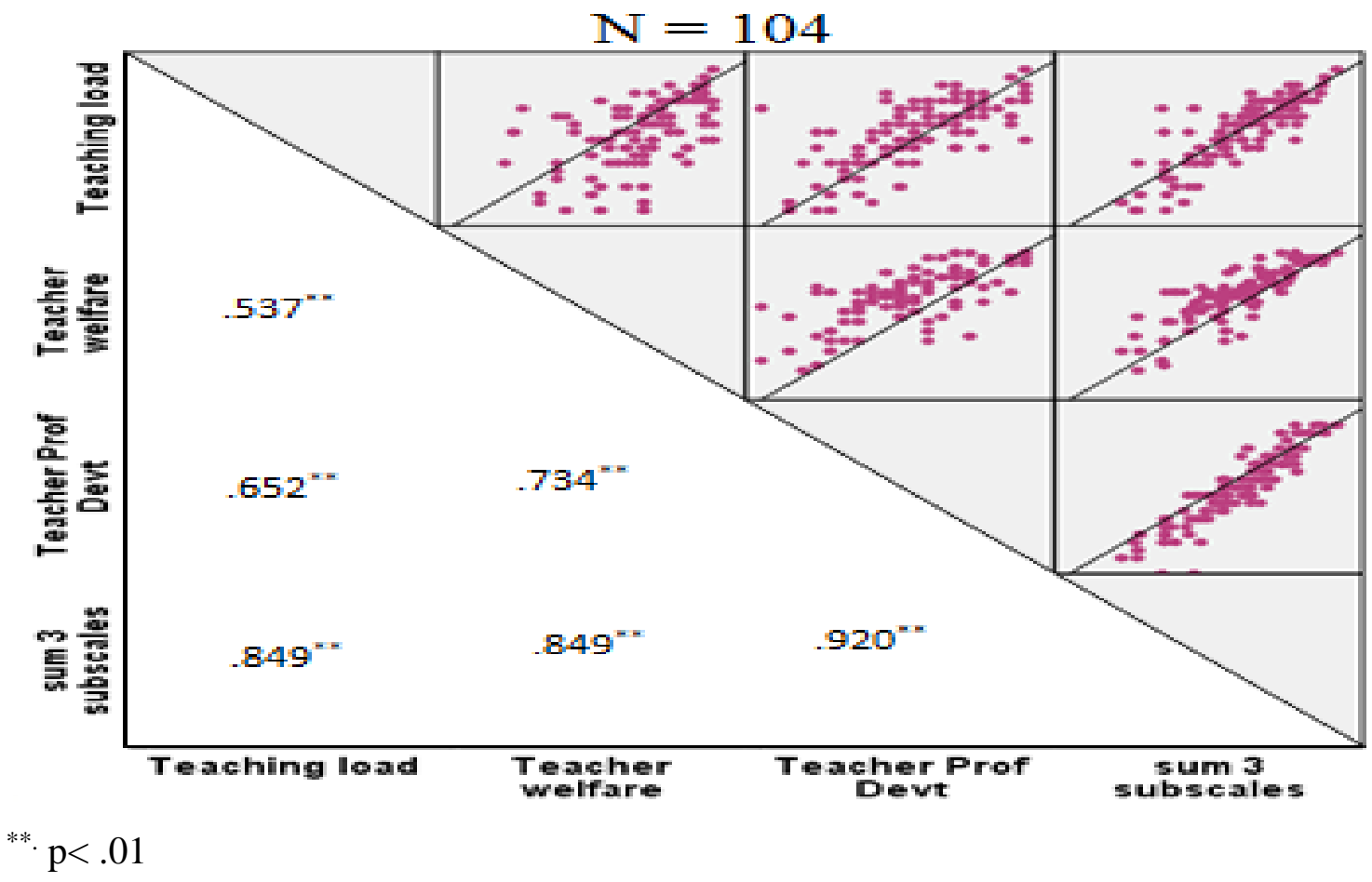


Figure 16 above, shows the correlation examination between subscales in order to monitor the strong and weak correlations among subscales rated and marked by 104 teachers. The examination made it clear that it is statistically significant and a high positive relation between subscales and sum-subscale $\left(\sum r=.845^{* *}\right)$ was found. It means that the causes of teachers' burnout partly relate to school board management, based on the respondents' consensus and agreed throughout three subscales. Figure 17 shows the examination of confirmation of consensus on the teaching career.

Figure 17. Confirmation examination of agreement level of burnout syndrome among three sub-scales $(\mathrm{N}=104)$

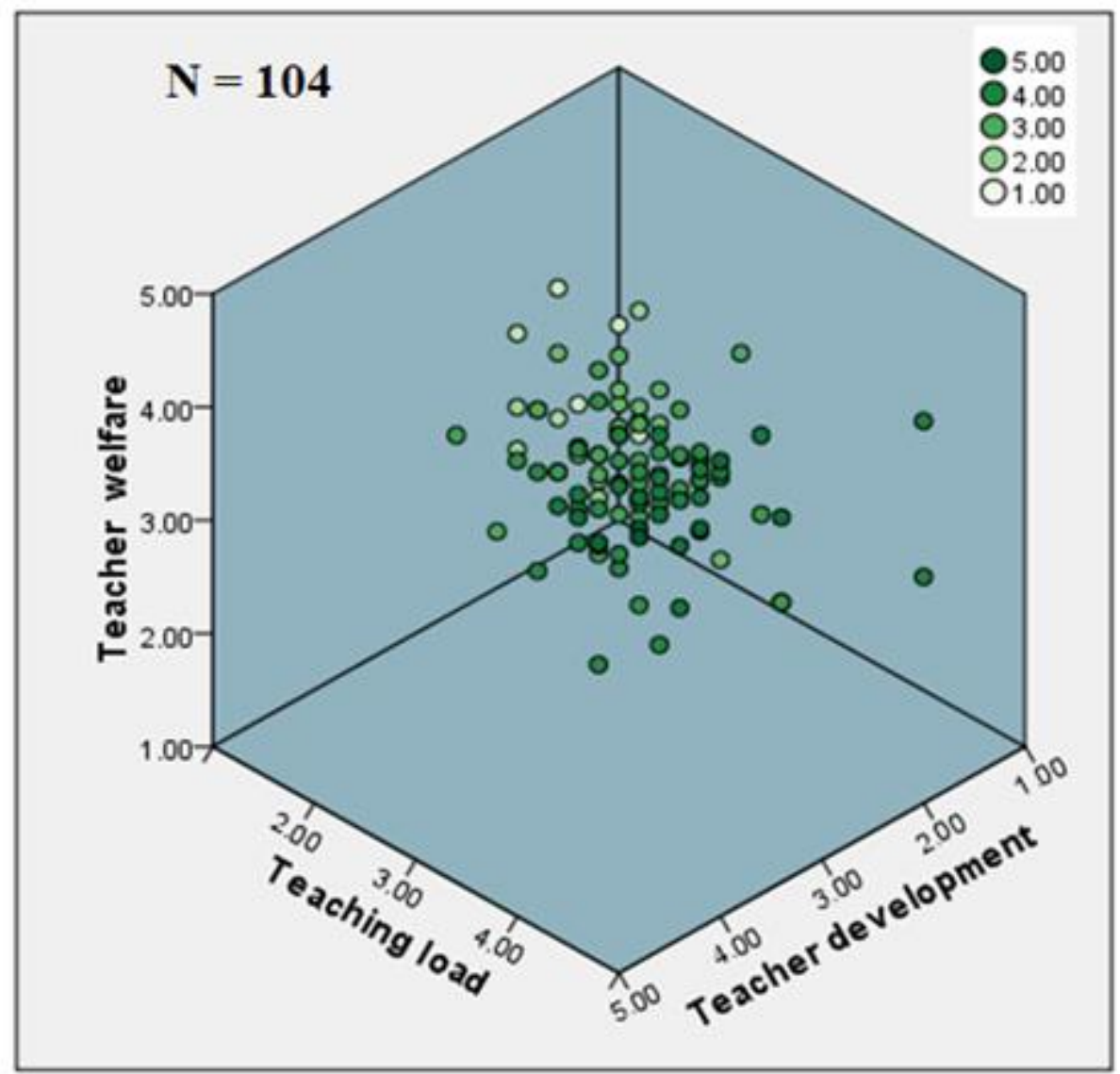

Figure 17 shows the confirmation examination by subscales regarding the respondents' consensus, in order to monitor which subscale among these was a pressure source in the teaching profession. The examination has shown that several dots or green markers were slightly above the anchor and trends point towards the teacher welfare segment.

Therefore, it can be confirmed that teacher welfare was the main cause of teachers' burnout at the Sathid practice schools of the Faculty of Education, National University of 
Laos, and these findings can provide vital information for school board management for the sake of better performance onward.

\subsubsection{Teachers' voices or feedback}

$74.88 \%$ of the asked 104 teachers suggested that school boards and leading staff members within Sathid practice schools should define in details the duties, tasks, functions and responsibilities or teacher job description prior to assigning the work (subject area) to the teacher employees. Besides, the school board must be committed in the staff placement process by handling the right subject taught to the right teacher with the specializedknowledge, skills, performance, time, position, attitude and aptitude. In addition, school boards should bear in mind that clear procedures and contracts can contribute to the schools' success.

Besides, $56 \%$ of teachers considered the social welfare improvement to meet the basic needs important; such as providing a free tuition for teachers' children, accommodation, morale and motivation, listening to and respecting teachers' feedback and complaints, continuous job-oriented training, promoting a balance among teachers to attend the training, self-esteem towards functioning, and reducing the monthly meetings. $48 \%$ of them suggested that the school board should be self-aware of functioning by respecting the professional ethics mainly.

\subsubsection{Summary}

It can be concluded that the main causes of teacher burnout syndrome in the teaching profession among teachers within Demonstration- or Practice schools in Laos which were concerned with the inefficacy of the management of school principals were low perception toward the principle of management that led the schools or teachers face many sufferings in the teaching profession such as compensation and benefits, division of work and delegate to teacher individually, bullying phenomena among colleagues, technology devices in instructional approaches was restricted, teachers often appointed to taught cross-subjects and other pressures happening so far. 


\subsection{Study 5. Instructional management of teachers in teacher training institutions, Lao PDR}

\subsubsection{Introduction}

This study 5 aimed to explore the problems of instructional management, to compare and to gather suggestions from the teaching staff to be a guideline in problem-solving concerning instructional management within three Faculties of Education in Public Universities in Laos. There were 196 teaching staff members from these faculties selected by using a convenience sampling technique (Krejcie and Morgan, 1970).

The semi-adapted questionnaire (Phaisane, 2015) consists of 38 items under four facets or aspects created with the help of experts. These four aspects are creating a lesson plan (12 items), instructional conduct ( 8 items), instruction via technological devices (10 items) and instructional assessment (8 items). A five-points Likert scale was used (Vagias, 2006). Openended questions were also provided to elicit information from the respondents to be guidelines in problem-solving in the future. The data collection took place in Laos in July, 2016, by paper and pencil.

\subsubsection{The overall mean score of the problem on instructional management}

The data analysis of the four subscales found the problem moderate $(\Sigma \bar{x}=2.77$; SD .68) and we indicated each facet from high to low mean score: instruction via technological devices; creating a lesson plan; instructional assessment and instructional practice $(\bar{x}=3.08$; SD .71; $\bar{x}=2.77 ; \mathrm{SD} .74 ; \bar{x}=2.70 ; \mathrm{SD} .84$ and $\bar{x}=2.54 ; \mathrm{SD} .90)$ respectively.

Figure 18. Summary of the four facets by Cronbach's alpha, mean and standard deviation $(\mathrm{N}=196$, study 5$)$

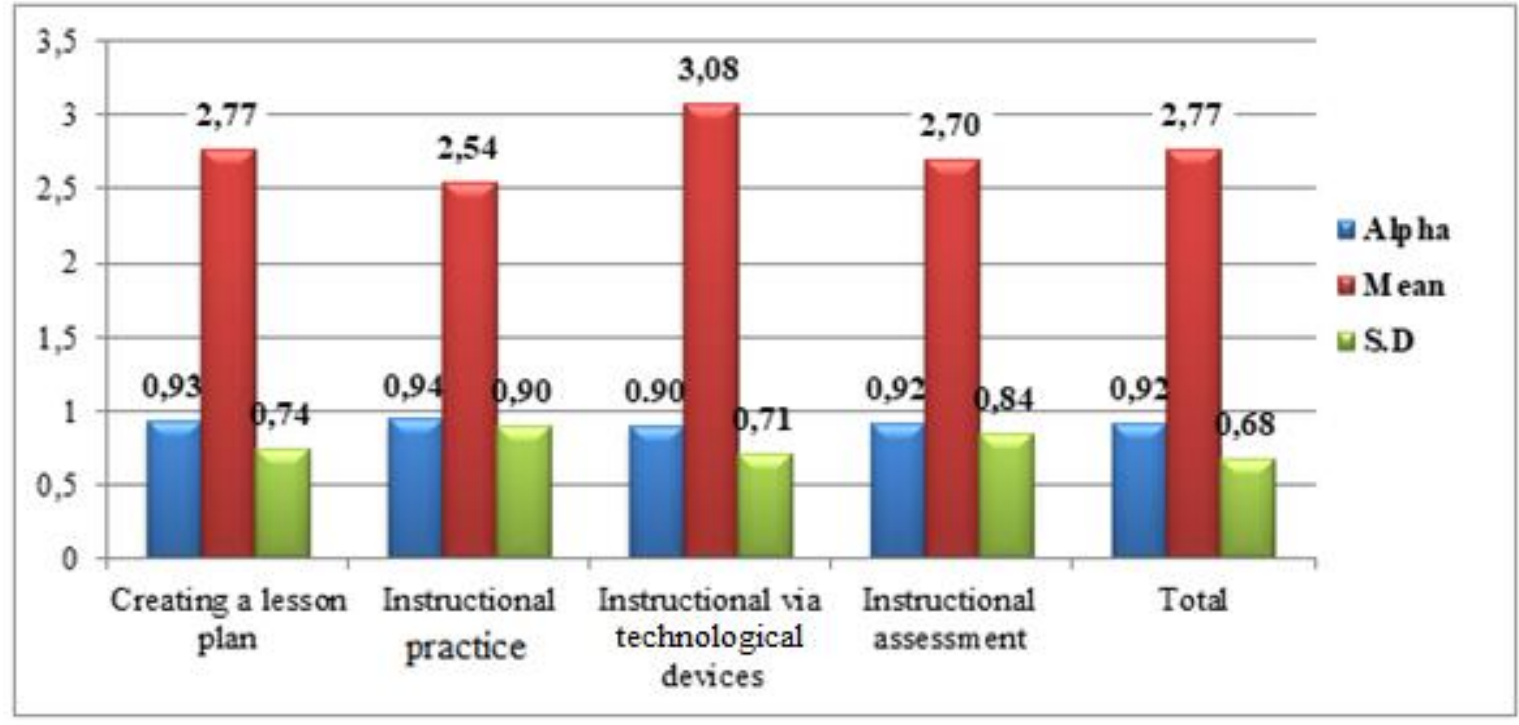


The next step was the selection of the high mean score items from each facet relating to the problem of instructional management within three Faculties of Education in Public Universities in Laos. The item selection was based on the main problem that teachers encountered in their teaching profession under the four facets, namely creating a lesson plan, instructional practice, instruction via technological devices, and instructional assessment, which is, presented as below:

\section{1) Creating a lesson plan.}

The survey showed that 4 out of 12 items were high level problems: formulate the objectives of the lesson plan; allocate time to each activity; specify the aims of each activity and schedule a lesson plan fitting the curriculum $(\bar{x}=3.30, \mathrm{SD}=.89 ; \bar{x}=2.96, \mathrm{SD}=.93 ; \bar{x}=$ 2.89, $\mathrm{SD}=1.05$ and $\bar{x}=2.79, \mathrm{SD}=1.01$ ). The remaining 8 items had a low problem level.

\section{2) Instructional practice.}

The study showed that 5 out of 8 items were high level problems: assessment at the end of each lesson plan; following each step of the designed activities; perform each procedure of examples designed to support the lesson plan, tracking the teaching method designed and assign student practice to each step taught $(\bar{x}=2.62, \mathrm{SD}=1.12 ; \bar{x}=2.59, \mathrm{SD}=.98 ; \bar{x}=2.58$, $\mathrm{SD}=1.04 ; \bar{x}=2.58, \mathrm{SD}=1.12$ and $\bar{x}=2.58, \mathrm{SD}=1.13)$ respectively. The remaining items had a low problem level.

\section{3) Instruction via technological devices.}

The survey showed that 6 out of 10 items were high level problems concerning instructional management, such as smart board $(\bar{x}=3.29, \mathrm{SD}=1.11)$, software programs $(\bar{x}=3.22, \mathrm{SD}$ $=.96)$, audiotape recording $(\bar{x}=3.18, \mathrm{SD}=1.00)$, Internet-interactive video conferencing ( $\bar{x}=3.15, \mathrm{SD}=1.00)$, Audio-Visual aid $(\bar{x}=3.12, \mathrm{SD}=1.03)$, and Long Crystal Display or LCD projector $(\bar{x}=3.03, \mathrm{SD}=.92$.$) . The remaining 4$ items were low level problems.

\section{4) Instructional assessment.}

The survey found that 4 out of 8 items were high level problems: Individual interviews on students' knowledge, checks of students' portfolios, apply the result of assessment and evaluation to enhance instructional assessment, and post-test at the end of each lesson $(\bar{x}=$ 
2.81, $\mathrm{SD}=1.04 ; \bar{x}=2.75, \mathrm{SD}=1.16 ; \bar{x}=2.73, \mathrm{SD}=1.17 ; \bar{x}=2.72, \mathrm{SD}=1.21$ ) respectively. The remaining 4 items were low level problems.

\subsubsection{Comparing the problems concerning instructional management}

Table 21. Hypothesis examination by gender (study 5. $\mathrm{N}=196$ ).

\begin{tabular}{|c|c|c|c|c|c|c|c|}
\hline \multirow{2}{*}{ No } & \multirow{2}{*}{ Subscales } & \multicolumn{2}{|c|}{ Men } & \multicolumn{2}{|c|}{ Women } & \multirow{2}{*}{$t$} & \multirow{2}{*}{$\begin{array}{c}p- \\
\text { value }\end{array}$} \\
\hline & & $\bar{x}$ & SD & $\bar{x}$ & $\mathrm{SD}$ & & \\
\hline 1 & Creating a lesson plan & 2.80 & 0.76 & 2.74 & 0.73 & 0.41 & 0.56 \\
\hline 2 & Instructional practice & 2.55 & 0.90 & 2.53 & 0.90 & 0.82 & 0.88 \\
\hline 3 & $\begin{array}{l}\text { Instruction via technological } \\
\text { devices }\end{array}$ & 3.10 & 0.72 & 3.06 & 0.71 & 0.60 & 0.73 \\
\hline 4 & Instructional assessment & 2.70 & 0.85 & 2.69 & 0.84 & 0.87 & 0.93 \\
\hline
\end{tabular}

Sig <0.05

Table 21 shows the results of comparing the teachers' opinions by gender, concerning the problems of instructional management under the four facets like creating a lesson plan, instructional practice, instruction via technological devices and instructional assessment. There were 196 teachers rating and marking the items according to their fit to the current situation associated with the problems in the teaching profession.

The examination found that there were no statistically significantly different opinions at 0.05 concerning the problems of instructional management. It can be said that the majority of respondents agreed and had a consensus on the chronic dilemma issues regarding instructional management.

Table 22 Hypothesis examination of instructional management by teaching experience (study 5. $\mathrm{N}=196$ ).

\begin{tabular}{clccccccc}
\hline \multirow{2}{*}{ No } & \multicolumn{1}{c}{ Subscales } & \multicolumn{2}{c}{$<\mathbf{1 0}$ years } & \multicolumn{2}{c}{$>$ 10 years } & \multicolumn{1}{c}{$\boldsymbol{p}$ - } \\
& & $\bar{x}$ & SD & $\bar{x}$ & SD & & value \\
\hline 1 & Creating a lesson plan & 2.92 & 0.68 & 2.70 & 0.76 & 0.32 & 0.04 \\
2 & Instructional practice & 2.72 & 0.95 & 2.45 & 0.87 & 0.26 & 0.05 \\
3 & Instruction via technological & 3.15 & 0.78 & 0.05 & 0.68 & 0.25 & 0.37 \\
& devices & 2.86 & 0.85 & 2.62 & 0.83 & 0.62 & 0.05 \\
\hline
\end{tabular}

Sig $<0.05$

Table 22 shows the examination of the comparison of teachers' opinions by teaching experiences. These independent variables were teaching records of less than 10 years and more than 10 years. The statistical examination revealed that within the observed three Faculties of Education there was no statistically significant difference at 0.05 in the opinions referring to the problems concerning instructional management. It can also be declared, that 
the 196 teachers had different teaching experiences, but they were at consensus and agreed on the issue's instructional management faces.

\subsubsection{The suggested guidelines concerning instructional management}

The majority of respondents suggested, that educational leaders within the Faculties of Education should organize soft-skills training by focusing on the utilization of technology, creating a lesson plan and related activities, providing high speed Internet and other learning sources sufficiently.

Besides, it was surprising that teachers were self-critical considering their functioning and responsibilities, that they should minimize the negative behaviors, promote learning outcomes through multiple teaching methods such as deductive and inductive methods, field trip, dramatization, role-play, game, simulation, learning-centered, brainstorming, problemsolving, peer-review, case study, and individual research.

\subsubsection{Summary}

Under those above mentioned findings, in the instructional management culture of these Faculties of Education belonging to the Public Universities in Laos there were many aspects relating to academic issues or affairs needed to be improved and development, especially teaching and learning via modern technology devices, soft-skills training on new instruction methods like creating a lesson plan or how to make a presentation smarter through online technologies, how to conduct an instruction smoothly in a diverse environment, and creating an own-made learning assessment of students. These problematic responsibilities of educational leaders should be taken into account, and perceive the need for knowledge pursue to bring new management skills and techniques to manage and maintain the institutions achieving the goals established effectively. 


\subsection{Study 6 or main study: Instructional management and stress factors affecting teacher trainers as perceived by the educational leaders of Laos.}

\subsubsection{Introduction}

Aside from teaching 6 hours a week (Decree, No. 177/GOL/2012-Laos) educational leaders within TTIs also have main functions and responsibilities indicated by the three famous acronyms as was stated above. Particularly, personnel issues including teachers' task shall be prioritized, because they are the determinant factors to the success of the institutions (Sergiovanni, 2009).

The main study aims to (1) examine the perception level of educational leaders of the six tasks, these tasks are connected to the teachers' rights and benefits that were the roots of teacher's loss or painful issues, (2) to investigate the main stress factors among teachers, (3) to compare the independent variables and the dependent variables, and (4) to collect the respondents' suggestions to improve the management of teachers within TTIs-Laos. The study findings are presented as below:

\subsubsection{Educational leaders' low perception of the six tasks.}

The questionnaire was distributed to 138 educational leaders in 8 Teacher Training Institutions (TTIs) in Laos, in September 2017. Figure 19 shows the overall score of each task by ranking mean score, standard deviation, and Cronbach's alpha.

Figure 19. Overall mean score, SD and Cronbach's Alpha of the six tasks $(\mathrm{N}=138$, study 6$)$

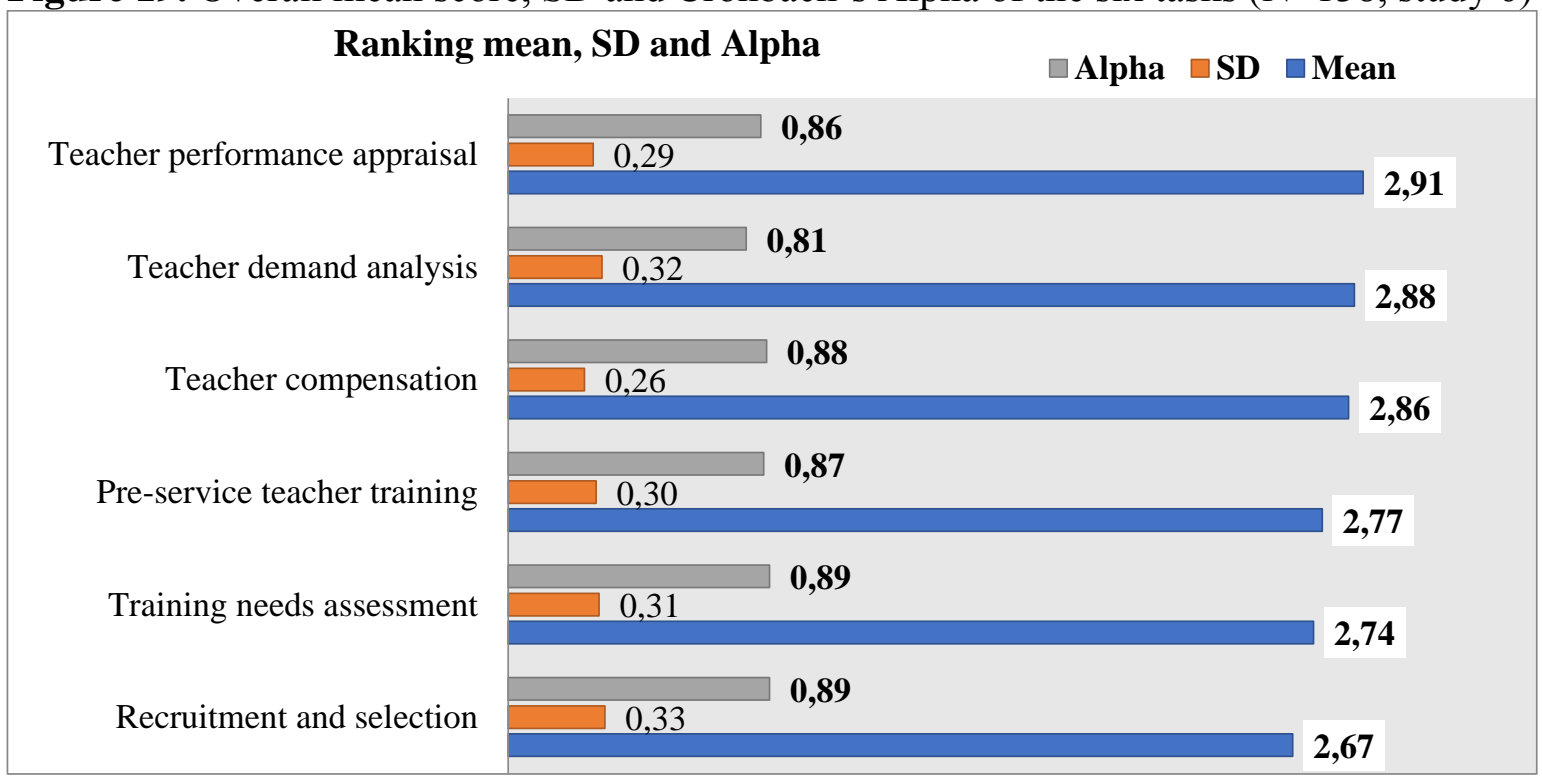


Figure 19 above shows the perception level of the educational leaders related to the 6 tasks by ranking mean score, SD and Cronbach's Alpha from low to high perception indicating the following order: recruitment-selection $(\bar{x}=2.67, \mathrm{SD}=.33$, and Alpha $=.89)$; training needs assessment $(\bar{x}=2.74, \mathrm{SD}=.31$, and Alpha $=.89)$; Pre-service teacher training $(\bar{x}=2.77, \mathrm{SD}=.30$, and Alpha $=.87)$; Teacher compensation $(\bar{x}=2.86, \mathrm{SD}=.26$, and Alpha $=.88)$; Teacher demand analysis $(\bar{x}=2.88, \mathrm{SD}=.32$, and Alpha $=.81)$, and Teacher performance appraisal ( $\bar{x}=2.91, \mathrm{SD}=.29$, and Alpha $=.86)$ respectively.

Next, we present the explanations of the outputs obtained from the statistical analysis of task 1-6, that is teacher demand analysis, recruitment and selection, pre-service teacher training, teacher performance appraisal, teacher compensation and training needs assessment. Figures 20-21, in the followings show the low and high perception level of educational leaders concerning the task of teacher demand analysis by ranking mean score and standard deviation.

Task 1: Teacher demand analysis (TCSDA)

Figure 20. Findings of teacher demand analysis by ranking $M$ and $S D(N=138$, study 6$)$

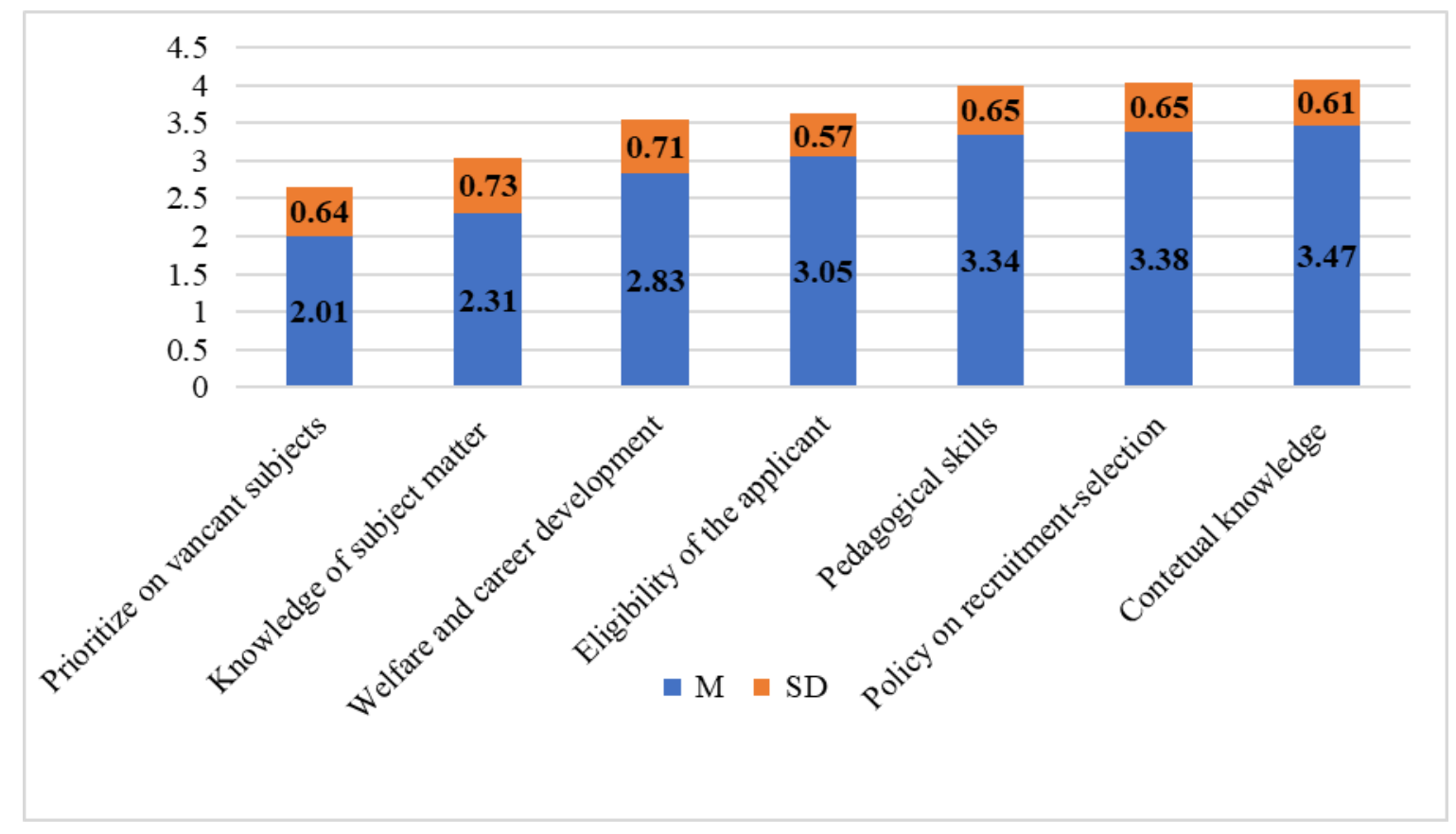

Figure 20 above shows the outputs of the statistical analysis to indicate the low and high perception levels of the educational leaders concerning the task of teacher demand analysis. Two low perception level items were found, like prioritize on vacant subjects $(M=2.01$, $\mathrm{SD}=.64)$ and knowledge of subject matter $(\mathrm{M}=2.31, \mathrm{SD}=.73)$. 
The study found high perception levels in case of welfare and career development $(\mathrm{M}=3.83, \mathrm{SD}=.71)$; eligibility of the applicant $(\mathrm{M}=3.05, \mathrm{SD}=.57)$; pedagogical skills $(\mathrm{M}=3.34, \mathrm{SD}=.65)$; policy on recruitment and selection $(\mathrm{M}=3.38, \mathrm{SD}=.65)$, and contextual knowledge $(\mathrm{M}=3.47, \mathrm{SD}=.61)$.

\section{Task 2: Recruitment and selection}

Figure 21. Findings of recruitment and selection by ranking $M$ and $S D(N=138$, study 6$)$

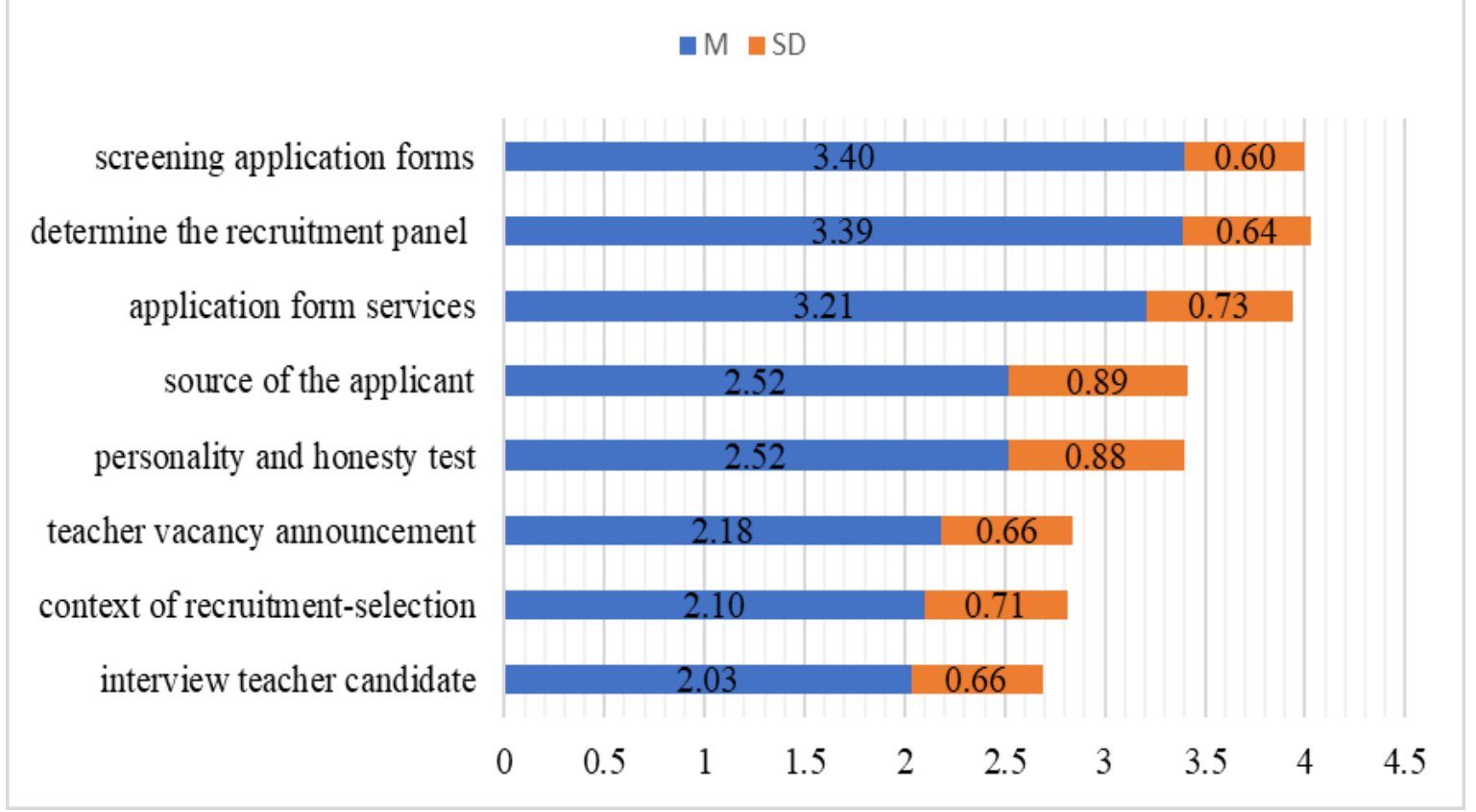

Figure 21 above revealed the low and high perception levels of educational leaders concerning recruitment and selection within TTIs. This task consisted of 8 items, and found three low perception levels like interview teacher candidate $(\mathrm{M}=2.03, \mathrm{SD}=.66)$; context of recruitment-selection $(\mathrm{M}=2.10, \mathrm{SD}=.71)$, and teacher vacancy announcement $(\mathrm{M}=2.18, \mathrm{SD}=$ $.66)$.

Besides, this task also found higher perception levels such as personality and honesty examination $(\mathrm{M}=2.52, \mathrm{SD}=.88)$; source of the applicant $(\mathrm{M}=2.52, \mathrm{SD}=.89)$; application form services $(\mathrm{M}=3.21, \mathrm{SD}=.73)$; determine the recruitment panel $(\mathrm{M}=3.39, \mathrm{SD}=.64)$, and screening application form $(\mathrm{M}=3.40, \mathrm{SD}=.60)$. 


\section{Task 3: Pre-service teacher training}

Figure 22. Findings of pre-service training by ranking $M$ and SD $(\mathrm{N}=138)$

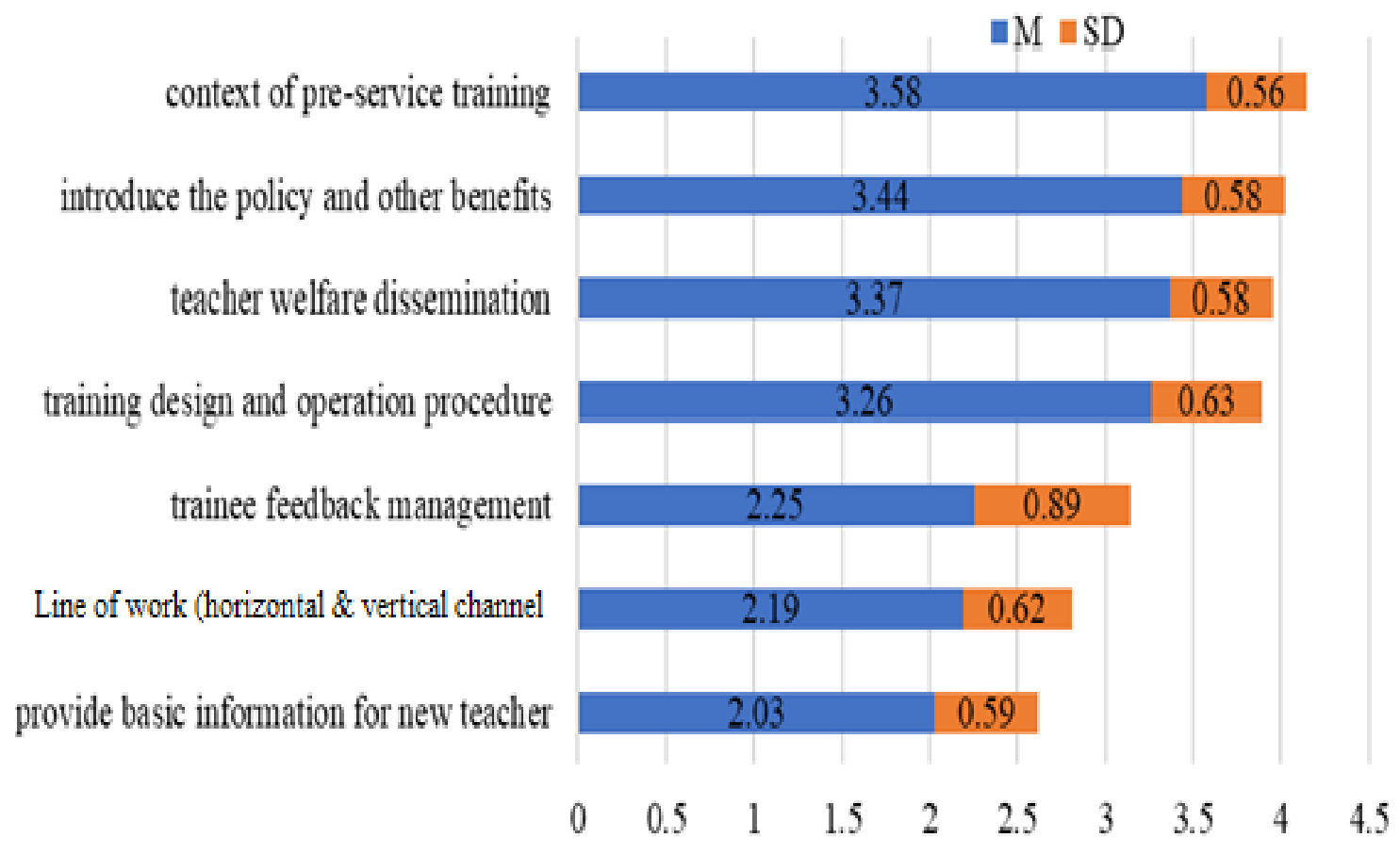

The figure 22 shows the output of data analysis concerning Pre-service teacher training; the author has ranked the mean scores and standard deviations. The study found three low perception levels of educational leaders concerning this task like provide basic information for new teacher $(M=2.03, S D=.59)$; line of work or horizontal-vertical channel $(M=2.19, S D$ $=.62)$, and trainee feedback management $(\mathrm{M}=2.25, \mathrm{SD}=.89)$.

In addition, this study found high perception level in such training design and operation procedure $(\mathrm{M}=3.26, \mathrm{SD}=.63)$; teacher welfare dissemination $(\mathrm{M}=3.37, \mathrm{SD}=.58)$; introduce policy and other benefits $(\mathrm{M}=3.44, \mathrm{SD}=.58)$, and context of pre-service training $(\mathrm{M}=3.58$, $\mathrm{SD}=.56)$. 


\section{Task 4: Performance Appraisal}

Figure 23. Findings of performance appraisal by ranking $M$ and SD $(N=138)$

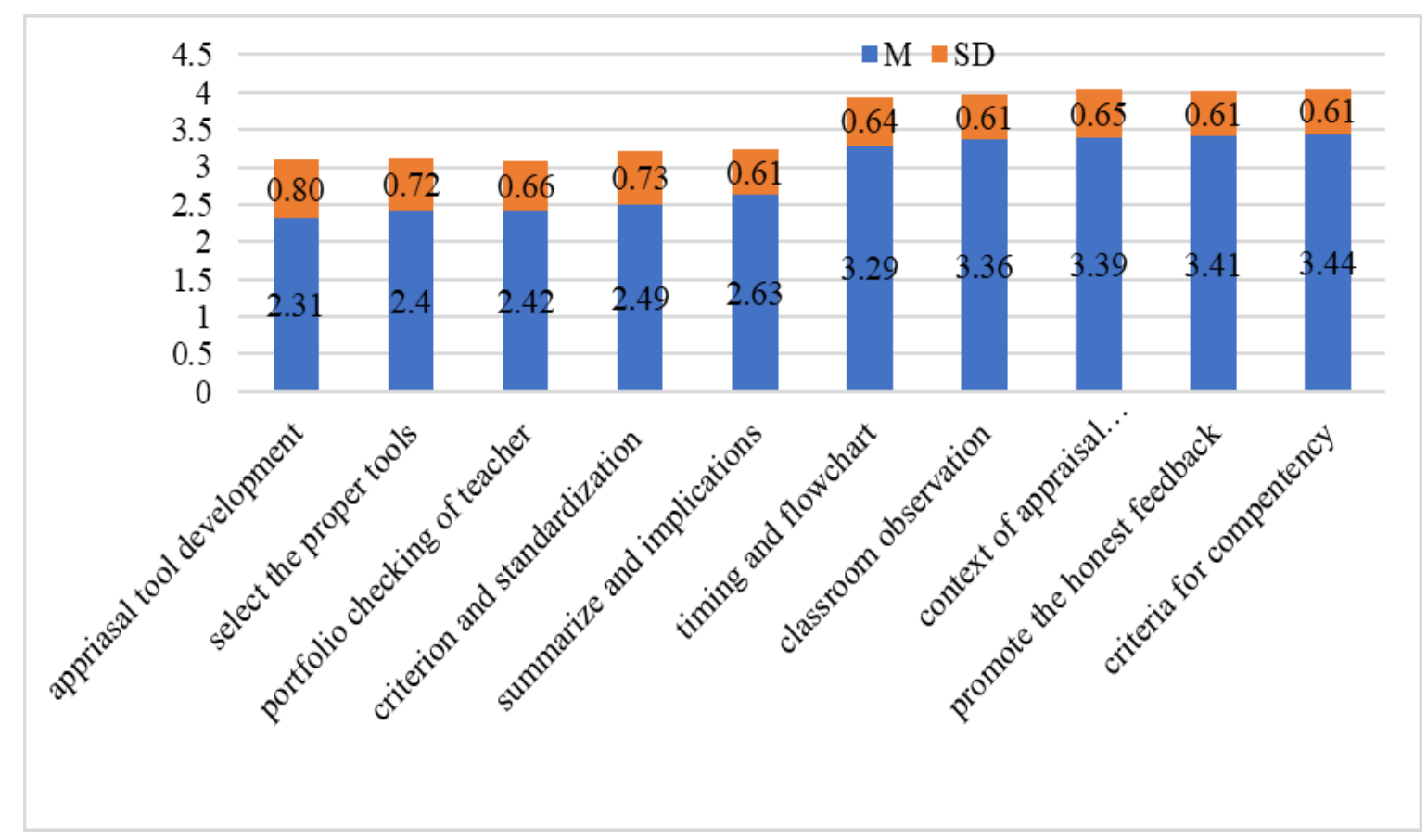

Figure 23 shows low and high perception levels of educational leaders concerning the tasks of teacher performance appraisal. Low level was found in case of appraisal tool development $(\mathrm{M}=2.31, \mathrm{SD}=.80)$; select the proper tools $(\mathrm{M}=2.40 ; \mathrm{SD}=.72)$; portfolio checking of teachers $(\mathrm{M}=2.42, \mathrm{SD}=.66)$, and criteria and standardization $(\mathrm{M}=2.49, \mathrm{SD}=.73)$.

This study has also found high perception levels of educational leaders concerning the tasks of TPA, like summarize and implications $(\mathrm{M}=2.63, \mathrm{SD}=.61)$; timing and flowchart $(\mathrm{M}=3.29, \mathrm{SD}=.64)$; classroom observation $(\mathrm{M}=3.36, \mathrm{SD}=.61)$; context of appraisal $(\mathrm{M}=3.39, \mathrm{SD}=.65)$; promote the honest feedback $(\mathrm{M}=3.41, \mathrm{SD}=.61)$, and criteria for competency $(\mathrm{M}=3.44, \mathrm{SD}=.61)$. 


\section{Task 5: Teacher compensation}

Figure 24. Findings of teacher compensation by ranking $M$ and $\mathrm{SD}(\mathrm{N}=138$, study 6$)$

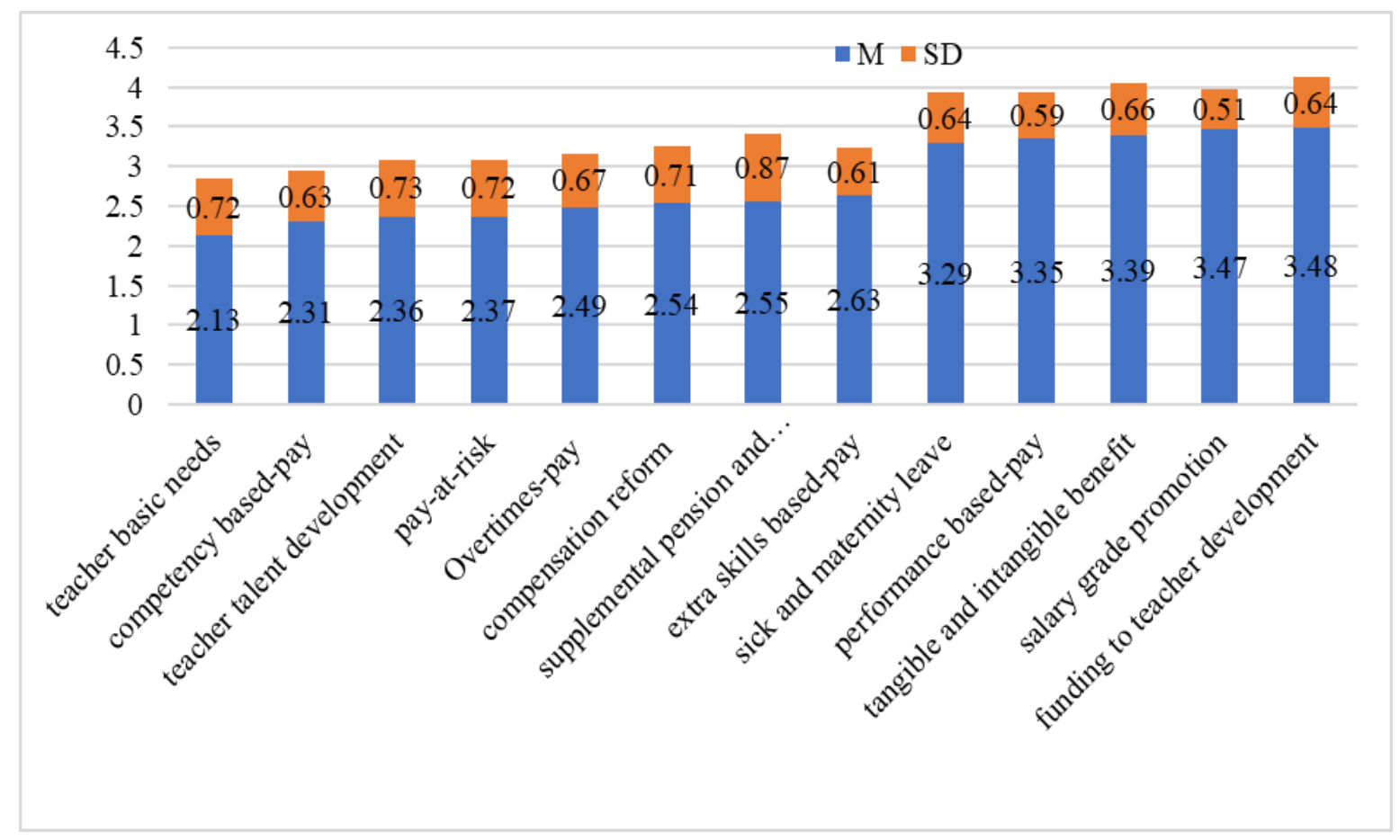

Figure 24 shows the low and high perception levels of educational leaders toward teacher compensation. A low level was found in the following cases: 'basic needs of the teacher.' M $=2.13, \mathrm{SD}=.72)$; 'competency-based pay' $(\mathrm{M}=2.31, \mathrm{SD}=.63)$; 'priority on teachers' talent development' $\left.^{\prime} \bar{x}=2.36, \mathrm{SD}=.73\right)$; Pay-at-risk, $(\mathrm{M}=2.37, \mathrm{SD}=.72)$, and 'overtime-pay $(\mathrm{M}=2.49, \mathrm{SD}=.67)$.

This study found high perception level of the educational leaders concerning the tasks of teacher compensation, such as compensation reform $(\mathrm{M}=2.54, \mathrm{SD}=.71)$; supplemental pension $(\mathrm{M}=2.55, \mathrm{SD}=.87)$; extra skills based-pay $(\mathrm{M}=2.63, \mathrm{SD}=.61)$; sick and maternity leave $(\mathrm{M}=3.29, \mathrm{SD}=64)$; performance based-pay $(\mathrm{M}=3.35, \mathrm{SD}=.59)$; tangible and intangible benefit $(\mathrm{M}=3.39, \mathrm{SD}=.66)$; salary grade promotion $(\mathrm{M}=3.47, \mathrm{SD}=.51)$, and funding to teacher development $(\mathrm{M}=3.48, \mathrm{SD}=.64)$. 


\section{Task 6: Training Needs Assessment}

Figure 25. Findings of training needs assessment by ranking $M$ and $\mathrm{SD}(\mathrm{N}=138$, study 6$)$

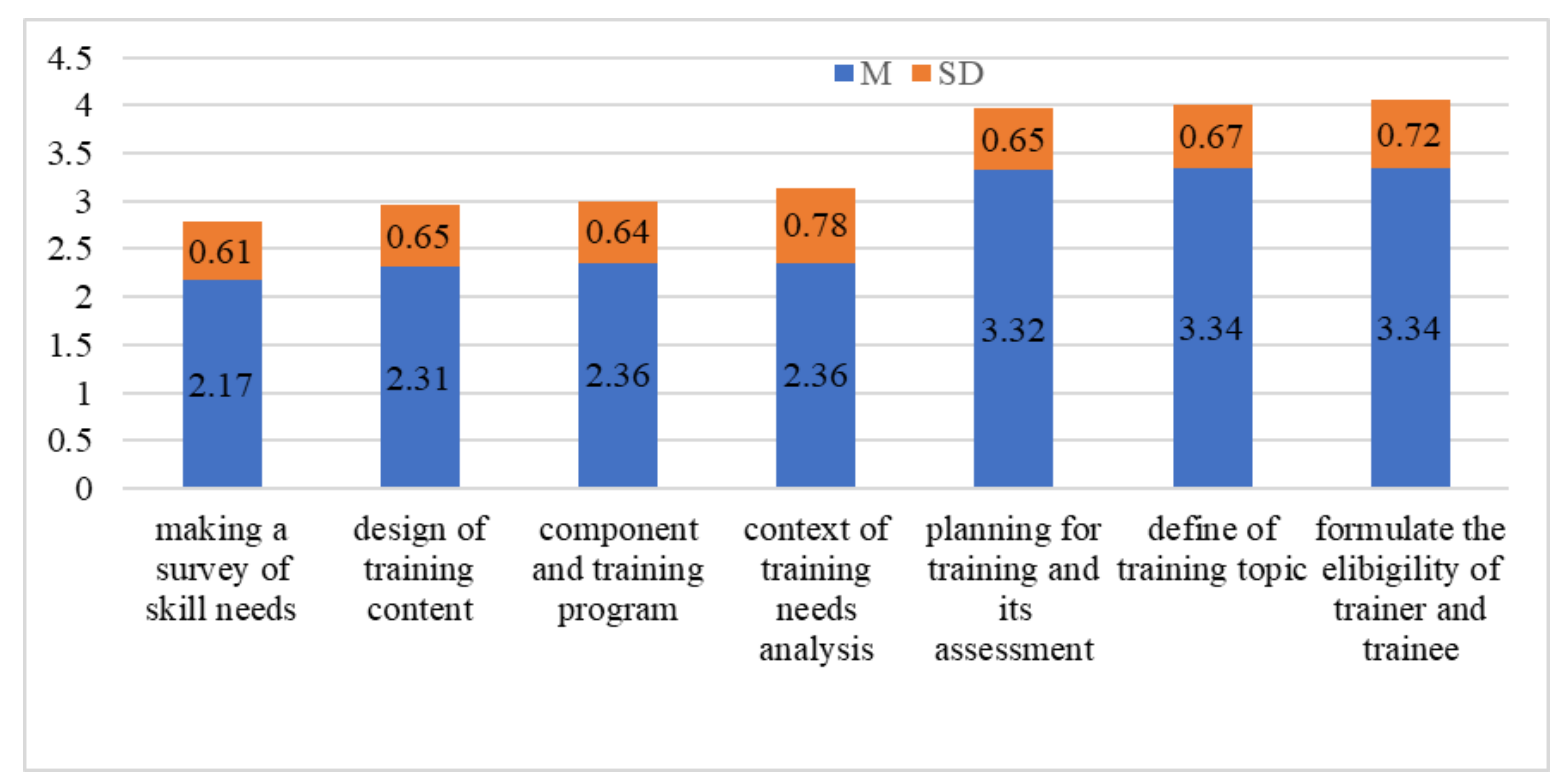

Figure 25 shows the low and high perception levels of the educational leaders concerning the tasks of training needs assessment. Low perception levels were found in case of making a survey of skill needs $(\mathrm{M}=2.17, \mathrm{SD}=.61)$; design of training content $(\mathrm{M}=2.31$, $\mathrm{SD}=.65)$; component and training program $(\mathrm{M}=2.36, \mathrm{SD}=.64)$, and context of training needs analysis $(\mathrm{M}=2.36, \mathrm{SD}=.78)$; these were low perception items that need to be improved and developed for the sake of better performance in teacher management within TTIs.

Furthermore, it also found high perception level items, like planning for training and its assessment $(\mathrm{M}=3.32, \mathrm{SD}=.65)$; define the training topic $(\mathrm{M}=3.34, \mathrm{SD}=.67)$; formulate the eligibility of the trainer and trainee $(M=3.34, S D=.72)$. Figure 26 shows the summary in the following page have indicated that 21 out of 52 items showed low perception by educational leaders concerning the six tasks by ranking mean score. 
Figure 26. Summary of the low-perception level of educational leaders concerning the 6 tasks by mean ranking (A selection of 21 out of 52 items)

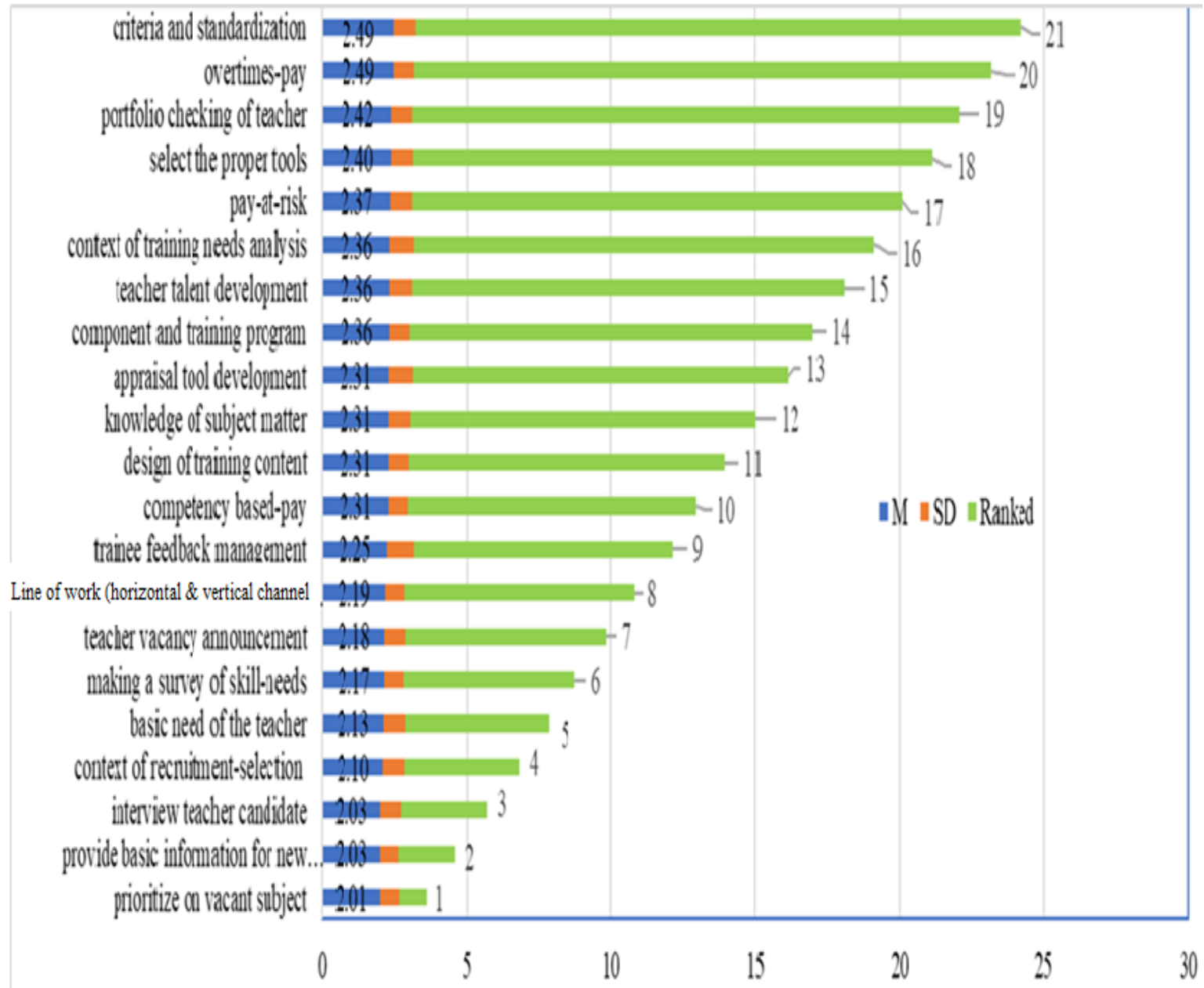




\subsubsection{Stress factors among teachers}

The questionnaire was delivered to 213 teachers, who have a teaching obligation not more than 12 hours a week (Decree on Lao teacher education, No. 177/GOL/2017-Laos), and they are currently working in 8 TTIs in Laos.

Figure 27. Overall scores of the stress factors among teachers by Alpha, $M ; S D,(N=213$, study 6)

\section{Teacher professional development}

Teacher welfare

Teaching load

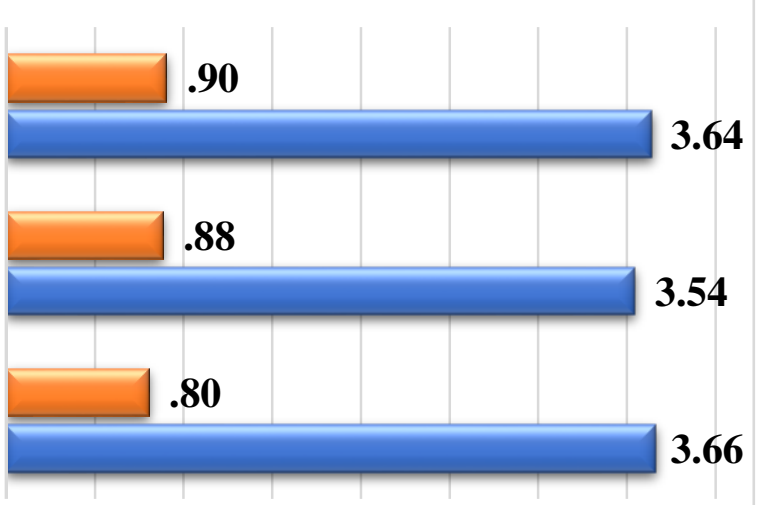

$\square$ Alpha $\square$ Mean

Figure 27 shows the overall mean scores, standard deviation, and Cronbach's alpha found to be of high-level stress factors among teachers within TTIs ( $\mathrm{M}=3.61, \mathrm{SD}=.58$ and $\alpha$ $=.91)$. The summary of each stress factor was ranked from high to low: teaching load $(\mathrm{M}=3.66, \mathrm{SD}=.57)$; teacher professional development $(\mathrm{M}=3.64, \mathrm{SD}=.80)$; teacher welfare $(\mathrm{M}=3.54, \mathrm{SD}=.72)$. In addition, the Cronbach's alpha examination of each subscale also found a high internal reliability, which is ranked from high to low: teacher professional development $(\alpha=.90)$; teacher welfare $(\alpha=.88)$, and teaching load $(\alpha=.80)$ respectively. 


\section{1) Stress factors relating to teaching load}

Figure 28. Findings of stress factors relating to teaching load by ranking $M$ and $S D(N=213$, study 6)

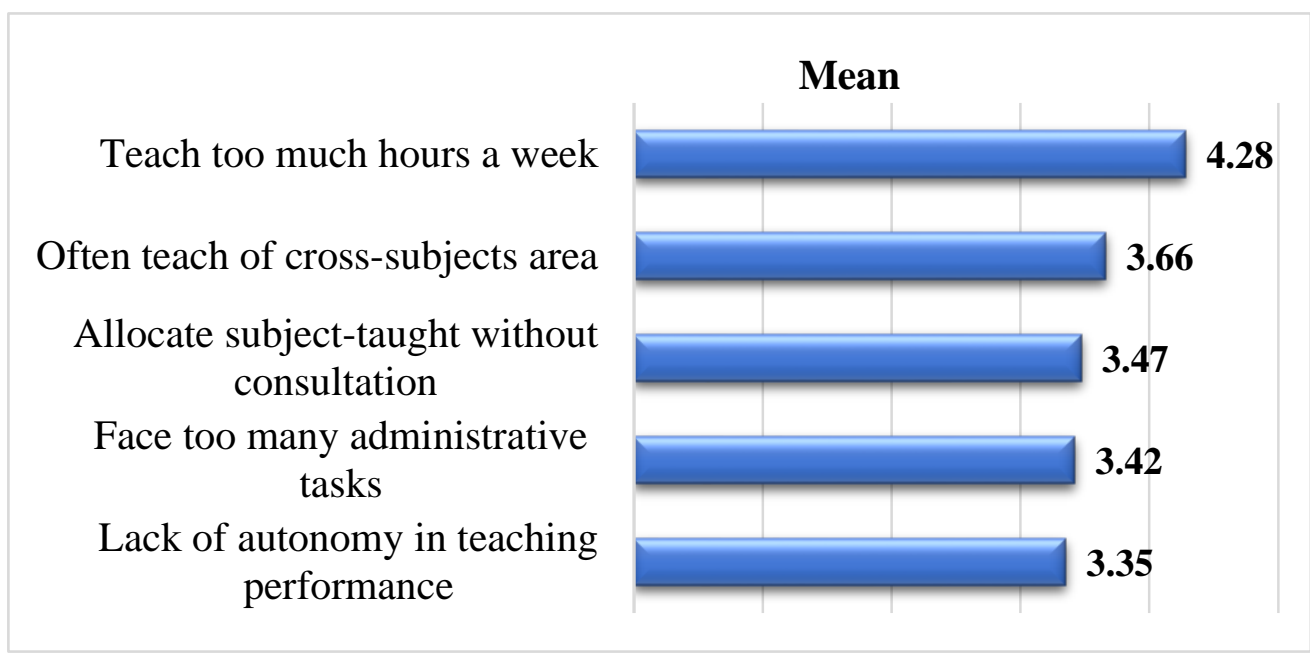

The findings by descriptive statistical analysis in figure 28 above show the results referring to the causes of stress factors among teachers due to the educational leader's low perception of their functioning and responsibilities. The analysis found that the overall mean score was at a high level $(\mathrm{M}=3.66, \mathrm{SD}=.57)$. In addition, among these stress sources 2 out of 5 question-items were found to be at a high level, like 'Too many teaching-hours per week' $(\mathrm{M}=4.28, \mathrm{SD}=.85)$ and 'often assigned to teach cross-subjects' areas' $(\mathrm{M}=3.66, \mathrm{SD}=.98)$.

However, the remaining three question items were relatively high level as well, such as 'allocate subjects taught without consulting me' $(\mathrm{M}=3.47, \mathrm{SD}=.96)$; followed by 'face too many administrative tasks $(\mathrm{M}=3.42, \mathrm{SD}=.94)$ and 'lack of autonomy in teaching practice $(\mathrm{M}=3.35, \mathrm{SD}=1.04)$. 


\section{2) Stress factors relating to teacher welfare}

Figure 29. Findings of stress factors relating to teacher welfare by ranking $M$ and SD $(\mathrm{N}=213$, study 6$)$

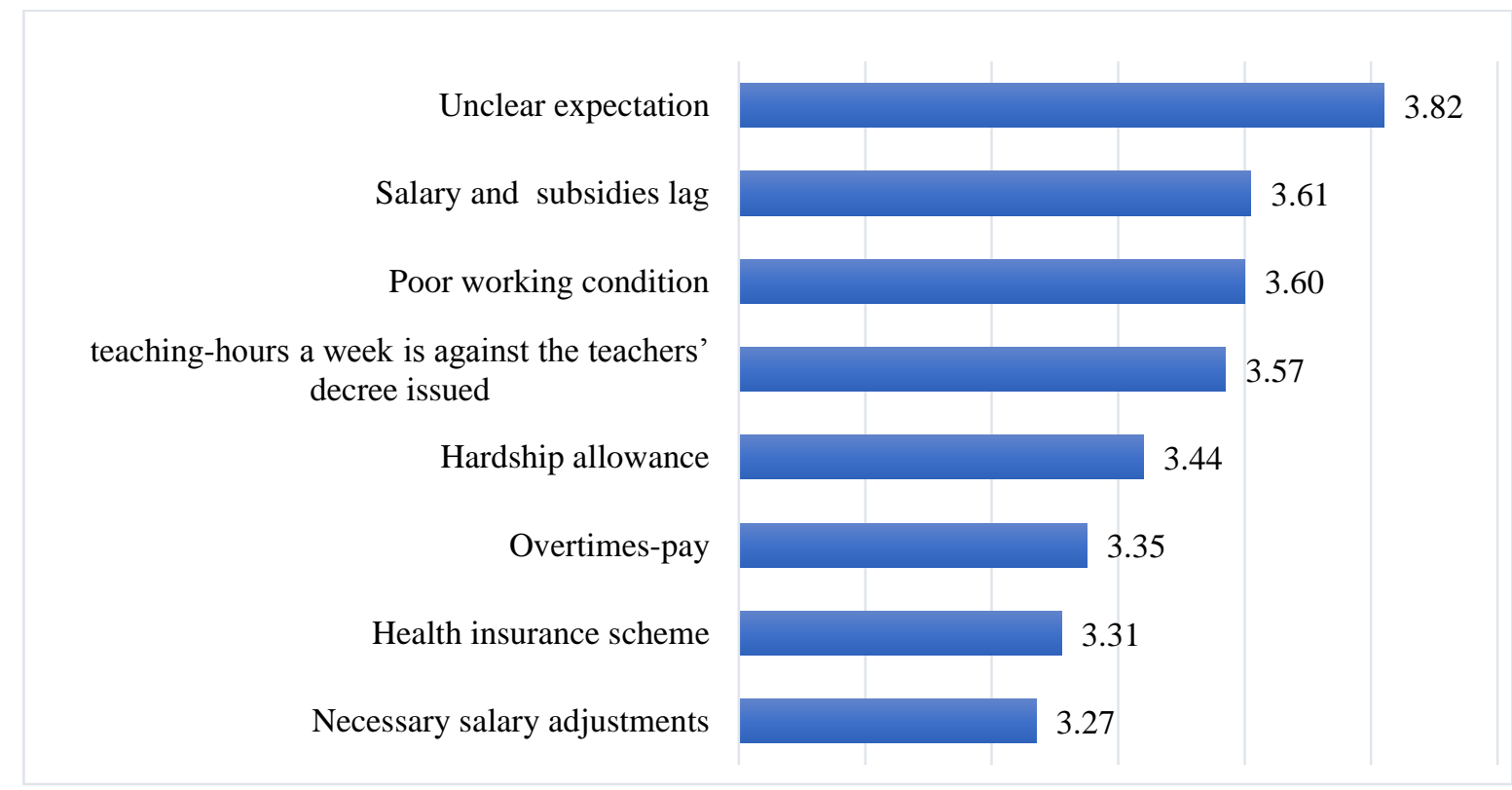

Figure 29 shows the results of the statistical analysis concerning stress factor No 2 . called teacher welfare, including 8 question-items with an overall mean score at a high level $(\mathrm{M}=3.54, \mathrm{SD}=.72)$. These analysis found that 4 out of 8 question-items were high level such as 'Unclear expectation concerning teachers' benefits' $(\mathrm{M}=3.82, \mathrm{SD}=1.08)$; 'salary and subsidies lag ( $\mathrm{M}=3.61, \mathrm{SD}=1.12)$; 'poor working condition' $(\mathrm{M}=3.60, \mathrm{SD}=1.02)$, and 'The number of teaching-hours a week is against the teachers' decree issued' $(\mathrm{M}=3.57, \mathrm{SD}=1.00)$ respectively.

The remaining four question-items were of moderate level like hardship allowance $(\mathrm{M}=3.44, \mathrm{SD}=.62)$; overtimes-pay $(\mathrm{M}=3.35, \mathrm{SD}=.24)$; health insurance scheme $(\mathrm{M}=3.31$, $\mathrm{SD}=.12)$, and necessary salary adjustment $(\mathrm{M}=3.27, \mathrm{SD}=.84)$. 


\section{3) Stress factors relating to teacher professional development}

Figure 30. Findings of stress factors relating to teacher's professional development by ranking $\mathrm{M}$ and $\mathrm{SD}(\mathrm{N}=213$, study 6)

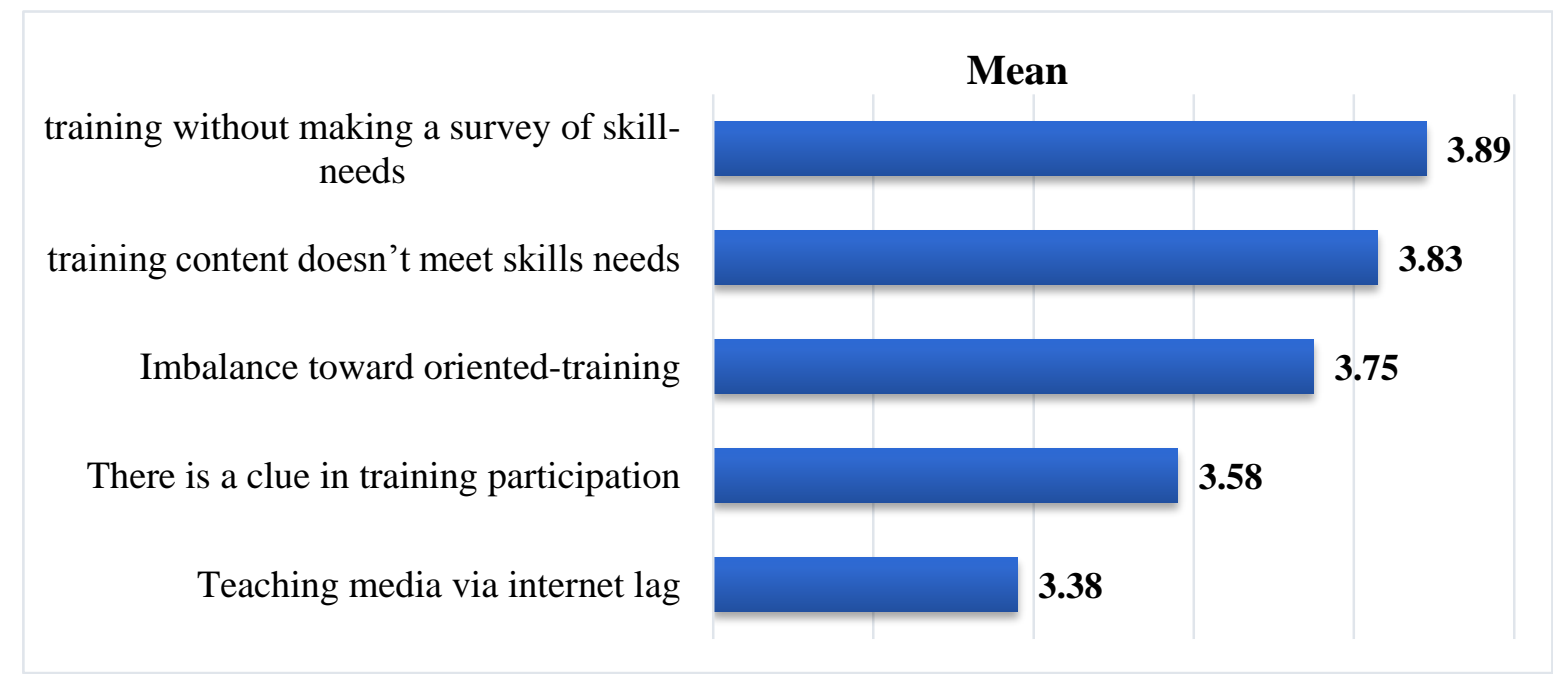

Figure 30 above shows that the 213 teachers involved in this study found to be keen in knowledge-pursuit and they had a vision on how to move forward through professional growth. The above statement is indicated by the overall mean score at a high level $(\mathrm{M}=3.64$, $\mathrm{SD}=.80$ ). In addition, almost all question-items had a high mean score as well, like 'training without making a survey of skill-needs $(\mathrm{M}=3.89 . \mathrm{SD}=1.06)$; 'training content doesn't meet skills needs' $(\mathrm{M}=3.83, \mathrm{SD}=1.07)$, accompanied by 'imbalance toward oriented-training' ( $\mathrm{M}$ $=3.75, \mathrm{SD}=1.10)$, followed by and 'there is a clue in training participation' $(\mathrm{M}=3.58$, $\mathrm{SD}=.96$ ). The remaining question-item had a low mean score: 'teaching media via internet lag' $(\mathrm{M}=3.38, \mathrm{SD}=1.10)$. 
Figure 31. Summary of high stress factors among teachers by mean ranking

(A selected high-level item of causes, 10 out of 18 items from three stress sources)

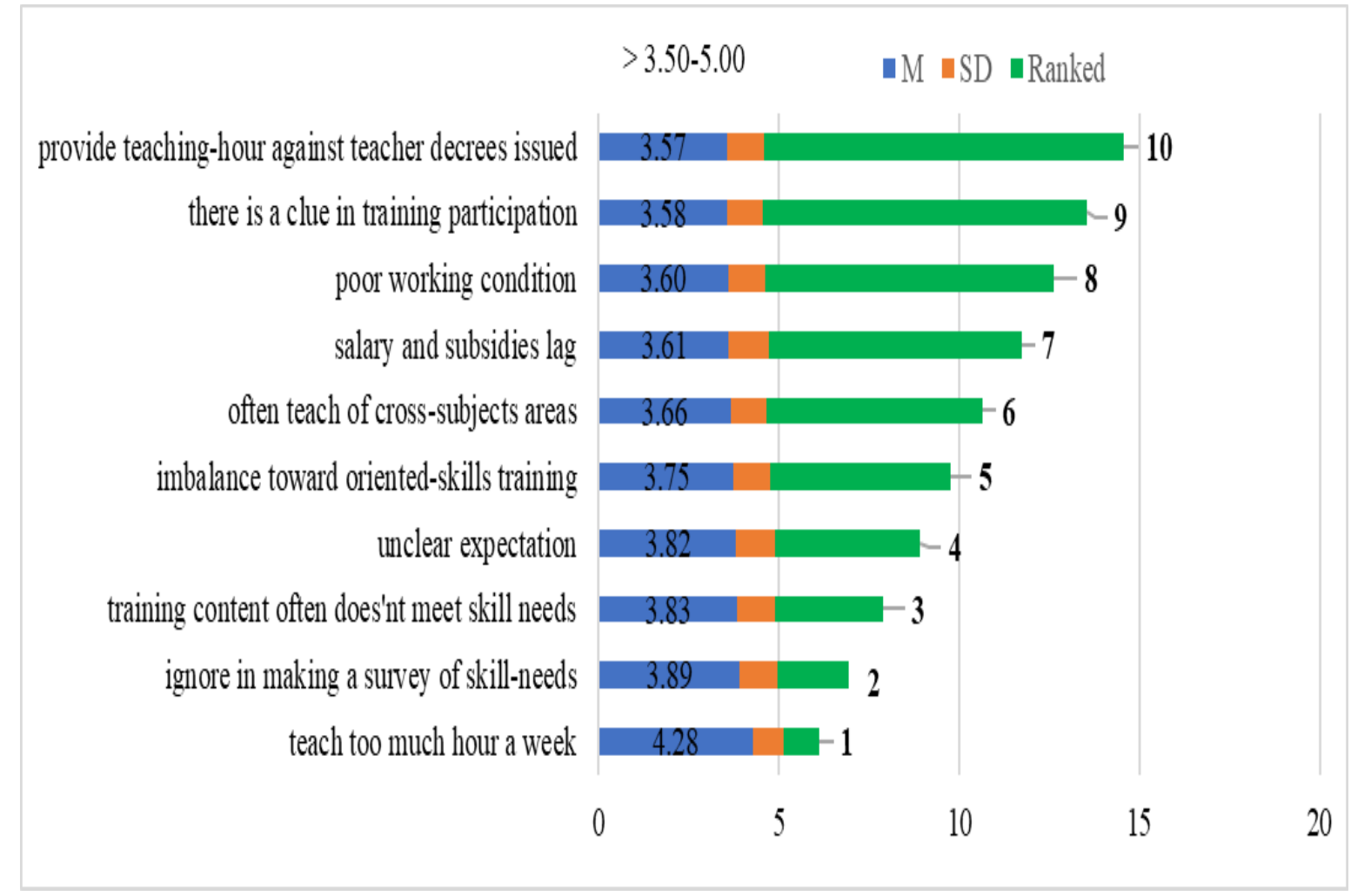

Figure 31 shows the summary of the high main causes of stress factors among teachers affected by mismanagement toward the teaching load, teacher welfare, and teacher professional development. The summary above revealed the lowest to low level of perception such as assigned teacher to teach too much hours a week, absent in making survey of skill needs, training provided and skills needs against each other, unclear expectation among novices, training opportunity, teach cross-subjects, salary and subsidies lag, poor working condition, training participation, teaching scheduling against the Lao legal enactments that ranked the perception of educational leaders from lowest to low respectively. 


\subsubsection{Hypothesis examination}

\subsubsection{Independent variable of educational leaders}

Hypothesis 1: There are no statistically significant differences in the perception level of the educational leaders concerning the six tasks analyzed by gender, qualification level and working experience, and TTIs location. I will analyze data according to each independent sub-variable below:

Table 23. Analysis of educational leaders' perception of the six tasks by gender by t-test (study 6. $\mathrm{N}=138$ )

\begin{tabular}{lcccccccc}
\hline \multirow{2}{*}{ Leaders' perception of the six tasks } & \multicolumn{2}{c}{ Men } & \multicolumn{2}{c}{ Women } & & \multicolumn{2}{c}{$\boldsymbol{p}-$} \\
\cline { 2 - 6 } & $\overline{\boldsymbol{X}}$ & S.D & $\overline{\boldsymbol{X}}$ & S.D & & value \\
\hline 1.Teacher demand analysis & 2.86 & .33 & 2.92 & .30 & .48 & .37 \\
2. Recruitment and selection & 2.68 & .33 & 2.67 & .34 & .86 & .88 \\
3. Pre-service teacher training & 2.75 & .26 & 2.81 & .35 & .06 & .22 \\
4. Teacher performance appraisal & 2.92 & .29 & 2.90 & .27 & .35 & .62 \\
5. Teacher compensation & 2.88 & .26 & 2.82 & .26 & .73 & .26 \\
6.Training needs assessment & & 2.73 & .31 & 2.75 & .31 & .77 & .60 \\
& $\mathbf{\Sigma} \bar{x}$ & $\mathbf{2 . 8 0}$ & $\mathbf{. 2 9}$ & $\mathbf{2 . 8 1}$ & $\mathbf{. 3 0}$ & & \\
\hline
\end{tabular}

*p<.05

Table 23 above shows the results of the t-test by gender (men and women). No statistically significant differences were found at .05 in the perception level of educational leaders concerning the six tasks. The $p$-value is higher or greater than .05 meaning a fail to reject $\mathrm{H}_{\mathrm{o}}$ and should accept the null hypothesis setting due to the fact that there is insufficient proof to underline that male and female teachers both have a different perception level. However, if we examine the mean score, we find a little higher perception level in case of female leaders concerning tasks 1,3 , and 6 ., than in case of male leaders. 
Table 24. Qualification examination of educational leaders by ANOVA (study 6. N=138)

\begin{tabular}{|c|c|c|c|c|c|}
\hline Leaders' perception of the six tasks & df & SS & MS & $\boldsymbol{F}$ & $\boldsymbol{P}$ \\
\hline 1. Teacher demand analysis & 136 & .04 & .02 & .20 & .81 \\
\hline 2. Recruitment and selection & 136 & .06 & .03 & .29 & .74 \\
\hline 3. Pre-service teacher training & 136 & .23 & .11 & 1.26 & .28 \\
\hline 4. Teacher performance appraisal & 136 & .17 & .08 & 1.00 & .37 \\
\hline 5. Teacher compensation & 136 & .24 & .12 & 1.80 & .16 \\
\hline 6. Training needs assessment & 136 & .07 & .03 & .37 & .69 \\
\hline
\end{tabular}

In connection with the six tasks, table 24 above shows the results of the ANOVAexamination relating to the educational qualification of educational leaders within TTIs in Laos. The examination found no statistically significant differences at .05 in the perception level of leaders concerning the six tasks. The examination score was higher than .05 which implies that there is inadequate evidence to conclude that higher qualification leads to a different perception level. The working experience examination is shown in table 25.

Table 25. Working experience examination of educational leaders by ANOVA $(\mathrm{N}=138)$

\begin{tabular}{lcc|ccc}
\hline \multicolumn{1}{c}{ Leaders' perception of the six tasks } & df & SS & MS & $\boldsymbol{F}$ & $\boldsymbol{P}$ \\
\hline 1. Teacher demand analysis & 136 & .05 & .029 & .26 & .76 \\
2. Recruitment and selection & 136 & .51 & .257 & 2.33 & .10 \\
3. Pre-service teacher training & 136 & .27 & .135 & 1.48 & .23 \\
4. Teacher performance appraisal & 136 & .27 & .137 & 1.62 & .20 \\
5. Teacher compensation & 136 & .44 & .221 & 3.28 & .04 \\
\hline 6. Training needs assessment & 136 & .21 & .108 & 1.09 & .33 \\
\hline${ }^{*} p<.05$ & & & & &
\end{tabular}

In connection with the six tasks, table 25 above displays the results of the ANOVAexamination regarding the working experiences of the educational leaders in TTIs. The results indicated that educational leaders had a significantly different perception level at .05 concerning the task of teacher compensation. In order to monitor the different perceptions among those leaders, the Scheffe examination was conducted. Results are shown in table 26. 
Table 26. Examination of educational leaders' working experiences by Sheffe (study 6. $\mathrm{N}=138)$

\begin{tabular}{ccccccccc}
\hline Educational leaders' & \multirow{2}{*}{ df } & \multicolumn{3}{c}{$<\mathbf{1 0}$ years } & \multicolumn{2}{c}{$\mathbf{1 0 - 1 5}$ years } & \multicolumn{2}{c}{$\mathbf{1 6}$ years > } \\
Perception of: & & $\bar{X}$ & $\mathbf{M}_{\text {diff }}$ & $\bar{X}$ & $\mathbf{M}_{\text {diff }}$ & $\bar{X}$ & $\mathbf{M}_{\text {diff }}$ \\
Teacher compensation & \multirow{2}{*}{136} & 2.74 & $-.17458^{*}$ & 2.91 & .17458 & 2.86 & .11817 \\
\hline${ }^{*} \mathrm{p}<.05$ & & & & & & & &
\end{tabular}

Table 26 above indicates that those educational leaders who had a less than 10 years working experience had a low perception level concerning the task of teacher compensation $\left(\bar{x}=2.74\right.$ and $\left.\mathrm{M}_{\mathrm{dff}}=-17458 *\right)$.

Hypothesis 2: There are statistically significant differences in the perception level of the six tasks among educational leaders in a Faculty of Education (FOE) and in a Teacher Training College (TTC).

Table 27. Perception level of educational leaders between FOE and TTCs by t-test (study 6 .

\begin{tabular}{|c|c|c|c|c|c|c|}
\hline \multicolumn{7}{|c|}{$\mathrm{N}=138)$} \\
\hline \multirow{2}{*}{$\begin{array}{c}\text { Educational Leaders' perception } \\
\text { level of the six tasks }\end{array}$} & \multicolumn{2}{|c|}{ FOE } & \multicolumn{2}{|c|}{ TTC } & \multirow{2}{*}{$t$} & \multirow{2}{*}{$\begin{array}{c}p- \\
\text { value }\end{array}$} \\
\hline & $\bar{X}$ & S.D & $\bar{X}$ & S.D & & \\
\hline 1. Teacher demand analysis & 2.75 & .30 & 2.90 & .32 & .55 & .56 \\
\hline 2. Recruitment and selection & 2.69 & .34 & 2.66 & .33 & .95 & .53 \\
\hline 3. Pre-service teacher training & 2.74 & .25 & 2.79 & .34 & .06 & .28 \\
\hline 4. Teacher performance appraisal & 2.91 & .28 & 2.92 & .29 & .78 & .77 \\
\hline 5. Teacher compensation & 2.89 & .26 & 2.83 & .26 & .54 & .14 \\
\hline 6. Training needs assessment & 2.86 & .28 & 2.72 & .36 & .22 & .50 \\
\hline$\Sigma \bar{x}$ & 2.80 & .18 & 2.81 & .22 & & \\
\hline
\end{tabular}

\footnotetext{
${ }^{*} \mathrm{p}<.05$

Table 27 indicates that the educational leaders in the different levels of TTIs showed no statistically significant differences at .05 in their perception level concerning the six tasks. On the basis of this examination result the hypothesis has to be rejected as there is unreliable evidence of both FOE and TTC to conclude differently. Besides, this analysis also found that educational leaders in FOE had a lower perception level than leaders in TTCs $(\bar{x}=2.80$, SD
} 
$=.18 ; \bar{x}=2.81, \mathrm{SD}=.22$ ). Next comes the hypothesis examination to observe the reliability of correlation between tasks and perception distribution displayed in table 28 below:

Hypothesis 3: There will be no relationships between the six tasks and the distribution of low perception of educational leaders within 8 TTIs, Laos.

Table 28. Correlation between tasks and perception distribution (study 6. $\mathrm{N}=138$ )

\begin{tabular}{lcccc}
\hline \multicolumn{1}{c}{ Dependent variables } & M & SD & SE & Correlation \\
\hline 1. Teacher demand analysis & 2.88 & .32 & .28 & $.372^{\text {** }}$ \\
2. Recruitment and Selection & 2.67 & .33 & .60 & $.447^{\text {** }}$ \\
3. Pre-service teacher training & 2.77 & .30 & .58 & $.406^{\text {** }}$ \\
4. Teacher Performance Appraisal & 2.91 & .29 & .49 & $.495^{\text {** }}$ \\
5. Teacher compensation & 2.86 & .26 & .54 & $.524^{\text {** }}$ \\
6. Training Needs Assessment & 2.74 & .31 & .86 & $.719^{\text {** }}$ \\
\hline
\end{tabular}
$* * . p<.01$

The second main hypothesis examination focused on the correlation between tasks and perception levels among educational leaders concerning the six tasks. The analysis shows that educational leaders within 8 TTIs, Laos had a relatively high-level perception of the six tasks as indicated by the interpretation criteria $(<2.50-3.49>2.67-2.91)$. The examination also displays a strong relationship between tasks at $\left(\mathrm{p}<.01 ;>r=.372^{* *}-.719^{* *}\right)$ and there is insufficient proof to conclude that there is no relationship between tasks and low perception of educational leaders, and they may need training.

In summary of the hypothesis concerning educational leaders, it can be concluded that educational leaders within 8 TTIs in Laos selected to this main study have different gender, qualification, working experience, and different institutions. The examination results have indicated that there were no statistically significant differences at .05 in their perception level of the six tasks according to gender, qualification and institutions.

An exception occurred in case of leaders with a less than 10 years working experience, where a low perception level concerning teacher compensation was found. However, the correlation and perception distribution examination have found that there was a strong correlation between tasks $\left(r_{\text {mini }}=.372^{* *}\right.$ to $\left.r_{\max }=.719^{* * *}\right)$, and the perception distribution examination have found that educational leaders in FOEs had a lower perception of the six tasks than educational leaders in TTCs had. Figure 32 presents the summary of hypothesis examination in graphs. 
Figure 32. Summary of the hypothesis analysis concerning the perceptions of educational leaders of the six tasks $(\mathrm{N}=138$, study 6$)$

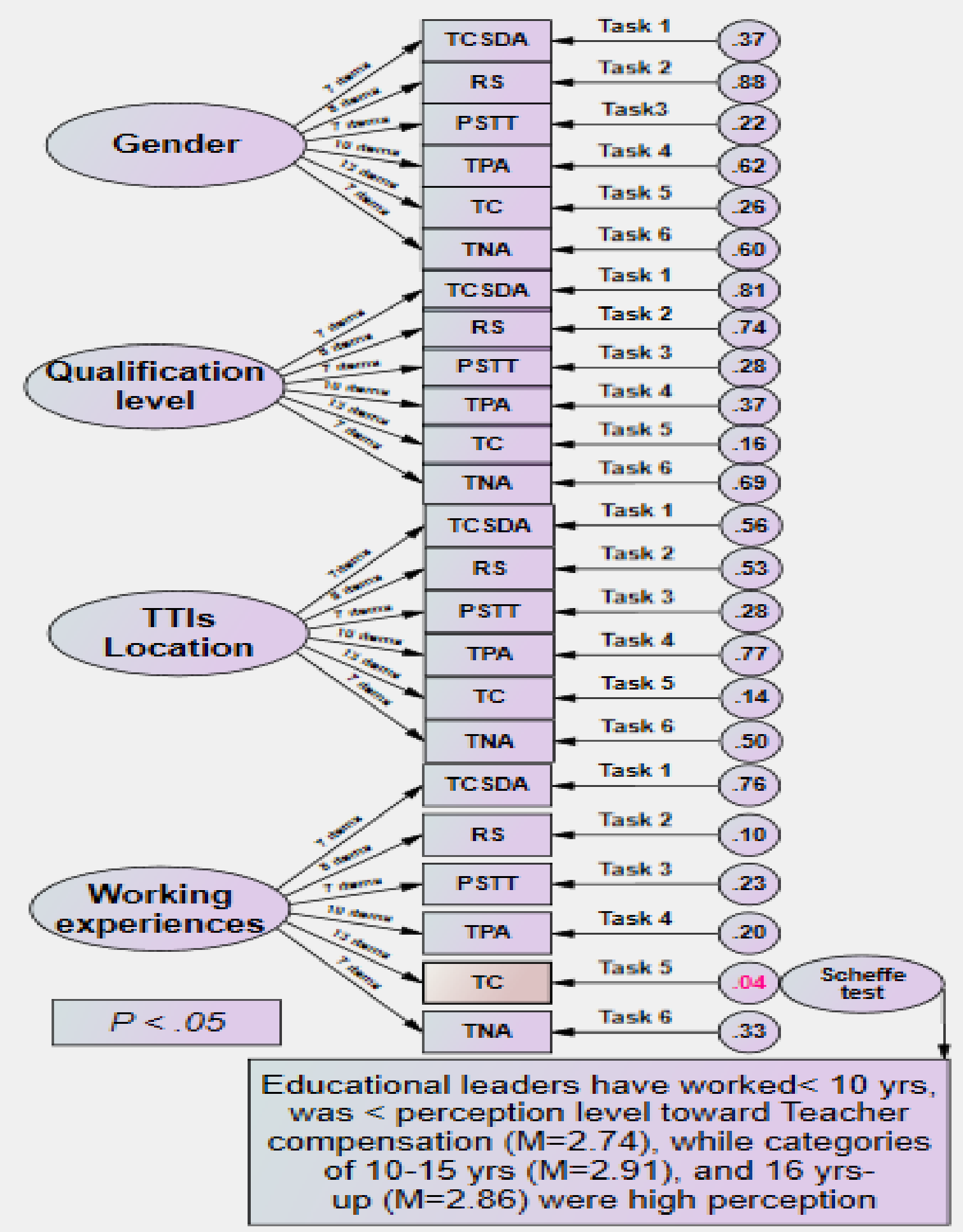

Abbreviations: TDA = Teacher Demand Analysis; RS= Recruitment and Selection; PST = Pre-Service Teacher Training; TPA $=$ Teacher Performance Appraisal; TC $=$ Teacher Compensation, and TNA =Training Needs Assessment; FOE =Faculty of Education; TTC = Teacher Training College. 


\subsubsection{Hypothesis examination of stress factors among teachers}

Hypothesis 1: Teachers of different gender will have different stress factors related to the three stress sources. I will analyze each sub-independent variable like gender, qualification level and teaching experience and TTIs location as below:

Table 29. Analysis of teachers' sources of stress factors by gender by t-test. (study 6 . $N=213$ )

\begin{tabular}{|c|c|c|c|c|c|c|c|}
\hline \multirow{2}{*}{$\begin{array}{c}\text { Source of stress factors } \\
\text { among teachers }\end{array}$} & \multirow{2}{*}{ df } & \multicolumn{2}{|c|}{ Men } & \multicolumn{2}{|c|}{ Women } & \multirow[t]{2}{*}{$t$} & \multirow{2}{*}{$P$} \\
\hline & & $\bar{X}$ & S.D & $\bar{X}$ & S.D & & \\
\hline 1. Teaching load & 211 & 3.68 & .59 & 3.64 & .56 & .80 & .62 \\
\hline 2. Teacher welfare & 211 & 3.51 & .75 & 3.55 & .70 & .26 & .63 \\
\hline \multirow[t]{2}{*}{$\begin{array}{l}\text { 3. Teacher professional } \\
\text { development }\end{array}$} & 211 & 3.68 & .82 & 3.62 & .79 & .33 & .59 \\
\hline & & 3.55 & .67 & 3.54 & .65 & & \\
\hline
\end{tabular}

$p<.05$

Table 29 shows the results of analysis by gender of the stress factors among teachers within 8 TTIs, related to the three stress sources in the teaching profession, like teaching load, teacher welfare, and teacher professional development. The examination found that there were no statistically significant differences at.05 in case of three stress sources leading to burnout syndrome. The p-value was greater than .05 meaning the null hypothesis has to be rejected because there is poor evidence to indicate differences.

Next comes the ANOVA examination regarding the qualification level $(<$ Higher diploma; BA, and Master Degree) of the teachers compared to the three stress sources in the teaching profession. The results will be presented in table 30 below:

\section{Sub-H 1.2: Qualification level}

Table 30. Qualification level of teachers by ANOVA (study 6. N=213)

\begin{tabular}{lc|c|cccc}
\hline \multicolumn{1}{c}{ Source of stress factors among teachers } & df & SS & MS & $\boldsymbol{F}$ & $\boldsymbol{P}$ \\
\hline 1. Teaching load & 212 & 2.24 & 1.12 & 3.46 & .03 \\
2. Teacher welfare & 212 & .52 & .26 & .50 & .60 \\
\hline 3. Teacher professional development & 212 & .77 & .38 & .59 & .55 \\
\hline \multicolumn{1}{c}{$P<.05$} & & & &
\end{tabular}


Table 30 above shows the examination results referring to the qualification level of teachers within TTIs and causes of burnout syndrome relating to the three stress sources, by using ANOVA-examination. The examination found that there were no differences at .05 in the causes of burnout syndrome in teaching profession concerning teacher welfare and teacher professional development, but teaching load as a stress source showed significant differences at .05 by the level of qualification. Therefore, the Scheffe examination is needed to verify the different variables. The reexamination results were displayed in Figure 33 below:

Figure 33. Different qualification levels and teaching load, by Scheffe examination $(\mathrm{N}=213$, study 6)

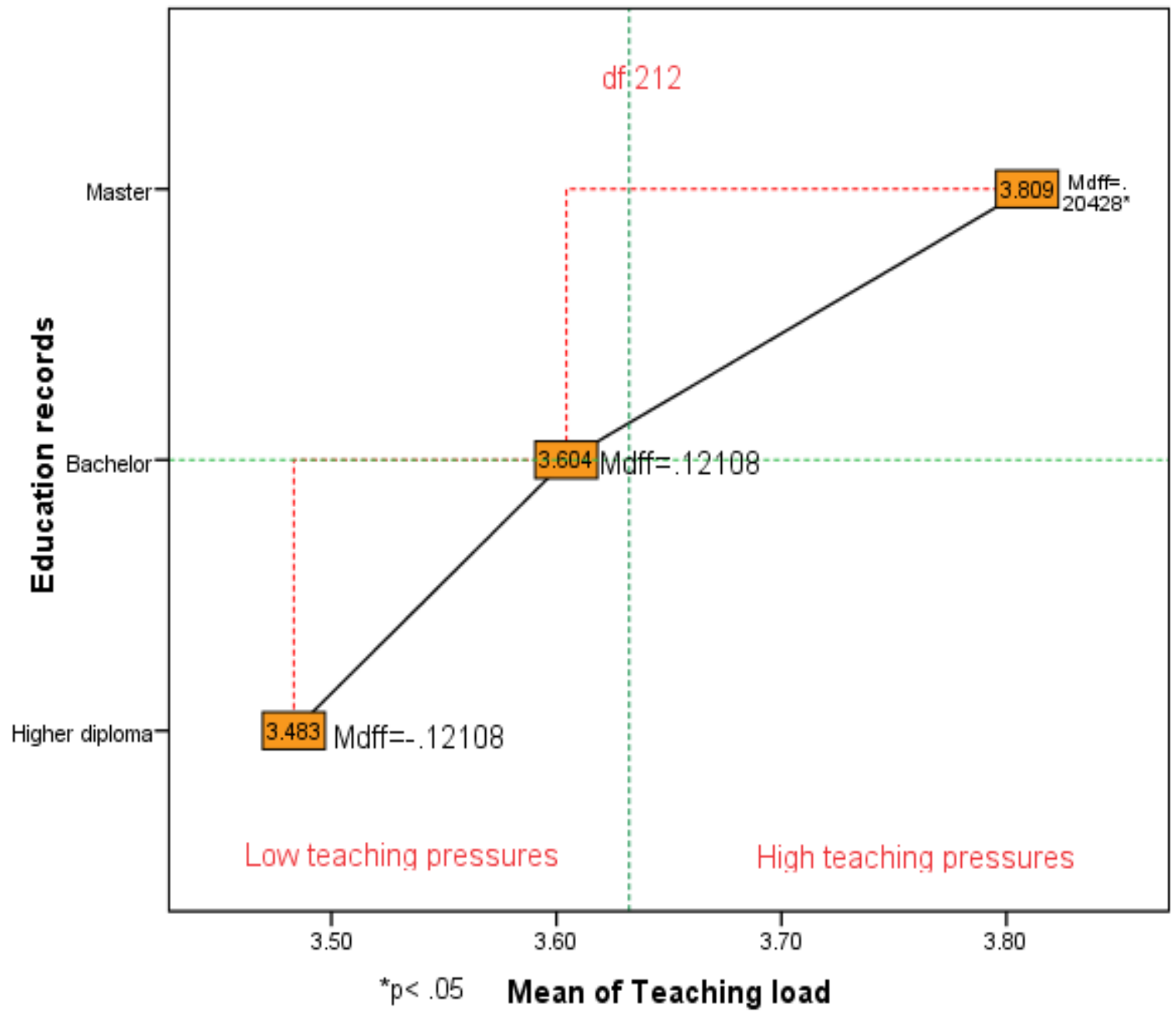

The reexamination shows that those teachers in 8 TTIs in Laos who have obtained a Master Degree experienced stress in their teaching profession related to teaching load at .05 ( $>\mathrm{M}_{\mathrm{dff}}=3.809$ ), which value is higher than in case of other categories of qualification levels like higher Diploma and Bachelor Degree. Table 31 indicates the hypothesis 
examination about teaching experiences of the teachers within 8 TTIs in Laos. The teaching experiences consist of three categories, such a less than 5 years; 5-10 years, and 11 years and more.

\section{Hypothesis 1.3: Teaching experiences}

Table 31. Teacher's teaching experience by ANOVA (study 6. N=213)

\begin{tabular}{lc|c|ccc}
\hline Source of stress factors among teachers & df & SS & MS & $\boldsymbol{F}$ & $\boldsymbol{P}$ \\
\hline 1. Teaching load & 212 & 2.381 & 1.191 & 3.683 & .02 \\
2. Teacher welfare & 212 & 109.038 & .519 & .831 & .43 \\
\hline 3. Teacher professional development & 212 & 3.695 & 1.847 & 2.908 & .05 \\
\hline \multicolumn{1}{c}{$P<.05$} & & & & &
\end{tabular}

Table 31 shows the results of the ANOVA-examination and the examination found that there were no statistically significant differences at .05 among stress sources concerning teacher welfare. Teaching load and teacher professional development showed statistically significant differences at .05 as stress sources in the teaching profession.

Thus, the Scheffe examination is necessary to investigate the heterogeneity in each categories' variance of teaching experiences. The Scheffe examination have indicated the results presented in table 32 below:

Table 32. Teaching load examination by Scheffe (study 6. N=213)

\begin{tabular}{|c|c|c|c|c|}
\hline \multirow{2}{*}{ Teaching experiences } & \multirow{2}{*}{$\bar{X}$} & $<5$ years & 5-10years & 11 years > \\
\hline & & 3.60 & 3.61 & 3.86 \\
\hline$<5$ years & 3.60 & - & .00748 & .28717 \\
\hline $5-10$ years & 3.61 & & - & $-.27969^{*}$ \\
\hline$>11$ years & 3.86 & & & - \\
\hline
\end{tabular}

$P<.05$

Table 32 above shows the results of the Scheffe reexamination to monitor the different teaching experiences concerning the stress sources of teaching load. It was found at .05 that teachers who had a more than 11 years teaching experience faced more teaching load than teachers in other categories of teaching experiences like less than 5 years and 5-10 years. The next examination was conducted in connection with teaching experience and the three stress sources of teacher professional development. The results are indicated in table 33. 
Table 33. Teachers' professional development by Sheffe retest (study 6. N=213)

\begin{tabular}{ccccc}
\hline \multirow{2}{*}{ Teaching experiences } & $\bar{X}$ & < 5 years & $\mathbf{5 - 1 0 y e a r s}$ & $\mathbf{1 1}$ years $>$ \\
\cline { 3 - 5 } & & 3.51 & 3.63 & 3.91 \\
\hline < 5 years & 3.51 & - & -.40 & .13 \\
5-10 years & 3.63 & & - & .40 \\
$>11$ years & 3.91 & & & - \\
\hline
\end{tabular}

$P<.05$

Table 33 above shows the results of Scheffe reexamination between teaching experience and facing stress sources of teacher professional development. The examination found at .05 a strange result, namely, those teachers within the 8 TTIs who had a more than 11 years teaching experience indicated higher stress concerning teachers' professional development than other categories like less than 5 years and 5-10 years.

Hypothesis 2: There are no statistically significant differences in the causes of burnout syndrome of teachers by the level of TTIs (FOE and TTC) within 8 TTIs, concerning the three stress sources

Table 34. Stress factors among teachers between FOE and TTCs by t-test (study $6 . \mathrm{N}=213$ )

\begin{tabular}{|c|c|c|c|c|c|c|}
\hline \multirow{2}{*}{$\begin{array}{c}\text { Source of stress factors among } \\
\text { teachers }\end{array}$} & \multicolumn{2}{|c|}{ FOE } & \multicolumn{2}{|c|}{ TTC } & \multirow{2}{*}{$t$} & \multirow{2}{*}{$\begin{array}{c}p- \\
\text { value }\end{array}$} \\
\hline & $\bar{X}$ & S.D & $\bar{X}$ & S.D & & \\
\hline 1. Teaching loads & 3.60 & .85 & 3.69 & .74 & .25 & 1.32 \\
\hline 2. Teacher welfare & 3.58 & .78 & 3.60 & .69 & .85 & .03 \\
\hline 3. Teacher professional development & 3.35 & .72 & 3.47 & .69 & .43 & .615 \\
\hline $\boldsymbol{\Sigma}_{x}^{-}$ & 3.51 & .70 & 3.58 & .71 & & \\
\hline
\end{tabular}

The t-test was carried out to observe the causes of burnout syndrome among teachers at Faculties of Education (FOE) and Teacher Training Colleges (TTC) within 8 TTIs in Laos. The analysis found that two stress sources were not significantly different in FOE and in TTC. However, teacher welfare showed a statistically significant difference at .05 . In order to monitor the differences, the Scheffe examination was conducted and found that teachers 
in TTCs experience higher stress in their teaching profession than teachers in FOEs $(\bar{x}=3.60$, $\mathrm{SD}=.69)$.

Hypothesis 3: There will be no relationship between teachers and the three stress sources like teaching load, teacher welfare and teacher professional development within 8 TTIs in Laos.

Table 35. Correlation between three stress factors among teachers (study 6. $\mathrm{N}=213$ )

\begin{tabular}{llrrc}
\hline \multicolumn{1}{c}{ Dependent variables } & M & SD & SE & Correlation \\
\hline 1. Teaching load & 3.41 & .71 & .04 & $.662^{* *}$ \\
2. Teacher welfare & 3.58 & .74 & .05 & $.712^{* *}$ \\
3. Teacher professional development & 3.64 & .80 & .05 & $.591^{* *}$ \\
\hline
\end{tabular}
$* * . p<.01$

The reliability examination presented in table 35 found that there was a strong correlation between the tasks at .05 and the distribution of the three stress sources of teachers within 8 TTIs in Laos, according to which the examination was rejected to the hypothesis setting at .05 . It can be concluded that the majority of teachers still face the homogeneous phenomena concerning TTIs' mismanagement. In addition, this ANOVA examination also found that teachers' professional development among the teachers within 8 TTIs was at a higher level than other stress sources in their teaching profession $(M=3.64, S D .80 ; M=3.58$, $\mathrm{SD}=.74 ; \mathrm{M}=3.41, \mathrm{SD}=.71$ respectively).

In Summary of the hypothesis on teachers we can see, that they were different in gender, qualification, institution level, and teaching experience records. The examination has found no significant differences at .05 between male and female teachers in facing stress in their teaching profession associated to the three stress sources.

Teachers who have obtained a Master Degree, and had a more than 11 years teaching experience records experienced high teaching stress at .05 concerning teaching load and teacher professional development.

In addition, the examination also found that teachers in TTCs experienced higher stress in their teaching profession than teachers in FOEs respectively. However, for more understanding, please observe the summary presented by graphs on Figure 34 below. In addition, there were strong correlations between the six tasks and stress sources in the teaching profession. 
Figure 34. Summary of the hypothesis examination concerning the three stress factors among teachers within 8 TTIs in Laos. $(\mathrm{N}=213$, study 6$)$

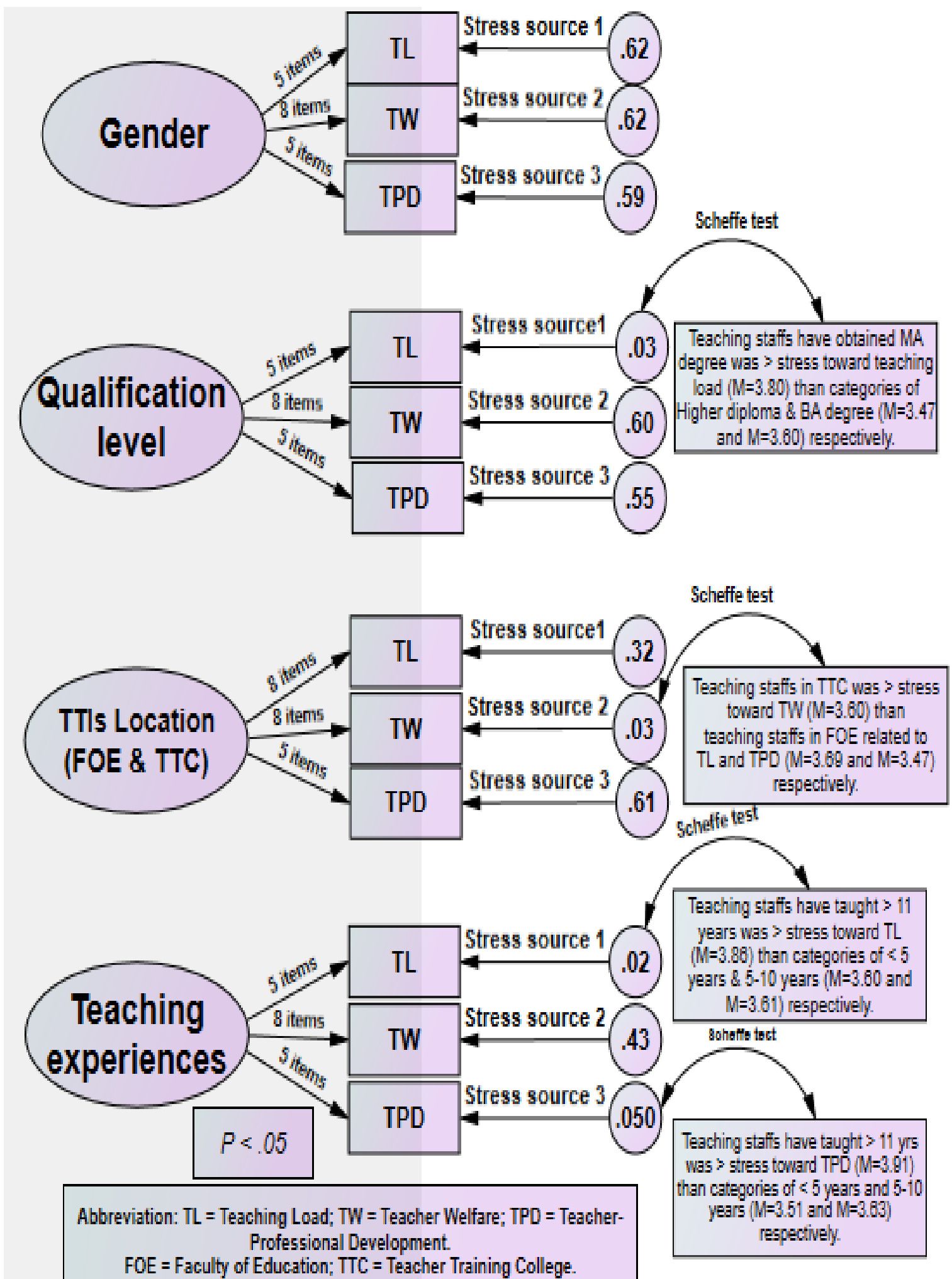


4.7.5 Content analysis of Open-ended questions, and attitude examination for the task of recruitment and selection

\subsubsection{Educational leaders' perception of the six tasks}

I have provided some empty spaces at the end of each task to elicit valid information from respondents' suggestions relating to the six tasks and three stress factors. The questions are as below.

1) What are your suggestions for improving the task of teacher demand analysis within TTIs? (Study 6. N=138)

The majority of educational leaders have suggested that the Ministry of Education and Sports or MOES should provide enough oriented skills and other soft skills trainings relating to teacher demand analysis, with special regard to the analysis of the characteristics of teachers to be employed (78 out of 138 or $56.52 \%$ ); followed by the need to take part in trainings about management and utilization of educational personnel (49 out 138 or 35.5\%). This study obtained no suggestions from 11 (7.98\%) sample members out of the 138 ones.

2) How do you promote the validity and reliability of the recruitment and selection process of a new teacher candidate and within TTIs? (Study 6. N=138)

Two-thirds of the educational leaders within 8 TTIs suggested that MOES-Laos should reduce its intervention in the recruiting and selection process, should provide a handbook, ad hoc committee and strongly improve professional ethics (55 out of 138 or $39.86 \%$ ); advice oriented skills training for the selection panel (39 out of 138 or $28.26 \%$ ); selecting a novice teacher must be transparent and auditable ( 22 out of 138 or $15.95 \%$ ); they need to take part in training about interview skills (18 out of 138 or $13.04 \%$ ); promote neutrality in the selection process ( 4 out of 138 or $2.89 \%$ ).

There was also an attitude examination of educational leaders through two shortstories in order to monitor the leader's perception on time management and decision-making skills concerning the recruitment and selection process. The examination found that the majority of educational leaders $(\mathrm{N}=138)$ lack time management and decision-making skills, and they (leaders) need to improve and develope these absent skills attentionally and continually. 
3) How important do you think the managing and performing of pre-service teacher training should be within TTIs? (study $6 . \mathbf{N}=138$ )

The majority of respondents proposed that top organizations should provide manual and other information related to civil servants' rights and benefits (78 out of 138 or $56.54 \%$ ); Rules, regulations, organizational culture, functions, responsibilities, allocating teachinghours a week (28 out of 138 or $20.28 \%$ ); accessible learning sources or websites (17 out of 138 or $12.31 \%$ ); clear line of work or vertical and horizontal communication (15 out of 138 or $10.87 \%)$.

4) Which technical requirements of teacher performance appraisal should be applied within TTIs? (study $6 . \mathrm{N}=138$ )

Almost half of the educational leaders within 8 TTIs needs the top organization to provide technical staff, oriented skills training regularly, handbook or manual, budgeting for performance appraisal tasks (53 out of 138 or $38.40 \%$ ); follow up by reducing appraisal activity by promoting teaching practice instead, field trip and workshop for novice teachers (38 out of 138 or $27.55 \%$ ); application of the proper metrics and compliance with ethical standards, rating criteria, normalization, flowchart of operation (23 out of 138 or $16.67 \%$ ); Clear systems of performance management and fairness (17 out of 138 or $12.31 \%$ ), and the utilization of new modern technology ( 7 out of 138 or $5.07 \%$ ).

5) Which is the most important requirement in teacher compensation that should be improved within TTIs? (study 6. $\mathrm{N}=138$ )

The majority of the educational leaders within TTIs recommended that the top organization should provide enough in-service trainings, observation, workshop for the person in charge of compensation tasks ( 40 out of 138 or $28.99 \%$ ); fairness in compensation supplies (35 out of 138 or $25.36 \%$ ); create proper rules and regulations (33 out of 138 or $23.92 \%$ ); manage people in various situations (30 out of 138 or $21.73 \%$ ).

\section{$\mathbf{N}=138$ )}

6) How should the training needs assessments be improved within TTIs? (study 6

More than half of the educational leaders suggested oriented or soft skills trainings (62 out of 138 or $44.93 \%$ ); Making a survey of training needs via online system or other methods (43 out of 138 or $31.15 \%$ ); training resources should be adequate (27 out of 138 or $19.59 \%$ ); defining the skill gaps is needed (6 out of 138 or $4.34 \%$ ). 


\subsubsection{Source of stress factors among teachers rooted by inefficient management}

Stress factor is not only a mental state but is also a true psychological condition that destructively affects every aspect of a teacher's working life. However, three stress sources in the teaching career will be presented in the followings, which are among the several causes that contribute to teachers' huge dilemma issues so far.

1) To which point of teaching load would you have suggestions for educational leaders to reduce the stress sources relating to teaching load within TTIs? (study 6. $\mathrm{N}=\mathbf{2 1 3}$ )

Two-thirds of the teachers suggested that TTIs should reduce the number of teaching hours a week by merging or cancelling some unnecessary subjects or courses, with attention to operation based on the educational provisions, decrees, and educational enactments or career ethics solidly ( 89 out of 213 or $41.79 \%$ ); promote sharing or exchange of teaching experience among teachers within TTIs (57 out of 213 or 26.76\%); provide enough ICT devices, Internet, and other information sources to create a multi-teaching technique (34 out of 213 or $15.97 \%$ ); do not delegate the administrative task to the teacher, promote morale and motivate among personnel continually (22 out of 213 or $10.32 \%$ ), and there were some missing comments also (11 out of 213 or $5.16 \%$ ).

2) To which point of teachers' welfare would you like educational leaders to operate and manage properly within TTIs? (Study 6. N=213)

Most of the teachers have recommended that payment to teachers must be based on legal education and teachers' decrees, attentiveness to the teachers' basic needs, and more praise than criticism (102 out of 213 or $48 \%$ ); salary, pension, and other subsidies should arrive in time and be fair (74 out of 213 or 35\%); Insurance, transportation, tuition-free for teachers' children, and teacher career development should be scheduled as priority (23 out of 213 or $11 \%$ ), and promote teachers high IQ by initiating wage analysis (14 out of 213 or $6 \%$ ).

3) What would you like educational leaders to improve and develop concerning the teacher professional development within TTIs? (study 6. $\mathrm{N}=213$ )

More than half of the teachers at TTIs stated that teacher professional development should be focused on unqualified teachers, teachers' low income, learning opportunities and skills 
in creating a lesson plan (114 out of 213 or 53.52\%); oriented skills training on foreign language competency, computer, communication, socializing skills, ICT, and other learning online and via modern technological devices (54 out of 213 or $25.35 \%$ ); promote lifelong learning and individual scientific research (33 out of 213 or 15.49\%; development of teaching profession must be based on the results of surveys and training and other academic forum or activities should be operated during the school break or summer (12 out of 213 or $5.64 \%)$.

\subsection{Chapter summary}

This chapter presented results of the developmental process of self-constructed questionnaires through study 1,2, and 3. Questionnaire form A designed for educational leaders could obtain a completed version 52 out of 63 items (three times of examinations), and questionnaire form B designed for teachers could be completed version of 18 out of 25 items of the original (two times of examinations) and both forms were high external and internal consistency.

Study 4 have found that school leaders' or principals' low perception on the teachers' welfare, followed by division of teaching load to teacher, and teacher professional development were the factors that made teachers at the practice schools in Laos develop a burnout syndrome automatically.

Study 5 have indicated that educational leaders within three Faculties of Education were of a low perception toward the advantages of the technological devices to create the teaching and learning process smartly and happily.

Study 6 or the main study on the educational leaders' perception of the six tasks revealed, that these tasks linked to three-factors that created teacher stress. The study found that most educational leaders within 8 out of 16 TTIs across Laos were of low perception on recruitment and selection of new teacher candidates, training needs assessment, pre-service training or orientation, as well as teacher compensation, whereas teacher stress has shown that teaching load, professional development, and teacher welfare were those factors that made almost all teachers face stress syndrome in their teaching profession within 8 out of 16 TTIs in Laos. 


\section{CHAPTER 5. CONCLUSIONS, DISCUSSIONS, IMPLICATIONS, SUMMARY BY SWOT ANALYSIS, AND FUTURE RESEARCH SUGGESTIONS}

\subsection{Introduction}

Studies 1, 2, and 3 were examining the validity and reliability of the self-constructed questionnaires. Study 4 dealt with the causes of teachers' burnout syndrome concerning school board management at practice school in Laos. Study 5 examined the instructional management of the teaching staff in teacher training institutions, Lao PDR. Study 6 (or main study) focused on instructional management and stress factors affecting teacher trainers as perceived by the educational leaders of Laos. This chapter presents each study finding in brief to answer the research questions, and hypotheses, there will be a summary by SWOT analysis, discussions, and I also highlight at the limitations, implications and offer recommendations.

\subsection{Conclusions}

This section offers a brief review of each study finding (study 1 to study 6) concerning the management of teachers at TTIs in Laos. The main findings are introduced below:

\subsubsection{Study 1, 2, and 3 examining the validity and reliability of the self-} constructed questionnaires

The aim of these studies was to detect and eliminate all erroneous words and phrases loaded into the questions, in both forms (A and B). These questionnaires were designed specifically, and their quality measurement was conducted through study 1,2, and 3 to meet the criteria bounded.

The main results have shown in the final stage of the measuring process that the complete version of 52 out of 63 items (form A) and 18 out of 25 items (form B) respectively can be obtained, as well as established open-ended questions were placed at the end of each task and stress factors to gather the respondents' feedback. These completed versions have it's a proven strong external and internal consistency, hence, the hypotheses $\left(\mathrm{H}_{1}-\mathrm{H}_{3}\right)$ were confirmed, and prepared for study 6 (main study). 


\subsubsection{Study 4 Causes of teachers' burnout syndrome concerning school board}

management at practice schools in Laos.

This study aimed to explore the main causes of teachers' burnout syndrome affected by school board management at practice schools in Laos. The major findings specified the main causes of teachers' burnout syndrome in these schools such as compensation, professional development and teaching load respectively. These findings proved the school principals' or leaders' low perception level in managing and maintaining teachers, that they had a vital role in driving the schools towards success, but they do not get full support from the organization.

Besides, the majority of teachers' voice expressed in the open-ended questions indicated shed and frustration on the ambiguities concerning the division of work individually, offering more criticism than praise, bullying, and other leaders' misbehaviors. Also, the hypothesis analyzed was significantly different according to genders as male teachers had higher stress than female teachers in their teaching profession, and the other tests were not significant, therefore the hypothesis $\left(\mathrm{H}_{4}\right)$ was confirmed. These findings seemed to motivate for a further investigation in study 5 .

\subsubsection{Study 5 Instructional management of teaching staff in teacher training}

\section{institutions, Lao PDR}

Instructional management is one in several tasks under the scope of the academic issues, and it also was one among eight issues or affairs of educational leaders in Laos that have to be taken into account and operation in routine manner.

However, study 5 have found that the process of instruction via technological devices was a high problem when teachers applied it in creating a lesson plan or planning a presentation and assisting in the assessment and evaluation of students. Besides, teachers of different genders did not have statistically significantly different opinions while according to teaching experience they did: teachers who have taught less than 10 years encountered problems in creating a lesson plan in their instructional practice, and performing instructional assessment, and therefore, our hypothesis $\left(\mathrm{H}_{5}\right)$ was confirmed and proved that most teachers have gaps of skills in their teaching profession within the three Faculties of Education at the Public Universities in Lao PDR. 


\subsubsection{Study 6 (Main study). Instructional management and stress factors}

affecting teacher trainers as perceived by the educational leaders of Laos.

The working cultures of educational leaders in Laos must be perceived and performed following the principles of management like the 6 factors to success (6Ms), 7 functions (POSDCoRB), and 8 responsibilities (PARMSCOF) to ensure the optimal utilization of organizational resources, like teachers in particular.

The main findings pointed out that recruitment and selection, training needs assessment, and pre-service training, compensation, teacher demand analysis, and performance appraisal were the tasks ranked as having a low perception among educational leaders and these became the main causes of stress factors among teachers such as hard teaching loads, inefficacy in teacher professional development, and lack of social welfare and other incentives at TTIs-Laos.

Besides, the hypothesis test has found no significant differences in the perception of the six tasks by gender, qualifications level, working experiences, and workplace (FOE and TTC) whereas educational leaders who have worked less than 10 years had low perception about teacher compensation. A strong correlation between subscales (tasks) and leaders' attitude test through two-short stories were revealed on decision-making skills, therefore our hypotheses $\left(\mathrm{H}_{6}-\mathrm{H}_{8}\right)$ was confirmed.

In addition, there were significant differences in the stress sources among teachers at TTIs by qualification levels, TTIs locations, and teaching experiences records, while teachers of different genders did not have different stress sources in their teaching profession, and this test also found a strong correlation between subscales (three stress sources), hence our hypotheses $\left(\mathrm{H}_{9}-\mathrm{H}_{11}\right)$ were confirmed, and the above findings proved the low perception of leaders of the six tasks related to management of teachers at TTIs to which they should improve their capacity about the analysis of teacher demands and recruitment and selection of teacher candidates.

\subsection{Discussions}

The following discussions and recommendations were based consequently on the above presented findings that needed to be confirmed by the previous studies, theories, concepts and legal educations which are presented below: 


\subsubsection{Study 1,2 and 3}

These studies were concerned with the developmental process of a research instrument (questionnaire). It was noted that field-words and phrases loaded into the questions should avoid ambiguous, complex and double-barrier questions, bias terminologies, and these would be replaced by easy or understandable words, local perspectives, and perceptions as well as with those related to the field or area of the major research study (e.g. Oppenheim, 1992; Warwick and Lininger, 1975; Krosnick, 1999; Sisaad, 2002; Likitwattan, 2012; Tourangeau and Yan (2007).

In addition, several expert-committees in the field of instrument design have a consensus on its essential components like factor of ethics and etiquette of the researchers, measurement experts, scale, criteria, and methods, relevant reading materials, knowledgeable language, time allowance and financial sources. These essential components must be perceived by the instrument developers (e.g. Likert, 1932; Thurstone, 1928; Krosnick et. al. 1999; Johnson and Christensen, 2012). In my point of view, the selfconstructed research instruments can give a freedom on the structure design corresponding to the local respondents' perspectives and perception, and freedom in loading the most familiar words and phrases in the questions that enables us to elicit the factual information from the target participants accurately and reliably.

\subsubsection{Study 4}

This study observed the causes of teachers' burnout syndrome concerning school board management at practice schools in Laos. The results indicated that teachers in these practice schools lack welfare or benefits, have a hard teaching load, unfairness, and bullying, and absent motivations and these findings proved that a strong correlation between aspects was congruent to the previous researched and theories listed in the bracket (e.g. Blazer, 2010; Whitehead, 2001; Day et. al. 2017; Landrum et. al. 2012; Toth and Hodi, 2014).

Moreover, absent administrative support, and frustration among people within organizations became more threats. Several scholars (e.g. Bakker et. al. 2014; Christie, 2010; Moczydłowska, 2016; Nwikina \& Nwanekezi, 2010; Pines \& Keinan, 2005; Roloff \& Brown, 2011; Govardhan et. al. 2012; Herioux, 2012; Kim, 2008; Küçükoğlu, 2014; Landrum et. al. 2012; Martin, et.al. 2012; Sichambo. et. al. 2012; Taheri et. al. 2012; Yan \& Xin, 2007; Csapó and Funke, 2017) stated that the laborer and social welfare are both factors 
that never separate from each other, and it was a responsibility of the school's principals in operation to have such a problem-solving approach based on principles of school management.

Thus, it is recommended that the success of companies or firms should be based on the quality of employees and managers should pay attention to and maintain subordinates in a proper policy and inspire laborers continually, and those schools' principals should handle or tackle the problem in the same situation.

\subsubsection{Study 5}

This study related to the problems faced in the instructional management of the teaching staff in teacher training institutions, Lao PDR. In the generalized results, it would be identified that educational leaders within these faculties of education lack instructional leadership skills to foster and reinforce their teachers to use multi-technological devices to assist in creating a lesson plan or planning a presentation, and instructional assessment for smarter and more interesting teaching practices in the classroom, because teaching culture often changes based on the vibrating technological development. A strong positive correlation between subscales or facets were found from this study.

These above findings were coherent with several previous studies (e.g. Phisane 2014; Tosti and Harmon, 1972; Mayer, 2008; Kohn, 1993; Manivong, 2012; Sisomphou, 2007; Khomswane,1993; Unkeo, 1997; Chankhana, 1993; Nongtoum, 2005; Phiengphanyoukorn, 1991, and Decree, No.1728/MOES/2015-Laos). They have viewed that the majority of changes in the culture of teaching and the learning quality today does not depend on content knowledge of pedagogy and soft-skills, but the learning environment and other classroom technological devices should be prioritized and supported by educational leaders to foster and guide teachers in using new teaching tools smartly.

In my opinions, it should be emphasized that good quality instruction is a required part of leaders' tasks in providing enough teaching tools and other teaching aids installed, together with organizing the soft-skills trainings sufficiently and continually, as well as following a clear policy in order to promote teachers' teaching growth. 


\subsubsection{Study 6 (Main study)}

As it was earlier presented, the scope of study 6 covers two major contexts (educational leaders' perception of the six tasks and three stress factors among teachers), where both contexts were connected and interacted mutually. The main findings have indicated that educational leaders within 8 TTIs still have a low perception on their accountabilities that is underlined by their being unclear concerning the division of work or the analysis of teacher position requirements, which led to the mismanagement of recruitment and selection process, pre-service training, and other incentives and compensation supply. These results have found a strong positive correlation between both contexts and individual aspects or subscales, which is congruent with the several theories, education enactments, conceptualization and previous research studies (e.g. Champathong, 2015; Nyasha et.al. 2013; Mavis, 2014; Abdou, 2012; Akala, 2014; Hudson; 2009 and 2011; Decree. No. 2943/MOES/PO/2016-Laos; OBEC, 2010; TRM, 2010; Kubdee, 2012; Tomovic, 2012; Elliott, 2015; Ford, 2012; Campos, 2009; Harris, 2007; Act CCIV of 2011 on Hungarian National Higher Education; CCIV, 2011 on Public Education of Hungary; Decree, No. 177/GOL/2012-Laos, and Ferreira \& Abbad, 2012; Cullen. et. al., 2014). The listed scholars confirmed that understanding teachers' potential and characteristics were difficult and it is also the main duty of leaders' or managers' in operation to promote the production of institutions. Therefore, a good educational leadership and instructional leadership is the main determinant in driving quality education.

The stress factors among teachers proved to be connected between two contexts, based on the mean score analyzed; when leaders' low perception of the six tasks occurred it meant that teachers faced massive pressure because teachers could not receive what they needed. These mismanagement phenomena were confirmed and also coherent with previous research studies presented in the bracket (e.g. Nwanekezi, 2010; Christie, 2010; Sichambo et. al, 2012; Phongphanit, 2017; Yotanyamaneewong, 2012; Kıranl1, 2013; Akkermans et. al., 2015; Mizell, 2010; Moczydłowska, 2016; Barabanshchikova, et. al., 2014, and Decree, No. 177/GOL, 2012-Laos), who mainly mentioned that stress factor sources of the teaching profession were frequently concerned with the leaders' mismanagement due to the lack of ownership and activeness toward the functioning and responsibilities assigned by the institutions. 
Based on the results, a strong correlation between two contexts was found and it confirmed the factual information that if leaders or managers neglect or ignore the teachers it can bring them stress immediately in their teaching profession. This result is underlined by several previous studies mentioned in the bracket (e.g. Moczydłowska, 2016; Sirikul, 2003; Kiranl1, 2013; Chalearnswat, 2010, and Mutuwong, 2010; Kiranl1, 2013; Kim and Stoner, 2008; Phongphanit, 2017 and 2018; Kıranlı, 2013; Akala, 2014; Moczydłowska, 2016).

In addition, educational leaders' suggestions have revealed that they accepted the current potential-capacity in managing and maintaining teachers and they wished to participate in all soft-orientations and they have seen lifelong learning as the best way to enrich work efficiency. These proposals were coherent with those mentioned in the brackets (e.g. Sergiovanni, 2009; Prempridy, 2000; Bodor, 2011; Levine, 2005; Cuban, 1988; Darling et.al., 2007; Fullan, 2001; Mazzeo, 2003 and Muffs, 1999; Farkas, 2013; 2015).

Whereas teachers' suggestions emphasized morality and motivation, fairness, equality in training, and that other welfare and compensation should be prioritized tasks and supported by TTIs continually. These teachers' voices were congruent to several scholars as stated in the brackets (e.g. Decree, No. 177/GOL/2012-Laos; Cuban, 2004; Johnson, 1990; Honawar, 2007; Banks, 2006; Monk, 1994; Fenstermacher, 2005; Bolman, 2000, Wayne and Miskel, 2005; Law of Lao's civil servant, No (023/NA/2016-Laos) who have viewed that it is well understood and accepted that without good educational leaders or managers we cannot have good teachers, and they (teachers) were asserted as a backbone to the socioeconomic growth and automatically became the central builders or home of all professions.

In my opinion, the TTIs should have a clear position and division of work for educational leaders to make them (leaders) analyze and define teachers' positions or teacher demand analysis. If job description has a clear policy on teachers, it will help in the other tasks of the teacher personnel issues, such as recruitment and selection with the right qualified teacher, a training matching the right trainees' skill requirements, assisting to draft the tool for performance appraisal activity, and it helps institutions in managing the compensation with the right-outstanding teachers. 


\subsection{Implications}

These findings have given immense factual information about the gaps or lacunae skills among educational leaders/principals to which both organizations (TTIs and MOES) must work closely with in drafting a proper policy for improving the absent skills. Especially, description of the position of teachers in details, interview the teacher candidates and making a survey study technique, compensation management as well as morality and motivations.

These studies have attempted to examine insights into the stress factors among teachers and that found that the main cause or root of stress is related to the educational leaders' or managers' efficacy and effectiveness as well as to leaders' potential capacity in managing and maintaining teachers were needed to be solved immediately to avoid pressure among teachers.

Besides, I can utilize these results to make my teaching profession better, because the six tasks were one among those themes or contents in the course Human Resource Management in the education sector that I was appointed to teach for the Bachelor and Master program in Laos.

\subsection{Summary by SWOT analysis}

The overall goals of these studies were to examine the management efficacy of educational leaders/principals through their perception level in functioning and responsibilities, to answer all the research questions, and to elicit the factual or valid information from the different attitudes of the sample members that inspired me to create self-made questionnaires to be piloted through three sub-studies in order to fit the local situation. I summarize all the findings by SWOT analysis as follows.

\subsubsection{Strengths}

- Study 1,2, and 3 can obtain a rare information concerning the developmental process of research instruments such as the scope of research structure and the draft of instrument, as well as people involved must be connected to each other. These lessons learnt make us recognize and perceive accurately the practices on the principles of instrument construction like in case of the currently developed questionnaires. Both forms were obtained in a completed version with a high external and internal consistency. 
- Study 4, 5, and 6 concerned with the management of teachers within TTIs in Laos, focusing on educational leaders'/principals' perception of the personnel issues or affairs including low awareness of teachers' social welfare, instruction via technological devices, teacher demands analysis, selection of new teachers, communication, collaboration, and making a survey of skill needs of teachers.

\subsubsection{Weaknesses}

- Study 1,2, and 3 made me spend a lot of time for measuring or examining to reach the standardization criteria. The relevant publications to supports the measurement process are difficult to find. There were low response rates in case of the open-ended questions, high expenses, some respondents skipped questions, collect data by paper and pencil mainly in Laos.

- Study 4, 5, and 6 have shown a lot of shortcomings of educational leaders/principals like lack of instructional leadership traits and charismatic leadership. Evident were in many tasks the low perception of teachers' welfare and teaching career development (study 4), instructional technology devices and creating a lesson plan or planning a presentation (study 5), teacher demand analysis, training needs assessment, pre-service training, and selection of teacher candidates (study 6).

\subsubsection{Opportunities}

- Study 1, 2, and 3 can apply the valid information associated to the self-constructed instrument in the future in what we should prepare in advance for both specific experts and other relevant supports including time and economic factors.

- According to study 4, 5, and 6 findings the Demonstration or Practice Schools, TTIs and MOES in Laos can benefit from a factual information as there is a rare support in policy re-making, planning for training and activities related to the improvement and development of teachers in these TTIs.

\section{5..5. 4 Troubles/Threats}

- In case of study 1,2 , and 3 , it was difficult to look for specific experts to check the appropriate words and phrases loaded in the questions and for relevant academic staff members to assess the understandable words. It was hard to fulfil the measurement 
standardization in a short span across the multi-examination in case of each technique applied having an own unique process, and other resource allowances will be faced unavoidably.

- In case of study 4, 5, and 6 it was quite difficult to propagate and cultivate the educational leaders/principals in changing their working attitudes into a positive way or inactive into active leaders on their responsibilities. Especially physical needs, prestige and job- advancement of teachers.

\subsection{Future research suggestions}

Based on the results of the above studies, we should conceptualize a large-scale study on educational leadership traits, instructional, transformational and charismatic leadership in the educational context, in order to monitor which factor influences the lack of professional ethics and low perception level amongst educational leaders/principals, concerning teacher demand analysis, training needs assessment, recruitment and selection, and compensation management, time management and decision-making skills as well as enlarge the scope of study and sample size should be a prioritized design in accordance with the problem situation. 


\section{REFERENCES}

Abdou, A.A and Zaalouk, M. (2012). Teachers' Recruitment and Selection Practices within DifferentSchooling Systems in Egypt (Master thesis) 74-78.

Achinsamacharn, S. (2012). Planning a lesson plan, K\&P books, Sound Inchon, Faculty of Education, Rajchaphat leoi, Thailand. [Thesis,142-148].

Act CCIV of (2011). On Higher Education. Part 3, chapter VII article 13; Article 20. Hungary, 10-17.

Act CCIV of (2011). on National Public Education. Section 4 and 70, Hungary. 3-46.

Afful-Broni, A; \& Duodu, E.A. (2013). Effective Leadership through Efficient Utilization of Educational Facilities: A Ghanaian Case Study. 4 (24), 42.

Aina, L.O. (2004). Library and Information Science Text for Africa. Ibadan: Third worldServices Limited. 103-104.

Akala. J. M (2014). Effects of Teacher Recruitment and Utilization Policy on Quality of Secondary School Education in Kenya. IOSR Journal of Research \& Method in Education (IOSR-JRME) 4(1;3), 13-15.

Akkermans, J; Brenninkmeijer, V; Schaufeli, W, B; Blonk,R.W.B (2015) It's all about teacher skills effectiveness of a teacher development intervention for young employees, Human Resource Management, 54(4), 532-543.

Ali, A. (2013). Significance of human resource management in organizations: linking global practices with local perspective Journal of Arts, Science \& Commerce 4 (1), $1-2$.

Alison,G (1998). Verbal Protocol Analysis in Language examination Research: a handbook. Studies in Language Examination, 5. Cambridge: Cambridge University Press. [Abstract].

Almeida, S.T; Resende, T.L, \& Stobaus, C.D. (2015). Validity, Reliability and Convergent Analysis of Brazilian Version of Selection, Optimization and Compensation Questionnaire (QSOC). 7(15), [Abstract].

Alwin, D.F; \& Krosnick, J.A. (1982). The measurement of Values in Surveys: A Comparison of Ratings and Rankings. The Public Opinion Quarterly. 49(4), 524527.

Amadi, E.C. (2008). Introduction to Educational Administration: A module. 32-35.

Anderson, V. (2004). Research Methods in Human Resource Management. Proceedings. 115.

Annual movement reported of the progress, (2016-2017). Teacher Training Institutions TTIs, Ministry of Education and Sports. Lao People's Democratic Republic. 12.

Annual movement reported of the progress (2016-2017). Department of teacher Education, Ministry of Education and Sports, Lanexang Avenue, Vientiane capital, Lao PDR. 2-4

Annual movement report (2016-2017). Department of Higher education, Ministry of Education and Sports, Lanexang Avenue, Vientiane capital, Lao PDR. 2-3 
Arhipova, O; Kokina, I; Rauckiene, A \& Michaelsson. (2018). School Principal's Management Competences for Successful School Development. 78(1), [Abstract]. .

Arif, A., Naveed, S., \& Aslam, R. (2017). Factors causing stress among Pakistani working women. Pakistan Administrative Review, 1(3), 159-174.

Arora, S., Russ, S., Petrides, K., Sirimanna, P., Aggarwal, R., Darzi, A., \& Sevdalis, N. (2011). Emotional intelligence and stress in medical students performing surgical tasks. Academic Medicine, 86(10), 1313-1315.

Ayuk, E.E (2012).The Demand and Supply of Secondary School Teachers in the Western Cape, Cape Peninsula University of Technology, [Abstract and discussion].

Bai, N. (2014). The relationship between school organizational climate and physical education teachers' stress factors (Case study: Ramian-Iran); [Abstract]

Bakker, A; Demerouti, E; \& Vergel, A, I. (2014). Stress factors and Work Engagement: The JD-R Approach, 400-402.

Banks, J; Cochran-Smith, M; Moll, L; Richart, A; Zeichner,K; Lepage,P; DarlingHammond, L; \& Duffy, H; (2006). Teaching diverse learners. In LDarling-Hammond \& J.Bransford (Eds.), Preparing teacher for a changing world: what teacher should learn and be able to do. 220-221.

Banks, C.M. (2000). Gender and race as factors in educational leadership. In the JosseyBass reader on educational leadership.96-98.

Barabanshchikova, V. Meshkova, P.R and Darja N. Surova, N.D. 2014). Comparison of Stress Level among School Teachers in the Period of Organizational Changes. Procedia - Social and Behavioral Sciences 146 (2014) 372-373.

Bauer, J; Stamm, A; Virnich, K; Wissing, K; Muller, U; Wirsching, M and Schaarchmidt, U. (2006). Correlation between stress factors and psychological and psychosomatic symptoms among teachers. 200-203.

Beehr, T.A; \& Adams, G.A. (1998). Turnover and retirement: A comparison of their similarities and differences. Personnel Psychology. 17-22.

Beheshtifar, M, \& Omidvar, A. (2013). Causes to Create Job Stress factors in Organizations. International Journal of Academic Research in Business and Social Sciences. 3(6, 110-112.

Berk, R.A. (1984). Conducting the Item Analysis. A guide to criterion referenced examination construction. 97-120.

Birkett, M. \& Day, S.J. (1994). Internal pilot studies for estimating sample size, Lilly Research Centre Ltd., Windlesham, Surrey, U.K. [Abstract].

Bivona, K.N. (2002). Teacher Morale: The Impact of Teaching Experience, Workplace Conditions, and Workload. ERIC Document Reproduction Service. [Abstract].

Blanch, A.P., Aluja, A.F. \& Biscarri, J.G. (2003). Stress factors and coping strategies: a structural relat ions model. Psychology in Spain, 7(1), 46-55.

Blazer, C. (2010). Teacher stress factors. (1003), 12-13.

Bloom, B., Englehart, M. Furst, E., Hill, W., \& Krathwohl, D. (1956). Taxonomy of educational objectives: The classification of educational goals. Handbook I: 
Cognitive domain. New York, Toronto: Longmans, Green. Cited by Hughes, C. (2012). Passion for Beauty: A Model for Learning. 3(3), [Abstract].

Bodor, M. (2011). The Similarities and Differences of HRM in Higher Education Institutions in Hungary and England, Act Sci Soc (34), 67.

Bokdam, J \& Ende, I.V.D. (2014). Teaching Teachers: Primary Teacher Training in Europe State of Affairs and Outlook. 23-29.

Bollen, K. (2002). Latent variables in psychology and the social sciences. Annual RevPsychology. 58-96.

Bolman, L; \& Deal, T. (2000). The manager as politician. In The Jossey-Bass reader on educational leadership. San Francisco: Jossey-Bass. 124-126.

Bose. D. C, (2012) Principles of Management and Administration. Printed by Meekshi Art printers, Delhi-110006, $2^{\text {nd }}$ edition. 23-24.

Brancato, G; Macchia, S; Murgia, M; Signore, M; Simeoni, G. (2006). Handbook of Recommended Practices for Questionnaire Development and Examination in the European Statistical System. 42-44.

Bransford, J., Darling-Hammond, L., \& LePage, P. (2005). Introduction. In L. DarlingHammond \& J. Bransford (Eds.), Preparing teachers for a changing world: What teachers should learn and be able to do. San Francisco: John Wiley and Sons. pp $11-15$.

Brewster, C; Sparrow, P; Vernon, G \& Houldsworth, E. (2011). International Human Resource Management. $3^{\text {rd }}$ Edition, 14-15.

Brown, J.W; Kenneth, D.N; \& Srygley, S.K. (1972). Administering educational media: instructional technology and library services. 386-389.

Brusoni, M; Damian, R; Sauri, J,G; Jackson, S; Komurecugil, H; Malmdy, M; Matveeva, O; Motova, G; Pisarz, S; Pol, P; Rostlund, A; Soboleva, E; Tavares, O; \& Zobel, L. (2014). The concept of excellence in higher education. European Association for Quality Assurance in Higher Education AISBL. Brussels. 9-14.

Burns, J.M. (1978). Leadership. New York: Harper \& Row. 18-24.

Burns, J.M. (2013, January 2). Teacher morale 'dangerously low' suggests survey [Web log post].

Bush, T. (2005). Leadership and Management development, SAGE Publications Ltd.1 Oliver's Yard 55 City Road London EC1Y 1SP. 1-32.

Bush, T and Chew, J. (1999). Developing human capital: training and mentoring for principals, Compare, 29 (1) 41-52

Bush, T and Chew, J. (1995). Theories of Educational Management, $2^{\text {nd }}$ Edition. SAGE Publications. 1-3.

Campos, R; Pina, M \& Rego, A. (2009). Exploring the Role of Leader-Subordinate Interactions in the Construction of Organizational Positivity. [Abstract]

Cannon, R., Arlianti, R., and Riu, I. (2014). Dissemination and Sustainability of DBE and USAID PRIORITAS Programs. USAID Indonesia. Jakarta. 
Cannon, F.W. (1992). Performance Management: A New Perspective", Executive Development, 5(4) 23-28.

CEART-UNESCO (2015) Final report Twelfth Session Joint ILO -UNESCO Committee of Experts on the Application of the Recommendations concerning Teaching Personnel. 1-5.

Center on Education and Policy. (2005). NCLB: what schools district are doing to improve teacher qualify in high-need schools. CEP policy.

Chalearnswat, P. (2010). A problem in personnel administration in the office of the Mahasarakarm University, The Kingdom of Thailand [Thesis-Abstract].

Champathong, P. (2015). Surplus and Minus teacher education, Ministry of Education and Sports, Lanexang Avenue, Vientiane capital, Laos. [Abstract].

Champathong, P \& Soukanya, K. (2008). Handbook for training of education administration, scientific research center, Ministry of Education and Sports, Lanexang Avenue, Vientiane capital, Laos. 1-15.

Chand, S. (2015) Staffing: It's Meaning, Nature and Importance Business Management

Chankhana, J. (1993). Studied on the situation and problem in teaching and learning of demography environment course, Thailand. [Thesis-Abstract],

Channam, V. (1997). Study of situation and problem on the implementation of primary school's curriculum, Teacher training institutes, Lei province, Thailand. [Abstract]

Chanthala, K; Phommanimit, K and-UNESCO (2004). Glossary of Education terms, Department of Organization and Personnel, Ministry of Education and Sport, Vientiane, Lanexnag Avenue, Laos. $1^{\text {st }}$ edition. 2-71.

Charles, M., \& Grusky, D. B. (1995). Models for describing the underlying structure of gender segregation. American Journal of Sociology, 100(4), 942-946.

Chien Hsu, C \& Sandford, B.A. (2007). The Delphi Technique: Making Sense of Consensus. Practical Assessment Research \& Evaluation. 12(10), 4-5.

Chongsirikul, P. (2003). Personnel Schools Management in Private Schools, Aumphur Muang, KhonKaen Province, Thailand. [Abstract].

Christie, B. (2010). Teacher stress factors. Information Capsule. ERIC,1003. [Abstract].

Cockburn, A. (2000). Selecting a project's methodology. 65-68.

Comb, A.W (1964). The Professional Education of Teachers: A Perceptual View of Teacher Preparation. Boston: Allyn and Bacon. 91-93.

Condrey, S.E. (2010). The Human Capital Phenomenon: Putting People First. Public Administration Review. 1-2.

Connolly, M; James, C, \& Fertig, M. (2017). The difference between educational management and educational leadership and the importance of educational responsibility. Educational Management and Leadership. 1(16), 3-7.

Connelly, L.M. (2008). Pilot studies. Measure Nursing, 17(6), 411-412.

Conley, S., \& Bacharach, S. (1990). From site management to a participatory school site management. Phi Delta Kappan, 17(7), 539-544. 
Cooper, J.M and Alvarado, A. (2006). Preparation, recruitment, and retention of teachers, The International Institute for Educational Planning (IIEP). 4-9.

Crawford, A; Weber, C; Lee, J; Dennison, D. (2013). An Exploratory Analysis of Soft Skill Competencies Needed for the Hospitality Industry. 327-329.

Crocker, L. M., \& Algina, J. (1986). Introduction to classical and modern examination theory. New-York: Holt, Rinehart and Winston.

Cronbach, L. J. (1951). Coefficient alpha and the internal structure of examinations. Psychometrical16(3), 331-332.

Csapó, Benő and Joachim Funke (2017). The development and assessment of problem solving in 21st-century schools, in Benö Csapó and Joachim Funke (eds.), The Nature of Problem Solving: Using Research to Inspire 21st Century Learning, OECD Publishing, Paris. 22-23.

Cuban, L; (2004). the blackboard and the bottom line: why school can't be business. Cambridge, MA: Harvard University Press. 126-130.

Cuban, L; (1988). The managerial imperative and the practice of leadership I, schools. Albany: SUNY Press. 181-183.

Culbertson, J.A. (1988). A century's quest for a knowledge base, chapter 1. In N. J. Boyan (Ed.), Handbook of research on educational administration, 10-17.

Cunningham, G (2009). Lesson Plans and Unit Plans: The Basis for Instruction, 3-7.

Cullen, K., Willburn, P., Chrobot-Mason, D., \& Palus, C. (2014). Networks: How collective leadership really works. Greensboro, NC: Center for Creative Leadership. 13-16.

Cuthbert, R. (1984). The management process, E324 management in Post Compulsory Education, Block 3, Part 2, Open University Press,

Deem, R. (2002). Globalization, New Managerialism, Academic capitalism and Entrepreneurialism in Universities: Is the Local Dimension Still Important? Comparative Education, 37(1), 14-16.

Daft, R.L. (2010). Management. $9^{\text {th }}$ edition, Vanderbilt University. 43-51.

Daniel, C.J \& Gupta, M. (2009). Overvaluation and Earnings Management. Journal of Banking and Finance, 33(9), 23-25.

Darling-Hammond, L; LPointe, M; Meyerson, D; \& Orr, M. (2007). Preparing school leaders for a changing world. Palo Alto, CA: Stanford Educational Leadership Institute. 13-14.

Day, A; Crown, S.N; \& Ivany, M. (2017). Organizational change and employee stress factors: The moderating effects of support and job control, ELSEVIER, 8-9.

Day, R.R., \& Conklin, G. (1992). The knowledge base in ESL/EFL teacher education. Paper presented at the TESOL Conference, Vancouver, Canada. 23-24.

Day, R.R. (2014). Pre-service teachers' perceptions on the contribution of EFL teacher education programme to their teaching skills. 4-5.

Day, C \& Sammons, P. (2013). Successful leadership: A reviews of the International literature. 9-21. 
Decree, No. (204/MOES/PO/2017). Teacher Performance Appraisal. The Ministry of Education and Sports, Vientiane capital, Lao PDR. (Issued, February 13, 2017).

Decree, No. (1232/MOES/2010). On teacher's normalization. The Ministry of Education and Sports, Vientiane capital, Lao PDR. (Issued, December 10, 2010).

Decree, No. (177/GOL/2012). Lao teacher civil servant. Vientiane capital, Laos. 2-9. (Issued April 5, 2012).

Decree, No. (4924/MOES/2016). Handbook on Forecasting and annual building plan of teacher (amended issued) Department of Personnel and Organization, The Ministry of Education and Sports, Lineage Avenue, Vientiane capital, Laos. 7-15. (Issued September 16, 2016).

Decree, No. (282/PM/2011). On the Movement of the Ministry of Education and Sports. Vientiane capital, Lao PDR. (Issued August 7, 2011).

Decree, No. (0047/MOES/PO/2014). On recruitment and selection, teacher education. The Ministry of Education and Sports, Vientiane capital, Lao PDR. (Issued May 25, 2016)

Decree, No.1728/MOES/2015). On Lao teacher's ethics and etiquette in teaching career. The Ministry of Education and Sports, Vientiane capital, Lao PDR. (Issued, June 12, 2015)

Decree, No. (82/PM/2003). Lao Government on Civil Servant, Rules and Regulation, Vientiane capital, Laos. 7-12. (Issued, January 14, 2003).

Delbecq, A.L., Van de Ven, A.H. and Gustafson, D.H. (1975) Group Techniques for Program Planning: A Guide to Nominal Group and Delphi Processes. Scott, Foresman Glenview.

Deem, R. (2002). Globalization, New Managerialism, Academic capitalism and Entrepreneurialism in Universities: Is the Local Dimension Still Important. Comparative Education, 37(1), 14-16.

Doornenbal, E. Stitselaar, W. and Jansen, L. (2012). Recruitment and selection. Christian University of Applied Sciences. 3-20.

Drucker P, F. (2013) Staffing for Performance: Systematically Matching People's Strengths with Opportunities, 34-41.

Drucker, P.F. (1988). Management and world's work. Harvard Business Review (66), 3.

Drucker, P.F. (1995). The information executive truly needs. Harvard Business Review. 73(1),56-59.

Duret, G.G, \& Tournier, B. (2009). Crucial Management Aspects of equitable teacher provision. UNESCO's Global Monitoring report. 6-8.

Dworkin, A.G. (2001). Perspectives on Teacher Stress factors and School Reform, International Education Journal 2(2), 76-77.

Dworkin, A.G. (1987). Teacher Stress factors in the Public Schools: Structural Causes and Consequences for Children. Albany, NY: State University of New York Press.

ECDC or European Centre for Disease Prevention and Control. (2017). Immunization information systems in the EU and EEA - Results of a survey on implementation and system characteristics. Stockholm: 
EIU/SHRM. (2013). Managing Human Resource in a changing world: Challenges for human resource management and global business strategy. 1-6.

Ellen A. Drost, (2011). Validity and Reliability in Social Science Research, Education Research and Perspectives. 38(1), 120-123.

Elliott, K. (2015). Teacher Performance Appraisal: More about Performance or Development. Australian Journal of Teacher Education,40(9), 104-108.

Engle, A. D., Sr., Dowling, P. J., \& Festing, M. (2008). State of origin: Research in Global performance management, a proposed research domain, and emerging implications. European Journal of International Management, (2), 151-149.

Espnes, G.A; Innstrand, S.T; \& Mykletun, R. (2002). Stress factors among people working with intellectually disabled persons: a theory update and an example, 16(3) [Abstract].

Eunice, L.A; Nyangia, E, O; Orodho, J.A. (2014). Challenges Facing Implementation of Inclusive Education in Public Secondary Schools in Rongo Sub-County, Migori County, Kenya. Journal of Humanities and Social Science. (20(4), 46-48.

European Commission (2008). Entrepreneurship in higher education, especially within non-business studies: Final Report of the Expert Group. 23-32.

Fairholm, G.W. (2001). Mastering Inner Leadership. West Port, CT: Quorum Books

Farber, B. A. (2000). Treatment strategies for different types of teacher stress factors. Journal of Clinical Psychology, 56(5),673-680.

Farkas, É. (2015). Financing the adult education system in Hungary, in Balázs Németh (Eds), Research and Development in Adult Learning and Education in Hungary. 4849.

Farkas, É. (2013). The practice of adult education and vocational training in Hungary, Szeged University. 7-12.

Fenstermacher, G.D., \& Richardson, V. (2005). On making determinations of quality in teaching. Teachers College Record, 107 (1), 210-212.

Ferreira, R.R \& Abbad, G. (2012). Training Needs Assessment: Where We Are and Where We Should Go, 10 (1),55-85.

Ferriero, D. S; \& Powers, K, A. (1982). Stress factors at the Reference Desk, 21(3), 274275.

Firdousi, F. (2011). Significance of determining assessment needs and training in the service sector. International Journal of Business and Social Science, 2(17), 114116.

Fisher, D., \& Frey, N. (2011). Asking questions that prompt discussion. Principal Leadership, 12(3), 55-61.

Fitzpatrick, S; Kemp, P, \& Klinker, S. (2000). Single homelessness: An overview of research in Britain. 30-35.

Flippo, E.B. (1984). Personnel Management. (6 $6^{\text {th }}$ edition). McGraw Hill. Book. 604-607.

Foley, L.M. (2013). Digital Storytelling in Primary Grade Classrooms. [Thesis]. 229-230. 
Ford, M. (2012). A Modern Teacher Compensation System for Wisconsin, Badger Institute, 1(25), 43-45.

Freedman, Z.R; Williams, G.C; McGregor, H.A. \& Zeldman, A. (2004). examination a Self-Determination Theory Process Model for Promoting Glycemic Control Through Diabetes Self-Management. Health Psychology. 23(1),64-66.

Friedman, I, A; \& Gavish, F. (2010). Novice teachers' experience of teaching: a dynamic (13), 161-164.

Friedman, I, A. (2003). Self-Efficacy and Stress factors in Teaching: The Importance of Interpersonal-Relations Efficacy, 6(3), [Abstract].

Freeman, N.K. (2007). Preschoolers' Perceptions of Gender Appropriate Toys and their Parents' Beliefs About Genderized Behaviors: Miscommunication, Mixed Messages, or Hidden Truths?.Early Childhood Education Journal. 35(5), 361-363.

Friedman, I.A. (1991). High- and Low-stress factors schools: school culture aspects of teacher stress factors. The Journal of Educational Research, 84(6), 325-333.

Freudenberger, H.J. (1974). Staff burn-out. Journal of social issues, 30 (1) 161- 163.

Fullan, M \& Scott, G. (2001). Education plus: New pedagogies for deep learning, a global partnership. 6-7.

Furlong, J; Barton, L; Miles, S; Whiting, C, \& Whitty, G. (2000). Teacher Education in Transition: Re-forming Professionalism? (Developing Teacher Education). [Abstract].

Gagne, R.M; Briggs, L.J; Wager.W.W.(1998). Principles of Instructional Design. 224-234.

Gay, L.R \& Airasian, P. (2005) Educational Research: Competencies for Analysis and Application, Prentice-Hall, Inc. Pearson Education, Upper Saddle River, New jersey $07458,6^{\text {th }}$ edition. 147.

Gay. L.R \& Airasian, P.W. (2003). Educational Research: Competencies for Analysis and Applications, (4 ${ }^{\text {th }}$ Edition). 138-142.

Gaynor, C. (1998). Decentralization of Education: Teachers management. World bank, 1818 H street, N.W Washington D.C. 1-9.

Geddes, L. Cleone and Kooi, Y. Baverly. (1969). An Instructional Management System for Classroom Teachers. 69(7), 67-69.

Gill, E. (2013). What is Your Teaching Style? 5 Effective Teaching Methods for Your Classroom. 4-5.

Giroux, H, A. (1983) Theory and Resistance in Education: A Pedagogy for the Opposition, 12-15.

Glatthorn, A. (1995). Teacher development. In L.W. Anderson (Ed.). International Encyclopedia of Teaching and Teacher Education. ( $2^{\text {nd }}$ Ed). London: Pergamon Press. 41-45.

Glesne, C., \& Peshkin. (1992). Becoming qualitative researchers: An introduction. White Plains, NY: Longman. 102-105. 
Gliner, J.A \& Morgan, G.A. (2000) Research methods in applied settings: an integrated approach to design and analysis. 102-118.

Globler, PA. (2002). Human Resource Management in South Africa, 24-34.

Go, F.M., Monachello, M.L., Baum, T. (1996). Human Resource Management in the Hospitality Industry. New York: John Wiley \& Sons.

Golafshani, N. (2003). Understanding Reliability and Validity in Qualitative Research.

Gold, P.W., \& Chrousos, G.P. (2002). Organization of the stress system and its dysregulation in melancholic and atypical depression: High vs low CRH/NE states. Molecular Psychiatry 7(3), 254-275

Gold, Y. (2001). Stress factors: A Major Problem for the Teaching Profession. Education, 104 (3), 271-274.

Gold, Y., Bachelor, P. and Michael, W. B. (1989). The dimensionality of a modified form of the Maslach Stress factors Inventory for university students in a teacher-training program. Educational and Psychological Measurement (49), 549-561.

Göttelmann, G, \& Yekhlef, A. (2005). Teachers management: A selected bibliography. UNESCO: International Institute for Educational Planning 7-9 rue Eugène Delacroix, 75116 Paris. 11-14.

Govardhan, L. M., Pinelli, V., \& Schnatz, P. F. (2012). Stress factors, depression and job satisfaction in obstetrics and gynecology residents. Connecticut Medicine,76(7), 389-395.

Green, A; \& OECD. (2012). Skills for competitiveness: Country report for United Kingdom/OECD. 57-59.

Green, R.A. (2014). The Delphi Technique in Educational Research, SAGE Open. 2-6.

Green, S. B., \& Yang, Y. (2009a). Commentary on coefficient alpha: A cautionary tale. Psychometrika, 74(1), 123-128.

Greenberg, P.L; Tuechler, H; Schanz, J; Sanz, G; Garcia, M, \& Sole, M. (2012). Revised International Prognostic Scoring System for Myelodysplastic Syndromes. 7-8.

Grissom, J. A. (2015). Principal time management skills: Explaining patterns in principals' time use, job stress, and perceived effectiveness. Journal of Educational Administration. 53(6), 1-3.

Grissom, J. A., \& Loeb, S. (2015). Triangulating principal effectiveness: How perspectives of parents, teachers, and assistant principals identify the central importance of managerial skills. American Educational Research Journal, 48 (5), 110-117.

Gronn, P (2010) Where to next for educational leadership? In: Bush, T, Bell, L, Middlewood, D (eds.), The Principles of Educational Leadership and Management: Second Edition. London, Sage. 3-6.

Guglielmi, R.S. \& Tatrow, K. (1998). Occupational stress, stress factors, and health h in Teachers: a methodological and theoretical analysis. Review of Educational Research, 68(1), 61-99. 
Gulick, L, \& Urwick, L. (1937). Notes on the Theory of Organizations. Papers on the Science of Administration. NewYork: Institute of Public Administration, Columbia University, 36-42.

Gupta, K., Sleezer, C. M., \& Russ-Eft, D. F. (2007). A practical guide to needs assessment ( $2^{\text {nd }}$ Edition). San Francisco, CA, US: Pfeiffer/John Wiley \& Sons. 231-238. The Qualitative Report,8 (4), 597-606.

Haberman. (2004). The rationale for preparing mature adults as teachers of diverse children in urban poverty. [Summary].

Haimann, T. (1974). Management in the organization. 543-548.

Haki Elimu, (2009). Annual Report. 34-37.

Halasz, G. (2011). School leadership and pupil learning outcomes. Does leadership matter? Hunsem, University of Szeged. 19-33.

Hardesty, D and Bearden, W. (2004). The use of expert judges in scale development: Implications for improving face validity of measures of unobservable constructs. Journal of Business Research, 57(2), 105-106.

Harris, D, C. (2007) The Promises and Pitfalls of Alternative Teacher Compensation Approaches. Wisconsin Center for Education Research, University of WisconsinMadison. 1-5.

Harrison, A. (2007). A language examination handbook. Hong Kong: Macmillan,

Harvey, L. 1995, 'Editorial', Quality in Higher Education.1(1), 6-11.

Hastings RP \& Bham MS. (2003). The relationship between student behavior patterns and teacher stress factors. School Psychology International, (24), 115-127.

Hdiggui, EI, M. (2006). Human Resource Management in the Education Sector, Division of Educational Policies and Strategies, UNESCO 7, place de Fontenoy, 75352 Paris 07 SP. 21-41.

HEALEY, D. (1993). Learner choices in self-directed second language learning. Ann Arbor, MI: UMI Dissertation Services.

Herioux, J. (2012). Teacher stress factors: A review of factors and administrative support strategies. [Thesis], 25-26.

Hill, R. (1998). WHAT SAMPLE SIZE is "ENOUGH" in INTERNET SURVEY RESEARCH?. 6(6), 3-4.

Hilton, C, E. 2015). The importance of reexamination questionnaires: a field research example of cognitive reexamination the Exercise referral Quality of Life Scale (ERQLS) Faculty of Health and Life Sciences, Department of Psychology and Behavioral Science. [Abstract].

Hlatshwayo, RC. (1996). Black parents' perception of their educational responsibility in a changing educational dispensation. Unpublished D.ed. Thesis, KwaDlangezwa: University of Zululand. [abstract].

Hoepfl, M. C. (1997). Choosing qualitative research: A primer for technology education researchers. Journal of Technology Education, 9(1), 47-63. 
Hofmeyer, A., Sheingold, B. H., Klopper, H. C., \& Warland, J. (2015). Leadership In Learning And Teaching In Higher Education: Perspectives Of Academics In NonFormal Leadership Roles. Contemporary Issues in Education Research, 8(3), 7-9.

Honawar, V.(2007). Teachers tell researchers they like their jobs, Education week.

Howard, S., \& Johnson, B. (2004). Resilient Teachers: Resisting Stress and Stress factors.

Hudson, P. (2009). How can Pre-service Teachers be measured against Advocated Professional Teaching Standards? Australian Journal of Teacher Education. 34(5), 68-69.

Hudson, P., \& Hudson, S. (2011a). Converting theory to practice: University-school collaboration on devising strategies for mentoring pedagogical knowledge. International Journal of Learning, 18(2), 312-314.

Hughes, R. L., R. C. Ginnett, (2002). Leadership - Enhancing the lessons of experience. New York, USA, McGraw-Hill.

ILO, (2012). ILO (International Labor Organization), Handbook of good human resource practices in the teaching profession. 8-9.

Ingvarson, Lawrence; Kleinhenz, Elizabeth; Beavis, Adrian; Barwick, Helena; Carthy, Imelda; and Wilkinson, Jenny. (2007). Secondary teacher workload study: report." Teacher Workforce andCareers. 8-9.

IOE, Institute of Education, University of London (2012). Pre-Service and In-Service Teacher Training Strategy Document focusing on Published Teacher Training Curricula. [Summary].

Iverson, R.D; Olekalns, M; Erwin, P.J. (1998). Affectivity, Organizational Stressors, and Absenteeism: A Causal Model of Stress factors and Its Consequences, 52(1), [Abstract].

Isaac, S., \& Michael, W. B. (1995). Handbook in research and evaluation. San Diego, CA: Educational and Industrial Examination Services. 75-79.

Jabbarifar, T. (2009). The importance of classroom assessment and evaluation in educational system. 6-7.

Jackson, S. E., Schwab, R. L., \& Schuler, R. S. (1986). Toward an understanding of the stress factors phenomenon. Journal of Applied Psychology, 71(4), 631-633.

Jacobson, D.A. (2016). Causes and Effects of teacher stress factors, [Thesis-Abstract], 109-110.

Jagodics, B; \& Szabo, E. (2014). Job demands versus Resources: Workplace factor related to teacher stress factors. Practice Theory in System of Education, 9(4), 386-387.

John, S.A; Walsh, J.L \& Weinhardt, L.S. (2017).The information-Motivation-Behavioral Skills Model Revisited: A Network-perspective Structural Equation Model within a Public Genderually Transmitted infection Clinic Sample of Hazardous Alcohol users. 21(4), 7-9.

Johnson, B \& Christensen, L. (2012). Educational Research: Quantitative, Qualitative and Mixed Approaches. SAGE publication, Inc. 2455 Teller Road, Thousand Oaks, California 91320. $4^{\text {th }}$ edition. 162-164. 
Johnson M, Brems C, Mills M, Neal D, Houlihan J. (1990). Moderating effects of control on the relationship between stress and change. Administration and Policy in Mental Health and Mental Health Services Research.33 (4) 497-501.

Joppe, M. (2000) The Research Process, The Quantitative Report Journal, 8(4), 587-599.

Julious, S.A. (2005). Sample size of 12 per group rule of thumb for a pilot study. [Abstract].

Kaliath, T.J; O'driscoll, M, P; \& Gillespie, D.F. (1998) The relationship between stress factors and organizational commitment in two samples of health professionals, JournalWork \& Stress an International Journal of Work, Health \& Organizations, 12(2), [Abstract]

Karkoulian, S.K, (2002). Performance appraisal in higher education, University of Leicester, ProQuest LLC 2013 [Thesis dissertation], p. 23-28.

Khan, A (2015). Training Needs Analysis on Leadership Skills of University Librarians in Pakistan [Summary].

Khomswane, P. (1993). Studied the situation and problem in teaching-learning of local development course in field of social pedagogy at Northern east secondary school, Thailand, [Thesis-Abstract].

Khsent, P. (2003). Staff training programme. Office of education development, Thailand. 24-32.

Kim, H., Stoner, M. (2008). Stress factors and turnover intention among social workers: effects of role stress, job autonomy, and social support. Administration in Social Work, 32(3), 1.

Kiranll, S. (2013). Teachers' and school administrators' perceptions and expectations on teacher leadership. International Journal of Instruction, 6 (1) 190-192.

Kirk,J. \& Miller, M.L.(1986). Reliability and Validity in Qualitative Research, Beverly Hills, Ca.: Sage Publications

Kline, P. (1979). Psychometrics and Psychology. London: Academic Press

Klusmann, U. K. (2008). Engagement and emotional exhaustion in teachers: Does the school context make a difference? . Applied Psychology, 148-150.

Knorr, R. (2012). Pre-Service Teacher Cohorts: Characteristics and Issues: A Review of the Literature. 39-42.

Kohn, A (1993). Choices for Children: Why and How to Let Students Decide. 13-15.

Koontz, H., O’Donnell, C. \& Weihrich, H. (1982). Essentials of management. New York: McGraw-Hill. ( $3^{\text {rd }}$ edition). 63-64.

Krosnick, J.A (1999). Maximizing Questionnaire Quality (Ed.) John P. Robinson, (Ed) Measures of Political Attitudes. (Pp 37) San Francisco, Jossey Bass.

Krosnick, J.A, Narayan, S.S, \& Smith, W.R. (1999). Satisfying in survey: Initial evidence. In M. T. Braverman \& J.K Slater. (Ed) advance in survey research, San Francisco, Jossey Bass.

Küçükoğlu, H. (2014). Ways to Cope with Teacher Stress factors in ELT Classrooms, 116(21), 7-8. 
Kubdree, S. (2012). The motivation of the educational administrators at the office of education, Choonbury Province. [Abstract].

Kyriacou, C. (2001). Teacher stress: Directions for future research. Educational Review, 28-35.

Labesse, M.E. (2008). Terms of reference for training needs analysis, Continuing education component, 15-19.

Landrum, B.M.S; Knight, D.K; Flynn, P.M. (2012). The impact of organizational stress and stress factors on client engagement. Journal of Substance Abuse treatment. 42(2) [Abstract].

Lao SABER. (2016). Lao School Autonomy and Accountability: Country report. 2-5.

Lao education law. (2016). The Ministry of Education and Sports, Vientiane capital, Lao PDR.(Issued August 28, 2016).

Law of Lao's civil servant, No (023/NA/2016). National Assembly of Laos. (Issued, January 28, 2016).

Lazaurs, R.S. \& Folkman, S. (1984). Stress, Appraisal, and Coping. New York: Springer Publishing.

Levine, A. (2005). Educating School Leaders. Washington, DC: The Education School Project. 48-49.

Levy. A; Nasser, F and Alhija, A. (2015). Modelling beginning teachers' assessment literacy: the contribution of training, self-efficacy, and conceptions of assessment, 21(5-6) 396-397.

Lewis, R. B., \& Doorlag, D. H. (1998). Teaching special students in general education classrooms $\left(7^{\text {th }}\right.$ Ed), New Jersey: Simon \& Schuster (5), 1-3.

Likert, W. J. (1970). Research in education. Englewood Cliffs, New Jersey: PrenticeHall. ( $\left.2^{\text {nd }} E d\right)$.

Likitwattana, P. (2012). Educational Research, Printed: Faculty of industrial Pedagogy, King Mongkut's Institute of Technology Ladkrabang, Srongkrung road, Lat krabang, Bangkok, Thailand, $5^{\text {th }}$ edition. 86-89.

Lingam, I; \& Govinda. (2004). Teacher preparation for the world of work: A study prepare service primary teacher education in Fiji. [Abstract].

Linstone, H. A., Turoff, M. \& Helmer, O. (2002). General applications: Policy Delphi. In H. A. Linstone \& M. Turoff (Eds.), The Delphi method: Techniques and applications. 311-329.

Loewenthal, K. M. (2004). An introduction to psychological examinations and scales (2 ed.). Hove, UK: Psychology Press.

Louis, K.S. (2015). Linking leadership to learning. Department of Organizational Leadership, Policy, and Development, University of Minnesota, Minneapolis. 9-11.

Loyal, M.C (2016). The Importance of Validity and Reliability. 1-2.

Lupricharseth, K. (2012). The problem of Human Resource in the Rector's office, Mahasarakarm University, Thailand. [Abstract]. 
Manandhar, S. (2015). Impact of welfare facilities on the performance of employees in NGOs in Nairobi: A case of Kenya Red Cross Nairobi Branch, [V-VI].

Manivong, K. (2012). Academic affair development of teacher at secondary school, Thaluang, Vientiane capital education service, Mahasarakharm University Thailand, [Thesis-Abstract].

Martin, N. K., Sass, D.A., \& Schmitt, T. A. (2012). Teacher efficacy in student engagement, instructional management, student stressors, and stress factors: A theoretical model using in class variables to predict teachers' intent-to-leave. Teacher and Teacher Education, (28), 543-546.

Maslach, C., Schaufeli, W. B., \& Leiter, M. P. (2001). Job stress factors. Annual Review of Psychology, 52, 401-405.

Maslach, C; \& Leiter, M.P (1988). The impact of interpersonal environment on stress factors and organizational commitment, 9(4), [Abstract].

Mathis, R.L., Jackson; \& Jackson, J.H. (2004). Human Resource Management. $11^{\text {th }}$ edition. South Western College. 194-195.

Mavis, S. (2014). Principal Leadership for School, Family, and Community Partnerships: The Role of a Systems Approach to Reform Implementation, 120(2), 247-251.

Maxwell, G., Watson, S. and Quail, S. 2004. Quality Service in the International hotel Sector: a catalyst for strategic human resource development. Journal of European Industrial Training, 28 (2); 159-182.

Mayer, E.R. (2008). Learning and Instruction, Pearson Education, Inc., Upper Saddle River, New jersey 07458. ( $2^{\text {nd }}$ edition).

Mazzeo, C; (2003). Improving teaching and learning by improving school leadership. Washington, DC: National Governors' Association Center for Best Practices, Issue Brief.

Mergler, A.G. (2012) what pre-service teachers need to know to be effective at valuesbased education: Australian Journal of Teacher Education. 78-79.

Mette, I.M., Nieuwenhuizen, L., \& Hvidston, D.J. (2016). Teachers' perceptions of culturally responsive pedagogy and the impact on leadership preparation: Lessons for future reform efforts. International Journal of Educational Leadership Preparation, 11(1).

Meyer, B. (2001). Coping with severe mental illness: Relations of the Brief COPE with symptoms, functioning and well-being. Journal of Psychopathology and Behavioral

Meyer, J., Allen, N. \& Smith, C. (1993). Commitment to organizations and occupations: Journal of applied psychology, 78(4), 546-547.

Mizell, H. (2010). Why PROFESSIONALDEVELOPMENT Matters. 18-20.

Moczydłowska, J. (2016). Organizational reasons of job stress factors. Economics and Management. 8 (2), 9-10.

MOES, (1996). Handbook for Educational Administration, Lanexang Avenue, Vientiane capital, State Enterprise Print house (1), 45-48.

MOES, (2015). Education and Sports Sector Development Plan (2016-2020). 1-26. 
MOES-TVET. (2015). Structure, role and responsibilities of the Ministry of Education and Sports, Lanexang Avenue, Vientiane capital, Lao PDR.

MOHA or Ministry of Home Affair. (2013). Law of Anti-corruption, Vientiane capital, Lao PDR. 2-5.

Monk, R.A.G. (1994). Relationship Investing, 2(2), 65-68.

Morgan, G. (2006), Images of Organization. (Updated edition) Thousand Oaks, CA: Sage Publications. 1-18.

Muffs, M; \& Schmitz; L. (1999), November). Job sharing for administrators: A consideration for public schools. NASSP Bullentin, 83(610), 24.

Muguongu, M.M; Andrew, T; Muguna; Denis, K; \& Muriithi. (2015). Effects of Compensation on Job Satisfaction Among Secondary School Teachers in Maara Sub-County of Tharaka Nithi County, Kenya. Journal of Human Resource Management; 3(6), [Abstract].

Mutuwong, S. (2012). Personnel Management in Lower Secondary Schools Khonkaen Province, Thailand. [Abstract].

Naemiratch, B. \& Manderson, L. (2009). Pity and pragmatism: understandings of disability in Northeast Thailand. Disability \& Society, 24(4), 475-488.

Namuddu, J. (2010). Staff appraisal systems and teacher performance at Aga Khan Schools in Kampala District. [abstract]

NASSP or National Association of Secondary Schools Principal. (2015). Ten Skills for Successful School Leaders. (n/a).

Neo Ease (2013) Human Resource Management: Selection methods. 45-48.

Nongtoum, P. (2005). The situation and problem of teachers in teaching performance at primary school. Thailand. [Abstract].

Northouse, G.P. (2004). Leadership: Theory and Practice (Third Edition).London:Sage Publications 21(1), 116.

NSHRDP. (2016) or National Strategy of Human Resource Development Plan. from now to 2025. Vientiane capital, Lao PDR. 2-6.

Nunnally, J. C. (1978). Psychometric Theory. McGraw-Hill Book, Company, pp. 86-113, 190-255.

Nwanekezi, A. \& Nwikina, L. (2010). Management of job-related teacher stress factors in Nigerian schools. Report and Opinion, 2(8), 37-42.

Nyasha, Katsuro, Chazuza, Makaita, Mukondiwa, Farai, Kudakwashe, Tafadzwa, Taonga, 2013). Importance of Establishing a Job Analysis Exercise in an Organization: A Case Study of Bread Manufacturing Companies in Zimbabwe. Australian Journal of Business and Management Research. 2(11), 4042.

OBEC, The Office of the Basic Education Commission (20010) Handbook of Teacher Performance Assessment.

OECD, (2004). IIEP learning portal: Glossary. UNESCO 7 place de Fontenoy 75352 Paris 07 SP France.

OECD. (2007). Education at a glance: Dictators. 402-411. 
Okorie U, A. (2016). TEACHERS MANAGEMENT AS DETERMINANT OF TEACHERPRODUCTIVITY IN SECONDARY SCHOOLS IN DELTA STATE, NIGERIA, British Journal of Education, 4(8). [Abstract].

Olejniczak, A. (2013). Effective time management: A selective issues. Marketing of Scientific and Research Organizations. 1(7), 12-14.

O'leary, E. (2000). Leadership: ten minus guides, $\left(2^{\text {nd }}\right.$ Ed) Pearson Education, 201 West $103^{\text {rd }}$ Street, Indianapolis, IN 46290, 124-129.

O’Neill, G., McMahon, T. (2005). Student-Centred Learning: What does it mean for students and lecturers? In, Emerging Issues in the Practice of University Learning and Teaching. 24-29.

Ordho, J.A; \& Nzoka, J.T. (2014). School Management and Students' Academic Performance: How Effective are Strategies being Employed by School Managers in Secondary Schools in Embu North District, Embu County, Kenya?. International Journal of Humanities and Social Science. 4(9), 95-96.

Olson, K. (2010). An Examination of Questionnaire Evaluation by Expert Reviewers, Department of Sociology and Survey Research and Methodology Program,

Opatha, HHDNP. (2009). Human Resource Management., Nugegoda: Department of Human Resource Management, USJ. 25-27.

Oppenheim, A N. (1992). Questionnaire design, interviewing, and attitude measurement. London. Journal of community \& applied social psychology. 4(5) 302-306.

Otara, A. (2011). Perception: A Guide for Managers and Leaders. Journal of Management and Strategy, 2(3), 21-23.

Parker. S.K, Griffin M.A. (2011). Understanding active psychological states: embedding engagement in a wider homological net and closer attention to performance. Eur. J. Work Organ. European Journal of Work and Organizational Psychology. (20), 307402 .

Patrick, K.F; Macqueen, S; \& Reynolds, R. (2014). Pre-service perspectives on the importance of Global education: World and classroom views, Journal of teacher teaching > theory and practice, 20(4), [Abstract].

Phisane, V. (2014) Instructional Management of Lecturers in Public universities, Lao PDR, Faculty of Education, National University of Laos, (Master Thesis), 300-302.

Phiengphanyoukorn, S. (1991). Problem studied on the extra group learning of the teacher students under the four sub-scale at primary schools in Nongkhai, Thailand [Thesis].

Phommanimit, K. (2004). Principle of fundamental management, Ministry of Education and Sports, Lanexang Avenue, Vientiane capital, Laos. 3-41.

Phousion, T. (2011). SPSS Applications: Data analyses in educational research, MaSarakharm University, ISBN 978-974-7017-37-3, University Printing Publishing. $5^{\text {th }}$ edition. Thailand. 49-90.

Pines, A.M. \& Keinan, G. (2005). Stress and stress factors: the significant difference. Personality and Individual Differences, 39, 625-635.

Piscitella, B.L. (2016). Stress, Stress factors, and Attrition: Implications of Student Performance Data on Math Teacher Effectiveness Evaluations,116-117. 
Poempool, S. (2003). The development of personnel system in Chazengzao Province, Thailand. [Abstract].

Polychroni, F. (2000) Sources of stress and professional stress factors of teachers of special educational needs in Greece. 12-13.

Porter, S.R. \& Umbach, P.D. (2006). College major choice: an analysis of Person EnvironmentFit.ResearchinHigherEducation,47(4), 429-449.

Prempridy, T. (2000). Sixteen factors for effective school management or 16 Ms . Aksorn Thai print house, 410/10-13 soi $40 \mathrm{BKK}, 10700$. 17-87.

Prien, E \& Goodstein, L.D, et al. (2009). A practical Guideline to Job Analysis. An imprint of Wiley, 989 market Street, San Francisco. 21-24.

Provision, No. (720/MOES/2010). On recruitment, selection and employment of new teacher in Teacher Training. The Ministry of Education and Sports, Vientiane capital, Lao PDR.

PSC, (2015). The impact of recruitment and selection practice on the functionality of the selected national and provincial department. 67-69.

Radhakrishna, R. B. (2000). Tips for Developing and examination Questionnaires /Instruments, Journal of extension. 45(1), 1-2.

Rees, C. \& Johari, H. (2010). Senior managers' perceptions of the HRM function during times of strategic organizational change Case study evidence from a public sector banking institution in Malaysia. Journal of Organizational Change Management, 23(5). 519-521.

Reimer, M; \& Kaptain, L. (2013). Leadership in Higher Education, Journal of Performing Arts, (4), 14-19.

Richardson, P.W. \& Watt, H.M.G. (2006). Who chooses teaching and why? Profiling characteristics and motivations across three Australian universities. Asia-Pacific Journal of Teacher Education, 34(1), 27-56.

Roach, A. (2009). Teacher Stress factors: Special Education versus Regular Education [Theses, Dissertations and Capstones], 13-16.

Robertson, S. J; Kremer, P; Aisbett, B; Tran, J. (2017). Consensus on measurement properties and feasibility of performance tests for the exercise and sport sciences: a Delphi study, 3(1), 7-8.

Robertson, (2008). Teacher Education in s democratic society, Teacher education and practice, 22(4), 472-473.

Roloff, M.E., \& Brown, L.A. (2011). Extra-Role Time, Stress factors and Commitment: The Power of Promises Kept. Business Communication Quarterly, 74(4), 435-437.

Rovinelli, R. J., \& Hambleton, R. K. (1977). On the use of content specialists in the assessment of crite-rion-referenced, examination item validity. Dutch Journal of Educational Research. 2-4.

Rowan, L \& Geraldine, T. (2016). Early career teacher's beliefs about their preparedness to teach: Implication for the professional development of teacher working with gifted and twice-exceptional student. 24-25. 
Sackett, P.R, Laczo RM, Lippe ZP. (2003). Differential prediction and the use of multiple pre-dictors: the omitted variables problem. Journal applies Psychology. 88 (6), 8-9.

Saloman, M. (2005). Training and Learning in the Knowledge Economy. 9-12.

Sananh, T. (2009). Job Description. 16-24.

Sanchez, J. (2011). Experiencing the creative problem-solving thinking skills model in virtual worlds. Creative Studies Graduate Student Master's Projects. 12-16.

Savicki, V; Cooley, E, \& Wade, C.D. (1986). A longitudinal study of stress factors. Children and Youth Services Review. 8(2), [Abstract].

Schaufeli, W.B. \& Buunk, B.P. (2003). "Stress factors: An overview of 25 years of research and theorizing." In Schabracq, M.J., Winnubst, J.A.M. \& Cooper, C.L. (ed.) The Handbook of work and Health Psychology. West Susgender: John Wiley \& Sons.

Schaufeli, W. B; Maslach, C; \& Leiter, M.P. (1993). Job Stress factors. Annual Review of Psychology. (52), 420-421

Schaufeli, W. B., Maslach, C., \& Marek, T. (Eds.), (1993). Professional stress factors: Recent developments in theory and research. Washington, DC: Taylor \& Francis.

Schmidt, F.L., \&Hunter, J. E. (1992). Development of causal models of processes determining job performance. Current Directions in Psychological Science (1), 8992

Schwab, R.L; Jackson, S; \& Schuler, R.S. (1986). Toward an understanding of the Stress factors Phenomena. Journal of applied Psychology. 10-11.

Selye, H. (1991). History and present status of the Stress concept. In A Monat \& R.S Lazarus (Eds), Stress and coping: An Anthology, New York, Columbia Press. 5354.

Selye H. (1936). A syndrome produced by diverse nocuous agents, 138(3479), 28-31.

Senge, P. (2012). Creating the schools of the future: Education for a sustainable society. Leader to Leader, (65), 42-27.

Sergiovanni, T.J. (2001). Leadership: What's in it for schools? London: RoutledgeFalmer. [Synopsis].

Sergiovanni, T.J. (2009). Educational Governance and Administration, $\left(6^{\text {th }}\right.$ Ed) Publisher: Pearson, 47-75.

Shalom H. S, \& Tartakovsky, E. (2014). Motivation for emigration, values, wellbeing, and identification among young Russian Jews. International Journal of Psychology, [Abstack].

Shen, J., Leslie, J.M., Spybrook, J.K., \& Ma, X. (2012). Are principal background and school processes related to teacher job satisfaction? A multilevel study using schools and staffing survey, American Educational Research Journal, 4(49), 227. Social PsychologyEducation, 7 (4), 399-420.

Sichambo, N.M; Maragia.N.M \& Simiyu, N.S. (2012). Causes of Stress factors among Secondary School Teachers: A Case of Bungoma North District-Kenya, International Journal of Academic Research in Progressive Education and Development, 1(4), 199-200. 
Sim. J \& Lewis, M. (2012). The size of a pilot study for a clinical trial should be calculated in relation to considerations of precision and efficiency.

Siniscalco, T.M \& Auriat, N. (2005). Questionnaire design, International Institute for Educational Planning/UNESCO, 7-9 rue Eugène-Delacroix, 75116 Paris, France. 4-5

Sinjaru, T. (2012). Researches and Statistical Analysis through SPSS and AMOS: Basic to advances: SR Printing Mass Production LTD, 2/103-106 Group9,

Chengwatthana street, Parkred district, Nonthaburi Bangkok, PO BOX 11120, 13th edition. 65-85.

Sirikul, P. (2003). Personnel Management in Private Kindergartens at Muang District, KhonKaen Province, Thailand. [Abstract].

Sisaad, B. (2002). Foundation researches, 122/107-109 Prachauthit, Soi91/1Thoongkhru, Bangkok, Thailand. 74-94.

Sisomphou, K. (2007). Studied about academic assessment and evaluation management affair at Faculty of Education, National University of Laos. Faculty of Education Chiangmai University, Thailand. [Thesis]. 120-130.

Slipicevic, O \& Masic, I. (2012). Management Knowledge and Skills Required in the Health Care System of the Federation Bosnia and Herzegovina. 110-111.

Sloman, M. (2005). Training and Learning in the Knowledge Economy. 9-12.

Smith, C.A \& Fogarty, S. (2016). A survey of study participants 'understanding of informed consent to participate in a randomized controlled trial of acupuncture.

Somboon, P. (1997). Personnel Management in Lower Secondary Schools, Khonkaen Province. [Abstract].

Sonebounnark, C. (2012) Organization and Management, $3^{\text {rd }}$ edition, Bangkok, Thailand, 34-36.

Soukkhavong, S. (2010). Handbook of Research in Education: Faculty of Education, National University of Laos, Dongdok village, Saithani distirct Vientiane capital, Laos. 34-38.

Sprenger, J. (2011). Stress and coping behaviors among primary school teachers (Master thesis). East Carolina University. [abstrack].

Stamm, T; van der Giesen, F; Thorstensson, C; Steen E; Birrell, F; Bauernfeind, B; Marshall, N; Prodinger, B; Machold, K; Smolen, J, \& Kloppenburg, M. (2009). Patient perspective of hand osteoarthritis in relation to concepts covered by instruments measuring functioning: a qualitative European multicenter study. 68(9), [Abstract].

Stoner,J. A., Freeman,R. (2008). Management, Englewood Cliffs, NJ: Prentice Hall International Inc. Publishing House

Strock, A. L. (2014). Library Service for Teens: Who Are We? What Are We? and, Where Are We Going? Journal of Young Adult Library Services. 1-2.

Sudman, N.M; Bradburn, Sudman, S. \& Wansink, B. (2004). Asking Questions, The Definitive Guide to Questionnaire Design-For Market Research, Political Polls, and Social and Health Questionnaires, Revised Edition.315-316. 
Tafida, G. (2009). Pre-Service Teacher Training Program on Active Learning Strategies for Middle School Science Class in Egypt: A Case Study. 3 (33), 55-56.

Taheri1, M; Forouzandeh, E; Zameni, L; \& Seddighi, Z. (2012). Comparison of Stress factors and Job Stress Between Physical Education Employees and Industrial Workers, Annals of Biological Research, 3 (33), 1245-1246.

Tardif, M. (2011) Pre-service Teacher Training Programs: Outcomes of recent reforms and new trends towards effective professional training, 24-28.

Taris, T. W. (2006). Is there a relationship between stress factors and objective performance? Acritical review of 16 studies. Work \& Stress, 20, 316-334

Thalangsy, K (2005). Psychology education, Faculty of Education, National University of Laos, (Textbook. 1st Edition).

Thaveesouvanh, S. (2001) Model and Informal Education Training Methods. 34-37.

Thomas, R. Hoerr, T.R. (2005). The Principal Connection / Perception Is Reality. Educational leadership. 62, (6), p. 83.

Thompson, A, R. (1995) The utilization and professional development of teachers: issues and strategies, UNESCO. 7, place de Fontenoy, 75352 Paris 07 SP (France), 87-89.

Thosouvannachinda, V. (2001) Technique of training personnel, Administration Journal, 2(7), 54-59.

Thurstone, L.L. (1928). Attitudes Can Be Measured. American Journal of Sociology, (33), 552-553.

Tomovic, C.L. (2012) Performance Evaluation in the Process of Motivation: An Application of Expectancy Theory, Purdue University. 2-3.

Torjman, S. (2005). What is policy? Institute of Social policy. 10-14.

Tosti, D. T; \& Harmon N. Paul, H.N. (1972). The Management of Instruction. San Rafael, CA. [Summary].

Toth, E and Hodi, A (2014). Some Current Issue in Pedagogy (Ed); How do teacher in different stages of formal education respond to accountability pressure? International Research Institute. s.r.o. Komarno, Hungary, 156-157.

Tourangeau, R; \& Yan, T. (2007). Sensitive questions in survey. Psychological Bulletin, 133(5), 876-878.

Travers, C, J; \& Cooper, C. (1996). Psycho Physiological Responses to teacher Stress: A move towards More Objective Methodologies, European Review of Applied Psychology, (44), 139-142.

Treece, E. W., \& Treece, J. W. (1982). Elements of research in nursing ( ${ }^{\text {rd }}$ Ed.). St. Louis, MO: Mosby. 255-258.

TRM or Technical Requirements Manual, (2010) teacher performance appraisal. 11-12.

Truelove, S. (1992). Handbook of Training and Development. Oxford: Blackwell.

Trutkowski, C. (2016). Training Needs Analysis and National Training Strategies: How to ensure the right training at the right time to the right people? [Council of Europe]. 46. 
Tungsujarittam, N. (2014). Quality Evaluation of The English Proficiency Examination for Automotive, Specification Certificate Students at Nakhonsawan Technical College

Turner, R.C. and Carlson, L. (2009). Indexes of Item-Objective Congruence for Multidimensional Items.

Turner.R.C. (2003). Indexes of Item-Objective Congruence for Multidimensional Items (Ed). Zumbo.B.D, International Journal of examination. 3(2), 163-17.

Ugwulashi, C.S. (2013). Time management: Essential tools for teaching and learning improvement in challenging resource period in Nigeria. Education Research International. 1(2), 61-63.

Ukandu, N.E; \& Ukpere, W.I. (2011). Effects of Poor Training and Development on the Work Performance of the Fast Food Employees in Cape Town, Mediterranean Journal of Social Sciences, 4(14), 577-578.

Ugwulashi, S.C. (2012). Effective integration of administrative process in school administration, Academic research international, 2(2), 2-6.

Ugwulashi, S.C. (2012). Cost, time and quality implications in School Administration in Nigeria. 1(2), 2-7.

Ukandu, N.E. and Ukpere, W.I. (2011). The Causes of Low Employee Motivation within Cape Town's fast food industry. Cape Peninsula University of Technology, Cape Town.

UNESCO. (1994). The Salamanca Statement and Framework for Action on special needs education. 23-38.

UNESCO (2015). Teacher in Asia Pacific: Status and Rights. 7, place de Fontenoy, 75352 Paris 07 SP, France. 14-24.

UNESCO. (2011) Good policy and practice in HIV \&AIDS and education, Booklet 6: preservice teacher training, UNESCO 7 place de Fontenoy 75352 Paris 07 SP France.

Unkeo, N. (1997). Investigated the situation and problem of teaching-learning the Course of Social Science at Secondary School in Konkaen city, Thailand, [Abstract].

UNESCO-EFA .(2014). Teaching and Learning: achieving quality for all. 10-14.

UNESCO-IIEP. (2014). Strengthening institutional capacities for improved educational quality in Lao PDR. 1-8.

UNESCO-IIEP. (2016). National Education Account Project Public and External financing Report 2009-2014.

Vagias, Wade M. (2006). Likert type scale response anchors. Clemson International Institute for Tourism \& Research Development, Department of Parks, Recreation and Tourism Management. Clemson University. 1-2.

Van Belle, G. (2002). Statistical rules of thumb. New York: John Wiley

Vandenberghe, R; A. M Huberman, A.M. (1999). Understanding and preventing teacher stress factors: a sourcebook of international research and practice. Cambridge University press. $243-247$.

Vannasy, K; Keodara, K; and Phongphanit, T. (2014). Human Resource Management in Education, Faculty of Education, National University of Laos. 42-45. 
Vinesh. (2014). Role of Training \& Development in an Organizational Development, International Journal of Management and International Business Studies, 4(2), 217-218.

Viscardi, D. (2015). The teacher pays for performance phenomenon, Seton Hall University, Dissertation and Thesis. 86-88

Wainer, H., \& Braun, H. I. (1998). Examination validity. Hillsdale, NJ: Lawrence Erlbaum.

Wallance, M. (1991). Training Foreign Language Teacher: A reflective Approach. ELT Journal, 46(4), 12-17.

Warwick, D.P and Lininger, A. L. (1975). The sample survey: theory and practice. New York : McGraw-Hill. 304-309.

Wayne, K. H \& Miskel, C.G. (2005). Educational administration: Theory and Practices. ( $7^{\text {th }}$ Edition). 304-309.

Wheatley, K. F. (2002). Two approaches to teaching transformational lesson planning, Journal of Early Childhood Teacher Education. 23(4). 328-329.

Whitehead, A. J. (2001). Teacher stress factors: A study of occupational stress and stress factors in New Zealand School Teacher (Doctoral Dissertation) pp 125-127.

Wilkinson, D \& Birmingham, P. (2003) Using Instruments: A guide for researchers, Rout ledge Falmer, 29 West $35^{\text {th }}$ Street, New York, NY 10001. 2-4.

Williams, \& Mary. (2015). Training \& Technical Assessment Center. 3-6

Williams, D.R; Burns, H.L, \& Kelly, S.L. (2014). A framework for Leadership Sustainability Education at Portland State University. Journal of Sustainability Education. (6), 12-13.

Wills, M. (1994). Managing the Training Process: Putting the Basics into Practice." Journal of European IndustrialTraining 18, (6) 96-97.

Winter, G. (2000). A Comparative Discussion of the Notion of 'Validity' in Qualitative and Quantitative Research: The Qualitative Report. 4(3-4),

Wong, W. (2004). Data analysis for the Critical Decision Method. University of Otago. 1415.

Wood, T \& McCarthy, C. (2002). Understanding and preventing teacher stress factors. Washington, DC: United States Department of Education. (ERIC Document Reproduction Service, 2-8.

World Bank group report. (2016). SCHOOL AUTONOMY AND ACCOUNTABILITY. 2-9.

Woźniak, J. (2006), Podejście zewnętrzne i wewnętrznew badaniu efektywności szkoleń [External and internal approach to the research effectiveness of training]. In I. K. Hejduk, J. Korczak (Eds.), Gospodarka oparta na wiedzy [Knowledge-based economy],706-708.

Wozny, WK. Polowczyk, S, L. and Zygmunt, A. (2014). STRESS IN THE TEACHING PROFESSION, Journal of Education, Health and Sport. 2015;5(6): 195-196. 
Wright, P., and Geroy, G. (1992). Needs Analysis Theory and the Effectiveness of largescale Governmental-sponsored Training programs: A Case Study. Journal of Management Development, 11(5), 17-22.

Yan, Z; \& Xin, W.J. (2007). The stress factors phenomenon of teachers under various conflicts, US-China Education Reviews, 4(1), 42-43.

Yong, B.C.S. (1995). Teacher traineese motives for entering into a teaching career in Brunei Darussalam. Teaching \& Teacher Education, 11(3), 275-280.

Yoodee, Y. (2012). The satisfaction of the employees toward the performance of the educational administrators, $1^{\text {st }}$ office of the education, Chazengzao Province. Thailand. [Abstract].

Yotanyamaneewong, S. (2012). Preventing Teacher Stress factors: Exploring the Perceptions of Teachers for Children with Social, Emotional and Behavioral Difficulties (SEBD) in Thailand. (2), 140-145.

Yukl, G. 2006, Leadership in Organizations. Sixth Edition. New York: Pearson Prentice Hall. 


\section{Publications related to the dissertation}

Phongphanit, T. (2018). Instructional management of teaching staff in teacher training institutions, $L A O P D R$. International Conference on Education and New Development. (END 2018), 23 -25 June, 2018, Budapest, Hungary. In: Mafalda, C. (ed.) Education and New Development. InScience Press, Lisbon, Portugal, pp.361365.

Phongphanit, T. (2018). An overview of the education system in Hungary. Educational Scientific Research Institute, Ministry of Education and Sports. Lanexange Avenue, Vientiane capital of Laos, Lao PDR. New Education Journal,41(41),19-23, and 60.

Phongphanit, T. (2018). A possibility study of using a self-constructed questionnaire in teacher management in Laos. In: Vidákovich, T. - Füz, N. (ed.) CEA 2018. 16th Conference on Educational Assessment (26-28. April, 2018. Szeged, Hungary). Programme and abstract. SZTE Doktoral School of Education, Szeged. pp.78.

Phongphanit, T. (2017). Causal Teacher's burnout toward school board management at demonstration school in Laos, Global Scholastic Research Journal of Multidisciplinary. India republic. 3(6), 26-30.

Phongphanit, T. (2017). A pilot study of examining the validity and reliability of research questionnaires. In: D. Molnár, É. - V'igh, T. (ed.) $15^{\text {th }}$ Conference on Educational Assessment (CEA), 6-7 April, 2017, Szeged, Hungary. Program book and abstracts. SZTE Doctoral School of Education, pp.80.

Phongphanit, T. (2017). Examining the validity and reliability of research questionnaires. $6^{\text {th }}$ Interdiszciplináris Doktorandusz Konferencia (IDK2017) (6th Interdisciplinary Doctoral Conference), Pecs, Hungary, 19-21 May, 2017.

Phongaphanit, T. (2017). Re-examining the validity and reliability of research questionnaires. In: Proceedings of the $23^{\text {rd }}$ Universal Academic Cluster International July Conference, Bangkok. Thailand, pp. 21-35.

Phongaphanit, T. (2017). Causes of teacher burnout toward school board management in Laos. The $9^{\text {th }}$ International conference for Theory and Practice in Education, Budapest, Hungary. Association of Educational Sciences, p 39.

Phongaphanit, T. (2017). A pilot study of examining the validity and reliability of research questionnaires. In: Patricia, K. Contemporary Issues of societal development, International Conference in Ljubljana, Slovenia, pp. 10-30.

Phongphanit, T \& Khounsavath, P. (2017). The study of Lao Language in advertisement sign, Printed in National University of Laos, Dongdok campus. Scientific Journal of National University of Laos, (11), p 98-109.

Phongphanit, T. Thongthavy, V. Thalangsy, K. \& Kiengkhamyom, P. (2015) The Factor effecting to decision study of Lao Language Pedagogy program of the students in Faculty of Education, National University of Laos and Teachers Training Colleges in Lao PDR. Scientific Journal of National University of Laos (10), 194-206.

Phongphanit, T; Sisomphou, K; Soukhavong, S; Thalangsy, K; Chanming, P; Vannasy, V; Phommasack, M. (2012) The conduct of educational research at the Faculties, National University of Laos. Scientific Journal of National University of Laos (6), p.101-111. 


\section{Previous publications (Books)}

Phongphanit, T \& Sisomphou, K. (2016). Educational Management. Printed in Education's State Enterprise, LTD. Ministry of Education and Sport. Vientiane capital. Lao PDR. $1^{\text {st }}$ edition.

Phongphanit, T. \& Thalangsy, K. (2015). Basic Understanding Research, Printed in Education's State Enterprise, LTD. Ministry of Education and Sport. Vientiane capital. Lao PDR. $1^{\text {st }}$ edition.

Phongphanit, T. (2015). Communication through multimedia. In Sayavong, C. Keopasert, S. Maokhamphiew, B. \& Maokhamphiew, S. (Eds), Communication skill for students (pp 52-71) Hanoi printing house, Vietnam. 1st edition.

Phongphanit, T; Vannasy, K; Keodara, M. (2014). Personnel and Human Resource Management. Printed in Education's State Enterprise, LTD. Ministry of Education and Sport. Vientiane capital. Lao PDR. $1^{\text {st }}$ edition.

Phongphanit, T \& Chatouphonesay, A. (2014). Comparative Education. Printed in Education's State Enterprise, LTD. Ministry of Education and Sport. Vientiane capital. Lao PDR. $1^{\text {st }}$ edition.

Phongphanit, T \& Manivonce, T. (2014). School and Community Relation. Printed in Education's State Enterprise, LTD. Ministry of Education and Sports. Vientiane capital. Lao PDR. $1^{\text {st }}$ edition.

Phongphanit, T \& Champathong, P. (2014). Action Research for Teaching-Learning Development, Printed in Education's State Enterprise, LTD. Ministry of Education and Sport. Vientiane capital. Lao PDR. $1^{\text {st }}$ edition.

Phongphanit, T \& Silavong, N. (2014). Seminar on current issues and Trends in education, Printed in Education's State Enterprise, LTD. Ministry of Education and Sport. Vientiane capital. Lao PDR. $1^{\text {st }}$ edition.

Phongphanit, T; Kanyasan, K; Sengsourivong, L. (2013) Data analysis by SPSS program (Ed) Computer for Database and Researches, Education's State Enterprise, LTD. Ministry of Education and Sport. Vientiane capital Lao $\quad$ PDR. $\quad 1^{\text {st }}$ edition.

Phongphanit, T \& Khathavy, K, et, al. (2009). Management and Community Development, Printed in Education's State Enterprise, LTD. Ministry of Education and Sport. Vientiane capital. Lao PDR. $1^{\text {st }}$. edition. 


\section{Appendix A:}

Examining the validity and reliability of a self-constructed questionnaire on "Instructional management and stress factors affecting teacher trainers as perceived by the educational leaders of Laos"

(Form A: for educational leader)

\begin{tabular}{|c|c|c|c|c|c|c|c|c|c|}
\hline \multirow[b]{2}{*}{$\mathbf{I}$} & \multirow{2}{*}{$\begin{array}{c}\begin{array}{c}\text { Educational leaders' perception of the six } \\
\text { tasks }\end{array} \\
\text { Teacher demand analysis } \\
\end{array}$} & \multicolumn{3}{|c|}{$\begin{array}{l}\text { Validity by } \\
\qquad I O C\end{array}$} & \multicolumn{5}{|c|}{$\begin{array}{c}\text { Reliability by } \\
\alpha, r, M d n, I R, P I\end{array}$} \\
\hline & & +1 & $\mathbf{0}$ & -1 & 5 & 4 & 3 & 2 & 1 \\
\hline 1 & Sources of data and information supports & & & & & & & & \\
\hline 2 & Policy on recruitment panel & & & & & & & & \\
\hline 3 & Prioritize on vacant subjects & & & & & & & & \\
\hline 4 & Contextual knowledge & & & & & & & & \\
\hline 5 & Ranking on labor market demands basis. & & & & & & & & \\
\hline 6 & Eligibility of the applicant & & & & & & & & \\
\hline 7 & Welfare and career development & & & & & & & & \\
\hline 8 & Knowledge of subject matter & & & & & & & & \\
\hline 9 & Pedagogical context & & & & & & & & \\
\hline II & Recruitment and selection & +1 & $\mathbf{0}$ & -1 & 5 & 4 & 3 & 2 & 1 \\
\hline 10 & Aims and purpose of selection process & & & & & & & & \\
\hline 11 & Sources of the applicants & & & & & & & & \\
\hline 12 & Application form services & & & & & & & & \\
\hline 13 & Determine the recruit panel & & & & & & & & \\
\hline 14 & Job vacancy announcement procedures & & & & & & & & \\
\hline 15 & Interview the teacher candidate & & & & & & & & \\
\hline 16 & Screening the application form & & & & & & & & \\
\hline 17 & Context of recruitment and selection process & & & & & & & & \\
\hline 18 & $\begin{array}{l}\text { Personality and honesty examination of the } \\
\text { candidate. }\end{array}$ & & & & & & & & \\
\hline III & Pre-service training & +1 & $\mathbf{0}$ & -1 & 5 & 4 & 3 & 2 & $\mathbf{1}$ \\
\hline
\end{tabular}




\begin{tabular}{|c|c|c|c|c|c|c|c|c|c|}
\hline 19 & $\begin{array}{l}\text { Introduction about information of } \\
\text { organization background, vision, mission, } \\
\text { achievement, benefits, rule and regulation }\end{array}$ & & & & & & & & \\
\hline 20 & Information about job insurances & & & & & & & & \\
\hline 21 & Context of pre-service teacher training & & & & & & & & \\
\hline 22 & Information about division of work & & & & & & & & \\
\hline 23 & Teacher welfare dissemination & & & & & & & & \\
\hline 24 & $\begin{array}{l}\text { Line of work (Horizontal and vertical } \\
\text { channel) }\end{array}$ & & & & & & & & \\
\hline 25 & $\begin{array}{l}\text { Introduce the policies and other benefits of } \\
\text { teacher }\end{array}$ & & & & & & & & \\
\hline 26 & Training design and operation process & & & & & & & & \\
\hline 27 & Trainee's feedback management & & & & & & & & \\
\hline IV & Performance appraisal & +1 & $\mathbf{0}$ & -1 & 5 & 4 & 3 & 2 & 1 \\
\hline 28 & Context of teacher performance appraisal & & & & & & & & \\
\hline 29 & Appraisal tools development & & & & & & & & \\
\hline 30 & Criteria for competency statement & & & & & & & & \\
\hline 31 & Select the proper tools & & & & & & & & \\
\hline 32 & Classroom observation & & & & & & & & \\
\hline 33 & Criterion and standardization & & & & & & & & \\
\hline 34 & Portfolio checking of teacher workforce & & & & & & & & \\
\hline 35 & Timing and flowchart & & & & & & & & \\
\hline 36 & Promote an honest feedback & & & & & & & & \\
\hline 37 & Summary of appraisal and implications & & & & & & & & \\
\hline 38 & applications the resulted of assessment & & & & & & & & \\
\hline $\mathbf{V}$ & Compensation & +1 & $\mathbf{0}$ & -1 & 5 & 4 & 3 & 2 & 1 \\
\hline 39 & Pay for teachers' professional development & & & & & & & & \\
\hline 40 & Salary-grade promotion & & & & & & & & \\
\hline 41 & Overtime pay and other benefits & & & & & & & & \\
\hline 42 & Supplemental pension and subsidies & & & & & & & & \\
\hline 43 & Compensation reform & & & & & & & & \\
\hline 44 & Competency-based pay & & & & & & & & \\
\hline 45 & Pay-at-risk & & & & & & & & \\
\hline
\end{tabular}




\begin{tabular}{|c|c|c|c|c|c|c|c|c|c|}
\hline 46 & Tangible and intangible benefits of teachers & & & & & & & & \\
\hline 47 & Performance-Based Pay or merit pay & & & & & & & & \\
\hline 48 & Extra skill-based pay & & & & & & & & \\
\hline 49 & Teacher's basic needs & & & & & & & & \\
\hline 50 & Sick and maternity leave & & & & & & & & \\
\hline 51 & Priority on teacher's talent development & & & & & & & & \\
\hline 52 & Delivery of teacher's salary timely & & & & & & & & \\
\hline 53 & Praise teacher on a performance basis & & & & & & & & \\
\hline 54 & Transparency on compensation supply & & & & & & & & \\
\hline 55 & Teaching career development & & & & & & & & \\
\hline 56 & \begin{tabular}{|lll}
$\begin{array}{l}\text { Tuition reimbursement } \\
\text { disadvantaged teachers }\end{array}$ & program for \\
\end{tabular} & & & & & & & & \\
\hline VI & Training needs assessment & +1 & $\mathbf{0}$ & -1 & 5 & 4 & 3 & 2 & 1 \\
\hline 57 & Context of training needs assessment & & & & & & & & \\
\hline 58 & $\begin{array}{l}\text { Determine the eligibilities (trainer and } \\
\text { trainee) }\end{array}$ & & & & & & & & \\
\hline 59 & Component and training program & & & & & & & & \\
\hline 60 & Define of the training topic & & & & & & & & \\
\hline 61 & Training content design & & & & & & & & \\
\hline 62 & Making a survey of training needs & & & & & & & & \\
\hline 63 & Planning for training and its assessment & & & & & & & & \\
\hline
\end{tabular}

\section{Thank you !}




\section{Appendix B: Examining the validity and reliability of a self-constructed}

questionnaire

on "Instructional management and stress factors affecting teacher trainers as perceived by the educational leaders of Laos"

(Form B: for teacher)

\begin{tabular}{|c|c|c|c|c|c|c|c|c|c|}
\hline & \multirow{2}{*}{ Stress factors among teachers caused by } & \multicolumn{3}{|c|}{$\begin{array}{l}\text { Validity by } \\
\text { IOC }\end{array}$} & \multicolumn{5}{|c|}{$\begin{array}{c}\text { Reliability test by } \\
\alpha, r, M d n, I R, P I\end{array}$} \\
\hline & & +1 & $\mathbf{0}$ & -1 & 5 & 4 & 3 & 2 & 1 \\
\hline 1 & $\begin{array}{l}\text { Allocate subjects taught without } \\
\text { consultation }\end{array}$ & & & & & & & & \\
\hline 2 & Teach too much hours a week & & & & & & & & \\
\hline 3 & Role ambiguity among junior and senior & & & & & & & & \\
\hline 4 & often face a substitute teaching hour & & & & & & & & \\
\hline 5 & Face too many administrative tasks & & & & & & & & \\
\hline 6 & Poor relations with leaders/managers & & & & & & & & \\
\hline 7 & Often teach cross-subject areas & & & & & & & & \\
\hline 8 & Lack of autonomy in teaching performance & & & & & & & & \\
\hline 9 & Unclear expectation & & & & & & & & \\
\hline 10 & Salary and subsidies lag & & & & & & & & \\
\hline 11 & poor working conditions & & & & & & & & \\
\hline 12 & $\begin{array}{l}\text { Provide teaching-hours unmet teacher's } \\
\text { decrees stated }\end{array}$ & & & & & & & & \\
\hline 13 & Hardship allowance & & & & & & & & \\
\hline 14 & Overtimes-pay & & & & & & & & \\
\hline 15 & Health care & & & & & & & & \\
\hline 16 & Necessary salary adjustment & & & & & & & & \\
\hline 17 & Teaching media via internet lag & & & & & & & & \\
\hline 18 & Ambiguity in promoting teacher position & & & & & & & & \\
\hline 19 & Imbalance toward oriented-skills training & & & & & & & & \\
\hline 20 & Management and communication patterns & & & & & & & & \\
\hline 21 & Training content mismatch of skill-needs & & & & & & & & \\
\hline 22 & There is a clue in training participation & & & & & & & & \\
\hline
\end{tabular}




\begin{tabular}{|c|l|l|l|l|l|l|l|l|l|}
\hline 23 & lack of equilibrium in showing/sharing ideas & & & & & & & & \\
\hline 24 & Absence in making a survey of skill-needs & & & & & & & & \\
\hline 25 & Criticism than praise from leader/manager & & & & & & & & \\
\hline
\end{tabular}


Appendix C:

Cause of teacher burnout syndrome concerning to school board management at Practices Schools in Laos.

\begin{tabular}{|c|c|c|c|c|c|}
\hline \multirow{2}{*}{ Cause of teacher burnout syndrome } & \multicolumn{5}{|c|}{ Level of causal } \\
\hline & 5 & 4 & 3 & 2 & $\mathbf{1}$ \\
\hline teach too many teaching hours per week & & & & & \\
\hline face too many administrative tasks & & & & & \\
\hline allocate subject taught without consultation & & & & & \\
\hline lack of autonomy in teaching performance & & & & & \\
\hline often teach of cross-subject areas & & & & & \\
\hline teaching-hour unmet teacher's decrees & & & & & \\
\hline salary and subsidies lag & & & & & \\
\hline overtimes-pay & & & & & \\
\hline hardship allowance & & & & & \\
\hline health care & & & & & \\
\hline necessary salary adjustment & & & & & \\
\hline poor working condition & & & & & \\
\hline unclear expectation & & & & & \\
\hline ignore in making a survey of skill-needs & & & & & \\
\hline there is a clue in training participation & & & & & \\
\hline training contents unmet skill needs & & & & & \\
\hline teaching media via internet lag & & & & & \\
\hline imbalance toward oriented-skills training & & & & & \\
\hline
\end{tabular}

\section{Thank you very much!}


Appendix D:

\section{Instructional management of teaching staff in teacher training} institutions, Lao PDR

\begin{tabular}{|c|c|c|c|c|c|c|}
\hline \multirow[b]{2}{*}{$\mathbf{I}$} & \multirow{2}{*}{$\begin{array}{c}\text { Educational leader's perception of the six tasks } \\
\text { Creating a lesson plan }\end{array}$} & \multicolumn{5}{|c|}{$\begin{array}{c}\text { Problems of instructional } \\
\text { management }\end{array}$} \\
\hline & & 5 & 4 & 3 & 2 & 1 \\
\hline 1 & formulate the objectives of the lesson plan & & & & & \\
\hline 2 & Establishing an objective & & & & & \\
\hline 3 & Specify the material support & & & & & \\
\hline 4 & State the scope of contents & & & & & \\
\hline 5 & allocate time to each activity & & & & & \\
\hline 6 & Procedure on each lesson & & & & & \\
\hline 7 & schedule a lesson plan fitting the curriculum & & & & & \\
\hline 8 & Type and kind of home work & & & & & \\
\hline 9 & specify the aims of each activity & & & & & \\
\hline 10 & Drafting the assessment and evaluation & & & & & \\
\hline 11 & Role play bound & & & & & \\
\hline 12 & Specify technology device supportive & & & & & \\
\hline II & Instruction practices & 5 & 4 & 3 & 2 & 1 \\
\hline 13 & Conducting follow the lesson planned & & & & & \\
\hline 14 & Check attendants & & & & & \\
\hline 15 & assessment at the end of each lesson plan & & & & & \\
\hline 16 & Check assignments & & & & & \\
\hline 17 & Following each step of the designed activities; & & & & & \\
\hline 18 & assign student practice in each step taught & & & & & \\
\hline 19 & Revise previous activities & & & & & \\
\hline 20 & $\begin{array}{l}\text { perform each procedure of examples designed to } \\
\text { support the lesson plan }\end{array}$ & & & & & \\
\hline III & Instruction via technology devices & 5 & 4 & 3 & 2 & 1 \\
\hline 21 & Perform via Audio-Visual aid & & & & & \\
\hline
\end{tabular}




\begin{tabular}{|l|l|l|l|l|l|l|}
\hline 22 & Conduct via smart board & & & & & \\
\hline 23 & Knowledges transmission via multi-apps & & & & \\
\hline 24 & Introduce new information sources via websites & & & & & \\
\hline 25 & Present short stories via software programs & & & & & \\
\hline 26 & Each lesson plans links or available via internet & & & & & \\
\hline 27 & Role-play via audiotape recording & & & & & \\
\hline 28 & Internet-interactive video conferencing & & & & & \\
\hline 29 & Perform via LCD projector & & & & & \\
\hline 30 & Introduce about search engine skills & & & & & \\
\hline IV & Instructional assessment & $\mathbf{5}$ & $\mathbf{4}$ & $\mathbf{3}$ & $\mathbf{2}$ & $\mathbf{1}$ \\
\hline 31 & Perform in accordance with a scope of lesson plan & & & & & \\
\hline 32 & $\begin{array}{l}\text { apply the result of assessment and evaluation to } \\
\text { enhance instructional assessment }\end{array}$ & & & & \\
\hline 33 & Role-plays based on existing gaining & & & & & \\
\hline 34 & Individual interviews on students' knowledge & & & & & \\
\hline 35 & Group discussion & & & & & \\
\hline 36 & Post-test at the end of each lesson & & & & & \\
\hline 37 & checks of students' portfolios & & & & \\
\hline 38 & Oral and letter individual reports & & & \\
\hline
\end{tabular}

Thank you for your kind cooperation 


\section{Appendix E: (Form A, for educational leader)}

\section{Instructional management and stress factors affecting teacher trainers as perceived by the educational leaders of Laos.}

\section{Instructions:}

Educational leaders in this study included Dean-Vice Dean; Head and Deputy Head of Department and Division at University level; Director-Deputy Director; Head and Deputy Head of office and center at college level, these participants have teaching obligation not more than 6 hours a week at TTIs-Laos (Decree on Lao Teacher Education, No. 1479/MOES, 2014-Laos).

\section{The Questionnaires are divided into 2 sections:}

Section1: Respondents' personal, socio-demographic data (Gender; Qualification level; Working Experience, TTIs level)

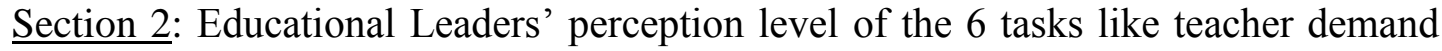
analysis; recruitment and selection; pre-service training; performance appraisal; teacher compensation, and training needs assessment, by using Four-Points Likert scales ( $4=$ Very high perception; 3 = High perception; 2 = Low perception, and $1=$ very low perception level).

\section{\# Attitude examination:}

At the end of task 2 recruitment and selection, asides from your personal expression in the space provided about open-ended questions. You are strong-invites to answer questions of two short-stories related your own decision-making skills base.

Your cooperation in giving HONEST information is greatly appreciated and we will use it for academic purposes only; confidentiality will be assured, please do not hesitate to provide as authentic information as possible.

Thank you for your kind cooperation. 
Section 1: Socio-demographic data

Instructions: Please put $\checkmark$ into the $\square$ preceding the answers relating to You!

\begin{tabular}{|c|l|}
\hline No. & \multicolumn{2}{|c|}{ Checklist items } \\
\hline 1 & $\begin{array}{c}\text { Gender: } \\
\square \text { Male }\end{array}$ Female \\
\hline 2 & $\begin{array}{l}\text { Qualification level: } \\
\square \text { Bachelor Degree; }\end{array}$ Master Degree; $\square$ Ph.D. Degree \\
\hline 3 & $\begin{array}{l}\text { Working Experience: } \\
<10 \text { years } \square ; 10-15 \text { years } \square ;>16 \text { years } \square ;\end{array}$ \\
\hline 4 & TTIs location $\quad$ FOE $\square$ TTC $\square$ \\
\hline
\end{tabular}

Section 2: Educational leaders' perception level of the functions and responsibilities within the Teacher Training Institutions in Laos, concerning the six tasks, by using a four-point Likert scales to mark Your perception level.

Instructions: Please put a $\checkmark$ in case of each line into the relevant box indicating your perception level!

\begin{tabular}{|c|c|c|c|c|c|}
\hline \multirow{2}{*}{$\begin{array}{l}\text { No. of } \\
\text { item }\end{array}$} & \multirow{2}{*}{$\begin{array}{l}\text { Educational leader's perception of } \\
\text { Teacher demand analysis }\end{array}$} & \multicolumn{4}{|c|}{ Level of perception } \\
\hline & & 4 & 3 & 2 & 1 \\
\hline 1 & Pedagogical context & & & & \\
\hline 2 & Policy on recruitment panel & & & & \\
\hline 3 & Prioritize on vacant subjects & & & & \\
\hline 4 & Contextual knowledge & & & & \\
\hline 5 & Knowledge of subject matter & & & & \\
\hline 6 & Eligibility of the applicant & & & & \\
\hline 7 & Welfare and career development & & & & \\
\hline \multicolumn{6}{|c|}{ 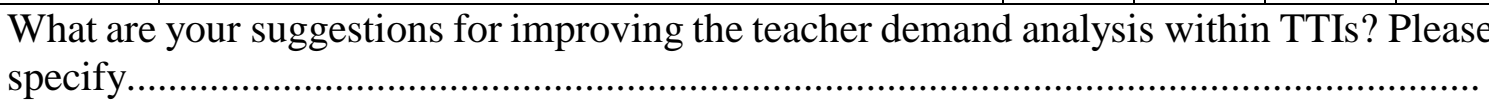 } \\
\hline
\end{tabular}




\begin{tabular}{|c|l|c|c|c|c|}
\hline \multirow{2}{*}{$\begin{array}{c}\text { No. of } \\
\text { item }\end{array}$} & \multicolumn{1}{|c|}{$\begin{array}{c}\text { Educational leader's perception of } \\
\text { Recruitment and Selection }\end{array}$} & \multicolumn{4}{|c|}{ Level of perception } \\
\cline { 4 - 6 } & \multicolumn{1}{|c|}{4} & 3 & 2 & 1 \\
\hline 8 & Sources of the applicants & & & & \\
\hline 9 & Application form services & & & & \\
\hline 10 & Determine the recruit panel & & & & \\
\hline 11 & Job vacancy announcement procedures & & & & \\
\hline 12 & Interview the teacher candidate & & & & \\
\hline 13 & Screening the application form & & & & \\
\hline 14 & Context of recruitment and selection process & & & \\
\hline 15 & $\begin{array}{l}\text { Personality and honesty examination of the } \\
\text { candidate. }\end{array}$ & & & & \\
\hline
\end{tabular}

\# How do you promote the validity and reliability of the recruitment and selection process of a new teacher candidate within TTIs? Please specify!.

\section{\# Please answer the questions from two stories below:}

Story 1: There are seven very important people such as a King, a pregnant woman, a President, an old man with a serious fever, a Prime minister, a Lawyer and a Preacher; these important peoples are stuck on an archipelago in the middle of an ocean. Suppose you have been appointed by the organization to take an airplane to pick up one person only. Question: Who will you choose among those seven people? Please write down here.

Story 2: At the midnight while you are sleeping, there were unforeseen emergencies happening at the same time, like your beloved baby was crying very loud, your water supply in the kitchen had a severe tube breakage, and someone knocked loudly on the door. Question: Which one among these emergencies will you handle first? Please write down here...

\begin{tabular}{|c|l|c|c|c|c|}
\hline \multirow{2}{*}{$\begin{array}{c}\text { No. of } \\
\text { item }\end{array}$} & \multicolumn{1}{|c|}{$\begin{array}{c}\text { Educational leader's perception of } \\
\text { Pre-Service Teacher Training }\end{array}$} & \multicolumn{4}{|c|}{ Level of perception } \\
\cline { 5 - 6 } & & 4 & 3 & 2 & 1 \\
\hline 16 & Context of pre-service teacher training & & & & \\
\hline 17 & Provide basic information for novice teachers & & & & \\
\hline 18 & Teacher welfare dissemination & & & & \\
\hline
\end{tabular}




\begin{tabular}{|c|c|c|c|c|c|}
\hline 19 & Line of work (Horizontal and vertical channel) & & & & \\
\hline 20 & $\begin{array}{l}\text { Introduce the policies and other benefits of } \\
\text { teacher }\end{array}$ & & & & \\
\hline 21 & Training design and operation process & & & & \\
\hline 22 & Trainee's feedback management & & & & \\
\hline \multicolumn{6}{|c|}{$\begin{array}{l}\text { How important do you think the managing and performing of pre-service teacher } \\
\text { training should be within TTIs?. Please specify! .............................. }\end{array}$} \\
\hline \multirow{2}{*}{$\begin{array}{l}\text { No. of } \\
\text { item }\end{array}$} & \multirow{2}{*}{$\begin{array}{l}\text { Educational leader's perception of } \\
\text { Teacher Performance appraisal }\end{array}$} & \multicolumn{4}{|c|}{ Level of perception } \\
\hline & & 4 & 3 & 2 & 1 \\
\hline 23 & Context of teacher performance appraisal & & & & \\
\hline 24 & Appraisal tools development & & & & \\
\hline 25 & Criteria for competency statement & & & & \\
\hline 26 & Select the proper tools & & & & \\
\hline 27 & Classroom observation & & & & \\
\hline 28 & Criterion and standardization & & & & \\
\hline 29 & Portfolio checking of teacher workforce & & & & \\
\hline 30 & Timing and flowchart & & & & \\
\hline 31 & Promote an honest feedback & & & & \\
\hline 32 & Summary of appraisal and implications & & & & \\
\hline \multicolumn{6}{|c|}{$\begin{array}{l}\text { Which technical requirements of teacher performance appraisal should be applied within } \\
\text { TTIs? Please specify } \ldots \ldots \ldots \ldots \ldots \ldots \ldots \ldots \ldots \ldots \ldots \ldots \ldots \ldots \ldots \ldots \ldots \ldots \ldots \ldots \ldots \ldots \ldots \ldots \ldots \ldots \ldots \ldots \ldots \ldots\end{array}$} \\
\hline \multirow{2}{*}{$\begin{array}{l}\text { No. of } \\
\text { item }\end{array}$} & \multirow{2}{*}{$\begin{array}{l}\text { Educational leader's perception of } \\
\text { Teacher compensation }\end{array}$} & \multicolumn{4}{|c|}{ Level of perception } \\
\hline & & 4 & 3 & 2 & 1 \\
\hline 33 & Pay for teachers' professional development & & & & \\
\hline 34 & Salary-grade promotion & & & & \\
\hline 35 & Overtime pay and other benefits & & & & \\
\hline 36 & Supplemental pension and subsidies & & & & \\
\hline 37 & Compensation reform & & & & \\
\hline
\end{tabular}




\begin{tabular}{|c|c|c|c|c|c|}
\hline 38 & Competency-based pay & & & & \\
\hline 39 & Pay-at-risk & & & & \\
\hline 40 & Tangible and intangible benefits of teachers & & & & \\
\hline 41 & Performance-Based Pay or merit pay & & & & \\
\hline 42 & Extra skill-based pay & & & & \\
\hline 43 & Teacher's basic needs & & & & \\
\hline 44 & Sick and maternity leave & & & & \\
\hline 45 & Priority on teacher's talent development & & & & \\
\hline \multicolumn{6}{|c|}{ 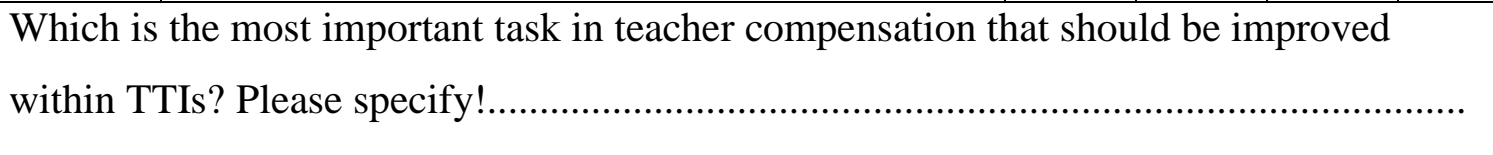 } \\
\hline \multirow{2}{*}{$\begin{array}{l}\text { No. of } \\
\text { item }\end{array}$} & \multirow{2}{*}{$\begin{array}{l}\text { Educational leader's perception of } \\
\text { Training Needs Assessment }\end{array}$} & \multicolumn{4}{|c|}{ Level of perception } \\
\hline & & 4 & 3 & 2 & 1 \\
\hline 46 & Context of training needs assessment & & & & \\
\hline 47 & Determine the eligibilities (trainer and trainee) & & & & \\
\hline 48 & Component and training program & & & & \\
\hline 49 & Define of the training topic & & & & \\
\hline 50 & Training content design & & & & \\
\hline 51 & Making a survey of training needs & & & & \\
\hline 52 & Planning for training and its assessment & & & & \\
\hline \multicolumn{6}{|c|}{ 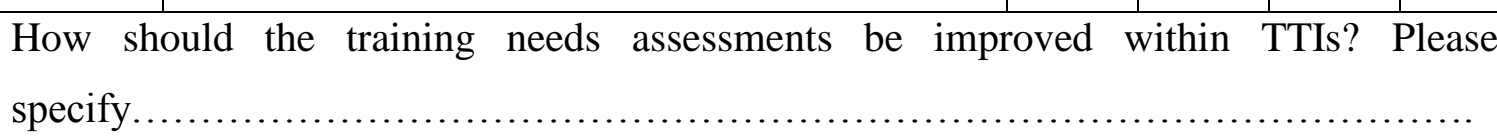 } \\
\hline
\end{tabular}




\section{Appendix F: \\ Stress factors among teacher}

\section{Instructions:}

The respondents have invited in this study including teacher civil servant, these teachers have teaching obligation not more than 12 hours a week at TTIs-Laos (Decree, No. 1479/MOES, 2014-Laos).

\section{The Questionnaires are divided into 2 sections:}

Section1: Respondents' personal, socio-demographic data (Gender; Qualification level; teaching experience records, TTIs level)

Section 2: Cause of stress factors among teachers constitute of three main stress sources like teaching load, teacher welfare, and teacher professional development. A fivepoints Likert scale was used that I have adopted from Vagias and Wade (2006) as follows: $5=$ extreme cause, $4=$ strong cause, $3=$ medium cause, $2=$ Slight cause, $1=$ No cause

Your cooperation in giving HONEST information is greatly appreciated and we will use it for academic purposes only; please do not hesitate to provide as authentic information as possible.

Thank you for your kind cooperation!

Thongsay PHONGPHANIT

$\mathrm{PhD}$ student in Hungary.

(SHS holder 2015-2018) 
Section 1: Socio-Demographic data

Instructions: Please put a $\checkmark$ into the preceding the answers relating to You!

\begin{tabular}{|c|l|}
\hline No. & \multicolumn{2}{|c|}{ Checklist items } \\
\hline 1 & $\begin{array}{l}\square \text { Male } \\
\text { Gender: }\end{array}$ \\
\hline 2 & $\begin{array}{l}\text { Qualification level: } \\
\square \text { Higher Diploma; }\end{array} \quad$ BA Degree; $\square$ MA Degree \\
\hline 3 & $\begin{array}{l}\text { Teaching Experience: } \\
<5 \text { years } \square ; 5-10 \text { years } \square ;>11 \text { years } \square ;\end{array}$ \\
\hline 4 & TTIs location: $\quad$ FOE $\square \quad$ TTC $\square$ \\
\hline
\end{tabular}

Section 2: Cause of stress factors among teachers within 8 TTIs-Laos

Instructions: Please put a $\checkmark$ in case of each line into the relevant box indicating your stress source level!

\begin{tabular}{|c|c|c|c|c|c|c|}
\hline \multirow{2}{*}{$\begin{array}{c}\text { No. } \\
\text { of } \\
\text { item }\end{array}$} & \multirow{2}{*}{$\begin{array}{l}\text { Causes of teachers' stress factors in } \\
\text { connection with teaching load }\end{array}$} & \multicolumn{5}{|c|}{ Stress source level } \\
\hline & & 5 & 4 & 3 & 2 & 1 \\
\hline 1 & Teach too much hours a week & & & & & \\
\hline 2 & Often teach of cross-subject areas & & & & & \\
\hline 3 & Allocate subjects taught without consultation & & & & & \\
\hline 4 & Face too many administrative tasks & & & & & \\
\hline 5 & Lack of autonomy in teaching performance & & & & & \\
\hline \multicolumn{7}{|c|}{ 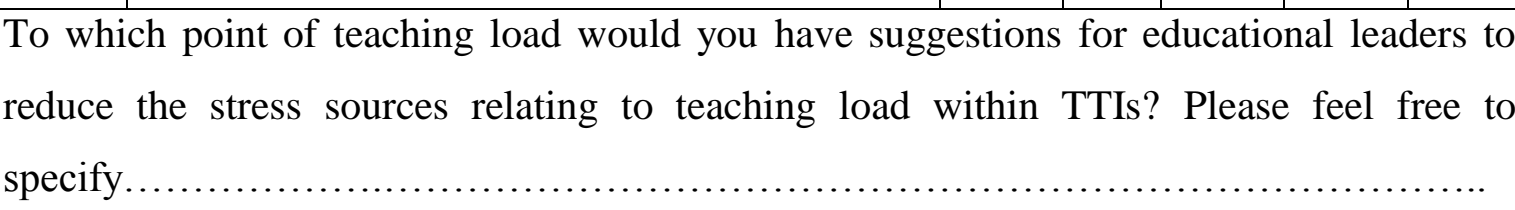 } \\
\hline
\end{tabular}




\begin{tabular}{|c|c|c|c|c|c|c|}
\hline \multirow{2}{*}{$\begin{array}{l}\text { No. of } \\
\text { item }\end{array}$} & \multirow{2}{*}{$\begin{array}{l}\text { Causes of teachers' stress factors in } \\
\text { connection with teacher welfare }\end{array}$} & \multicolumn{5}{|c|}{ Stress source level } \\
\hline & & 5 & 4 & 3 & 2 & 1 \\
\hline 6 & Unclear expectation & & & & & \\
\hline 7 & Salary and subsidies lag & & & & & \\
\hline 8 & Poor working condition & & & & & \\
\hline 9 & Provide teaching-hours unmet teacher's decrees & & & & & \\
\hline 10 & Hardship allowance & & & & & \\
\hline 11 & Overtimes-pay & & & & & \\
\hline 12 & Health care & & & & & \\
\hline 13 & Necessary salary adjustment & & & & & \\
\hline \multicolumn{7}{|c|}{$\begin{array}{l}\text { To which point of teachers' welfare would you like educational leaders to operate and } \\
\text { manage properly within TTIs? Please feel free to specify.............................. }\end{array}$} \\
\hline \multirow{2}{*}{$\begin{array}{l}\text { No. of } \\
\text { item }\end{array}$} & \multirow{2}{*}{$\begin{array}{c}\text { Causes of teachers' stress factors in } \\
\text { connection with teachers' professional } \\
\text { development }\end{array}$} & \multicolumn{5}{|c|}{ Stress source level } \\
\hline & & 5 & 4 & 3 & 2 & 1 \\
\hline 14 & Teaching media via internet lag & & & & & \\
\hline 15 & There is a clue in training participation & & & & & \\
\hline 16 & Imbalance toward oriented-skills training & & & & & \\
\hline 17 & Ignore in making a survey of skill-needs & & & & & \\
\hline 18 & Training content mismatch of skill-needs & & & & & \\
\hline \multicolumn{7}{|c|}{$\begin{array}{l}\text { What would you like educational leaders to improve and develop concerning the teaching } \\
\text { profession development within TTIs? Please feel free to specify!........................ }\end{array}$} \\
\hline
\end{tabular}

Thank you for your kind cooperation.

Thongsay PHONGPHANIT 